S100

- S100-Protein

\section{S-100a und b}

$\checkmark$ Calprotectin

- S100-Protein

\section{SAA}

- Serum-Amyloid A

- Standardarbeitsanweisung

\section{Sa-Autoantikörper}

> Autoantikörper gegen Sa

\section{Saccharase-Isomaltase}

R. Tauber und F. H. Perschel

Synonym(e) Sucrase-Isomaltase

Englischer Begriff sucrase-isomaltase
Definition Glykohydrolase der intestinalen Bürstensaummembran, die die Hydrolyse von Saccharose, Maltose, Isomaltose und $\alpha$-Grenzdextrinen katalysiert.

Beschreibung Saccharase-Isomaltase (Molmasse ca. $235 \mathrm{kDa}$ ) ist eine membranständige Glykohydrolase der intestinalen Bürstensaummembran insbesondere des Duodenums und des Jejunums. Das Enzym besteht aus 2 Untereinheiten mit jeweils unterschiedlicher katalytischer Aktivität, wobei die Saccharaseuntereinheit (EC 3.2.1.48) Saccharose zu Glukose und Fruktose, die Isomaltaseuntereinheit (EC 3.2.1.10) die $\alpha(1-6)$ glykosidische Bindung von Isomaltose und von $\alpha$-Grenzdextrinen spaltet. Beide Untereinheiten spalten Maltose und am nicht reduzierenden Ende die $\alpha(1-4)$ glykosidische Bindung in $\alpha$-Grenzdextrinen. Fehlende oder reduzierte Enzymaktivität bei der seltenen autosomal rezessiven hereditären SaccharaseIsomaltase-Defizienz führt zu Symptomen der Malassimilation mit Diarrhoe, Dehydratation und Gedeihstörungen.

\section{Literatur}

Semenza G, Auricchio S (1995) Small-intestinal dissacharidases. In: Scriver CR, Beaudet AL, Sly WS et al (Hrsg) The metabolic and molecular basis of inherited disease, Bd 3. McGraw-Hill, New York, S $4451-4480$

\section{Saccharose-Hämolyse-Test}

Zuckerwasser-Test

\section{Sahli-Hämometer}

> Sahli-Hämometrie 


\section{Sahli-Hämometrie}

\section{A. M. Gressner und O. A. Gressner}

\section{Synonym(e) Sahli-Hämometer}

Englischer Begriff Sahli hemoglobinometer; Sahli hemometer; Sahli's tube

Definition Historische, heute obsolete kolorimetrische Methode der Bestimmung von Hämoglobin.

Beschreibung Vom Schweizer Arzt Hermann Sahli (1856-1933) im Jahr 1902 eingeführte kolorimetrische Methode ( $\triangleright$ Kolorimetrie); gehört zu den ersten (semi-) quantitativen Bestimmungsverfahren von > Hämoglobin, das dessen Umwandlung (,Transformation“) in gelbgrünes Salzsäurehämatin (Häminchlorid) mit visueller oder (später) photometrischer (bei $540 \mathrm{~nm}$ für oxidiertes Hämoglobin) Auswertung zur Grundlage hat. Beim visuellen Verfahren wird das mit einer Sahli-Pipette entsprechend verdünnte und behandelte Blut neben einem graduell eingefärbten Glaskeil in eine Probenküvette eingefüllt und die Farbgleichheit von Glaskeil und Probe an einer numerischen Skala in „SahliEinheiten“" abgelesen.

\section{Literatur}

Kaufmann CP (1998) Das Hämometer von Herman Sahli: Methode - Typen - Bedeutung. Medizinhistorisches Institut der Universität, Bern

Sahli H (1902) An apparatus for the clinical estimation of haemoglobin. Verh Dtsch Kongr Inn Med 20:230-234

\section{Salicylate}

C. Vidal und W.-R. Külpmann

\section{Englischer Begriff salicylates}

Definition $\mathrm{Zu}$ den Salicylaten rechnen Salicylsäure sowie Derivate der Salicylsäure, die in vivo in Salicylsäure übergehen, wie z. B. Acetylsalicylsäure (s. Abbildung):

- Salicylsäure: externe Anwendung als Keratolytikum

- Salicylamid: als Analgetikum (Kombinationspräparat mit Paracetamol, Coffein)
- Na-Salicylat: als Analgetikum (Kombinationspräparat mit Paracetamol, Kodein)

- Acetylsalicylsäure: als Analgetikum, Antipyretikum, Antiphlogistikum, Thrombozytenaggregationshemmer (Monound Kombinationspräparate)

Strukturformel von Acetylsalicylsäure:

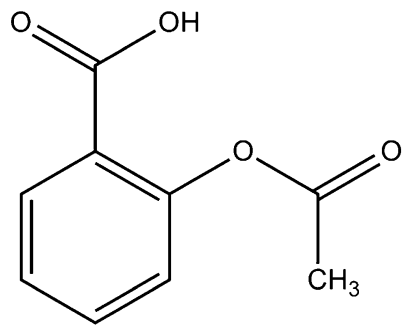

Molmasse 180,16 g (Acetylsalicylsäure); 138,1 g (Salicylsäure).

Synthese - Verteilung - Abbau - Elimination Acetylsalicylsäure (ASS) ist das mit Abstand am häufigsten eingesetzte Salicylat. Es wird bei oraler Gabe innerhalb von 1-2 Stunden fast vollständig resorbiert. Mit einer Halbwertzeit von 15 Minuten wird ASS zu Salicylsäure im Plasma hydrolysiert. Die Halbwertzeit für Salicylsäure beträgt 2-3 Stunden, bei Salicylatvergiftung ist sie auf 15-30 Stunden verlängert. Die Abbauprodukte werden überwiegend renal eliminiert.

Funktion - Pathophysiologie Bei akuter Vergiftung findet sich Hyperpnoe, Störung der Temperaturregulation oder Hyperthermie, respiratorische Alkalose. Der pH-Anstieg führt zur renalen Gegenregulation mit vermehrter Ausscheidung von Kalium, Chlorid sowie Wasser und Ausbildung einer metabolischen Acidose. Im weiteren Verlauf kommt es zu Blutungen durch Abfall der Prothrombinkonzentration und Schädigung von Kapillaren.

Untersuchungsmaterial - Entnahmebedingungen Serum (S), Plasma (P), Urin.

Analytik Photometrisch durch Reaktion mit $\mathrm{FeCl}_{3}$ zum Schnellnachweis ( Trinder-Reaktion); I Immunoassay, Hochleistungs-Flüssigkeitschromatographie, > GC-MS, LC-MS/MS.

Indikation Verdacht auf Salicylatvergiftung, selten Drug Monitoring (Prüfung auf Compliance).

Diagnostische Wertigkeit Zum eindeutigen Nachweis einer Salicylatvergiftung ist die Salicylatbestimmung erforderlich. Das Diagramm nach Done erlaubt eine Abschätzung der Prognose. 
Die folgende Abbildung zeigt das Nomogramm zur Darstellung des Zusammenhangs zwischen Salicylatkonzentrationen im Serum und dem Schweregrad einer Intoxikation nach Ingestion einer einzigen Salicylatdosis (nach: Done 1960):

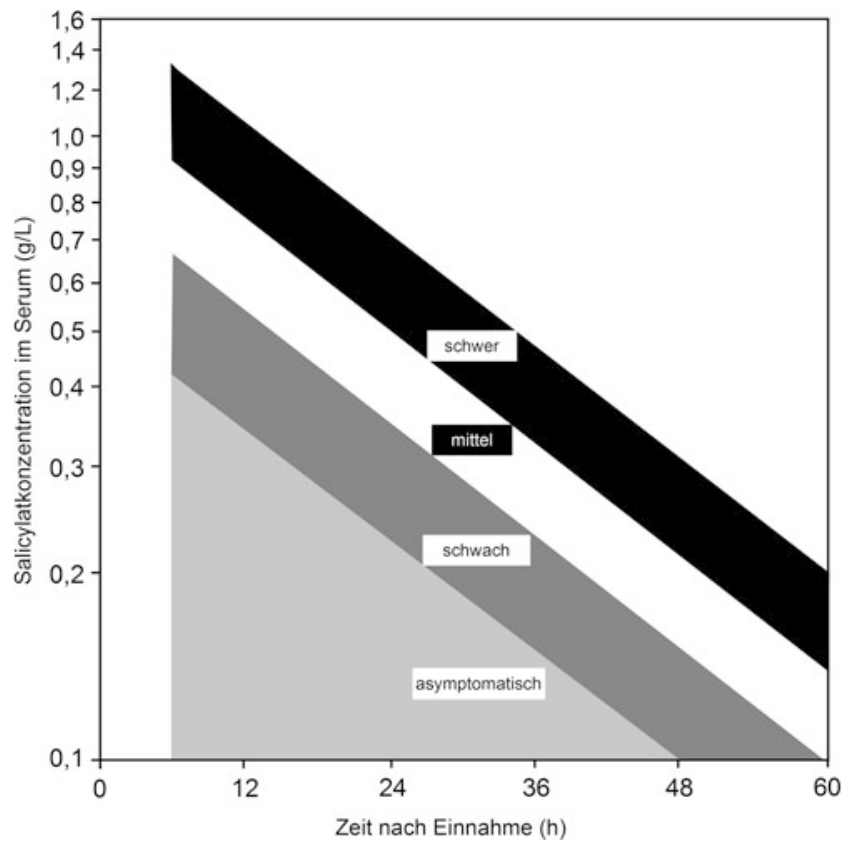

Interpretation Therapeutischer Bereich (S, P): 20-200 mg/L; toxisch: $\geq 300 \mathrm{mg} / \mathrm{L}$; komatös-letal: $\geq 400 \mathrm{mg} / \mathrm{L}$.

\section{Literatur}

Done AK (1960) Salicylate intoxication, significance of measurement of salicylate in blood in case of acute ingestion. Pediatrics 26:800-807

König H, Hallbach J (2009) Nonopioid analgesics and antirheumatics. In: Külpmann WR (Hrsg) Clincial toxicological analysis. WileyVCH, Weinheim, S 209-214

\section{Salicylate, Schnellnachweis mit Trinder-Reagenz}

- Trinder-Reaktion

\section{Salivaanalytik}

- Speichelanalytik

\section{Salivatestung}

K. Kleesiek, C. Götting, J. Diekmann, J. Dreier und M. Schmidt

Synonym(e) Speicheltestung

Englischer Begriff saliva testing

Definition Nachweis der Anwesenheit der Blutgruppenantigene $\mathrm{A}, \mathrm{B}$ und $\mathrm{H}$ ( $\triangleright$ Blutgruppenantigene, erythrozytäre) sowie des Lewis-Antigens im Speichel.

Beschreibung Funktion: Die Salivatestung dient in der Transfusionsmedizin zum Nachweis von ABH-Blutgruppensubstanzen und Lewis-Antigenen ( $\vee$ Lewis-(Le-)Blutgruppensystem) im Speichel. Personen, bei denen diese Substanzen im Speichel nachweisbar sind, werden als Sekretoren bezeichnet, während sie bei Non-Sekretoren nicht im Speichel, sondern nur auf der Erythrozytenoberfläche vorhanden sind. Der $\triangleright$ Sekretorstatus einer Person wird bestimmt über die Aktivität der Fucosyltransferase 2 (Se-Transferase), einer Glykosyltransferase, die vom FUT2-Gen auf Chromosom 19q13.3 kodiert und in sekretorischen Drüsen exprimiert wird. Durch die Aktivität der Se-Transferase wird ein lösliches H-Antigen ( $\triangleright$ H-Substanz) mit endständiger Fucose synthetisiert, das im Speichel und anderen Körperflüssigkeiten nachweisbar ist. Personen, die mindestens eine funktionsfähige Kopie des FUT2-Gens aufweisen, können die lösliche Form des H-Antigens bilden und im Speichel exprimieren. Die Zugehörigkeit zu den Blutgruppen A, B, 0 oder $\mathrm{AB}(\triangleright$ Blutgruppe) ist jedoch unabhängig vom Sekretorenstatus.

Methode: Bei der Salivatestung wird Speichel gewonnen, in dem die Existenz der entsprechenden Antigene durch einen Neutralisationstest mit Anti-A-, Anti-B-, Anti-H-, Anti-Le (a)- und Anti-Le(b)-spezifischen Antiseren nachgewiesen wird. Zur Gewinnung des Probenmaterials wird der Mund des Probanden mit Wasser ausgespült. Anschließend lässt man ca. $1 \mathrm{ml}$ Speichel aus dem Mund in ein Probengefäß tropfen, um es danach für 10 Minuten auf ca. $95^{\circ} \mathrm{C}$ zu erhitzen, um die im Speichel vorhandenen Enzyme zu inaktivieren. Nach Zentrifugation wird der klare Überstand 1:1 mit isotoner Natriumchloridlösung verdünnt und im Neutralisationstest eingesetzt.

Der Sekretionsnachweis beruht auf der Hemmung von z. B. Anti-A-Seren durch die im Speichel vorhandenen korrespondierenden Antigene. So bindet beispielhaft die A-Substanz im Speichel eines Sekretors der Blutgruppe A an Antikörper der Spezifität Anti-A und neutralisiert bzw. inhibiert diese. Diese Antikörper reagieren dann nicht mehr oder nur noch schwach 
mit Erythrozyten der Blutgruppe A, was in einem $>$ Agglutinationstest nachweisbar ist. Bei einem Non-Sekretor der Blutgruppe A ist keine A-Substanz im Speichel vorhanden, sodass es nicht zur Neutralisation von Antikörpern der Spezifität Anti-A durch Zusatz von Speichel kommt. Diese Antikörper können dann direkt mit Erythrozyten der Blutgruppe A reagieren. Analog ist das Vorgehen, um die anderen Antigene durch Antiseren der Spezifität Anti-B, Anti-H, Anti-Le(a) und Anti-Le(b) nachzuweisen.

\section{Literatur}

American Association of Blood Banks (2014) Technical manual, 18. Aufl. Kiefel V (Hrsg) (2010) Transfusionsmedizin: Grundlagen Therapie-Methodik, 4. Aufl. Springer, Berlin/Heidelberg/New York Metaxas-Bühler M (1993) Blutgruppen und Transfusionsmedizin. Verlag Hans Huber, Bern/Göttingen/Toronto/Seatle

\section{Sammelurin}

$\checkmark$ Spontanurin

> Urinsammelbehälter

\section{Sandell-Kolthoff-Reaktion}

T. Arndt

Synonym(e) Iodbestimmung nach Sandell-Kolthoff

Englischer Begriff Sandell-Kolthoff reaction

Definition Redoxchemische, photometrische Iodbestimmung (im Urin).

Beschreibung Die Iodversorgung des Organismus lässt sich am besten durch die Ausscheidung von $>$ Iod im Urin erfassen. Hierzu wird eine Urinprobe zunächst in saurem Milieu bei ca. $90-100{ }^{\circ} \mathrm{C}$ oxidativ aufgeschlossen. Dabei werden einerseits Iodid $\left(\mathrm{I}^{-}\right)$, Iodat $\left(\mathrm{IO}^{3-}\right)$ und proteingebundenes Iod in freies, molekulares $\mathrm{I}_{2}$ überführt und andererseits die Nachweisreaktion störende Substanzen wie z. B. Ascorbinsäure und Urinpigmente zerstört. Anschließend werden dem Reaktionsgemisch nacheinander Lösungen von $\mathrm{As}^{3+}$ - und $\mathrm{Ce}^{4+}$ Ionen zugesetzt. In einem ersten Reaktionsschritt wird $\operatorname{Iod}\left(\mathrm{I}_{2}\right)$ zu Iodid $\left(\mathrm{I}^{-}\right)$durch $\mathrm{As}^{3+}$ reduziert und $\mathrm{I}^{-}$anschließend wieder durch $\mathrm{Ce}^{4+} \mathrm{zu} \mathrm{I}_{2}$ oxidiert. Dabei wird die gelbe $\mathrm{Ce}^{4+}$-Lösung mit einer Geschwindigkeit proportional zur $\mathrm{I}_{2}$-Konzentration im Reaktionsansatz entfärbt. Die Sandell-Kolthoff-Reaktion ist also eine indirekte Iodbestimmung nach folgendem Reaktionsschema:

$$
\begin{gathered}
\mathrm{As}^{3+}+\mathrm{I}_{2} \rightarrow \mathrm{As}^{5+}+2 \mathrm{I}^{-} \\
2 \mathrm{Ce}^{4+}+2 \mathrm{I}^{-} \rightarrow 2 \mathrm{Ce}^{3+}+\mathrm{I}_{2}
\end{gathered}
$$

Die Entfärbung der Lösung wird in bestimmten Zeitabständen nach Zugabe der $\mathrm{Ce}^{4+}$-Lösung gemessen und über eine geeignete Kalibrationsfunktion der Iodkonzentration der Urinprobe zugeordnet. Die Sandell-Kolthoff-Reaktion ist noch heute Grundlage der WHO-Methode zur Iodbestimmung, u. a. weil sie nach wiederholten Modifikationen des Probenaufschlusses und damit verbundenem Austausch der ursprünglich eingesetzten, nicht ungefährlichen Chlorsäure $\left(\mathrm{HClO}_{3}\right)$ gegen das besser handhabbare Ammoniumpersulfat $\left[\left(\mathrm{NH}_{4}\right)_{2} \mathrm{~S}_{2} \mathrm{O}_{8}\right]$ relativ einfach und mit geringem Aufwand (auch innerhalb von Ernährungsprogrammen der Entwicklungsländer) einsetzbar ist.

\section{Literatur}

Husniza H, Wan NWM (2006) A cost-effective modified micromethod for measuring urine iodine. Trop Biomed 23:109-115

Pino S, Fang S-L, Braverman LE (1996) Ammonium persulfate: a safe alternative oxidizing reagent for measuring urinary iodine. Clin Chem 42:239-243

Sandell EB, Kolthoff IM (1937) Micro determination of iodine by a catalytic method. Microchem Acta 1:9-25

\section{Sandfliegen-Fieber-Viren}

W. Stöcker

Englischer Begriff sandfly fever virus

Beschreibung des Erregers Familie: Bunyaviridae; Gattung: Phlebo-Virus; Art: Sandfliegen-Fieber-Virus; wichtige Serotypen: Sicilian (SFSV), Naples (SFNV), Toscana (TOSV), Cyprus (CYPV). Häufig findet man Doppelt- und Dreifachinfektionen. Minusstrang-RNA-Virus, behüllt, 80-120 nm Durchmesser.

Erkrankungen Sandfliegen-Fieber (Pappataci-Fieber). Verbreitung: Mittelmeerraum bis Südchina.

Vektor: Stechmücken (Sandfliegen; besser: Sandmücken, vor allem Phlebotomus papatasi). 
Wirte: Nutztiere (vor allem Wiederkäuer), Nagetiere, Fledermäuse, Mensch.

Klinik: Die meisten Infektionen verlaufen subklinisch. Die Krankheit beginnt mit plötzlich auftretendem hohen Fieber und grippeähnlicher Symptomatik, bei TOSV meist und bei SFSV häufig zusätzlich aseptische Meningitis oder Meningoenzephalitis mit lymphozytärer Pleozytose und spezifischer intrathekaler Antikörperproduktion sowie neurologischen Störungen und wochen- bis monatelang persistierender Cephalgie. Selten Hämorrhagie.

Therapie und Prophylaxe: Bisher kann nur symptomatisch behandelt werden. Es gibt noch keinen Impfstoff. Prävention: Schutz vor Mückenstichen, Bekämpfung der Vektoren.

Analytik Das Arbeiten mit dem Erreger erfordert ein Laboratorium der Sicherheitsklasse 3.

Direktnachweis: RT-PCR ( $\triangleright$ PCR (Polymerase-Kettenreaktion)) oder Virusanzucht in der Zellkultur.

Serologie: Bestimmung spezifischer Antikörper (IgG, IgM) durch indirekte Immunfluoreszenz ( $\triangleright$ Immunfluoreszenz, indirekte), ELISA ( $\triangleright$ Enzyme-linked Immunosorbent assay) oder $\triangleright$ Neutralisationstest.

Probenmaterial und -stabilität Direktnachweis und Kultur: Untersucht werden Blutbestandteile, Liquor oder Biopsiematerial. Das Material sollte bis zur Weiterverarbeitung bei +4 bis $+8{ }^{\circ} \mathrm{C}$ aufbewahrt werden. Direktnachweise sind innerhalb von 24 Stunden durchzuführen, Kulturen innerhalb von 6 Stunden anzulegen. Bei längerer Transportzeit ist das Material einzufrieren.

Serologie: Serum oder Plasma für den Nachweis der Antikörper sind bei $+4^{\circ} \mathrm{C}$ bis zu 2 Wochen lang beständig, Liquor nur eine Woche, bei $-20{ }^{\circ} \mathrm{C}$ über Monate und Jahre hinweg. Zur Tiefkühlkonservierung des IgM kann man den Proben $80 \%$ gepuffertes Glyzerin beifügen.

Diagnostische Wertigkeit Ein Direktnachweis des Erregers wird nur in Ausnahmefällen durchgeführt. Die Vermehrung in Zellkultur und die sich anschließende positive spezifische Immunreaktion ebenso wie eine positive PCR beweisen die Anwesenheit der Viren. Im negativen Fall kann die Infektion aber nicht ausgeschlossen werden, insbesondere da der Organismus bereits innerhalb weniger Tage spezifische Antikörper bildet, die das Virus neutralisieren.

Serologie: Spezifische Antikörper (IgG, IgM) treten im Serum ab dem 5. Krankheitstag auf. Das IgG erreicht seine höchste Konzentration in der Phase der Rekonvaleszenz und persistiert über mehrere Jahre. Ein vierfacher Anstieg des spezifischen IgG-Titers innerhalb von 2-3 Wochen kann als eindeutiger Nachweis einer frischen Infektion gewertet werden. Aufgrund großer genetischer Unterschiede schützt die Immunität gegen einen bestimmten Serotyp nicht vor einer Infektion durch einen anderen. Es ist sinnvoll, für die indi- rekte Immunfluoreszenz Biochip-Mosaike mit den verschiedenen Serotypen einzusetzen und durch einen Vergleich der Reaktionsstärken den aktuellen Serotyp zu identifizieren.

Differenzialdiagnosen: $>$ West-Nil-Fieberviren, $>$ Rift-Valley-Fieber-Viren, $\triangleright$ Dengue-Viren, Influenza-Viren $(\triangleright$ Influenza-Viren A, B und C).

Durch die Verordnung zur Anpassung der Meldepflichten nach dem Infektionsschutzgesetz an die epidemische Lage (IfSG-Meldepflicht-Anpassungsverordnung), die am 01.05.2016 in Kraft getreten ist, wurde die Meldepflicht für Labore nach $\S 7$ Abs. 1 Satz 1 Infektionsschutzgesetz (IfSG) auf den direkten oder indirekten Nachweis von > Chikungunya-Viren, \DengueViren, > West-Nil-Fieberviren, \Zika-Viren und sonstige Arboviren ausgedehnt, soweit der Nachweis eine akute Infektion anzeigt. Darüber hinaus können allgemeine nicht erreger- oder krankheitsspezifische Meldepflichten bestehen.

\section{Literatur}

Brett-Major DM, Claborn DM (2009) Sandfly fever: what have we learned in one hundred years? Mil Med 174(4):426-431

Dionisio D, Esperti F, Vivarelli A, Valassina M (2003) Epidemiological, clinical and laboratory aspects of sandfly fever. Curr Opin Infect Dis 16(5):383-388

Robert Koch-Institut (2011) Steckbriefe seltener und importierter Infektionskrankheiten. Robert Koch-Institut, Berlin

\section{Sandkühler-Ringprobe}

A. M. Gressner und O. A. Gressner

Synonym(e) Bence-Jones-Proteinnachweis nach Sandkühler

\section{Englischer Begriff Sandkühler's test}

Definition Heute obsolete orientierende Nachweisreaktion von Bence-Jones-Proteinen ( $\vee$ Bence-Jones-Protein) im Urin.

Beschreibung Die von dem Heidelberger Internisten St. Sandkühler um 1950 eingeführte Nachweisreaktion von Bence-Jones-Proteinen im Urin, bei der der Harn in einem Reagenzglas in senkrechter Haltung mittels seitlich gerichteter Bunsenbrennerflamme etwa $5 \mathrm{~cm}$ unterhalb des Harnspiegels erwärmt wird, ist heute nicht mehr in Gebrauch. An der Stelle, die eine Temperatur von ca. $50-70{ }^{\circ} \mathrm{C}$ erreicht, bildet sich eine ringförmige Trübung, die in dem darüber befindlichen, höher temperierten Teil des Harns ebenso fehlt wie in dem unteren, kühleren Harnanteil. 


\section{Literatur}

Hallmann L (1980) Klinische Chemie und Mikroskopie, 11. Aufl. Georg Thieme Verlag, Stuttgart/New York

Sandkühler S (1951) Das heutige Bild des Plasmozytoms. Dtsch med Wschr 76(6):168-171

\section{Sanduhrförmige Kristalle}

> Oxalatkristalle

\section{Sandwich-Assay}

W. Stöcker und W. Schlumberger

Synonym(e) Capture Assay

Englischer Begriff sandwich assay

Definition Der Sandwich-Assay ist ein heterogener, nichtkompetitiver Assay, bei dem das zu messende Antigen oder der zu bestimmende Antikörper einer Probe zwischen 2 Reaktionspartnern (Antikörpern bzw. Antigenen) gebunden wird.

Beschreibung Beim Sandwich-Assay wird das zu messende Antigen ( $\triangleright$ Antigen Capture Assay) oder der zu bestimmende Antikörper ( $\triangleright$ Antibody Capture Assay) einer Probe zwischen 2 Antikörpern bzw. 2 Antigenen gebunden. Es kommen alle für Immunoassays verwendeten Marker und Detektionssysteme in Betracht. Es gibt Festphasen- und FlüssigphasenSandwich-Assays.

Bei Festphasenassays wird zur Antigenbestimmung das Antigen der Probe in einem ersten Inkubationsschritt mit einem an die feste Phase fixierten Antikörper zur Reaktion gebracht. Anschließend werden die ungebundenen Anteile der Probe mit einem Waschschritt entfernt. Je höher die Antigenkonzentration der Probe ist, umso mehr Antigen bindet sich. Im nächsten Schritt lässt man markierte Antikörper mit den Immunkomplexen der festen Phase reagieren und nach Beendigung der Reaktionszeit wird überschüssiger Marker mit einem Waschschritt entfernt. Die Antigenbestimmung kann auch als Einschritt-Sandwich-Assay durchgeführt werden: Dann werden die Probe und die markierten Antikörper initial simultan mit den Festphasen-fixierten Antikörpern inkubiert.

Zur Antikörperbestimmung wird der Antikörper der Probe in einem ersten Inkubationsschritt mit einem an die feste Phase fixierten Antigen zur Reaktion gebracht. Anschließend werden die ungebundenen Anteile der Probe mit einem Waschschritt entfernt. Je höher die Antikörperkonzentration der Probe, umso mehr Antikörper bindet sich. Im nächsten Schritt reagieren markierte (gegen den nachzuweisenden Antikörper der Probe gerichtete) Antikörper oder markierte Antigene (,labelled antigen assay“) mit den Immunkomplexen an der festen Phase, und nach Beendigung der Reaktionszeit wird der überschüssige Marker mit einem Waschschritt entfernt. Auch die Bestimmung eines Antikörpers kann als Einschritt-Sandwich-Assay erfolgen.

Bei Flüssigphasenassays werden Immunkomplexe gebildet, die ungebundenen Antigene und Antikörper werden nach der Immunreaktion durch Adsorption, Fällung, Immunpräzipitation oder Affinitätsbindung entfernt.

Es existiert eine Vielfalt von Varianten dieser nichtkompetitiven Immunoassays: Beim $\mu$-Capture-Assay werden speziesspezifische IgG-Antikörper, die gegen das Fc-Fragment des IgM-Antikörpers gerichtet sind, an die feste Phase gekoppelt. An dieses bindet sich das IgM der Probe. Antigenspezifisches IgM wird durch Zugabe des korrespondierenden Antigens identifiziert. Dieses ist entweder selbst markiert (,,markierter Antigenassay“") oder es wird ein spezifischer, gegen das Antigen gerichteter markierter IgG-Antikörper hinzugegeben.

Ein Störfaktor der Sandwich-Assays ist der > High-DoseHook-Effekt (Prozonen-Phänomen), er kann insbesondere bei Einschrittinkubationen zu einer starken Verfälschung der Messwerte führen.

\section{Literatur}

Wild D (2001) The Immunoassay handbook. Nature Publishing Group, New York, S 3-5

\section{Sanfte lonisierungsmethoden}

- Massenspektrometrie

\section{Sanger, Frederick}

A. M. Gressner und O. A. Gressner

Lebensdaten Englischer Biochemiker, geboren am 13. August 1918 in Rendcomb, Gloucestershire, gestorben am 19. November 2013 in Cambridge, UK.

Verdienste F. Sanger erhielt seine schulische und universitäre Ausbildung in Cambridge, UK, wo er das Studium 
der Chemie aufnahm und 1943 mit der Promotion abschloss. Anschließend arbeitete er am Medical Research Council (MRC). Dort entwickelte er eine Methode zur Proteinsequenzierung unter Einsatz von Dinitrophenylderivaten. Mit dieser Methode konnte Sanger in mehrjähriger Arbeit die komplette Aminosäuresequenz des humanen Insulins bestimmen und 1955 publizieren, was 1958 mit dem Nobelpreis für Chemie gewürdigt wurde. In der Folge verlagerte Sanger seinen Schwerpunkt auf die Entwicklung einer Methode zur Sequenzierung von Nukleinsäuren, die zur Etablierung der Didesoxymethode für Desoxyribonukleinsäuren (DNA) geführt hat ( $\triangleright$ Sanger-Sequenzierung). Diese epochale Leistung wurde 1980 mit der Verleihung des zweiten Nobelpreises für Chemie ausgezeichnet. Sangers fundamentale methodischen Entwicklungen und biochemischen Arbeiten führten nicht nur zu der seltenen Würdigung mit zwei Nobelpreisen, sondern auch zu vielen weiteren Ehrungen. Viele grundlegende biomedizinische Forschungen wurden durch Sangers Entwicklungen möglich gemacht.

\section{Literatur}

Brownlee G (2014) Fred Sanger- double Nobel laureate. A biography. Cambridge University Press. ISBN 9781107083349

\section{Sanger-Sequenzierung}

J. Arnemann

Synonym(e) DNA-Sequenzierung nach Sanger

Englischer Begriff Sanger sequencing

Definition Die DNA-Sequenzierung nach Sanger ermöglicht die Bestimmung der Nukleotidfolge in einem DNA-Molekül mittels der Didesoxy- oder Kettenabbruchmethode.

Beschreibung Dem Biochemiker Sanger $(\triangleright$ Sanger, Frederick) gelang der entscheidende Durchbruch zur Sequenzierung, d. h. Bestimmung der Nukleotidfolge, eines definierten DNA-Moleküls. Sanger entwickelte hierfür die sog. Kettenabbruchmethode, die anfangs alle 4 Basen getrennt analysierte.

Im ersten Schritt der Reaktion wurde die zu sequenzierende doppelsträngige DNA-Matrize durch Hitze zu einzelsträngigen Molekülen denaturiert und anschließend eine synthetisierte DNA-Sequenz, ein sog. Primer, hinzugefügt, der mit Abkühlen der Reaktion an die DNA-Matrize hybridisierte.
Parallel wurden 4 Reaktionsansätze pipettiert, die als G-, A-, T- oder C-Reaktion markiert wurden. In jeden Ansatz wurde ein Mix aus Reaktionspuffer, den 4 dNTPS (Deoxynukleotidtriphoshate; dGTP, dATP, dTTP, dCTP), zu einem geringen Anteil radioaktiv markierte dNTP-Moleküle (meist ${ }^{35} \mathrm{~S}-\mathrm{dCTP}$ ) und ein weiterer Anteil der für jede Reaktion spezifischen ddNTP-Moleküle (Dideoxynukleotidtriphoshate; ddGTP, ddATP, ddTTP oder ddCTP) hinzugefügt. Nach anschließender Zugabe des DNA-Gemischs und DNAPolymerase (Klenow-Enzym) wurde die eigentliche Sequenzierreaktion durch Inkubation bei $37^{\circ} \mathrm{C}$ gestartet.

Bei der Synthese des neuen DNA-Strangs werden radioaktive Moleküle und, in jedem Reaktionsansatz spezifisch nach dem Zufallsprinzip die jeweiligen ddNTPs eingebaut. Da den ddNTPs eine OH-Gruppe am 3'C-Atom fehlt, kann nach Einbau eines ddNTP-Moleküls in den neuen DNAStrang keine weitere Verknüpfung erfolgen und es kommt zum Kettenabbruch. Da dieser Einbau nach dem Zufallsprinzip abläuft, werden in jedem Reaktionsansatz DNAFragmente unterschiedlicher Länge synthetisiert, die alle mit dem gleichen ddNTP enden, d. h. im G-Ansatz mit ddGTP, im A-Ansatz mit ddATP etc.

Zur Auswertung und Lesen der Nukleotidabfolge wurden die 4 Reaktionsansätze denaturiert und parallel in ein besonders langes Polyacrylamid-Gel (Sequenziergel) pipettiert und elektrophoretisch aufgetrennt. Nach dem Elektrophoreselauf wurde das Gel fixiert und anschließend mit einem Röntgenfilm in einer Autoradiographiekassette „exponiert“. Nach dem Entwickeln des Röntgenfilms waren in den jeweils 4 parallelen Spuren dunkelgraue Banden mit unterschiedlichem Leitermuster zu sehen. Die radioaktive Markierung hat die Banden auf dem Film sichtbar gemacht. Jede Bande zeigt die Größe eines DNA-Fragments an, das in der entsprechenden Spur beispielsweise mit einem $G$ geendet hatte. Nach den Prinzipien der Elektrophorese sind die kürzesten DNAFragmente und damit der Beginn der Sequenz im unteren Bereich des Films zu finden. Zum Lesen der Sequenz fängt man daher unten an und ,hangelt" sich quer über die 4 Spuren wie auf einer Leiter nach oben und notiert dabei die Abfolge der Nukleotide. Diese Nukleotidfolge entspricht dabei der komplementären Sequenz der DNA-Matrize.

Diese Methode wurde über die vergangenen Jahrzehnte immer mehr modifiziert, vereinfacht und tauglich für eine automatische Abarbeitung gemacht:

Durch Einsatz des Cycle-Sequencings, einer PCRMethode, bei der aber nur mit einem Primer in eine Richtung amplifiziert wird, wie auch durch den Einsatz von ddNTPS, die mit je 4 verschiedenen Fluoreszenzfarbstoffen markiert sind, lässt sich auch aus relativ geringen DNA-Mengen eine Sequenzanalyse durchführen. Der mit besonderen Sicherheitsmaßnahmen gekoppelte Einsatz radioaktiver Moleküle entfällt. Die nun fluoreszenzmarkierten Sequenzierreaktionen werden durch Kapillarelektrophorese in einem DNA- 
Sequencer aufgetrennt und die Fluoreszenzmoleküle bzw. die entsprechenden Nukleotide beim Vorbeiwandern an einem Laserdetektor automatisch dokumentiert und nachfolgend mittels spezifischer Computerprogramme benutzergerecht aufbereitet.

\section{Literatur}

Brown TA (1994) DNA sequencing. Oxford University Press, Oxford, UK

\section{S- und s-Antigen}

- MNS-Blutgruppensystem

\section{Sapporo-Kriterien}

\section{A. M. Gressner und O. A. Gressner}

Synonym(e) Sydney-Kriterien

Englischer Begriff Sapporo criteria; Sydney criteria

Definition Kombiniert klinisch-labormedizinische Kriterien zur Klassifikation des Antiphospholipid-Syndroms.

Beschreibung Ein aus je zwei wesentlichen klinischen und labormedizinischen Kriterien bestehender, im Jahr 1999 publizierter Katalog zur Diagnose eines AntiphospholipidSyndroms (APS), der 2006 als Konsensusempfehlung zur Diagnostik des APS als sog. Sydney-Kriterien aktualisiert wurde. Das Syndrom gilt als diagnostiziert, wenn mindestens eines der klinischen und eines der labormedizinischen Kriterien erfüllt sind und zweimal im Abstand von 12 Wochen Lupus-Antikoagulanzien im Screening und Bestätigungstest und/oder mittel- bis hochgradig erhöhte Titer von Anticardiolipin-Antikörper (ACLA) ( $\triangleright$ Cardiolipin) gemessen wurden.

\section{Klinische Kriterien}

- Eine oder mehrere Episoden von arteriellen, venösen oder Small-vessel-Thrombosen in irgendeinem Gewebe oder Organ; Bestätigung durch bildgebende oder histopathologische Verfahren

- Erkrankungen in der Schwangerschaft

- Eine oder mehrere Totgeburten nach der 10. Schwangerschaftswoche (SSW) bei sonst morphologisch normalem Fetus
- Eine oder mehrere Frühgeburten bei morphologischem Normalbefund vor der 34. SSW aufgrund schwerer Präeklampsie, Eklampsie oder Plazentainsuffizienz

- Drei oder mehr Spontanaborte vor der 10. SSW bei Ausschluss anatomischer, hormoneller und chromosomaler Ursachen

\section{Labormedizinische Kriterien}

- ACLA vom IgG und/oder IgM-Typ, mittel- oder hochtitrig gemessen durch einen standardisierten, $\beta 2$-Glykoproteinabhängigen ELISA

- Lupus-Antikoagulanzien im Plasma, Nachweis an zwei oder mehreren Zeitpunkten, die mindestens 6 Wochen auseinanderliegen; Nachweis entsprechend den Kriterien der International Society on Thrombosis and Haemostasis

Entsprechend der derzeitig aktuellen Klassifikationskriterien für die Definition eines APS nach den Richtlinien des 11. Internationalen Kongresses der Antiphospholipid-Antikörper (APA) in Sydney (November 2004) gibt es 2 wesentliche Veränderungen:

- Die Kontrolluntersuchungen nach erstmaligem ACLANachweis sollten im Mindestabstand von 12 (anstatt bisher 6) Wochen erfolgen, wobei ein mindestens zweiter Nachweis mittlerer oder hoher ACLA-Titer ( $>40$ GPL oder MPL oberhalb der 99. Perzentile) als laboranalytisches Kriterium für ein APS zu werten ist.

- Der positive, mindestens zweimalige Nachweis von 32 GPI-AK vom IgG- und/oder IgM-Typ in Serum oder Plasma mit einer Titerhöhe oberhalb der 99. Perzentile ist unter Verwendung standardisierter ELISA als laboranalytisches Kriterium für ein APS einzustufen.

Liegen zwischen dem Nachweis der APA und dem Auftreten eines definitionsgemäßen klinischen Ereignisses höchstens 5 Jahre, sollte ein APS angenommen werden.

\section{Literatur}

Miyakis S et al (2006) International consensus statement on an update of the classification criteria for definite antiphospholipid syndrome (APS). J Thromb Haemost 4:295-306

Schuchmann S, Dörner T (2007) Antiphospholipid-Syndrom 2007. Aktuelle Aspekte in der Labordiagnostik und deren therapeutische Konsequenzen. Z Rheumatol 66:198-205

Wilson WA, Gharavi AE, Koike T et al (1999) International consensus statement on preliminary classification criteria for definite antiphospholipid syndrome: report of an international workshop. Arthritis Rheum 42:1309-1311 


\section{S100A12-Protein}

A. M. Gressner und O. A. Gressner

Synonym(e) Calgranulin-C; Neutrophiles S100-Protein

Englischer Begriff S100A12 protein

Definition Polypeptid der S100/Calgranulin-Familie von proinflammatorischen Zytokinen.

Beschreibung Die Exon-Intron-Struktur des S100A12Gens ähnelt denen der meisten anderen S100-Gene (3 Exons, 2 Introns; Codierung durch Exon 2 und 3).

Als Sekretionsprodukt bindet S100A12 gemeinsam mit S100B, und S100A8/A9 an lösliches RAGE ( $\triangleright$ Receptor of advanced glycation end-products) und weitere Rezeptoren auf inflammatorischen, epithelialen und neuronalen Zellen, wodurch es proinflammatorisch wirkt. S100A12 wird in entzündlich veränderten Geweben, insbesondere an Stellen vaskulärer Läsionen, vermehrt gefunden und wirkt hier expressionssteigernd auf RAGE. Die Serumkonzentrationen korrelieren mit der Entzündungsaktivität.

\section{Literatur}

Wicki R et al (1996) Characterization of the human S100A12 (calgranulin C, p6, CAAF1, CGRP) gene, a new member of the S100 gene cluster on chromosome 1q21. Cell Calcium 20:459-464

\section{Sargdeckelkristalle}

- Tripelphosphat-Kristalle

\section{Sarkomerproteine}

K. J. Lackner und D. Peetz

Englischer Begriff sarcomere proteins

Definition Proteine, die das Grundgerüst der funktionellen Einheit (Sarkomer) der Myofibrille bilden.
Beschreibung Das Sarkomer ist ein Zylinder von 1,5 $\mu \mathrm{m}$ Durchmesser und $2 \mu \mathrm{m}$ Länge. Es bildet das Grundgerüst der Myofibrille, indem sich eine Vielzahl von Sarkomeren longitudinal zu einer Myofibrille zusammenlagern.

Die Hauptbestandteile des Sarkomers bilden die beiden Proteine Aktin und Myosin. Die Begrenzung eines Sarkomers stellt auf beiden Seiten die Z-Membran dar, die größtenteils aus $\alpha$-Aktinin besteht. An den Z-Membranen sind jeweils in Längsrichtung der Muskulatur verlaufend Aktine fixiert. In der Mitte des Sarkomers sind zwischen den Aktin-Ketten Mysion-Ketten eingelagert, die die eigentliche Kraftentwicklung der Muskulatur bewirken ( $\triangleright$ Myosin). In der Mitte des Sarkomers werden die Myosin-Ketten durch das M-Protein untereinander verbunden. An Aktin werden über angelagertes Tropomyosin die Troponine gebunden, die die Muskelkontraktion über Regulation der Calcium-Bindung steuern ( $\triangleright$ Troponin). Als stabilisierendes und Signal-transduzierendes Exo-Sarkomerprotein bindet Dystrophin an Aktin. Die Struktur und Elastizität des Sarkomers wird im Ruhezustand über die Makromoleküle Titin und Nebulin aufrechterhalten, die das Sarkomer auf der gesamten Länge durchspannen und mit Molmassen von 300 bzw. 800 kDa zu den größten Proteinen des Körpers gehören.

\section{Sarkosin}

\section{A. C. Sewell}

\section{Englischer Begriff sarcosine}

Definition Methylderivat von Glyzin.

Beschreibung Sarkosin (Sar) ist ein Zwischenprodukt bei der Umwandlung von Cholin in - Glyzin. Erhöhte Werte im Serum und Urin werden bei Sarkosinämie gefunden-, (eine seltene angeborene Stoffwechselstörung mit unspezifischen Symptomen). Aktuell wird geprüft, ob es in der Behandlung von Schizophrenien aufgrund der Erhöhung der Glyzinkonzentration im Gehirn mit Aktivierung der N-Methyl-D-Aspartat(NMDA)-Rezeptoren eingesetzt werden kann.

\section{Literatur}

Duran M (2008) Amino acids. In: Blau N, Duran M, Gibson KM (Hrsg) Laboratory guide to the methods in biochemical genetics. Springer, Berlin/Heidelberg/New York, S 53-90

Sewell AC, Krille M, Wilhelm I (1986) Sarcosinaemia in a retarded amaurotic child. Eur J Pediatr 144:508-510 


\section{Sarkosyl-Elektrophorese}

R. Westermeier

Synonym(e) $N$-Lauroylsarcosin-Elektrophorese; SarkosylPolyacrylamidgel-Elektrophorese; Sarkosyl-PAGE

Englischer Begriff sarcosyl electrophoresis

Definition Bei der Elektrophorese im Polyacrylamidgel in Gegenwart des anionischen Detergenz Sarkosyl wird - analog zur SDS-PAGE - eine Trennung von Protein-Detergenzkomplexen nach Molekülgrößen durchgeführt.

Physikalisch-chemisches Prinzip Manche Formen von synthetischem $>$ Erythropoetin (EPO) sind PEGyliert und werden deshalb nach einer SDS-PAGE und Western Blotting nicht mit der gleichen Empfindlichkeit detektiert wie EPO-Moleküle ohne PEG. Weil das Sarkosyl nur an den Proteinanteil und nicht an den Polyethylenglykolanteil von PEGylierten Proteinen bindet, kann man diese mit PEG modifizierten Proteine beim nachfolgenden Western Blotting mit Antikörpern gegen Erythropoietin detektieren. Diese Methode ersetzt bei bestimmten Fragestellungen die SDS-Polyacrylamidgel-Elektrophorese, denn SDS bindet sowohl an die Proteine als auch an die PEG-Reste; deshalb kann der generell verwendete AntiEPO-Antikörper nicht mit den komplett mit SDS beladenen Molekülen interagieren.

Einsatzgebiet Dopingkontrolle zur Unterscheidung des synthetischen Erythropoetin vom körpereigenen Hormon in Human-Urinproben.

Untersuchungsmaterial Meist Humanurin

Instrumentalisierung Ausrüstung für PolyacrylamidgelElektrophorese bestehend aus Horizontal- oder Minivertikalkammer, Blotting-System, Stromversorger, Umlaufthermostat und Chemilumineszenz-CCD-Kamerasystem.

Spezifizität Hoch, weil es sich um ein immunanalytisches Verfahren handelt.

Sensitivität Je nach verwendetem Chemolumineszenz-Substrat im Bereich niedriger Picogramm bis hoher Femtogramm.

Fehlermöglichkeit Fehler bei der Elektrophorese können bei Verwendung von Fertiggelen minimiert werden. Für den Elektrotransfer bei Western Blotting können fertige Pufferkits eingesetzt werden.
Praktikabilität - Automatisierung - Kosten Mehrschrittige Methode, Aufwand wie bei normalem Western Blotting. Bei der Verwendung von Fertigprodukten ist mit höheren Kosten zu rechnen.

Bewertung - Methodenhierarchie (allg.) Sarcosyl-Elektrophorese ist eine Methode für biochemisch arbeitende Labors. Siehe auch $\triangleright$ PEGylierte Proteine.

\section{Literatur}

Reichel C, Abzieher F, Geisendorfer T (2009) SARCOSYL-PAGE: a new method for the detection of MIRCERA and EPO-doping in blood. Published online in Wiley Interscience, 16 Dec 2009. www. drugtestinganalysis.com. https://doi.org/10.1002/dta.97

\section{Sarkosyl-PAGE}

- Sarkosyl-Elektrophorese

\section{Sarkosyl-Polyacrylamidgel- Elektrophorese}

- Sarkosyl-Elektrophorese

\section{SARS-Corona-Viren}

W. Stöcker und C. Krüger

Synonym(e) Schweres-akutes-respiratorisches-SyndromCorona-Viren

Englischer Begriff severe acute respiratory syndrome (SARS) associated coronavirus

Beschreibung des Erregers Familie: Coronaviridae; Subfamilie: Coronavirinae; Gattung: Betacoronavirus; Plusstrang-RNA-Genom, behüllt, 80-90 nm Durchmesser.

Der Erreger wurde im Jahr 2003 neu identifiziert. Anhand der Gensequenzen wird vermutet, dass ein bekanntes CoronaVirus entweder mutiert ist oder dass eine Virusart, die bisher nur Tiere befallen hat, auf den Menschen „übergesprungen“ ist.

Erkrankungen SARS ist eine durch das SARS-assoziierte Corona-Virus (SARS-CoV) ausgelöste Infektionskrankheit. 
Die Hauptsymptome der Erkrankung sind Fieber, Pharyngitis, Bronchitis, Atemnot und Pneumonie. Die Letalitätsrate betrug $10 \%$, bei über 65 -jährigen Menschen bis zu $50 \%$. Die Erregerübertragung erfolgte überwiegend direkt durch Tröpfcheninfektion aus kurzer Distanz oder durch Kontaktinfektion. Auch infizierte Tiere, z. B. Kakerlaken, haben die Krankheit übertragen. Die Inkubationszeit lag bei 2-7 Tagen.

Der einzige größere Ausbruch der Krankheit war die SARS-Pandemie 2002/2003 mit 8098 Erkrankungen und 744 Todesfällen. Die größte Anzahl an SARS-Fällen wurde in Asien registriert, wo das Virus endemisch ist. Es traten aber auch Fälle in Nordamerika und Europa auf. Ärzte verabreichten damals zunächst als Virostatikum das NukleosidAnalogon Ribavirin sowie Cortison. Danach erhielten die Betroffenen meist einen Cocktail aus verschiedenen Antibiotika, um die begleitende bakterielle Entzündung der Atemwege zu bekämpfen.

Zur Prävention wurden die Erkrankten und Kontaktpersonen isoliert, für die Öffentlichkeit Massenveranstaltungen abgesagt, Kinos und Theater geschlossen, Besuche in Hospitälern unterbunden und überall konsequent desinfiziert.

Analytik Direktnachweis: Nachweis der SARS-CoronaViren durch RT-PCR (Reverse-Transkriptase-PCR; > PCR (Polymerase-Kettenreaktion)).

Kultur:Virusisolation und Vermehrung in Zellkultur (z. B. Verozellkultur).

Serologie: Darstellung einer Serokonversion durch indirekte Immunfluoreszenz (IIFT, s. Abbildung; > Immunfluoreszenz, indirekte) oder $>$ Enzyme-linked Immunosorbent Assay (ELISA).

Indirekte Immunfluoreszenz: Antikörper gegen SARSCorona-Viren:

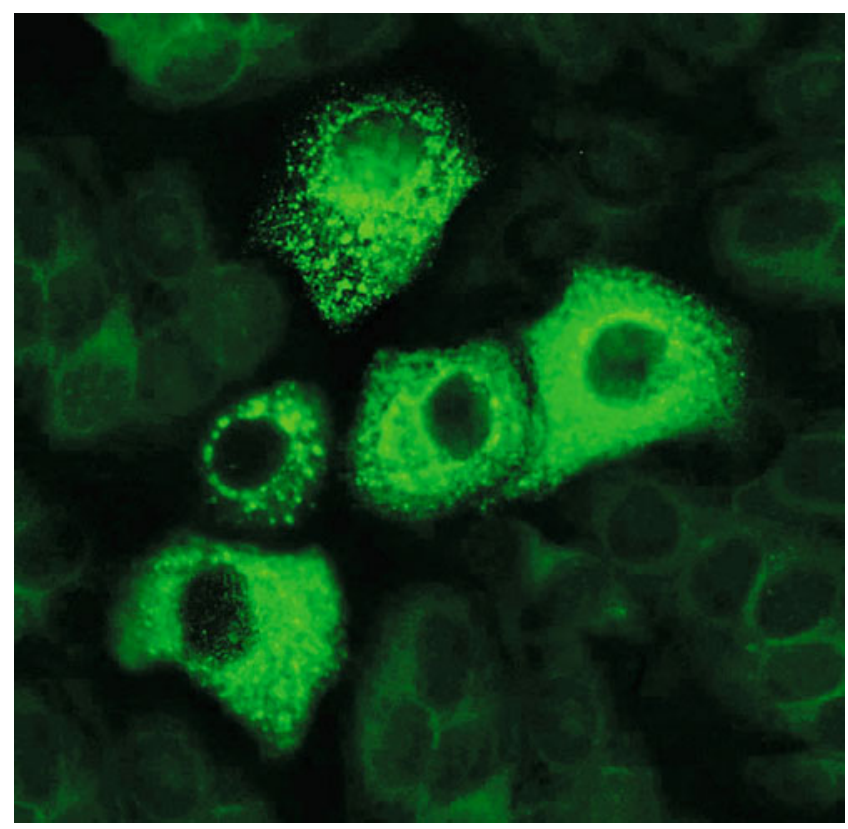

Untersuchungsmaterial - Probenstabilität Direktnachweis und Kultur: Nasenrachen-Absaugsekret, Rachenspülwasser, Rachenabstriche und andere menschliche Proben (PCR). Die Proben sollten gekühlt transportiert und innerhalb von 6 (PCR) und 24 Stunden (Kultur, IFT) analysiert werden.

Serologie: Serum oder Plasma sind für den Nachweis der Antikörper bei $+4{ }^{\circ} \mathrm{C}$ bis zu 2 Wochen lang beständig, bei $-20{ }^{\circ} \mathrm{C}$ über Monate und Jahre hinweg. Zur Tiefkühlkonservierung des IgM kann man den Proben $80 \%$ gepuffertes Glyzerin beifügen.

Diagnostische Wertigkeit Zur vollständigen Labordiagnostik einer Virusinfektion gehört der Nachweis sowohl von Virusbestandteilen (Direktnachweis) als auch spezifischer Antikörper im Serum. Bei einem großen Teil der SARS-Fälle 2002/2003 ließ sich in bestimmten Krankheitsphasen nur mit einem der beiden diagnostischen Prinzipien das Vorliegen einer Infektion beweisen. Für einen positiven SARS-Befund sollten mindestens 2 Proben (unterschiedliches Probenmaterial oder das gleiche Material, entnommen an 2 verschiedenen Tagen) mit RT-PCR positiv auf virale RNA getestet werden. Alternativ gilt eine nachgewiesene Serokonversion mithilfe von ELISA oder IIFT oder ein vierfacher Titeranstieg zwischen 2 Proben aus der akuten und der konvaleszenten Phase als beweisend für eine Infektion.

\section{Literatur}

Berger A, Drosten C, Doerr HW et al (2004) Severe acute respiratory syndrome (SARS) - paradigm of an emerging viral infection. J Clin Virol 29:13-22

Ksiazek TG, Erdman D, Goldsmith CS, SARS Working Group et al (2003) A novel coronavirus associated with severe acute respiratory syndrome. N Engl J Med 348:1953-1966

Niedrig M, Sonnenberg K, Yan H et al (2003) Antibody response in patients infected with the new coronavirus causing severe acute respiratory syndrome (SARS). J Clin Virol 27:1-15

World Health Organization. Emergencies preparedness, response. Use of laboratory methods for SARS diagnosis. http://www.who.int/csr/ sars/labmethods/en/. Zugegriffen am 07.03.2017

\section{Sättigungskinetik}

C. Vidal und W.-R. Külpmann

\section{Englischer Begriff saturation kinetics}

Beschreibung Die Kapazität von Enzymen zum Abbau von Pharmaka ist begrenzt. Deshalb kann eine Dosissteigerung zu einem überproportionalen Anstieg der Konzentration des 
Arzneistoffes im Plasma führen. Bei manchen Pharmaka liegt diese Situation bereits im oberen therapeutischen Bereich vor, z. B. bei $>$ Phenytoin.

Die pharmakokinetischen Daten unterscheiden sich im Bereich oberhalb der Substratsättigung der entsprechenden Enzyme deutlich von den Daten bei niedrigeren Konzentrationen.

\section{Literatur}

Knorre WA (1981) Pharmakokinetik. F. Vieweg u. Sohn, Braunschweig

\section{Satz von Bayes}

$>$ Bayes, Satz von

\section{Sauerstoffaffinität}

- Sauerstofftransport

\section{Sauerstoffdifferenz, arteriovenöse}

- Sauerstofftransport

\section{Sauerstoffdissoziationskurve}

- Sauerstofftransport

\section{Sauerstoffkapazität}

- Sauerstofftransport

\section{Sauerstoffkonzentration}

- Sauerstofftransport

\section{Sauerstoffpartialdruck}

O. Müller-Plathe

Synonym(e) Sauerstoffspannung

Englischer Begriff partial pressure of oxygen; oxygen tension

Definition $>$ Partialdruck.

Molmasse Sauerstoff: $31,998 \mathrm{~g}$.

Funktion - Pathophysiologie $>$ Sauerstofftransport.

Untersuchungsmaterial - Entnahmebedingungen Heparinisiertes Blut, $>$ Blutgasanalyse.

Probenstabilität $>$ Blutgasanalyse.

Präanalytik $>$ Blutgasanalyse.

Analytik Die Messung erfolgt im Rahmen der Blutgasanalyse mit einer amperometrischen Messzelle ( $>$ Amperometrie), bestehend aus einer Platinkathode ( $>$ Kathode), Phosphatpufferlösung und einer Silber/Silberchlorid-Anode ( $\triangleright$ Referenzelektrode). Diese Anordnung ist durch eine gasdurchlässige Membran (meistens Polypropylen) vom Blut in der Messkammer getrennt (Clark-Elektrode, s. - Sauerstoffpartialdruck). Mit einer Kathodenspannung von $650 \mathrm{mV}$ werden die in die Zelle diffundierenden $\mathrm{O}_{2}$ Moleküle reduziert. Die Stärke des dabei entstehenden Reduktionsstroms (Größenordnung nA) hängt ab von der Menge der in der Zeiteinheit diffundierenden $\mathrm{O}_{2}$-Moleküle und damit von $p \mathrm{O}_{2}$. Die Kalibration erfolgt mit einem $\mathrm{O}_{2}$-freien und einem ca. $12 \% \mathrm{O}_{2}$-enthaltenden (dem Bereich um $85 \mathrm{mmHg}$ entsprechend) zertifizierten Gasgemisch.

Qualitätskontrolle $>$ Blutgasanalyse. Alternativ wird $p \mathrm{O}_{2}$ in einigen Geräten für das POCT (point of care testing, ( $\triangleright$ Patientennahe Sofortdiagnostik) mit optischen Methoden gemessen: entweder wie beispielsweise im OPTI (Firma Osmetech) mit einer spezifischen fluorimetrischen „Optode“ oder wie im NPT7 (Firma Radiometer) durch Nutzung der Eigenschaften des Sauerstoffs die Abklingzeit eines zur - Phosphoreszenz angeregten Farbstoffs zu verkürzen.

Konventionelle Einheit $\mathrm{mmHg}$.

Internationale Einheit $\mathrm{kPa}$. 
Umrechnungsfaktor zw. konv. u. int. Einheit $\mathrm{mmHg} \times 0,1333=\mathrm{kPa} ; \mathrm{kPa} \times 7,5=\mathrm{mmHg}$.

Referenzbereich - Erwachsene Arteriell: $80-105 \mathrm{mmHg}$; $10,6-14,0 \mathrm{kPa}$.

Gemischt-venös: 36-44 mmHg; 4,8-5,9 kPa.

Referenzbereich - Kinder s. Erwachsene. Neugeborene: arteriell (nach 30 Minuten): 31-85 mmHg; 4,1-11,3 kPa.

Indikation Beurteilung der Lungenfunktion, Kontrolle der künstlichen Beatmung und der Sauerstofftherapie.

Interpretation Der arterielle $\mathrm{pO}_{2}$ ist kein $\mathrm{Ma}$ für die Sauerstoffversorgung des Organismus, sondern lediglich für die Arterialisierung des Bluts in der Lunge, die bestimmt wird durch die Lungenfunktion, den Sauerstoffgehalt der Einatmungsluft und den Luftdruck.

$p \mathrm{O}_{2}$-Verminderung mit $p \mathrm{CO}_{2}$-Erhöhung ist Ausdruck alveolärer Hypoventilation. Beispiele: bronchostenotisches Emphysem; neurologisch, muskulär oder medikamentös bedingte Atemstörungen.

$p \mathrm{O}_{2}$-Verminderung ohne $p \mathrm{CO}_{2}$-Erhöhung kommt vor bei Lungenerkrankungen, bei denen Störungen des BelüftungsDurchblutungs-Verhältnisses, der Diffusion oder der Perfusion im Vordergrund stehen. Beispiele: Pneumonie, Atelektase, Tumor, Fibrose, Lungenödem, Rechts-Links-Shunt, mangelnde Sauerstoffzufuhr.

Bei der Höhenatmung liegt eine $p \mathrm{O}_{2}$-Verminderung gemeinsam mit einer $p \mathrm{CO}_{2}$-Erniedrigung (respiratorische Alkalose) vor.

$p \mathrm{O}_{2}$-Erhöhung ist Folge von Sauerstoffanreicherung in der Einatmungsluft, meistens im Rahmen künstlicher Beatmung oder Intubationsnarkose.

Diagnostische Wertigkeit Leichte Hypoxämie von 65-80 $\mathrm{mmHg}$ ist bei sehr alten Patienten nicht immer Ausdruck einer manifesten Lungenerkrankung. Werte von 50-65 mmHg stellen bereits eine Gefahr dar und müssen diagnostisch abgeklärt werden. Werte $<50 \mathrm{mmHg}$ sind lebensgefährlich und erfordern eine sofortige Intervention.

\section{Literatur}

Clark LC (1956) Monitor and control of blood and tissue oxygen tensions. Trans Am Soc Artif Intern Organs 2:41-48

\section{Sauerstoffradikal-Produktion}

$>$ Oxidativer Burst

\section{Sauerstoffsättigung}

O. Müller-Plathe

$\operatorname{Synonym(e)} s \mathrm{O}_{2}$

Englischer Begriff oxygen saturation

Definition Anteil des Oxihämoglobins am bindungsfähigen Hämoglobin:

$$
s \mathrm{O}_{2}=\frac{c \mathrm{O}_{2} \mathrm{Hb}}{c \mathrm{O}_{2} \mathrm{Hb}+c \mathrm{HHb}}
$$

Oxihämoglobinfraktion $\left(f \mathrm{O}_{2} \mathrm{Hb}\right)$ s. Abschn. Interpretation.

Funktion - Pathophysiologie $>$ Sauerstofftransport.

Untersuchungsmaterial - Entnahmebedingungen $>$ Blutgasanalyse.

Probenstabilität $>$ Blutgasanalyse.

Präanalytik Blutgasanalyse.

Analytik Sauerstoffsättigung und Oxihämoglobinfraktion können in Blutgasanalysatoren mit Oximetereinrichtung gemeinsam mit den weiteren Hb-Fraktionen gemessen werden ( $>$ Oximetrie). Die automatische Berechnung der Sauerstoffsättigung aus $\mathrm{pO}_{2}$ und $\mathrm{pH}$, bei der Verschiebungen der $\mathrm{O}_{2}$-Dissoziationskurve unberücksichtigt bleiben, ist obsolet.

Konventionelle Einheit Prozent (\%).

Internationale Einheit Dimensionslos (Fraktion).

Umrechnungsfaktor zw. konv. u. int. Einheit 0,01 .

Referenzbereich - Erwachsene Arteriell: 95,0-98,5\%; 0,950-0,985.

Gemischt-venös: 70,0-80,0\%; 0,700-0,800.

Referenzbereich - Kinder s. Erwachsene. Neugeborene: arteriell: 40-90\%; 0,40-0,90.

Indikation Beurteilung der Lungenfunktion, Kontrolle der künstlichen Beatmung und der Sauerstofftherapie.

Interpretation Erniedrigte $s \mathrm{O}_{2}$ im arteriellen Blut spricht für mangelhafte Arterialisierung in der Lunge. Ursachen dafür $\triangleright$ Sauerstoffpartialdruck. $s \mathrm{O}_{2}$ ist wegen des fast horizon- 
talen Verlaufs der $\mathrm{O}_{2}$-Dissoziationskurve im oberen Bereich für die Beurteilung der Lungenfunktion deutlich weniger sensitiv als $p \mathrm{O}_{2}$.

$f \mathrm{O}_{2} \mathrm{Hb}$ Im klinischen Sprachgebrauch wird oft die Fraktion des $\mathrm{O}_{2} \mathrm{Hb}$ vom gesamten Hämoglobin ebenfalls als Sauerstoffsättigung bezeichnet. Die korrekte Bezeichnung dieser Größe lautet aber Oxihämoglobinfraktion $\left(f \mathrm{O}_{2} \mathrm{Hb}\right)$, engl. „fractional Oxihemoglobin“:

$$
f \mathrm{O}_{2} \mathrm{Hb}=\frac{c \mathrm{O}_{2} \mathrm{Hb}}{c \mathrm{O}_{2} \mathrm{Hb}+c \mathrm{HHb}+\mathrm{COHb}+\mathrm{MetHb}+\mathrm{SulfHb}}
$$

$f \mathrm{O}_{2} \mathrm{Hb}$ ist normalerweise um etwa $0,01-0,02$ (1-2 \%) niedriger als $s \mathrm{O}_{2}$. Der Referenzbereich reicht deshalb bis etwa 0,940 (94\%). Unter pathologischen Bedingungen wie Kohlenmonoxideinwirkung oder Methämoglobinämie unterscheiden sich $f \mathrm{O}_{2} \mathrm{Hb}$ und $s \mathrm{O}_{2}$ gravierend. Für einen Raucher mit $f \mathrm{COHb}=0,08$ und $f \mathrm{MetHb}=0,02$ errechnet sich bei $s \mathrm{O}_{2}$ von $0,96 \operatorname{ein} f \mathrm{O}_{2} \mathrm{Hb}$ von 0,86 .

Diagnostische Wertigkeit Werte zwischen 0,85 und 0,93 im arteriellen Blut stellen bereits eine Gefahr dar und müssen diagnostisch abgeklärt werden. Werte $<0,85$ sind lebensgefährlich und erfordern eine sofortige Intervention.

\section{Sauerstoffspannung}

- Sauerstoffpartialdruck

\section{Sauerstoffspezies, reaktive}

- Reaktive Sauerstoffspecies

\section{Sauerstofftransport}

O. Müller-Plathe

Englischer Begriff oxygen supply
Definition Der Sauerstofftransport umfasst die Aufnahme des Sauerstoffs in der Lunge, seinen Transport im Blut und die Bedingungen seiner Abgabe ans Gewebe.

Beschreibung Unterteilt in pulmonaler Gasaustausch, Transport durch Hämoglobin und Sauerstoffabgabe im Gewebe.

Pulmonaler Gasaustausch Das venöse Blut erreicht die Lungenkapillaren mit $p \mathrm{CO}_{2}=46 \mathrm{mmHg}$ und $p \mathrm{O}_{2}=40 \mathrm{mmHg}$. Bei einer Gesamtoberfläche der Lungenalveolen von 50-80 $\mathrm{m}^{2}$ und einem Diffusionsweg von etwa $1 \mu \mathrm{m}$ reicht eine Kontaktzeit von $0,3 \mathrm{~s}$ aus, um das Blut mit der Alveolarluft auf $p \mathrm{CO}_{2}=40 \mathrm{mmHg}$ und $p \mathrm{O}_{2}=100 \mathrm{mmHg}$ zu äquilibrieren. Durch physiologische venoarterielle Kurzschlüsse wird der endgültige arterielle Sauerstoffpartialdruck um etwa $10 \mathrm{mmHg}$ gesenkt.

Nach dem Henry-Gesetz ( $\triangleright$ Partialdruck) bestimmt $p \mathrm{O}_{2}$ die Menge des physikalisch gelösten Sauerstoffs $c \mathrm{dO}_{2}$ (d für „dissolved“):

- $c \mathrm{dO}_{2}[\mathrm{mmol} / \mathrm{L}]=0,010 \times p \mathrm{O}_{2}[\mathrm{kPa}]$ oder

- $c \mathrm{dO}_{2}[\mathrm{~mL} / \mathrm{L}]=0,031 \times p \mathrm{O}_{2}[\mathrm{mmHg}]$.

Bei normalem $p \mathrm{O}_{2}$ von $90 \mathrm{mmHg}$ sind somit $2,8 \mathrm{ml} \mathrm{O}_{2}$ in 1 L Plasma entsprechend $1,4 \%$ der gesamten $\mathrm{O}_{2}$-Konzentration gelöst.

\section{Transport durch Hämoglobin}

O2-Kapazität

Der $\mathrm{O}_{2}$-Transport erfolgt zu über $98 \%$ durch reversible Bindung an Hämoglobin. Die $4 \mathrm{Hb}-$ Monomere (Molmasse $16,114 \mathrm{kDa}$ ) tragen je eine zur $\mathrm{O}_{2}$-Bindung fähige Hämgruppe. Das mit $\mathrm{O}_{2}$ beladene Hämoglobin heißt Oxihämoglobin $\left(\mathrm{O}_{2} \mathrm{Hb}\right)$, das unbeladene wird als Deoxihämoglobin $(\mathrm{HHb})$ bezeichnet.

Die $\mathrm{O}_{2}$-Kapazität des Blutes - diejenige Menge $\mathrm{O}_{2}$, die maximal an $\mathrm{Hb}$ gebunden werden kann - ergibt sich nach folgender Relation:

- $1 \mathrm{mmol} \mathrm{O}_{2}$ pro $1 \mathrm{mmol} \mathrm{Hb}-$ Monomer oder

- $1,39 \mathrm{~mL} \mathrm{O}_{2}$ pro $1 \mathrm{~g}$ funktionsfähiges Hämoglobin.

Bei einer normalen $\mathrm{Hb}-$ Konzentration von $9,3 \mathrm{mmol} / \mathrm{L}$ entsprechend $150 \mathrm{~g} / \mathrm{L}$ beträgt somit die $\mathrm{O}_{2}$-Kapazität $9,3 \mathrm{mmol} / \mathrm{L}$ bzw. $210 \mathrm{ml} / \mathrm{L}$. Referenzbereiche: Frauen 160-210 mL/L, Männer 180-230 mL/L. Den Anteil des $\mathrm{O}_{2} \mathrm{Hb}$ am gesamten bindungsfähigen $\mathrm{Hb}$ bezeichnet man als > Sauerstoffsättigung $\left(\mathrm{sO}_{2}\right)$. 
$\mathrm{O}_{2}$-Konzentration $\left(\mathrm{ctO}_{2}\right)$

Die Gesamtkonzentration des Sauerstoffs ( $t$ für total) ist die Summe des physikalisch gelösten und des gebundenen $\mathrm{O}_{2}$ :

- $c \mathrm{tO}_{2}[\mathrm{~mL} / \mathrm{L}]=1,39 c \mathrm{O}_{2} \mathrm{Hb}[\mathrm{g} / \mathrm{L}]+0,031 p \mathrm{O}_{2}[\mathrm{mmHg}]$

Referenzbereiche: arteriell $180-230 \mathrm{~mL} / \mathrm{L} ; 8,0-10,3 \mathrm{mmol} / \mathrm{L}$; gemischt-venös $130-180 \mathrm{~mL} / \mathrm{L} ; 5,8-8,0 \mathrm{mmol} / \mathrm{L}$.

ctO $\mathrm{O}_{2}$ ist die wichtigste Messgröße für die Beurteilung des Sauerstoffangebots an die Organe und die Grundlage für die Berechnung der arteriovenösen Sauerstoffdifferenz $\left(c_{(a-v)} O_{2}\right)$ :

- $c_{(\mathrm{a}-\mathrm{v})} \mathrm{O}_{2} \quad[\mathrm{~mL} / \mathrm{L}]=c t \mathrm{O}_{2(\mathrm{a})}-c t \mathrm{O}_{2(\mathrm{v})} \quad$ (Referenzbereich: $45-60 \mathrm{ml} / \mathrm{L})$

$c t \mathrm{O}_{2(\mathrm{v})}$ wird in einer gemischt-venösen Blutprobe aus der A. pulmonalis gemessen.

$c_{(\text {a-v })} \mathrm{O}_{2}$ ist über das Herzzeitvolumen $\left(\mathrm{Q}_{\mathrm{T}}\right)$ mit dem $\mathrm{O}_{2}$-Verbrauch $\left(\mathrm{VO}_{2}\right)$ des Gesamtorganismus verbunden

- $\mathrm{VO}_{2}[\mathrm{~mL} / \mathrm{min}]=c_{(\mathrm{a}-\mathrm{v})} \mathrm{O}_{2}[\mathrm{~mL} / \mathrm{L}] \times \mathrm{Q}_{\mathrm{T}}[\mathrm{L} / \mathrm{min}]$

Mit einer normalen arteriovenösen Differenz von $55 \mathrm{~mL} / \mathrm{L}$ und einem Herzzeitvolumen von 5,5 L/min wird der normale $\mathrm{O}_{2}$-Verbrauch von $300 \mathrm{~mL} / \mathrm{min}$ ermöglicht. Sinkt die Herzleistung, muss die arteriovenöse $\mathrm{O}_{2}$-Differenz steigen; sinkt diese, z. B. bei starker Anämie, muss $\mathrm{Q}_{\mathrm{T}}$ erhöht werden, um den Sauerstoffbedarf zu gewährleisten. Wird dieser erhöht wie bei Hyperthermie, steigen sowohl $\mathrm{Q}_{\mathrm{T}}$ als auch $c_{(\mathrm{a}-\mathrm{v})} \mathrm{O}_{2}$.

Sauerstoffabgabe im Gewebe Nicht nur die angebotene $\mathrm{O}_{2}$-Menge, sondern auch das Abgabeverhalten des $\mathrm{Hb}$, seine Affinität zum Sauerstoff, ist für die $\mathrm{O}_{2}$-Versorgung des Gewebes von Bedeutung. An der S-förmigen Standard- $\mathrm{O}_{2^{-}}$ Dissoziationskurve (s. Abbildung, mittlere Linie) erkennt man, dass im arteriellen Bereich auch bei sinkendem $p \mathrm{O}_{2}$ noch sehr viel $\mathrm{O}_{2}$ gebunden wird. Wenn $p \mathrm{O}_{2}$ von 100 auf $60 \mathrm{mmHg}$ sinkt, liegt $s \mathrm{O}_{2}$ immer noch bei 0,91 . Deshalb hat $p \mathrm{O}_{2}$ eine deutlich höhere Sensitivität zur Beurteilung der Lungenfunktion als $s \mathrm{O}_{2}$. Umgekehrt führen im venösen Bereich geringe $p \mathrm{O}_{2}$-Verminderungen zu starkem Absinken von $s \mathrm{O}_{2}$ und erhöhter $\mathrm{O}_{2}$-Abgabe. Hier ist $s \mathrm{O}_{2}$ der sensitivere Parameter zur Beurteilung der Sauerstoffabgabe.

Die folgende Abbildung zeigt die $\mathrm{O}_{2}$-Dissoziationskurven (ODK) für $3 \mathrm{pH}$-Werte. Linke Ordinate $s \mathrm{O}_{2}$, rechte Ordinate $c t \mathrm{O}_{2}$ unter der Annahme einer Hb-Konzentration von 108 $\mathrm{g} / \mathrm{L}$. Unter der Annahme eines arteriellen $p \mathrm{O}_{2}$ von 72 und eines venösen von $34 \mathrm{mmHg}$ ergibt sich auf der ODK für $\mathrm{pH}=7,4$ (Mitte) eine $\mathrm{O}_{2}$-Abgabe von $44 \mathrm{ml} / \mathrm{L}$. Der zugehörige Halbsättigungsdruck ( $p 50)$ beträgt $27 \mathrm{mmHg}$. Nach der Kurve für $\mathrm{pH}=7,2$ mit $p 50$ von $30 \mathrm{mmHg}$ würden $51 \mathrm{ml} / \mathrm{L} \mathrm{O} \mathrm{O}_{2}$ freigesetzt, bei $\mathrm{pH}=7,6(p 50=23 \mathrm{mmHg})$ jedoch nur $34 \mathrm{ml} / \mathrm{L}$. Das Beispiel veranschaulicht den Einfluss einer Alkalose auf die $\mathrm{O}_{2}$-Versorgung.

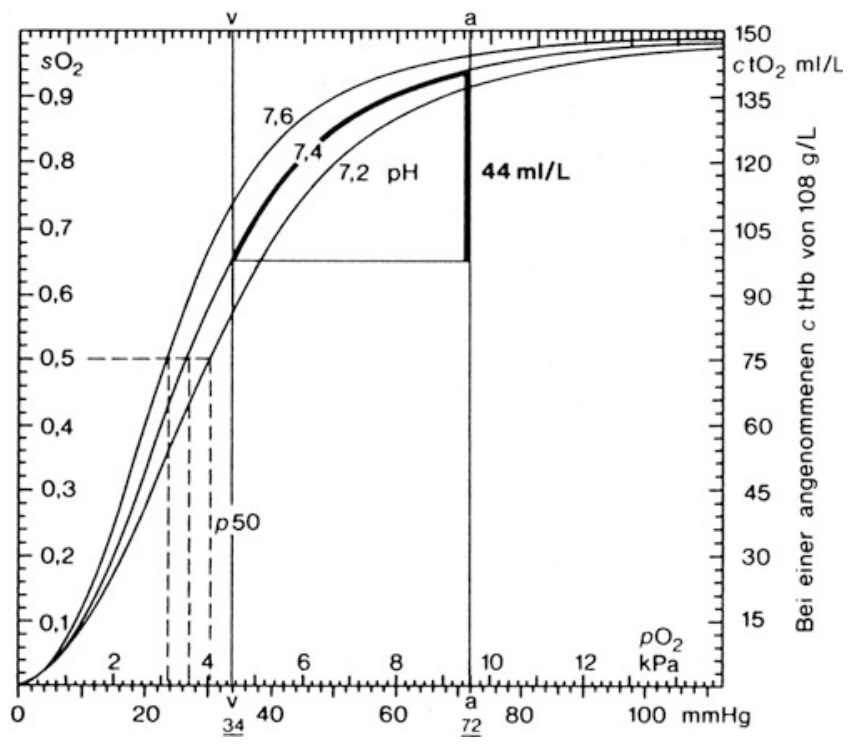

Zunahme der Affinität verschiebt die ODK nach links, Abnahme nach rechts. Ersteres bedeutet verminderte, letzteres erhöhte $\mathrm{O}_{2}$-Freisetzung.

Die $\mathrm{O}_{2}$-Affinität wird beeinflusst durch

1. Temperatur: Abnahme bei Hyperthermie, Zunahme bei Hypothermie

2. $p \mathrm{CO}_{2}$ : Abnahme bei Hyperkapnie, Zunahme bei Hypokapnie

3. pH: Abnahme bei Acidämie, Zunahme bei Alkalämie, sogenannter Bohr-Effekt (nach dem dänischen Physiologen Christian Bohr, 1855-1911)

4. 2,3-Diphosphoglyzerat (DPG)-Konzentration im Erythrozyten; Zunahme verschiebt die ODK nach rechts, Abnahme nach links

- 2,3-DPG -Anstieg bei:

- Chronischer Alkalose im Laufe von wenigen Tagen; dadurch Ausgleich des für die $\mathrm{O}_{2}$-Versorgung nachteiligen alkalämischen Bohr-Effekts (wichtig für die Höhenatmung!)

- Chronischer Hypoxie durch respiratorische oder kardiale Insuffizienz und Anämie 
- Hormonalen Einflüssen: Hyperthyreose, Schwangerschaft

- 2,3-DPG-Abfall bei:

- Chronischer respiratorischer oder metabolischer Acidose

- Blutkonserven, Erythrozytenkonzentrate, Massentransfusionen

- Diphosphoglyzeratmutasemangel

5. Hämoglobinvarianten: Einige Hämoglobinopathien, z. B. $\mathrm{HbS}$, führen zu einer verminderten, die meisten jedoch zu einer erhöhten $\mathrm{O}_{2}$-Affinität. Fetales $\mathrm{Hb}$ hat durch ein geringeres Bindungsvermögen für 2,3-DPG eine erhöhte $\mathrm{O}_{2}$-Affinität.

6. Dyshämoglobine: Carboxyhämoglobin und Methämoglobin erhöhen die $\mathrm{O}_{2}$-Affinität des funktionsfähig gebliebenen $\mathrm{Hb}$-Anteils.

Quantitativ wird die $\mathrm{O}_{2}$-Affinität durch den $>$ Halbsättigungsdruck (Hämoglobin) ( $p 50)$ ausgedrückt.

\section{Literatur}

Hsia CCW (1998) Respiratory function of hemoglobin. NEJM 338:239-247

Rensing H (2001) Lagerungsabhängige Beeinflussung der Sauerstofftransportkapazität von Erythrozytenkonzentraten. Anaesthesist 50(Suppl 1):9-15

\section{Säuglingsbilirubin}

\section{A. M. Gressner und O. A. Gressner}

Synonym(e) Neonatales Serumbilirubin

Englischer Begriff neonatal bilirubin

Definition Es handelt sich um ein transient auftretendes, unkonjugiertes (somit prähepatisches) $>$ Bilirubin bei Frühgeborenen und reifen Neugeborenen, dessen Konzentration im Serum 3-5 Tage post partum maximal ist.

Synthese - Verteilung - Abbau - Elimination Im Rahmen des physiologischen Neugeborenenikterus (Ikterus neonatorum), der sich vom 2.-3. Lebenstag an entwickelt, kommt es zu einer Zunahme der unkonjugierten Bilirubinfraktion im Blut (s. Abbildung), der folgende Pathogenese zugrunde liegt:

- 2- bis 3-fach gesteigerte Bilirubinproduktion durch kürzere Lebensdauer und höheren Hämoglobingehalt fetaler Erythrozyten
- Etwa 2-fach erhöhter Bilirubinanfall aus nicht erythrozytären Quellen und aus ineffektiver Erythropoese (Destruktion erythrozytärer Vorstufen; Erythropoese, ineffektive)

- Reduzierte Aufnahme in Hepatozyten durch relative Verminderung der zytosolischen Bilirubin-bindenden Proteine Ligandin und $Z$ Protein

- Verminderte Aktivität der $>$ UDP-Glukuronyltransferase in der Neonatenleber und damit reduzierte biliäre Exkretion

Die folgende Abbildung zeigt den zeitlichen Verlauf der medianen Konzentrationen von Bilirubin im Serum Reifgeborener $(\mathrm{NG})$ und Frühgeborener $(\mathrm{FG})$ :

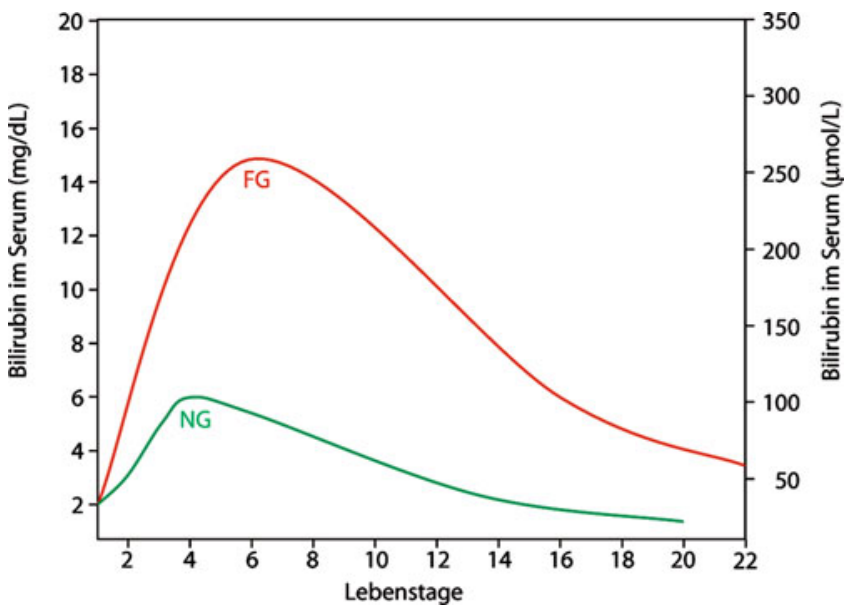

Funktion - Pathophysiologie Häufiger als bei Reifgeborenen entwickelt sich bei Frühgeborenen eine pathologische, therapiebedürftige Hyperbilirubinämie mit Anstiegen über $15 \mathrm{mg} / \mathrm{dL}$ (Ikterus gravis) (s. Abbildung). Es besteht die Gefahr des Kernikterus (Bilirubinenzephalopathie) aufgrund der Neurotoxizität des lipophilen Bilirubins. Risikofaktoren für eine verstärkte Hyperbilirubinämie sind:

- Positive Familienanamnese

- Ausgeprägter postnataler Gewichtsverlust

- AB0-Konstellation

- Hämatome (große Kephal-Subgalealhämatome, Nebennierenblutungen)

- Sphäro- oder Elliptozytose

- Glukose-6-Phosphat-Dehydrogenase-Mangel (insbesondere in Verbindung mit Morbus Gilbert-Meulengracht) und andere, mit Hämolyse assoziierte Enzymdefekte, die sich nicht in einem positiven Coombstest widerspiegeln

Bei der Mehrzahl der Kinder mit Kernikterus steht das Auftreten der schweren Hyperbilirubinämie nicht mit einem routinemäßig erfassbaren Risikofaktor in Zusammenhang. 
Untersuchungsmaterial-Entnahmebedingungen Serum.

Präanalytik Lichtgeschützte Probenverwahrung notwendig wegen Photosensibilität des Analyten ( $\triangleright$ Probenstabilität).

\section{Analytik}

- Transkutane (nicht invasive) Bilirubinometrie, bei der reflexionsphotometrisch die Gelbfärbung der Haut gemessen wird.

- Direkte quantitative spektrometrische Bestimmung des Bilirubins im Neugeborenenserum bei $455 \mathrm{~nm}$ (nahe dem Absorptionsmaximum) mit einem direkt lesenden Bilirubinometer. Die spektrale Interferenz von Hämoglobin bei $455 \mathrm{~nm}$ wird subtrahiert durch zusätzliche Messung der Absorption bei $575 \mathrm{~nm}$, bei der Oxyhämoglobin die gleiche Absorption wie bei $455 \mathrm{~nm}$ aufweist. Voraussetzung für die Anwendung der Methode ist die Abwesenheit von Lipochromen wie Karotin und Xanthophyllester, was während der ersten 2-3 Lebenswochen gewährleistet ist. Bei Konzentrationen über $18 \mathrm{mg} / \mathrm{dL}(>300 \mu \mathrm{mol} / \mathrm{L})$ sollte mit einer chemischen Methode Bilirubin bestimmt werden.

\section{Umrechnungsfaktor zw. konv. u. int. Einheit}

Umrechnungsfaktor: $\mathrm{mg} / \mathrm{dL} \stackrel{17,1}{\longrightarrow} \mu \mathrm{mol} / \mathrm{L} \stackrel{0,0585}{\longrightarrow} \mathrm{mg} / \mathrm{dL}$

\section{Referenzbereich - Kinder}

\begin{tabular}{|l|l|l|l|l|}
\hline Alter & \multicolumn{2}{|c}{ Frühgeburten } \\
& $(\mu \mathrm{mol} / \mathrm{L})$ & $(\mathrm{mg} / \mathrm{dL})$ & $\begin{array}{l}\text { Termingerechte Geburten } \\
(\mu \mathrm{mol} / \mathrm{L})\end{array}$ & $(\mathrm{mg} / \mathrm{dL})$ \\
\hline 24 Stunden & $17-136$ & $1-8$ & $34-102$ & $2-6$ \\
\hline 48 Stunden & $102-205$ & $6-12$ & $102-171$ & $6-10$ \\
\hline 3-5 Tage & $171-240$ & $10-14$ & $68-136$ & $4-8$ \\
\hline
\end{tabular}

Säuglinge $>1$ Monat haben Erwachsenenkonzentrationen.

Interpretation Ein pathologischer Neugeborenenikterus liegt vor bei:

- Klinisch sichtbarer Ikterus schon am 1. Tag

- Bilirubinanstieg um mehr als $5 \mathrm{mg} / \mathrm{dL}$ pro Tag

- Hyperbilirubinämie über $13 \mathrm{mg} / \mathrm{dL}$ bei Reifgeborenen in den ersten 5 Tagen

- Eine direkte (konjugierte) Bilirubinkonzentration über $1,5 \mathrm{mg} / \mathrm{dL}$

- Persistierender Ikterus, der länger als 1 Woche bei Reifgeborenen oder länger als 2 Wochen bei Frühgeborenen dauert.

Ursachen können neben einem verstärkten physiologischen Ikterus neonatorum ein Morbus haemolyticus neonato- rum, korpuskuläre hämolytische Anämie (Sphärozytose), kongenitale Hypothyreose, Abbau extravasaler Blutmassen (z. B. bei Kephalhämatom) oder das Crigler-Najjar-Syndrom (UDP-Glukuronyltransferasemangel) sein.

\section{Literatur}

Gesellschaft für Neonatologie und Pädiatrische Intensivmedizin Leitlinie Nr. 024/007 vom 21.11.2003: Hyperbilirubinämie - Diagnostik und Therapie bei reifen gesunden Neugeborenen. AWMF on line: www.uni-duesseldorf.de/WWW/AWMF/11/pneon-07.htm

\section{Säulenagglutinations-Test}

\author{
K. Kleesiek, C. Götting, J. Diekmann, J. Dreier und \\ M. Schmidt
}

Synonym(e) Gelkartentest; Geltest; Gelzentrifugationstest; Glaskugeltest; Kartentest

Englischer Begriff gel column test; column agglutination test

Definition Der Säulenagglutinations-Test ist eine immunhämatologische Technik zur Blutgruppenbestimmung, zum Antikörpersuchtest und zur Antikörperdifferenzierung.

Beschreibung Funktion und Methode: Der Vorteil des Säulenagglutinations-Tests, im Vergleich zum traditionellen - Röhrchentest, liegt in der Möglichkeit einer verbesserten Dokumentation der Ergebnisse, einer leichteren Mechanisierung und einer höheren Sensitivität. Darüber hinaus können Mischfeldagglutinationen deutlich besser als mit alternativen Techniken erkannt werden,

In diesem Verfahren werden freie Proteine, agglutinierte und nichtagglutinierte Erythrozyten in einer Trennsäule, dessen Matrix aus Mikropartikeln (Gel oder Glas) besteht, nach Partikelgröße getrennt. So wird in den Säulen eine Trennung von Agglutinaten und Nichtagglutinaten erreicht. In der Regel sind 6 Mikrosäulen zu einer Karte zusammengefasst. Abhängig von der immunhämatologischen Frage enthalten die Mikrosäulen LISS-Lösungen mit spezifischen Antikörpern (z. B. Anti-A, Anti-B, Anti-D, Anti-IgA, Anti-IgM, Anti-IgG, Anti-C3d) oder eine antikörperfreie physiologische Lösung (Neutralsäule). Führt das Reaktionsgemisch mit den Probandenerythrozyten zu einer Agglutination, verbleibt das Agglutinat nach Zentrifugation im oberen Teil oder innerhalb der Mikropartikelschicht. Ohne Agglutination sedimentieren die Erythrozyten an den Boden der Säule. 
Die Abbildung zeigt die Agglutinationsreaktion in der Säulentechnik ( $a=$ positives Ergebnis, $b=$ negatives Ergebnis):
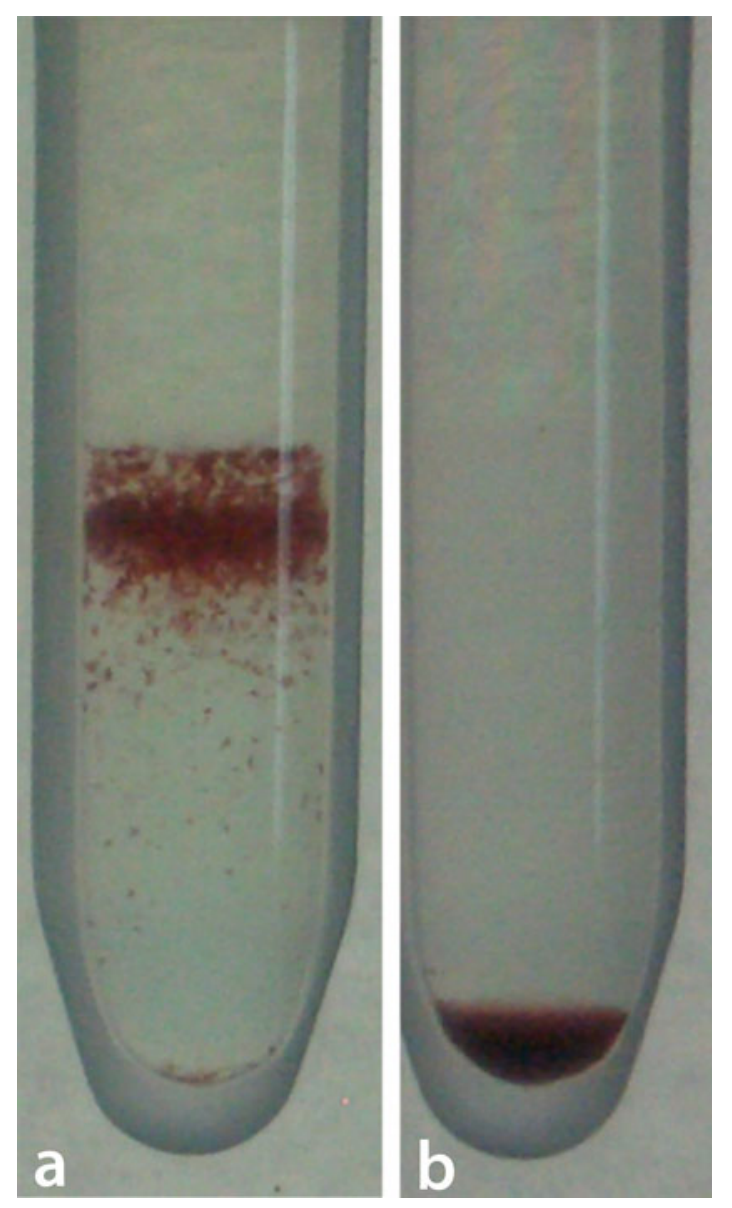

Darstellung der unterschiedlichen Reaktionsstärken als semiquantitatives Ergebnis:

- Negativ: - oder 0

- Diskret positiv: $(+)$ oder $0-1$

- Schwach positiv: + oder 1

- Deutlich positiv: ++ oder 2

- Stark positiv: +++ oder 3

- Maximal positiv: ++++ oder 4

\section{Literatur}

Eckstein R, Zimmermann R (2015) Immunhämatologie und klinische Transfusionsmedizin, 7. Aufl. Urban \& Fischer/Elsevier Verlag Engelfried CP, Meulenbroek AJ (Hrsg) (2003) Immunohaematology. Sanquin Blood Supply Foundation, Amsterdam

Kiefel V (Hrsg) (2010) Transfusionsmedizin: Grundlagen - Therapie Methodik, 4. Aufl. Springer, Berlin/Heidelberg/New York

\section{Säulenchromatographie}

- Chromatographie

\section{Säure, fixe}

> Säure-Basen-Stoffwechsel

\section{Säure, nichtflüchtige}

- Säure-Basen-Stoffwechsel

\section{Saure Phosphatase}

Dhosphatase, Saure

\section{Saure Phosphatase-Reaktion}

- Phosphatase-Reaktion

\section{Saure Prostataphosphatase}

Dhosphatase, Prostataspezifische Saure

\section{Säureausscheidung, renale}

O. Müller-Plathe

Synonym(e) Renale Säure-Basen-Regulation

Englischer Begriffz renal acid excretion

Definition Als renale Säureausscheidung fasst man die Vorgänge in den einzelnen Abschnitten des Nephrons zusammen, die durch Reabsorption von Bikarbonat sowie durch Elimination und Pufferung nicht flüchtiger Säuren zu einem ausgeglichenen Säure-Basen-Status des Organismus beitragen.

Beschreibung Die durch enterale Aufnahme oder durch Stoffwechselprozesse entstehenden nicht flüchtigen (fixen) Säuren, normalerweise 60-80 mmol/Tag, müssen vollständig 
durch die Nieren ausgeschieden werden ( $\triangleright$ Säure-BasenStoffwechsel). Die Nieren bewirken die Säure-Basen-Regulation mit mehreren Teilfunktionen:

\section{Rückgewinnung des filtrierten Bikarbonats im proximalen Tubulus}

$\mathrm{HCO}_{3}{ }^{-}$gelangt mit $25 \mathrm{mmol} / \mathrm{L}$ ins Glomerulumfiltrat. Bei $180 \mathrm{~L}$ Filtrat/Tag ergibt sich eine Bikarbonatmenge von ca. $4500 \mathrm{mmol}$, die in 24 Stunden zu reabsorbieren ist. Diese Leistung wird $\mathrm{zu} 80 \%$ von den proximalen Tubuluszellen erbracht, die mit 2 Isoenzymen der Carboanhydratase (CA) ausgestattet sind. Durch den $\mathrm{Na}^{+} / \mathrm{H}^{+}$-Antiporter NHE-3 sezerniert die Zelle Wasserstoffionen bis zu einem $\mathrm{pH}$-Gradienten von $1 \mathrm{im}$ Austausch mit $\mathrm{Na}^{+} . \mathrm{H}^{+}$tritt mit $\mathrm{HCO}_{3}{ }^{-} \mathrm{zu}$ Kohlensäure zusammen. $\mathrm{H}_{2} \mathrm{CO}_{3}$ wird durch die membranständige $\mathrm{CA}$ IV in $\mathrm{CO}_{2}$ und Wasser gespalten. $\mathrm{CO}_{2}$ diffundiert in die Zelle und wird dort durch die zytoplasmatische CA II der Bikarbonatbildung zugeführt. $\mathrm{H}^{+}$steht für die erneute Sekretion ins Tubuluslumen zur Verfügung. Über den Cotransporter NBC-1 kehren $\mathrm{Na}^{+}$und $\mathrm{HCO}_{3}{ }^{-}$in den extrazellulären Raum (EZR) zurück (Abb. 1).
Säureausscheidung, renale, Abb. 1 Proximale BicarbonatReabsorption, distale $\mathrm{H}^{+}$-Sekretion und Harnpufferung. $1=\mathrm{Na}^{+} / \mathrm{H}^{+}$Antiporter, $2=$ Cotransporter, $3=\mathrm{H}^{+}$-ATPase, $4=\mathrm{Cl}^{-} / \mathrm{HCO}_{3}{ }^{-}$Antiporter
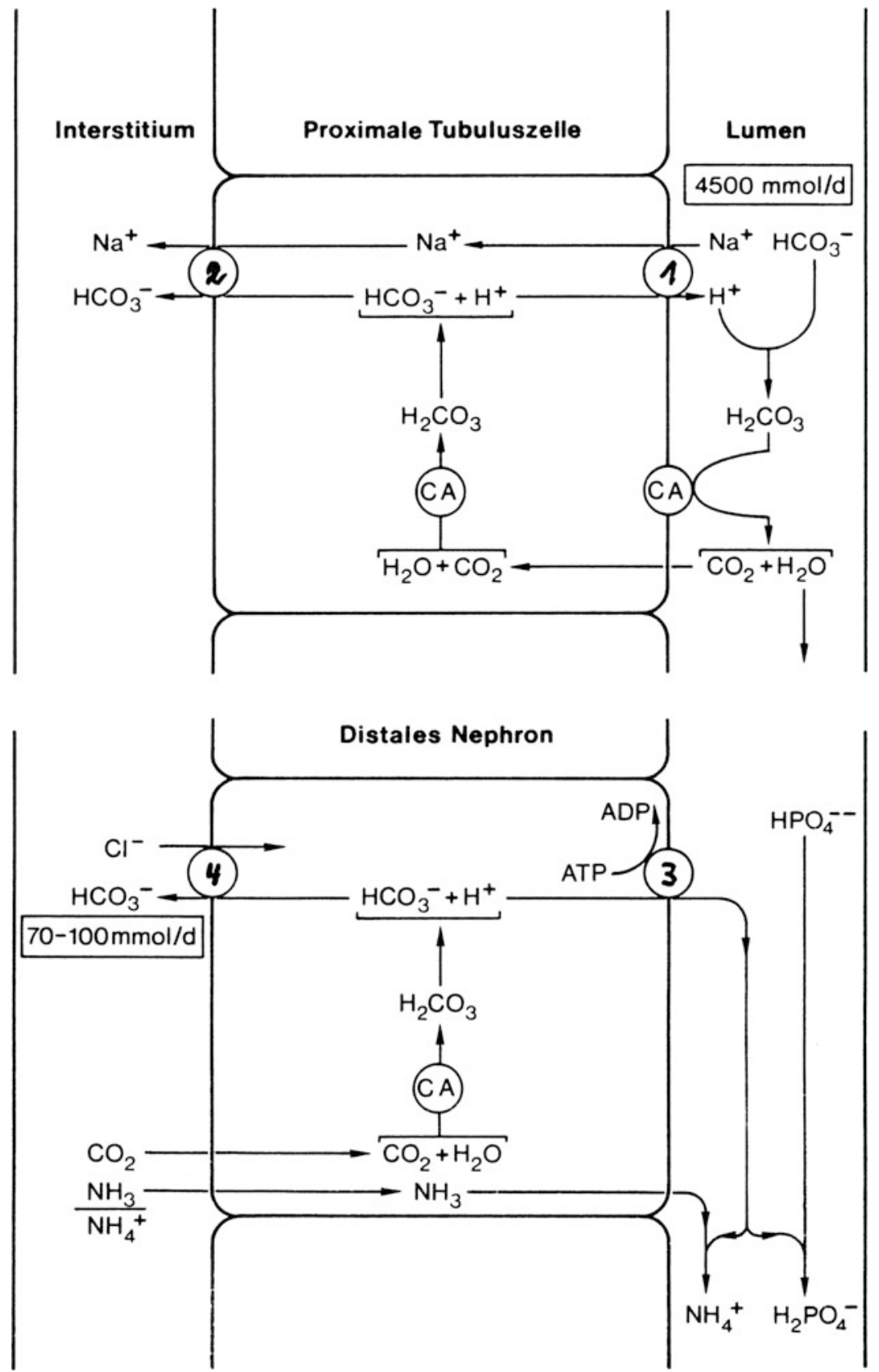
Die Kapazität des gesamten Prozesses ist mit etwa $4500 \mathrm{mmol} / \mathrm{Tag} \mathrm{sehr}$ hoch. Er wird durch extrazellulären Volumenmangel, Kaliummangel, Glukokortikoidexzess und Acidose einschließlich Hyperkapnie stimuliert. Durch Volumenüberschuss, Kaliumüberschuss, Hypokapnie, Parathormon und Acetazolamid wird er gehemmt.

\section{Adaptive $H^{+}$-Ausscheidung im distalen Nephron}

Diese und die damit verbundene Rückgewinnung von Bikarbonat finden vorwiegend in den kortikalen Anteilen der Sammelrohre statt. Deren Zellen verfügen über eine $\mathrm{H}^{+}$transportierende ATPase, die bis zu einem $\mathrm{pH}$-Gradienten $=$ 3, also der 1000-fachen Konzentration, $\mathrm{H}^{+}$sezernieren kann. Das entstehende Bikarbonat wird durch den $\mathrm{Cl}^{-} / \mathrm{HCO}_{3}{ }^{-}$. Antiporter AE1 dem EZR zugeführt (Abb. 1). Die Kapazität dieses der Feineinstellung und der Neubildung von $\mathrm{HCO}_{3}{ }^{-}$ dienenden Mechanismus ist mit $70-100 \mathrm{mmol} / \mathrm{Tag}$ gering. Der Prozess wird durch Aldosteron und Acidose einschließlich Hyperkapnie stimuliert und durch Alkalose und Hypokapnie gehemmt.

Die Epithelzellen der kortikalen Sammelrohre sind in der Lage, bei Alkalose $\mathrm{HCO}_{3}{ }^{-}$ins Lumen auszuscheiden. Es wird angenommen, dass neben dem vorherrschenden Zelltyp mit lumenseitiger $\mathrm{H}^{+}$-ATPase und basalseitigem $\mathrm{Cl}^{-} / \mathrm{HCO}_{3}{ }^{-}$Antiporter (Abb. 1) ein weiterer Zelltyp mit entgegengesetzter Anordnung existiert.

\section{Bildung und Ausscheidung von Ammonium}

Der größte Teil der Säureausscheidung entfällt auf die Exkretion von Ammonium. $\mathrm{NH}_{4}^{+}$wird in den proximalen Tubuluszellen hauptsächlich durch den Abbau von Glutamin gebildet, der wie in Abb. 2 dargestellt verläuft:

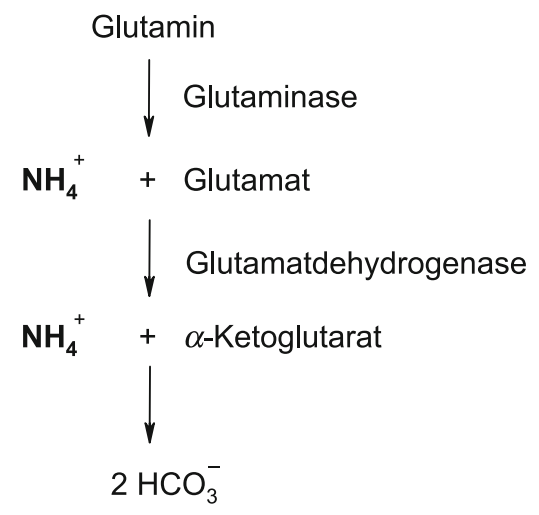

Säureausscheidung, renale, Abb. 2 Glutaminabbau/ Bildung von Ammonium in den proximalen Tubuluszellen
$\mathrm{NH}_{4}{ }^{+}$wird in das proximale Tubuluslumen sezerniert, im medullären dicken aufsteigenden Teil der Henleschen Schleife durch einen $\mathrm{Na}^{+} / \mathrm{K}^{+} /(\mathrm{NH}) / 2 \mathrm{Cl}^{-}$-Cotransporter (Chloridionen) teilweise wieder resorbiert, dadurch im Nierenmark zu hoher Konzentration kumuliert und von dort an die benachbarten Sammelrohre abgegeben. Das beim Glutaminabbau entstehende Bikarbonat wird dem EZR zugeführt.

Der Umsatz beträgt normal $20-50 \mathrm{mmol} / \mathrm{Tag}$. Unter Acidosebedingungen können Produktion und Sekretion von $\mathrm{NH}_{4}{ }^{+}$bis etwa $300 \mathrm{mmol} / \mathrm{Tag}$ ansteigen. Das wird unter anderem dadurch ermöglicht, dass die Leber bei Acidose weniger $\mathrm{NH}_{3}$ im Harnstoffzyklus abbaut und dafür mehr Glutamin synthetisiert als unter normalen Umständen.

\section{Pufferung des Urins}

Schon eine Säureausscheidung von $100 \mathrm{mmol} / \mathrm{Tag}$ in Form freier Wasserstoffionen würde zu einem für Niere und Harnwege unverträglichen $\mathrm{pH}-$ Wert von ca. 1 führen. Das wird im Wesentlichen durch 2 Puffersysteme verhindert:

Ammoniakpuffer $(\mathrm{pK}=9,4)$ :

$$
\mathrm{H}^{+}+\mathrm{NH}_{3} \rightleftarrows \mathrm{NH}_{4}^{+}
$$

Phosphatpuffer $(\mathrm{pK}=6,8)$ :

$$
\mathrm{H}^{+}+\mathrm{HPO}_{4}^{2-} \rightleftarrows \mathrm{H}_{2} \mathrm{PO}_{4}^{-}
$$

Phosphat stellt $90 \%$ der titrierbaren Acidität des Urins. Bei Acidose wird vermehrt Phosphat mobilisiert und ausgeschieden.

Nettosäureausscheidung im Urin Die Nettosäureausscheidung setzt sich wie folgt zusammen:

Titrierbare Acidität (normal $10-40 \mathrm{mmol} / \mathrm{Tag}$; maximal bis $100 \mathrm{mmol} / \mathrm{Tag}$ ) + Ammonium (normal $20-50 \mathrm{mmol} /$ Tag; maximal bis $300 \mathrm{mmol} / \mathrm{Tag}$ ) - Bikarbonat (normal $0 \mathrm{mmol} / \mathrm{Tag}$; nur im neutralen und alkalischen Urin vorhanden) $=$ Nettosäureausscheidung (normal $40-80 \mathrm{mmol} / \mathrm{Tag}$; maximal bis $400 \mathrm{mmol} / \mathrm{Tag}$ ).

Diagnostik Für klinische Belange wird im Allgemeinen nur die $\mathrm{pH}$-Bestimmung mit dem Teststreifen durchgeführt. Für den $>$ Säurebelastungstest und für wissenschaftliche Zwecke ist die Messung mit der Glaselektrode erforderlich. Referenzbereich 4,5-8,0.

Für die Bestimmung der Nettosäureausscheidung und ihrer Komponenten wird auf die spezielle nephrologische Literatur verwiesen. Der 24-Stunden-Sammelurin muss unter Luftabschluss (Überschichtung mit Paraffinum liquidum) und Konservierung mit $10 \mathrm{~mL}$ einer 10 \%igen Lösung von Thymol in Isopropanol gesammelt werden. 


\section{Literatur}

Karim Z, Attmane-Elakeb A, Bichara M (2002) Renal handling of NH in relation to the control of acid-base balance by the kidney. J Nephrol 15(suppl 5):128-134

Rodriguez-Solano J (2000) New insights into the pathogenesis of renal tubular acidosis - from functional to molecular studies. Pediatr Nephrol 14:1121-1136

\section{Säure-Basen-Modell nach Stewart}

O. Müller-Plathe

\section{Synonym(e) Stewart-Modell}

Englischer Begriff Stewart's acid base model; Stewart's approach

Definition Alternatives Säure-Basen-Konzept, das neben Veränderungen des Kohlendioxidpartialdrucks bestimmte Konzentrationsverhältnisse im Plasmaionogramm zur Grundlage hat und nicht auf der Henderson-Hasselbalch-Gleichung beruht.

Beschreibung Herkömmliches Konzept des Säure-BasenHaushalts nach Siggaard-Andersen ( $\triangleright$ Säure-Basen-Stoffwechsel).

Nach dem Konzept von Stewart (1983), weiterentwickelt von Figge und Fencl (1992), wird der Säure-Basen-Status beeinflusst durch drei voneinander unabhängige Größen:

1. Kohlendioxidpartialdruck $\left(p \mathrm{CO}_{2}\right)$

2. Differenz zwischen den Summen der starken Kationen und der starken Anionen, bezeichnet als SID (,strong ion difference“) mit dem Suffix a für ,apparent":

$\operatorname{SID}_{\mathrm{a}}(\mathrm{mmol} / \mathrm{L})=\mathrm{Na}^{+}+\mathrm{K}^{+}+2 \times \mathrm{Ca}^{2+}+2 \times \mathrm{Mg}^{2+}-$ $\mathrm{Cl}^{-}-$Laktat $^{-}$

$\mathrm{Ca}^{2+}$ und $\mathrm{Mg}^{2+}$, zusammen etwa $4 \mathrm{mEq} / \mathrm{L}$, bleiben in der Praxis oft unberücksichtigt.

3. Gesamtkonzentration der schwachen, d. h. nicht vollständig dissoziierten Säuren, bezeichnet als $\mathrm{A}_{\text {tot }}\left(\mathrm{A}_{\text {tot }}=\mathrm{Alb}^{-}+\mathrm{P}_{\mathrm{i}}^{-}\right)$

Berechnung der negativen Ladungen:

- $\mathrm{Alb}^{-}[\mathrm{mEq} / \mathrm{L}]=$ Albumin $[\mathrm{g} / \mathrm{L}] \times(0,123 \mathrm{pH}-0,631)$

- $\mathrm{P}_{\mathrm{i}}^{-}[\mathrm{mEq} / \mathrm{L}]=$ Phosphat $[\mathrm{mmol} / \mathrm{L}] \times(0,309 \mathrm{pH}-0,469)$

Von der apparenten $\operatorname{SID}_{\mathbf{a}}$ wird die effektive $\mathbf{S I D}_{\mathbf{e}}$ unterschieden (s. Abbildung).

- $\operatorname{SID}_{\mathrm{e}}[\mathrm{mmol} / \mathrm{L}]=\mathrm{HCO}_{3}{ }^{-}+\mathrm{Alb}^{-}+\mathrm{P}_{\mathrm{i}}^{-}$
Die Differenz zwischen apparenter und effektiver SID, normalerweise etwa $8 \mathrm{mmol} / \mathrm{L}$, wird als ,strong ion gap“ (SIG) bezeichnet:

- $\mathrm{SIG}[\mathrm{mmol} / \mathrm{L}]=\mathrm{SID}_{\mathrm{a}}-\mathrm{SID}_{\mathrm{e}}$

Plasmaionogramm mit Rechengrößen des StewartModells $\mathrm{SID}_{\mathrm{a}}$ und $\mathrm{SID}_{\mathrm{e}}=$ apparente und effektive ,strong ion difference“. $\mathrm{SIG}=\mathrm{SID}_{\mathrm{a}}-\mathrm{SID}_{\mathrm{e}}=$, ,strong ion gap“; $\mathrm{A}_{\text {tot }}=$ Summe der Ladungen von Albumin und Phosphat):

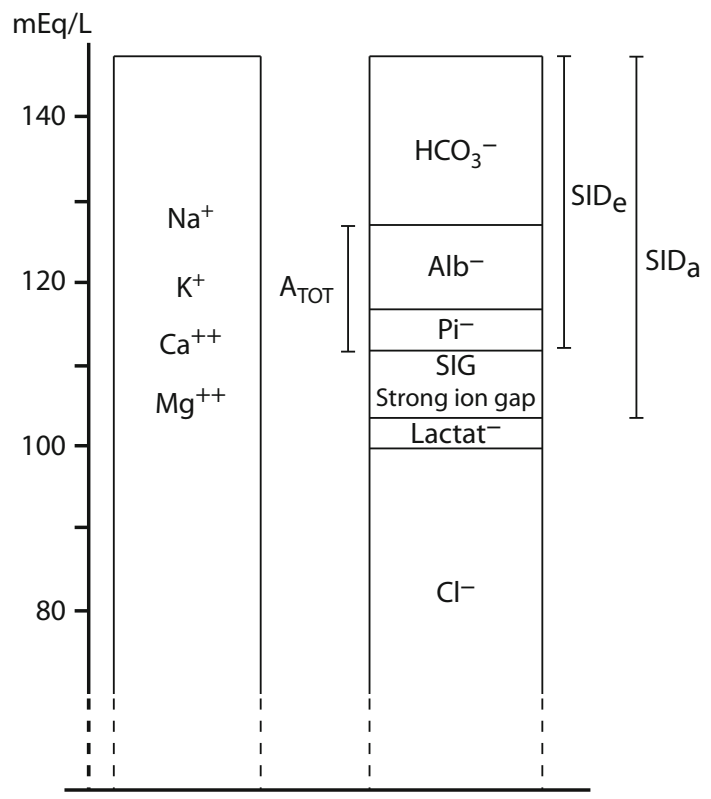

Die Höhe von SIG ist abhängig von der Menge ungemessener Anionen, z. B. Ketosäuren oder $\mathrm{SO}_{4}{ }^{2-}$. SIG hat somit eine ähnliche Aussage wie die Anionenlücke ( $\triangleright$ Anionenlücke im Plasma), jedoch ohne den Einfluss des Albumins, Phosphats und Laktats. Alle Parameter außer Albumin und Phosphat, die bei $\mathrm{pH}=7,40$ zusammen ca. $15 \mathrm{mEq} / \mathrm{L}$ Basenäquivalent ergeben, können mit modernen Blutgas-Elektrolyt-Automaten gemessen werden.

$\mathrm{pH}$ und Bikarbonat werden lediglich als abhängige GröBen verstanden, deren Wert durch SID, $\mathrm{A}_{\text {tot }}$ und $p \mathrm{CO}_{2}$ beeinflusst wird. Sie werden nicht wie im herkömmlichen System über die Henderson-Hasselbalch-Gleichung ( $\vee$ Säure-BasenStoffwechsel) zur Klassifizierung von Acidosen und Alkalosen herangezogen.

Abweichungen des pH-Werts werden als Acidämie bzw. Alkalämie bezeichnet.

Nach dem Stewart-Modell ergeben sich Acidosen durch:

- Zunahme von $p \mathrm{CO}_{2}$ : respiratorische Acidose

- Abnahme von SID: hyperchlorämische Acidose, Hyponatriämie (Verdünnungsacidose) 
- Zunahme von $\mathrm{A}_{\text {tot }}$ : Hyperphosphatämie, besonders bei Nierenversagen

- Zunahme von SIG: ungemessene Anionen, z. B. Ketoacidose, Vergiftungen, Urämie, Leberversagen

- Zunahme von Laktat: Laktatacidose durch Hypoxie, Vergiftungen und Medikamente

Alkalosen ergeben sich durch:

- Abnahme von $p \mathrm{CO}_{2}$ : respiratorische Alkalose

- Zunahme von SID: hypochlorämische Alkalose, z. B. durch Magensaftverlust, Diuretika, oder Kompensation einer chronischen Hyperkapnie(!), Hypernatriämie (Konzentrationsalkalose)

- Abnahme von $\mathrm{A}_{\text {tot }}$ : hypalbuminämische Alkalose

Im Stewart-Modell werden unter Acidose und Alkalose ausschließlich pathophysiologische Vorgänge mit acidifizierender bzw. alkalisierender Wirkung verstanden, nicht aber - wie im traditionellen System - gleichzeitig die entsprechenden klinisch-chemischen Zustände. Das ist ungewohnt, beispielsweise wenn die kompensierte chronische respiratorische Acidose in der Stewart-Systematik als gleichzeitiges Vorliegen einer respiratorischen Acidose und einer hypochlorämischen Alkalose beschrieben wird oder wenn bei der Konstellation Hyperchlorämie und Hypalbuminämie, die sich bis zur normalen Basenabweichung gegenseitig kompensieren können, im traditionellen System ein normaler SäureBasen-Status festgestellt wird, während nach dem StewartModell eine hyperchlorämische Acidose bei gleichzeitiger hypalbuminämischer Alkalose vorliegt.

Bei komplexen Säure-Basen-Störungen kann das StewartKonzept verdeckte Abweichungen erkennen, die mit dem traditionellen System nicht abgebildet werden.

Beispiel: Fortgeschrittenes Nierenversagen mit deutlicher Erhöhung der Retentionsparameter, aber im herkömmlichen System ohne Acidose (normale Basenabweichung). Die Stewart-Analyse ergibt eine Zunahme von SIG im Sinne einer renalen Acidose, aber zugleich Zunahme von SID durch hypochlorämische Alkalose und Abnahme von $\mathrm{A}_{\text {tot }}$ durch hypalbuminämische Alkalose, woraus sich durchaus therapeutische Ansätze ergeben können. Das Zusammenwirken dieser Einflüsse kann sich natürlich auch durch traditionelle Säure-Basen-Analytik, verbunden mit Elektrolytstatus, Phosphat- und Albuminbestimmung und sorgsamer Interpretation erschließen, wird aber im Stewart-Konzept besonders verdeutlicht.

Die Anwendung des Stewart-Konzepts mag sich als vorteilhaft erweisen bei der Aufklärung von komplexen SäureBasen-Störungen (zwei oder mehr Störungen gleichzeitig) und bei komplizierten Problemen der Infusions- und Nierenersatztherapie. Es lenkt die Aufmerksamkeit auf Albumin und
Phosphat, die in der traditionellen Säure-Basen-Diagnostik eine eher geringe Aufmerksamkeit erfahren.

Dem steht als Nachteil der für die Routinearbeit beträchtliche analytische Aufwand gegenüber. Um die vereinfachte $\operatorname{SID}_{\mathrm{a}}\left(\mathrm{Na}^{+}+\mathrm{K}^{+}-\mathrm{Cl}^{-}\right.$- Laktat) zu berechnen, braucht man bereits vier Messgrößen; die SIG-Berechnung erfordert gar 10 Parameter. Die Gefahr von Fehlberechnungen durch Addition analytischer oder präanalytischer Fehler liegt dabei auf der Hand. Hinzu kommt der hohe rechnerische Aufwand.

Obwohl inzwischen einige rechnerische Vereinfachungen publiziert worden sind (Funk 2007; Story et al. 2004) wird daher das Stewart-Modell unter Intensivmedizinern noch immer kontrovers diskutiert. Es stellt weniger eine Alternative zum traditionellen Siggaard-Andersen-Konzept als vielmehr eine ergänzende diagnostische Maßnahme dar.

\section{Literatur}

Figge J, Mydosh T, Fencl V (1992) Serum proteins and acid-base equilibria: a follow-up. J Lab Clin Med 120:713-719

Funk GC (2007) Das Säure-Basen-Modell nach Stewart. Wien Klin Wochenschr 119:390-403

Stewart PA (1983) Modern quantitative acid-base chemistry. Can J Physiol Pharmacol 61:1444-1461

Story DA, Morimatsu H, Bellomo R (2004) Strong ions, weak acids and base excess: a simplified Fencl-Stewart approach to clinical acid base disorders. Br J Anaesth 92:54-60

\section{Säure-Basen-Nomogramm}

- Siggaard-Andersen-Nomogramm

\section{Säure-Basen-Stoffwechsel}

O. Müller-Plathe

Englischer Begriff acid-base balance

Definition Der Säure-Basen-Stoffwechsel beschreibt die Einflüsse von Stoffwechsel-, Verteilungs- und Eliminationsvorgängen auf die Acidität des Bluts und anderer Körperflüssigkeiten, sowie die Modifikation dieser Einflüsse durch Pufferung und Kompensation. Dabei wird der Säure-BasenTerminologie nach Brønstedt (J. N. Brønstedt, 1879-1947, dänischer Chemiker) gefolgt, wonach eine Säure eine Substanz ist, die Wasserstoffionen freisetzen kann (Protonendonator), und eine Base dadurch gekennzeichnet ist, dass sie Wasserstoffionen aufnehmen kann (Protonenakzeptor). 
Beschreibung Für viele biochemische Prozesse und nervale Funktionen beim Menschen ist die Einhaltung des normalen pH-Werts von ca. 7,40 im Plasma (Isohydrie) von vitaler Bedeutung. Abweichungen und Gefährdungen müssen daher frühzeitig erkannt und behandelt werden. Das gilt für die gesamte Intensivmedizin, für die Diabetologie, Nephrologie, Toxikologie und für die Überwachung besonderer Therapien wie Beatmung, Dialyse, Infusionstherapie und Medikation mit Hormonen und Diuretika.

Umsatz, Transport und Elimination Zwei fortlaufend entstehende Metabolite wirken sich auf das Säure-BasenGleichgewicht aus:

- Kohlendioxid $\left(\mathrm{CO}_{2}\right)$ : Bei mäßiger körperlicher Aktivität entstehen pro Minute etwa $350 \mathrm{~mL} \mathrm{CO}$ entsprechend einem Säureäquivalent von $17 \mathrm{mmol} / \mathrm{min}$ bzw. $24000 \mathrm{mmol} / \mathrm{Tag}$, bei starker Belastung ein Vielfaches dieser Menge. $\mathrm{CO}_{2}$ wird nur zu $10 \%$ physikalisch gelöst im Plasma transportiert, 70 \% werden in den Erythrozyten nach Hydratisierung durch Carboanhydratase in Form von $\mathrm{HCO}_{3}{ }^{-}$transportiert. Die dabei entstehenden $\mathrm{H}^{+}$werden durch das bei der Gewebspassage entstehende und basisch wirkende Deoxyhämoglobin gepuffert. Die restlichen $20 \%$ lagern sich dem Hämoglobin reversibel als Carbaminoverbindung an. Bei der Lungenpassage setzt das als Säure wirkende Oxyhämoglobin $\mathrm{H}^{+}$frei und alle Vorgänge laufen in umgekehrter Richtung ab. Das dabei erneut gebildete $\mathrm{CO}_{2}$ wird durch die Lunge abgeatmet.

- Nicht flüchtige (,fixe“) Säuren: Normale Mischkost führt zu einem Überschuss an fixen Säuren von 40-80 mmol/ Tag, dessen $\mathrm{H}^{+}$durch die Nieren ausgeschieden werden. Die Säure stammt im Wesentlichen von schwefelhaltigen Aminosäuren tierischer Proteine sowie von Dihydrogenphosphat und organischen Phosphorverbindungen. Aus dem Intermediärstoffwechsel resultiert unter normalen Umständen keine zusätzliche Säurebelastung, wohl aber bei Störungen des Metabolismus, z. B. bei dekompensiertem Diabetes mellitus. Die Nieren können bei extremer Säurebelastung die Elimination bis auf etwa $400 \mathrm{mmol} /$ Tag steigern ( $\triangleright$ Säureausscheidung, renale).

Puffersysteme Der Plasma-pH ist auf 7,40 $\pm 0,04$ eingestellt (Isohydrie). Er wird durch Puffersysteme stabilisiert, die man unter funktionellen Aspekten unterteilen kann in den Bikarbonat-Kohlensäure-Puffer und die Gruppe der Nichtbikarbonatpuffer. Erst wenn die Pufferfähigkeit überschritten wird, tritt die Kompensation durch Lunge oder Niere in Aktion.

\section{Bikarbonat-Kohlensäure-Puffer}

Dieses System hat eine Gesamtkonzentration $\left(\mathrm{HCO}_{3}{ }^{-}+\mathrm{H}_{2} \mathrm{CO}_{3}+\right.$ $\mathrm{CO}_{2}$ ) von $25,4 \mathrm{mmol} / \mathrm{L}$, die sehr schnell variiert werden kann. $\mathrm{H}_{2} \mathrm{CO}_{3}$ und $\mathrm{CO}_{2}$ stehen in einem Gleichgewicht, das mit einer Relation von etwa 700:1 stark in Richtung $\mathrm{CO}_{2}$ verschoben ist. Der Wirkungsschwerpunkt liegt im Plasma und in der Extrazellulärflüssigkeit. Die Säurekomponente ist in Form von $\mathrm{CO}_{2}$ über die Lungen rasch eliminierbar. In diesem „offenen System“ mit konstant gehaltenem $p \mathrm{CO}_{2}$ beträgt die $>$ Pufferkapazität des Bikarbonatpuffers $57 \mathrm{mmol} / 1$ bei $\mathrm{pH}$ 7,40. Von der gesamten Pufferkapazität der Extrazellulärflüssigkeit einschließlich des Plasmas entfallen bei Belastung mit fixer Säure oder Base auf den Bikarbonatpuffer etwa $80 \%$.

Seine Funktionsweise wird durch die HendersonHasselbalch-Gleichung beschrieben:

$$
\begin{gathered}
\mathrm{pH}=\mathrm{pK}^{\prime}+\lg \frac{c \mathrm{HCO}_{3}{ }^{-}}{p \mathrm{CO}_{2} \times \alpha} \\
\mathrm{pH}=6,105+\lg \frac{c \mathrm{HCO}_{3}{ }^{-}(\mathrm{mmol} / \mathrm{L})}{p \mathrm{CO}_{2}(\mathrm{mmHg}) \times 0,0307}
\end{gathered}
$$

wobei $\mathrm{pK}^{\prime}$ (negativer Exponent der scheinbaren Dissoziationskonstante) $=6,105$ und $\alpha$ (molarer Löslichkeitskoeffizient für $\mathrm{CO}_{2}$ in Plasma) $=0,0307$ sind.

Bei $p \mathrm{CO}_{2}$ von $40 \mathrm{mmHg}$ ergibt sich im Nenner $c \mathrm{H}_{2} \mathrm{CO}_{3}$ von $1,2 \mathrm{mmol} / \mathrm{L}$. Bei $24 \mathrm{mmol} / \mathrm{L}_{c} \mathrm{HCO}_{3}{ }^{-}$im Zähler entspricht das einem Komponentenverhältnis von 20:1, dessen dekadischer Logarithmus 1,3 beträgt und somit zu einem $\mathrm{pH}=7,40$ führt.

In der Henderson-Hasselbalch-Gleichung repräsentiert $p \mathrm{CO}_{2}$ ausschließlich die respiratorische Seite, während $c \mathrm{HCO}_{3}{ }^{-}$überwiegend von nicht respiratorischen (,metabolischen“) Vorgängen bestimmt wird.

\section{Nichtbikarbonatpuffer (NB-Puffer)}

Im Gegensatz zum Bikarbonatpuffer sind die Konzentrationen der Nichtbikarbonatpuffer kurzfristig nicht variierbar. Der Wirkungsschwerpunkt liegt in den Erythrozyten. Von der gesamten Pufferkapazität der Extrazellulärflüssigkeit und der Erythrozyten entfallen bei Belastung mit fixer Säure oder Base auf diese Puffergruppe etwa $20 \%$.

NB-Puffer in den Erythrozyten:

- Hämoglobin. Als wichtigster NB-Puffer stellt es über $80 \%$ der Pufferkapazität der Erythrozyten. Seine Pufferwirkung geht vorwiegend von den Imidazolgruppen einiger Histidine aus. Sowohl Oxihämoglobin $(\mathrm{pK}=6,95)$ als auch Deoxyhämoglobin $(\mathrm{pK}=8,25)$ wirken als Puffer. Bei der Oxigenierung (in der Lungenkapillare) wirkt $\mathrm{Hb}$ als $\mathrm{H}^{+}$-Donator, bei der Deoxygenierung (in der Gewebskapillare) als $\mathrm{H}^{+}$-Akzeptor.

- 2,3-Diphosphoglyzerat. 
NB-Puffer im Plasma und der übrigen Extrazellulärflüssigkeit

- Plasmaproteine. Sie stellen bei einem pK um 7,3 etwa $95 \%$ der Pufferkapazität des Plasmas. Auch hier sind überwiegend die Imidazolgruppen des Histidins für die Pufferwirkung verantwortlich.

- Anorganisches Phosphat. Das System $\mathrm{H}_{2} \mathrm{PO}_{4}{ }^{-} / \mathrm{HPO}_{4}{ }^{2-}$ mit einem $\mathrm{pH}=6,8$ spielt angesichts seiner niedrigen Konzentration im Plasma nur eine geringe Rolle. Es hat eine große Bedeutung als Puffersystem für die renale Säureausscheidung.

\section{Interaktion der Puffersysteme}

Die Pufferung bei respiratorischen Störungen wird ausschließlich von den NB-Puffern, also vorwiegend vom Hämoglobin geleistet. Zunahme von $\mathrm{CCO}_{2}$ (Hyperkapnie) bewirkt folgende Reaktion:

$$
\mathrm{H}_{2} \mathrm{CO}_{3}+\mathrm{Hb}^{-} \rightarrow \mathrm{HCO}_{3}^{-}+\mathrm{HHb}
$$

Bei dieser Reaktion nimmt die Bikarbonatkonzentration auf Kosten des Hb-Puffers zu, ohne dass sich die Gesamtkonzentration der Pufferbasen ändert. Da sich das Bikarbonat jedoch auf den gesamten Extrazellulärraum verteilt, nehmen die Basenkonzentration und damit auch die auf das Blut bezogene $>$ Basenabweichung (BA) ab, wodurch eine zusätzliche metabolische Acidose vorgetäuscht werden kann. Dem wird begegnet durch den Bezug der BA auf den Extrazellulärraum.

Säure-Basen-Störungen Eine Acidose ist gekennzeichnet durch Zunahme an Säure oder Mangel an Base, eine Alkalose durch Zunahme von Base oder Mangel an Säure im Blut und im Extrazellularraum.

Ist die Säure-Basen-Störung durch Veränderungen der pulmonalen $\mathrm{CO}_{2}$-Ausscheidung verursacht, nennt man sie respiratorisch, ist sie durch nicht respiratorische Einflüsse hervorgerufen, wird sie als metabolisch bezeichnet. Somit resultieren 4 Kategorien:

- Respiratorische Acidose ( $\triangleright$ Acidose, respiratorische)

- Respiratorische Alkalose ( $>$ Alkalose, respiratorische)

- Metabolische Acidose ( $\triangleright$ Acidose, metabolische)

- Metabolische Alkalose ( $\triangleright$ Alkalose, metabolische)

\section{Kompensation von Säure-Basen-Störungen}

Unter Kompensation versteht man die Abschwächung einer SB-Störung durch aktive Organleistungen mit dem Ziel, Abweichungen des $\mathrm{pH}$ möglichst klein $\mathrm{zu}$ halten, also dem Quotienten $c \mathrm{HCO}_{3}{ }^{-} / \mathrm{H}_{2} \mathrm{CO}_{3}=20: 1$ möglichst nahe $\mathrm{zu}$ bleiben. Deshalb werden
- respiratorische Störungen „metabolisch“ kompensiert, durch renale Anpassung der Bikarbonatkonzentration ( $\triangleright$ Säureausscheidung, renale) und

- metabolische Störungen respiratorisch kompensiert, durch pulmonale Anpassung von $p \mathrm{CO}_{2}$.

Das Verhalten primär und kompensatorisch veränderter Messgrößen ist in dem folgenden orientierenden Schema zur Diagnostik von Säure-Basen-Störungen (aus: MüllerPlathe 1982) dargestellt:

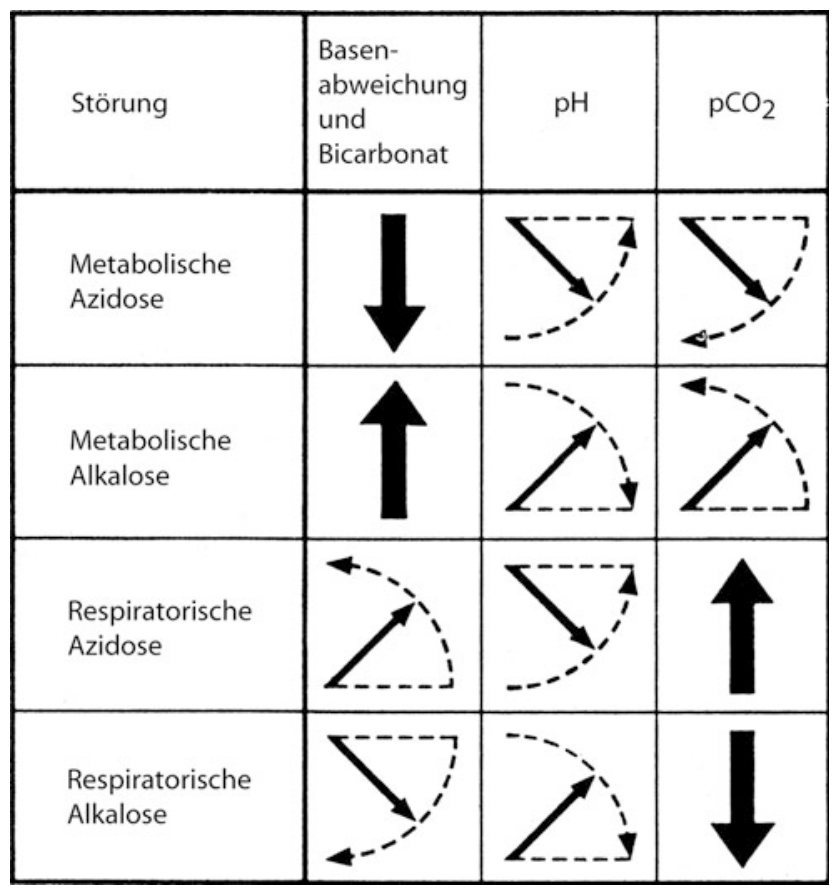

Die starken Pfeile markieren die jeweiligen primären Veränderungen. Die schräg weisenden dünnen Pfeile kennzeichnen das Verhalten der kompensierenden Messgröße und des $\mathrm{pH}$-Wertes. Die Richtung der Kreisbögen zeigt an, in welcher Richtung sich die Messgrößen mit fortschreitender Kompensation ändern.

Das Diagramm in Abb. 1 dient der Diagnostik von SäureBasen-Störungen. Der sich aus $p \mathrm{CO}_{2}$ auf der Abszisse und ${ } \mathrm{HCO}_{3}{ }^{-}$auf der Ordinate ergebende Statuspunkt erlaubt die Einordnung als Normalstatus, als normal-kompensierte Störung innerhalb der unterlegten Felder oder als kombinierte bzw. dekompensierte Störung außerhalb derselben. Liegt der Statuspunkt außerhalb, muss entschieden werden, ob

- die Störung so kurz besteht, dass noch keine vollständige Kompensation stattfinden konnte,

- die Funktion des kompensierenden Organsystems eingeschränkt ist oder

- eine zweite Säure-Basen-Störung gleichzeitig vorliegt. 


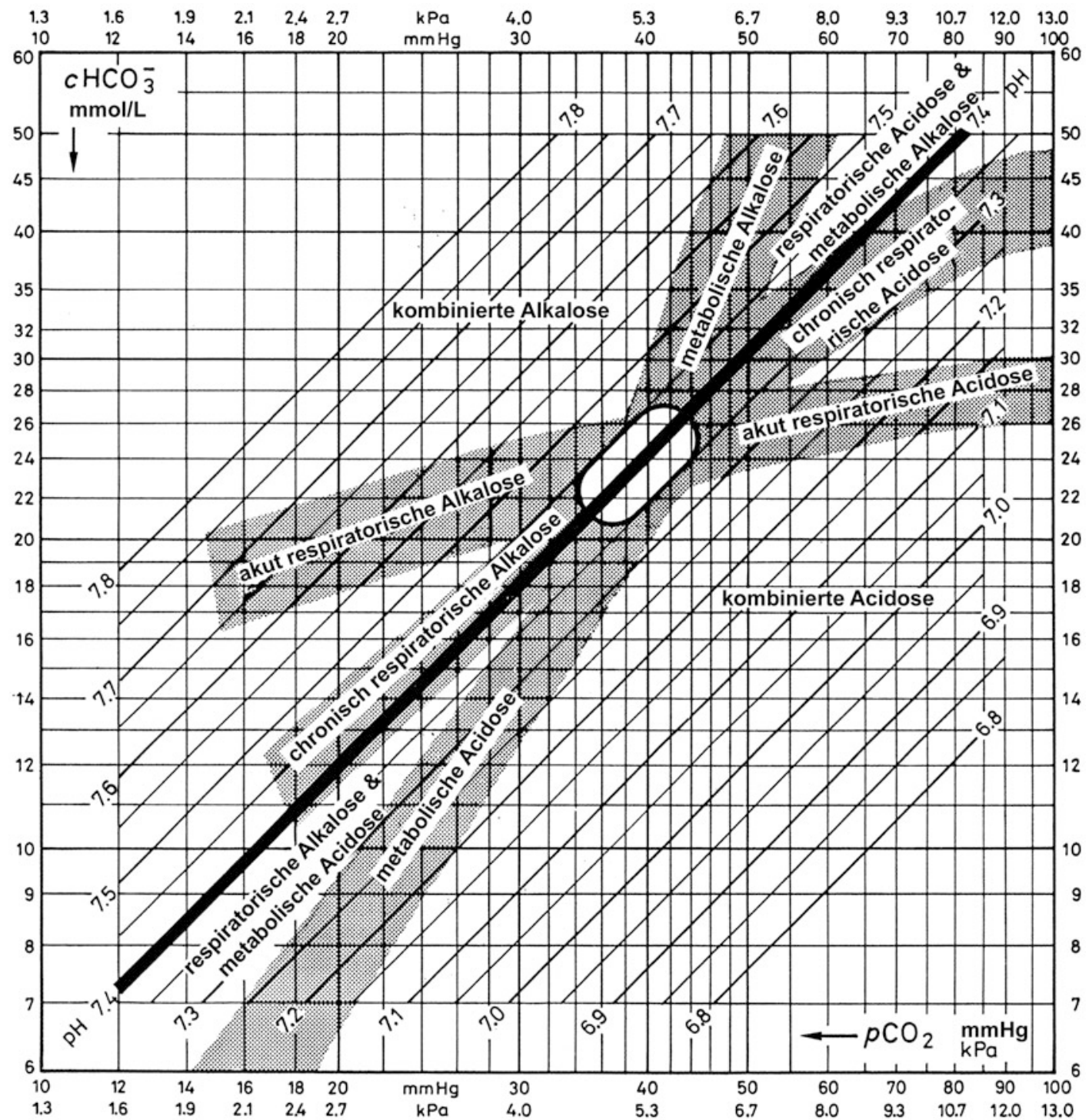

Säure-Basen-Stoffwechsel, Abb. 1 Diagnostik-Nomogramm für Säure-Basen-Störungen unter Berücksichtigung des Kompensationsgrades

\section{Literatur}

Adrogué HE, Adrogué HJ (2001) Acid-base physiology. Respir Care 46:328-341

Müller-Plathe O (1982) Säure-Basen-Haushalt und Blutgase, 2. Aufl. Thieme, Stuttgart

\section{Säure-Basen-Störungen, Kompensation}

> Säure-Basen-Stoffwechsel

\section{Säurebelastungstest}

O. Müller-Plathe

Synonym(e) Ammoniumchlorid-Belastung

Englischer Begriff ammonium chloride loading test

Definition Test zur Erkennung einer distalen renal-tubulären Acidose (RTA). 


\section{Beschreibung Durchführung:}

- Ausgangswert: $\mathrm{pH}$ im morgendlichen Urin nach nächtlicher Nahrungskarenz messen. Bei $\mathrm{pH}<5,5$ ist der Test nicht notwendig.

- Orale Gabe von 0,1 g Ammoniumchlorid pro kg KG, in Portionen über 1 Stunde verteilt.

- $\mathrm{pH}-\mathrm{Messung}$ in frischen stündlichen Urinproben über 8 Stunden.

Bewertung: Normalerweise fällt der $\mathrm{pH}$ nach 2-4 Stunden in mindestens einer Probe auf Werte $<5,5$. Bei distaler RTA bleiben die Werte deutlich darüber, meist $>6$. Ein Harnweginfekt durch $\mathrm{NH}_{3}$-bildende Bakterien mit nachfolgender Alkalisierung des Urins macht den Test unzuverlässig und sollte zuvor beseitigt werden.

Kontraindikationen: Erkrankungen der Leber, globale Niereninsuffizienz.

\section{Literatur}

Laski ME, Kurtzman NA (1989) Evaluation of acid-base disorders from the urine. In: Seldin DW, Giebisch G (Hrsg) The regulation of acidbase-balance. Raven, New York

\section{Säureelution}

- Elution erythrozytärer Antikörper

\section{Säurefestigkeit}

- Ziehl-Neelsen-Färbung

\section{Säure-Hämolyse-Test}

H. Baum

\section{Synonym(e) Ham-Test}

Englischer Begriff acidified-serum lysis test; Ham-Test

Definition Von Th. Ham 1937 beschriebener Test zum Nachweis einer komplementabhängigen Lyse der Erythrozyten im acidifierten Serum zur Diagnostik der paroxysmalen nächtlichen Hämoglobinurie (PNH).
Beschreibung Die $>$ Erythrozyten von Patienten mit PNH, einer erworbenen klonalen Erkrankung der Hämatopoese, zeigen eine erhöhte Empfindlichkeit zur Lyse durch $>$ Komplement. Diese erhöhte Lysebereitschaft kann durch den Säure-Hämolyse-Test nachgewiesen werden. Dazu werden Patientenerythrozyten mit acidifiertem (angesäuertem) Patienten- und Normalserum gemischt und das Ausmaß der Hämolyse fotometrisch bestimmt. Durch die Zugabe von - Magnesium im Testansatz kann die Empfindlichkeit gesteigert werden. Der Test wird nur noch selten angewandt, da durch die immunzytometrische Bestimmung des Defizits von GPI-verankerten Schutzfaktoren (CD55 und CD59) auf den Erythrozyten dieser Patienten eine sensitivere und einfacher durchführbare Methode zur Verfügung steht.

\section{Literatur}

Regan F, Newlands M, Bain BJ (2001) Acquired haemolytic anaemias. Paroxysmal nocturnal haemoglobinuria. In: Lewis SM, Bain BJ, Bates I (Hrsg) Practical haematology, 9. Aufl. Churchill Livingstone, London, S 219-225

\section{Säuren im Urin, organische}

\section{G. F. Hoffmann, C.-D. Langhans und A. Schulze}

Englischer Begriff organic acids in urine

Definition Die Bezeichnung „,organische Säure“ ist ein Sammelbegriff, der Mono- und Dicarbonsäuren wie auch Ketound Hydroxysäuren einschließt. Außerdem werden einige stickstoffhaltige Verbindungen wie 5-Oxoprolin und Hippursäure dazu gezählt.

Beschreibung Nahezu alle Intermediärstoffwechselwege spiegeln sich im Urin in niedermolekularen, polaren Schlüsselmetaboliten. Die Untersuchung der sauren Urinkomponenten liefert ein Profil der organischen Säuren, das qualitative bis semiquantitative Aussagen über die aktuelle Stoffwechselsituation zum Zeitpunkt der Probennahme zulässt.

Ebenfalls miterfasst werden exogene Bestandteile aus besonderen Ernährungsformen sowie Medikamentenmetabolite. Diese Komponenten können die Interpretation der endogenen Metabolite erschweren.

Die Untersuchung der organischen Säuren erfordert zunächst eine Extraktion der sauren Komponenten durch > Flüssig-Flüssig-Extraktion mit Ethylacetat oder Diethylether. Auch Anionenaustausch- sowie $>$ Adsorptionschromatographie werden zur Aufreinigung eingesetzt. 
Oxosäuren werden nach vorangegangener Umsetzung zu Oximen ebenfalls extrahiert.

Die Gaschromatographie-Massenspektrometrie-Kopplung ( $\triangleright$ GC-MS) ist immer noch die Methode der Wahl zur weiteren Differenzierung der sauren Extrakte.

Die Feinauftrennung der organischen Säuren erfolgt als Trimethylsilyl- (TMS-) oder Methyl-Derivate gaschromatographisch über Kapillarsäulen. Die Identifikation erfolgt über die > Retentionszeit (als Retentionsindex) und durch die Aufnahme von Massenspektren mittels Quadrupol- oder IonTrap-Massenspektrometern ( $\triangleright$ Massenspektrometrie). In den spezifischen Angaben zu den unter Kenngrößen aufgeführten organischen Säuren ist der Retentionsindex der TMS-Derivate nach Pentafluorobenzyloximierung auf einer DB-5-Kapillarsäule $(30 \mathrm{~m} \times 0,25 \mathrm{~mm})$ angegeben. Die Massenspektren können Software-seitig mit Datenbankeinträgen verglichen werden.

Einige organische Säuren sind immer im Urin nachweisbar. Dominant sind z. B. Succinat, Citrat und Hippurat. In sehr geringer Konzentration treten auch $>$ Methylmalonsäure, > 3-Hydroxyisovaleriansäure und > 2-Hydroxyglutarsäure auf. Der pathologische Zustand einer Organoacidopathie zeigt sich dabei im Chromatogramm durch die Erhöhung eines dieser Metabolite.

Andere Stoffwechselerkrankungen wiederum führen zum Auftreten von Metaboliten, die normalerweise nicht im Urin vorkommen, wie z. B. \ 3-Hydroxyglutarsäure bei der Glutaracidurie Typ I.

Die Tabelle gibt eine Übersicht über Stoffwechselerkrankungen und den organischen Säuren:

\begin{tabular}{|c|c|}
\hline Organische Säure & Krankheit \\
\hline $\begin{array}{l}\text { 2-Methyl-3- } \\
\text { Hydroxybuttersäure }\end{array}$ & 3-Ketothiolase-Mangel \\
\hline 2-Methylacetoacetat & 3-Ketothiolase-Mangel \\
\hline $\begin{array}{l}\text { 2-Hydroxy-3- } \\
\text { Methylvaleriansäure }\end{array}$ & Ahornsiruperkrankung (MSUD) \\
\hline 2-Hydroxyglutarsäure & $\begin{array}{l}\text { 2-Hydroxyglutarazidurie, } \\
\text { Glutarazidurie Typ II }\end{array}$ \\
\hline 2-Hydroxyisocapronsäure & Ahornsiruperkrankung (MSUD) \\
\hline 2-Hydroxyisovaleriansäure & Ahornsiruperkrankung (MSUD) \\
\hline 3-Hydroxypropionsäure & Propionazidurie \\
\hline 2-Oxo-3-Methylvaleriansäure & Ahornsiruperkrankung (MSUD) \\
\hline 2-Oxoadipinsäure & 2-Oxoadipinazidurie \\
\hline 2-Oxoisocapronsäure & Ahornsiruperkrankung (MSUD) \\
\hline 2-Oxoisovaleriansäure & Ahornsiruperkrankung (MSUD) \\
\hline 3-Methylcrotonylglyzin & $\begin{array}{l}\text { 3-Methylcrotonyl-CoA- } \\
\text { Carboxylase-, Biotinidase-, } \\
\text { Holocarboxylase-Synthetase- } \\
\text { Mangel }\end{array}$ \\
\hline 3-Methylglutaconsäure & $\begin{array}{l}\text { 3-Methylglutaconazidurien Typ } \\
\text { I-IV }\end{array}$ \\
\hline 3-Methylglutarsäure & 3-Methylglutaconazidurie Typ -VI \\
\hline $\begin{array}{l}\text { 3-Hydroxy-3- } \\
\text { Methylglutarsäure }\end{array}$ & 3-HMG-CoA-Lyase-Mangel \\
\hline
\end{tabular}

Organische Säure

3-Hydroxyglutarsäure

3-Hydroxyisovaleriansäure

$4-$

Hydroxycyclohexylessigsäure

5-Oxoprolin

Adipinsäure

Ethylmalonsäure

Fumarsäure

Glutarsäure

Glyzerinsäure

Hexanoylglyzin

Homogentisinsäure

Isovalerylglyzin

Methylcitrat

Methylmalonsäure

$\mathrm{N}$-Acetylasparaginsäure

Phenylpropionylglyzin

Propionylglyzin

Sebacinsäure

Suberinsäure

Succinylaceton

Tiglylglyzin
Krankheit

Glutarazidurie Typ I

Isovalerianazidämie,

3-Methylcrotonyl-CoA-

Carboxylase-, Biotinidase-,

Holocarboxylase-Synthetase-

Mangel

Hawkinsinurie

5-Oxoprolinurie (GlutathionSynthese)

Fettsäureoxidationsdefekte, Glutarazidurie Typ II

SCAD-Mangel, Glutarazidurie Typ II

Fumarazidurie,

Mitochondriopathien

Glutarazidurien Typ I-III

Glyzeratazidurie

MCAD-Defekt

Alkaptonurie

Isovalerianazidämie, 3-Methylcrotonyl-CoA-

Carboxylase-, Biotinidase-,

Holocarboxylase-Synthetase-

Mangel

Methylmalonazidurien,

Propionazidämie

Methylmalonazidurien, Vitamin-

B12-Mangel

Morbus Canavan

Mittelkettiger-Acyl-CoA-

Dehydrogenase-Mangel

Propionazidämie

Fettsäureoxidationsdefekte

Fettsäureoxidationsdefekte

Tyrosinämie Typ I

Propionazidämie, 3-Ketothiolase-

Mangel

\section{Literatur}

Blau N, Duran M, Gibson KM, Dionisi-Vici C (Hrsg) (2014) Physician's guide to the diagnosis, treatment, and follow-up of inherited metabolic diseases. Springer, Berlin/Heidelberg

\section{Saure-Phosphatase-Reaktion}

- Phosphatase-Reaktion

\section{Säure-Serum-Test}

- Ham-Test 


\section{Sayk-Sedimentierkammer für Liquorzellen}

Liquor-Sedimentierkammer-Verfahren

\section{Sb}

Antimon

\section{SBIC}

- Standardbicarbonat

Sc

- Scienna-Blutgruppensystem

\section{Scan}

B. Güssregen

\section{Englischer Begriff scan}

Beschreibung Die kontinuierliche Aufzeichnung von Massenspektren über einen definierten Massenbereich wird in der - Massenspektrometrie als Scan (,full scan“) bezeichnet. Analog wird die kontinuierliche Aufzeichnung von UV-Spektren ( $\triangleright$ UV/VIS-Spektrometrie) in der HPLC mit UV-Detektion ( $\triangleright$ Photodioden-Array-Detektor) als Scan bezeichnet.

\section{Scannen von Gelen}

$>$ Densitometrie

\section{Scanner}

$\checkmark$ Densitometer

> Dokumentenscanner

\section{SC-Antikörper}

- Autoantikörper gegen Aminoacyl-t-RNS-Synthetase

\section{Scatter factor}

- Hepatocyte growth factor

\section{Scavenger-Rezeptor}

K. J. Lackner und D. Peetz

Englischer Begriff Scavenger receptor

Definition Gruppe von zellulären Rezeptoren, die u. a. modifizierte Lipoproteine und Lipide binden und zu den sog. Pattern-recognition-Rezeptoren gezählt werden.

Beschreibung Scavenger-Rezeptoren haben gemeinsam, dass sie u. a. modifizierte $>$ Lipoproteine, Lipide oder Zelldetritus binden können. In dieser Funktion werden sie zu den immunologisch relevanten Pattern-recognition-Rezeptoren gezählt, zu denen auch die Toll-like-Rezeptoren, Komplementrezeptoren, CD14 und andere gehören. Daneben gibt es auch einzelne Mitglieder der Scavenger-Rezeptoren, die normale Lipoproteine binden und eine Rolle im Lipidstoffwechsel spielen. Aufgrund ihrer Funktion als Rezeptoren für gestrandete und oxidativ oder anderweitig modifizierte LDLPartikel sowie tierexperimenteller Daten wird vermutet, dass die Scavenger-Rezeptoren in die Pathogenese der Atherosklerose involviert sind. Inzwischen wurden 10 Klassen (A-J) von Scavenger-Rezeptoren bei Eukaryonten beschrieben, von denen die Klassen A und B eine wichtige Rolle im Lipoproteinstoffwechsel spielen. Die Scavenger-Rezeptoren der Klasse A sind in die Aufnahme modifizierter LDL in - Makrophagen involviert. Die Klasse B, zu der CD36 gerechnet wird, ist daneben auch in die Interaktion von HDL mit Zellen involviert. Die Rezeptoren der Klasse $\mathrm{C}$ haben als einzige Klasse keinen Vertreter bei Säugern und wurden bisher nur bei Drosophila beschrieben.

\section{Literatur}

Zani IA, Stephen SL, Mughal NA, Russell D et al (2015) Scavenger receptor structure and function in health and disease. Cell 4:178-201 
SCC

- Squamous cell carcinoma antigen

\section{SCCA}

- Squamous cell carcinoma antigen

\section{S-CCK-Test}

- Sekretin-Pankreozymin-Test

\section{sCD14-ST}

> Presepsin

\section{SCF}

- Stem Cell Factor

\section{Schätzer}

R.-D. Hilgers, N. Heussen und S. Stanzel

Synonym(e) Intervallschätzer; Intervallschätzung; Parameterschätzer; Parameterschätzung; Punktschätzer; Punktschätzung; Schätzung

Englischer Begriff estimator; estimate

Definition Ein Schätzer ist ein Näherungswert für einen unbekannten $>$ Parameter.

Beschreibung Ein Schätzer für einen Parameter wird auf der Grundlage von Daten einer $>$ Stichprobe ermittelt und dient als Näherung für den unbekannten Wert des Parameters in der - Grundgesamtheit, aus der die Stichprobe stammt. Die Angabe eines Schätzwertes für einen unbekannten Parameter der Verteilung ( $\triangleright$ Verteilung, statistische) in der Grundgesamtheit wird auch als Punktschätzer bezeichnet. Beispielsweise können Schätzer für den unbekannten Mittelwert ( $\triangleright$ Mittelwert, arithmetischer), die $>$ Varianz oder auch den $>$ Median einer Grundgesamtheit berechnet werden. Die Bezeichnung „Schätzer“ schließt auch den Begriff des „Intervallschätzers“ mit ein, der die Bestimmung eines Vertrauensintervalls ( $\triangleright$ Konfidenzintervall) für den unbekannten Wert des Parameters in der Grundgesamtheit beinhaltet.

\section{Literatur}

Hilgers R-D, Bauer P, Scheiber V (2002) Einführung in die Medizinische Statistik. Springer, Berlin/Heidelberg/New York

\section{Schätzung}

> Schätzer

\section{Schaumzellen}

H. Baum

Englischer Begriff foam cell

Definition Lipidspeichernder Makrophage mit schaumig degeneriertem Zytoplasma.

Beschreibung Schaumzellen sind morphologisch gekennzeichnet durch ein weites Zytoplasma, das viele fetthaltige Vakuolen, die an Schaum erinnern, enthält. Sie sind eine besondere Ausprägung eines phagozytierenden $>$ Makrophagen. Ihre klinische Relevanz ist gering.

Die Abbildung zeigt eine Schaumzelle in bronchoalveolärer Lavageflüssigkeit $(630 \times$, May-Giemsa-Grünwald-Färbung):

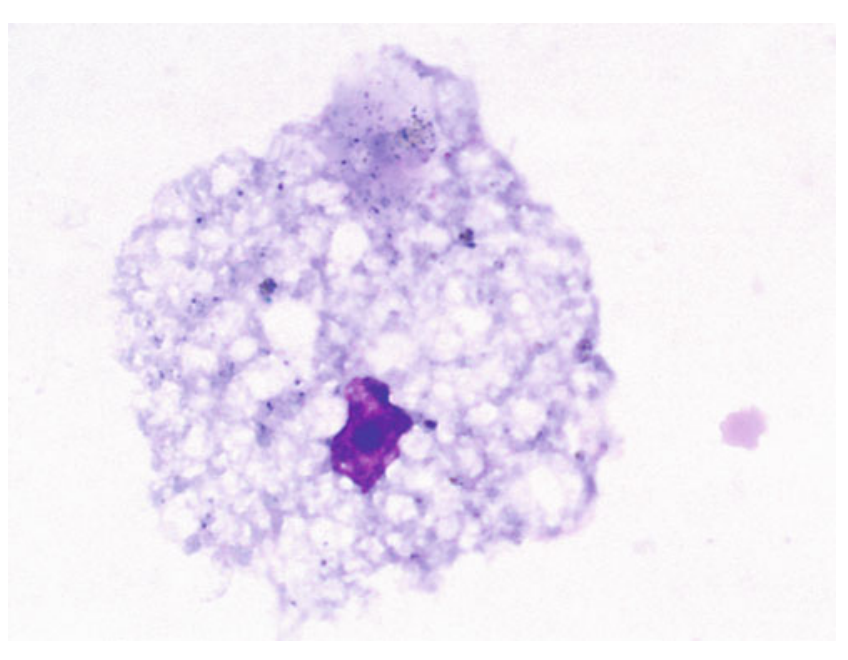




\section{Literatur}

Nerl C (1993) Monozyten-Makrophagen-System = MMS. In: Begemann H, Rastetter J (Hrsg) Klinische Hämatologie, 4. Aufl. Georg Thieme Verlag, Stuttgart, S 87

\section{Scherer, Johann Joseph von}

\section{A. M. Gressner und O. A. Gressner}

Lebensdaten Deutscher Chemiker und Mediziner, geboren am 13. März 1814 in Aschaffenburg, gestorben am 17. Februar 1869 in Würzburg.

Verdienste Scherer studierte in Würzburg Medizin und in München Chemie und war Assistent bei Justus von Liebig in Gießen. Ab 1847 ordentlicher Professor für Organische Chemie und Leiter des klinisch-chemischen Laboratoriums am Julius-Hospital in Würzburg. Klinisch-chemische und pathologisch-chemische Arbeiten zur Analyse des Bluts in enger Verbindung mit der Klinik führten u. a. zur Entdeckung von > Hypoxanthin und (Meso-)Inosit. Scherer gilt mit Johann Florian Heller ( $\$$ Heller, Johann Florian) und Johann Franz Simon ( $\triangleright$ Simon, Johann Franz) als Begründer der Klinischen Chemie ( $\triangleright$ Klinische Chemie) in Deutschland.

\section{Literatur}

Grund CR (2002) Der Würzburger Chemiker Johann Joseph von Scherer und die Begründung der Klinischen Chemie im 19. Jahrhundert. Shaker Verlag, Aachen

\section{Schichtdicke}

Lambert-Beer-Gesetz

\section{Schießscheibenzelle}

$>$ Target-Zelle

\section{Schilddrüsenhormon-Rezeptor $\beta$-Genmutation}

M. Bidlingmaier

Synonym(e) Familiäre Schilddrüsenhormon-Resistenz; Refetoff-Syndrom; Refetoff-De-Wind-De-Groot-Syndrom
Englischer Begriff thyroid hormone resistance; Refetoff syndrome; impaired sensitivity to thyroid hormone

Definition Mutation des Gens für den $\beta$-Schilddrüsenhormonrezeptor (THRB Gen), die die hormonbindende Domäne des Rezeptors betrifft und daher zu einer Resistenz gegenüber Schilddrüsenhormon führt.

Beschreibung Biochemisch charakteristisch ist die Kombination von erhöhten freien Schilddrüsenhormonen (T3, - Triiodthyronin, freies und T4, - Thyroxin, freies) mit nicht supprimiertem oder auch erhöhtem TSH ( $\triangleright$ Thyreotropin). Es handelt sich um eine seltene Erkrankung, eine $>$ Inzidenz von 1:50.000 bei Lebendgeburten ist beschrieben. Meist wird sie autosomal dominant vererbt ( $\triangleright$ Autosomal-dominante Vererbung), tritt gelegentlich aber auch sporadisch oder rezessiv vererbt auf ( $\triangleright$ Autosomal-rezessive Vererbung). Mutationen finden sich fast immer in $>$ Exon 7, 8, 9 oder 10 des THRB-Gens. Die Diagnosestellung bei Verdacht erfolgt durch Sequenzierung der entsprechenden Genabschnitte. Nachdem Schilddrüsenhormonrezeptoren durch 2 Gene auf unterschiedlichen Chromosomen kodiert und in verschiedenen Isoformen gewebsspezifisch exprimiert werden, ist die klinische Symptomatik bei SchilddrüsenhormonRezeptor- $\beta$-Genmutationen extrem heterogen. Dies gilt auch innerhalb einer betroffenen Familie. Grundsätzlich werden generalisierte Formen, bei denen die Rezeptoren in allen Organen betroffen sind, von hypophysenspezifischen Formen unterschieden, bei denen im Wesentlichen der negative Feedback auf die TSH-Sekretion gestört ist. Die meisten Patienten entwickeln eine Struma, relativ häufig kombiniert mit unterschiedlich stark ausgeprägten Einschränkungen des Gehörs. Insbesondere bei der partiellen, auf die Hypophyse beschränkten Resistenz zeigen sich auch Symptome einer Hyperthyreose (z. B. Tachyarrhythmien). Klinisch kann eine Behandlungsindikation bei hyper- oder hypothyreoter Symptomatik vorliegen. Die Dosisfindung muss jedoch rein klinisch erfolgen, da aufgrund der hypophysären Resistenz die TSH-Werte nicht aussagekräftig sind.

\section{Literatur}

Ferrara AM, Onigata K, Ercan O, Woodhead H, Weiss RE, Refetoff $S$ (2012) Homozygous thyroid hormone receptor $\beta$-gene mutations in resistance to thyroid hormone: three new cases and review of the literature. J Clin Endocrinol Metab 97(4):1328-1336. https://doi.org/ 10.1210/jc.2011-2642. Epub 2012 Feb 8

\section{Schilddrüsenperoxidase}

- Thyreoperoxidase 


\section{Schilling, Viktor}

H. Baum

Lebensdaten Deutscher Mediziner, geboren am 28. August 1883 in Torgau, gestorben am 30. Mai 1960 in Rostock.

Verdienste Internist und Hämatologe; arbeitete 1910-1913 im Hamburger Tropeninstitut und im Ersten Weltkrieg als Hygieniker bei der Armee, ab 1919 als Internist in der Charité in Berlin. Sein Hauptinteresse galt der Hämatologie und hier insbesondere des Einsatzes der morphologischen Differenzierung zur Erkennung von Erkrankungen ( $>$ Hämogramm nach Schilling, > Zählkammer).

\section{Schilling-Kammer}

- Erythrozytenzählung

- Leukozytenzählung

>Zählkammer

\section{Schilling-Test}

- Vitamin-B - $_{12}$-Resorptionstest

\section{Schistosoma spp.}

W. Stöcker

\section{Englischer Begriff schistosoma}

Beschreibung des Erregers Klasse: Trematoda (Saugwürmer); Familie: Schistosomatidae; Gattung: Schistosoma (Pärchenegel); Arten: S. haematobium, S. mansoni, S. intercalatum, S. japonicum, S. mekongi.

Erkrankungen Schistosomiasis (Bilharziose).

Verbreitung: tropische und subtropische Gebiete Afrikas, Lateinamerikas sowie Südwest- und Südostasiens:

- S. haematobium: Afrika, Naher und Mittlerer Osten

- S. mansoni: Afrika, Arabische Halbinsel, Südamerika, vereinzelt Karibik

- S. intercalatum: Westafrika, regional in Kamerun, Gabun und im Kongo
- S. japonicum: China, Philippinen, Indonesien, vereinzelt Japan

- S. mekongi: Laos, Kambodscha, Thailand

Wirt: Süßwasserschnecken (Zwischenwirt), End-/Reservoirwirte sind u. a. Säugetiere und Vögel.

Übertragung/Entwicklung: Mit dem Stuhl oder Urin des Endwirtes gelangen befruchtete Eier ins Wasser. Aus ihnen schlüpfen Wimpernlarven (Miracidium), die aktiv in den Zwischenwirt eindringen und sich zu Sporozysten entwickeln. Aus einer Sporozyste schlüpfen hunderte infektiöser Zerkarien, die ins Wasser ausgeschieden werden. Sie durchdringen die Haut des Endwirtes (Penetrationsphase) und wandern in dessen Blutbahn. Im Endwirt erfolgen die Entwicklung zum geschlechtsreifen Parasiten und die Paarung.

Erkrankung: Die Inkubationszeit bis zur ZerkarienDermatitis beträgt 6-48 Stunden. Vor allem bei Infektionen mit $S$. japonicum und $S$. mekongi kann nach 2-8 Wochen ein akutes fiebriges Krankheitsbild auftreten (Katayama-Fieber mit Schüttelfrost, Husten, Kopfschmerzen). Nach Jahren können Symptome einer chronischen Schistosomiasis (u. a. Blut in Urin/Stuhl, Abdominalschmerzen) einsetzen. Die gepaarten Parasiten besiedeln die Venen vor allem der Blase (S. haematobium), des Mesenteriums (S. mansoni, S. japonicum, S. mekongi) oder des Rektums (S. intercalatum), wobei prinzipiell jedoch alle Organe des Körpers befallen sein können. Mit zunehmender Zahl abgelegter Eier kommt es zum Verschluss der Kapillaren und zu chronischen, entzündlichen Immunreaktionen gegen die Eier in den betreffenden Organen (Blasenbilharziose, hepatolienale Bilharziose, Darmbilharziose). Als Folge können sich Granulome bis hin zu Fibrosen ausbilden.

Analytik Direktnachweis: Nachweis der Eier im Urin, Stuhl oder in Schleimhautbiopsaten aus Blase oder Darm; Nachweis der DNA durch Polymerase-Kettenreaktion in Speziallaboratorien.

Serologie: Nachweis spezifischer Antikörper (IgM, IgG) im Serum durch indirekte Immunfluoreszenz ( $\triangleright$ Immunfluoreszenz, indirekte), $>$ Enzyme-linked Immunosorbent Assay.

Probenmaterial Direktnachweis: Urin, Stuhl, Schleimhautbiopsate.

Serologie: Serum oder Plasma für den Nachweis der Antikörper sind bei $+4{ }^{\circ} \mathrm{C}$ bis zu 2 Wochen lang beständig, bei $-20{ }^{\circ} \mathrm{C}$ über Monate und Jahre hinweg. Zur Tiefkühlkonservierung des IgM kann man den Proben 80 \% gepuffertes Glyzerin beifügen.

Diagnostische Wertigkeit Die Anamnese des Patienten kann wichtige Hinweise geben (Reisen in verdächtige Regionen, Kontakt mit Binnengewässern, Auftreten von Hauterscheinungen). Der direkte Nachweis der Parasiteneier ist frü- 
hestens nach 4-10 Wochen möglich. Vorher ist eine Eosinophilie im Blutbild nachweisbar. Die Serologie spielt besonders bei Reiserückkehrern aus endemischen Gebieten eine besondere Rolle, da bei Erstinfektion mit Schistosoma ssp. die Eiproduktion oft intermittierend verläuft und eine Infektion dann nur über die Antikörperbestimmung auch während der Präpatenzzeit (ca. 3 Monate) nachgewiesen werden kann. Bei erfolgreicher Behandlung mit Praziquantel kann nach ca. 6-12 Wochen ein Abfall des Antikörpertiters gemessen werden. Kreuzreaktionen mit Antikörpern gegen andere Parasiten sind möglich.

\section{Differenzialdiagnosen:}

- Zerkariendermatitis: Allergien

- Akute Schistosomiasis: Typhus abdominalis, Malaria, Brucellose, Amöbiasis, Ancylostomiasis, lymphatische Filarose, Trichomonaden, viszerale Leishmaniose

- Chronische Schistosomiasis: je nach Lokalisation Blasen-, Darm- und Lebererkrankungen anderer Genese

\section{Literatur}

Centers for Disease Control and Prevention, Atlanta, 7. Nov 2012. Parasites -Schistosomiasis. https://www.cdc.gov/parasites/schisto somiasis/. Zugegriffen am 15.02.2017

Robert-Koch-Institut, Berlin (2011) Steckbriefe seltener und importierter Infektionskrankheiten. Robert-Koch-Institut, Berlin

World Health Organization. Media Centre, Jan 2017. Schistosomiasis. Factsheet. http://www.who.int/mediacentre/factsheets/fs115/en/. Zugegriffen am 15.02.2017

\section{Schistozyten}

- Fragmentozyt

- Helmzellen

\section{Schizont}

H. Baum

Synonym(e) Meront

Englischer Begriff schizont

Definition Ungeschlechtliche Teilungsform der Sporozoen mit mehreren Zellkernen.

Beschreibung Der Schizont ist die ungeschlechtliche Teilungsform von Sporozoen (z. B. der $>$ Plasmodien oder
Toxoplasmen) im Zwischenwirt. Der Schizont besitzt mehrere Zellkerne. Nach dem Zerfall des mehrkernigen Schizonten werden einkernige Merozoiten freigesetzt, die wiederum neue Zellen befallen oder aber sich zu Gametozyten, den geschlechtlichen Formen differenzieren.

Die Abbildung zeigt einen intraerythrozytären Schizonten bei Malaria quartana $(1000 \times$, May-Giemsa-Grünwald-Färbung):

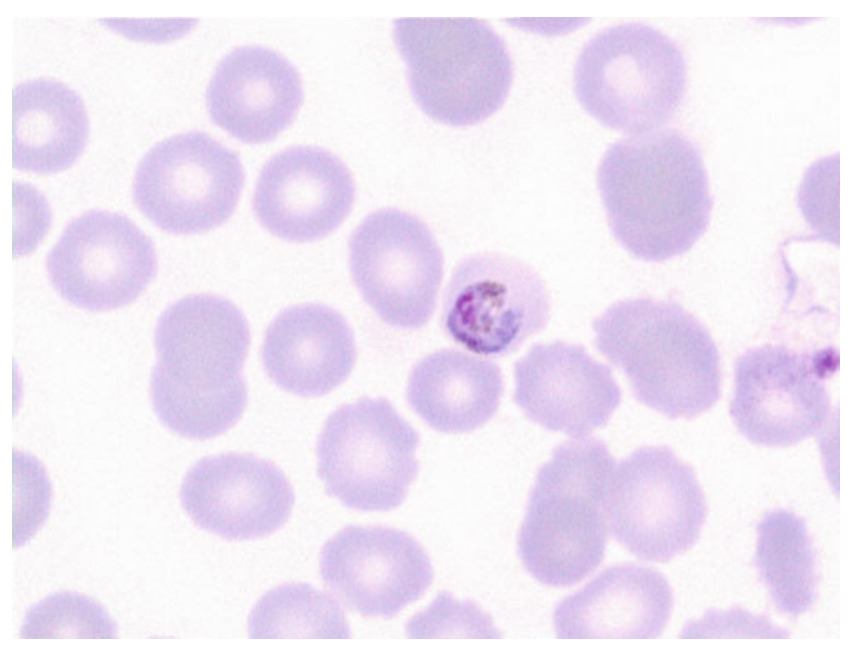

\section{Literatur}

Seitz HM, Maier W (1994) Parasitologie - Sporozoen. In: Brandis H, Köhler W, Eggers HJ et al (Hrsg) Lehrbuch der Medizinischen Mikrobiologie. Gustav Fischer Verlag, Stuttgart, S 654-667

\section{Schizozyten}

Fragmentozyt

\section{Schlafmohn}

$>$ Mohn

\section{Schlesinger-Probe}

A. M. Gressner und O. A. Gressner

Synonym(e) Urobilin- und Sterkobilinnachweis nach Schlesinger

Englischer Begriff Schlesinger's test 
Definition Heute obsoleter, qualitativer Nachweis von Urobilin und Sterkobilin in Urin oder Fäzes.

Beschreibung Bei dem vom Wiener Internisten Wilhelm Schlesinger (1869-1947) entwickelten qualitativen Nachweis bilden Urobilin ( $\triangleright$ Urobilin(ogen)) und Sterkobilin ( $\triangleright$ Sterkobilin (ogen)) mit $10 \%$ iger alkoholischer Zinkacetatlösung (Schlesinger-Reagenz) ein grün fluoreszierendes Zinksalz, das besonders bei Betrachtung gegen einen dunklen Hintergrund deutlich wird. Interferierendes $>$ Bilirubin (Grünfärbung) sollte erst ausgefällt werden. Störungen durch fluoreszierende Medikamente (z. B. Riboflavin). Nachweisverfahren heute nicht mehr im Gebrauch.

\section{Literatur}

Hallmann L (1980) Klinische Chemie und Mikroskopie, 11. Aufl. Georg Thieme Verlag, Stuttgart/New York

\section{Schließende Statistik}

- Statistik, induktive

\section{Schlussbericht}

- Abschlussbericht

\section{Schmelzkurvenanalyse}

\section{J. Arnemann}

Synonym(e) Melting curve-Analyse

Englischer Begriff melting curve analysis

Definition Die Schmelzkurvenanalyse charakterisiert die Dissoziation doppelsträngiger DNA während der Erhitzung und ermöglicht die spezifische Detektion von Sequenzabweichungen bzw. definierten pathogenen Mutationen.

Beschreibung Bei der Erhitzung doppelsträngiger DNA kann der Zustand der Dissoziation in 2 Einzelstränge optisch durch die Absorbierungsintensität oder Hyperchromazität verfolgt werden.
Die Doppelhelixstruktur der DNA ist in wässriger Lösung nur bedingt stabil. Unter extremen Bedingungen, wie z. B. starker Erhitzung oder hohen $\mathrm{pH}-$ Werten $(>11,5)$ werden die beiden Einzelstränge und hier insbesondere die Wasserstoffbrückenbindungen zwischen den Basen in der Helix aufgrund der Strukturänderung voneinander getrennt, sodass der Doppelstrang in 2 Einzelstränge dissoziiert oder ,aufgeschmolzen" wird. Dieser Prozess kann unter UV-Licht bei $260 \mathrm{~nm}$ verfolgt werden, da die doppelsträngige DNA einen niedrigen Absorptionskoeffizenten hat und die einzelsträngige DNA einen hohen. Diesen Prozess kann man als Zunahme der Absorption in Abhängigkeit von der Temperatur als Schmelzkurve dokumentieren (Hyperchromizitätseffekt). Die Schmelzkurve hat einen sigmoiden Verlauf, wobei der mathematische Wendepunkt der Kurve dem eigentlichen Schmelzpunkt, spezifisch für die eingesetzte DNA, entspricht und den Zustand von $50 \%$ einzelsträngiger und $50 \%$ doppelsträngiger DNA repräsentiert. Der Schmelzpunkt ist $\mathrm{u}$. a. auch davon abhängig, wie hoch der jeweilige Anteil an G-C- bzw. A-T-Paarungen ist. Da G-C-Bindungen über je 3 Wasserstoffbrückenbindungen, A-T-Bindungen aber nur über 2 verfügen, lösen sich die G-C-Bindungen unter höherer Energie, d. h. höherer Schmelztemperatur.

Dies ist auch das Prinzip der Schmelzkurvenanalyse, bei der heterozygote oder homozygote Varianten gegenüber einer Wildtyp-Sequenz eine leichte Verschiebung der Schmelztemperatur zeigen. Die Schmelzkurvenanalyse erfolgt immer im Anschluss an eine Realtime-PCR, bei der das PCR-Produkt unter langsamer Temperaturzunahme von beispielsweise $0,2{ }^{\circ} \mathrm{C} / \mathrm{s}$ in einem Temperaturbereich von typischerweise 40-80 ${ }^{\circ} \mathrm{C}$, aufgeschmolzen“ wird. Die Genauigkeit dieser Analyse kann dadurch verbessert werden, dass die in der PCR eingesetzten Hybridisierungsprobes (HybProbes) oder LightCycler-Sonden direkt über die bekannten Mutationshotspots gelegt werden. Die LightCycler-Sonden bestehen dabei aus 2 Oligonukleotiden, jeweils mit einem Donor- und Akzeptorfarbstoff, die auf der DNA direkt nebeneinander liegen und als FRET-Effekt (Fluoreszenz-Resonanz-Energie-Transfer) einen Energietransfer des Donors auf den Akzeptor bewirken. Dissoziiert eine dieser beiden Sonden aufgrund eines Basenmismatches bei einer anderen Temperatur, wird in einer grafischen Darstellung (-dF/dT-Werte zur Temperatur) ein unterschiedlicher, aber spezifischer Peak dargestellt, der in Kombination mit Peaks für homozygote Wildtypsequenzen, heterozygote oder homozygote Mutationen eine zuverlässige Diagnose liefert.

\section{Literatur}

Tsiatis AC et al (2010) Comparison of sanger sequencing, pyrosequencing, and melting curve analysis for the detection of KRAS mutations. J Molecular Diagnostics 12:425-432 


\section{Schmidt-Probe}

A. M. Gressner und O. A. Gressner

Synonym(e) Urobilinnachweis nach Schmidt

Englischer Begriff Schmidt's test

Definition Heute obsoleter, qualitativer Nachweis von Urobilin im Fäzes.

Beschreibung Urobilin ( $\triangleright$ Urobilin(ogen)) reagiert mit Quecksilber-(II)-Chlorid unter Bildung von intensiv rotem Quecksilberurobilin. B Bilirubin ergibt eine Grünfärbung, die nach etwa 15-30 Minuten auftritt ( $>$ Biliverdin-Bildung). Als Untersuchungsmaterial dient ein etwa haselnussgroßes Aliquot des frischen Fäzes, der im Mörser mit Quecksilber(II)-Chlorid-Lösung verrieben und mehrere Stunden zugedeckt inkubiert wird.

\section{Literatur}

Hallmann L (1980) Klinische Chemie und Mikroskopie, 11. Aufl. Georg Thieme Verlag, Stuttgart/New York

\section{Schmidt-Quotient}

$>$ Transaminasen-GLDH-Quotient

\section{Schnelltest}

- Teststreifen

\section{Schnelltest für Bilirubin im Liquor (CSF)}

Liquor-Bilirubin, Teststreifen-Test

\section{Schnelltests im Urin}

- Urinteststreifen

\section{Schnepper zur Blutentnahme}

$>$ Blutentnahme

\section{Schnitger- und Gross-Methode}

- Koagulometer

\section{Schnittstelle}

O. Colhoun

\section{Englischer Begriff interface}

Definition Berührungspunkt von EDV-Einheiten, die miteinander kommunizieren.

Beschreibung Über eine Hardware-Schnittstelle wird z. B. ein Analysegerät an die $>$ Labor-EDV angeschlossen, um die Datenübertragung zu ermöglichen. Aufbau und Belegung von Hardware-Schnittstellen sind genormt. Verbreitete PC-Hardware-Schnittstellen sind die parallele Centronics- und die serielle RS-232-Schnittstelle, PS/2-Anschlüsse sowie die Peripheriebusanschlüsse (USB, SCSI). Software-Schnittstellen dienen dem Datenaustausch von Anwendungen untereinander bzw. mit dem Betriebssystem. Hierzu gehört etwa die Normierung und Anpassung bzw. Übersetzung der Datenströme von der Labor-EDV zum Analysegerät und retour oder die Datenübertragung vom Labor-EDV-System zum $>$ KIS.

Querverweise $>$ Analysegeräte-Anschluss

\section{Schnüffelstoffe}

C. Vidal und W.-R. Külpmann

Englischer Begriff chemicals for inhalant abuse

Definition Leichtflüchtige organische Lösungsmittel oder Gase, die zur Erzeugung von Rauschzuständen eingeatmet werden.

Bewertung Beim „Schnüffeln“ werden leicht zugängliche, billige Produkte des privaten Konsums verwendet, z. B. Kleb- 
stoffe, Klebstoffverdünner, Fahrradschlauchkleber, Farb- und Lackverdünner, Nagellack und -entferner, Feuerzeuggas, Propangas (Campingkocher), Sprays, Benzin. Die Produkte enthalten in der Regel eine Mischung verschiedener Bestandteile wie $n$-Hexan, Cyclohexan, Benzol, Chlorkohlenwasserstoffe (z. B. Chloroform), Alkohole, Ester (z. B. Ethylacetat), Ether (z. B. Diethylether), organische Nitrite (z. B. Isoamylnitrit). Zum Nachweis wird u. a. die gaschromatographische Dampfraumanalyse ( $\triangleright$ Dampfraumanalyse, gaschromatographische) eingesetzt.

\section{Literatur}

Gibitz HJ (2009) Inhalant abuse. In: Külpmann WR (Hrsg) Clincial toxicological analysis. Wiley-VCH, Weinheim, S 533-555

\section{Schönheimer, Rudolf}

H. Fiedler

Lebensdaten Deutsch-amerikanischer Mediziner und Biochemiker, geboren 1898 in Berlin, gestorben 1941 in Yonkers (USA). Nach der Promotion forschte Schönheimer (auch Schoenheimer) am Moabit-Krankenhaus über Steroide als Risikofaktoren der Atherosklerose. Nach Weiterbildung in Biochemie bei Karl Thomas in Leipzig leitete er 1926 in Freiburg das Chemische Laboratorium des Pathologischen Instituts von Ludwig Aschoff (1876-1942). Hier hatte er wichtige Kontakte zu Adolf Windaus ( $\triangleright$ Windaus, Adolf Otto Reinhold), Georg von Hevesy (Tracertechnik, Neutronenaktivierungsanalyse), Sir Hans Adolf Krebs (Zitrat- und Harnstoffzyklus) und Siegfried Thannhauser (Stoffwechselforschung). 1933 musste er als Jude zusammen mit seiner jüdischen Frau (Salome Gluecksohn-Waelsch, 1907-2007, Begründerin der Entwicklungsgenetik der Säugetiere) Freiburg verlassen und ging zu Hans T. Clark, Department of Biological Chemistry, Columbia College New York.

Verdienste Bereits in Deutschland hatte Schönheimer erkannt, dass der intermediäre Stoffwechsel einer schnellen Dynamik unterliegt. Wichtiges Hilfsmittel war derzeit die Markierung von Substanzen: Phenylsubstituierung von Fettsäuren durch F. Knoop, Isotopenmarkierung durch von Hevesy und Einführung des Massenspektrographen durch F.W. Aston. In Amerika konnte Schönheimer die Isolierung von Deuterium/schwerem Wasser (1934) und von ${ }^{15} \mathrm{~N}$ (1937) durch H.C. Urey nutzen. Zusammen mit D. Rittenberg, Sarah Ratner und Konrad E. Bloch führte Schönheimer zahlrei- che Turnover-Untersuchungen durch: Stoffwechselwege diätetisch zugeführter Fettsäuren, Bestätigung des Harnstoffzyklus, Biosynthese von Cholesterin, Kreatin, Hippursäure sowie von Aminosäuren und deren Transaminierung. Schönheimer wird als Vater der Molekularen Biochemie betrachtet. Sein selbst gewählter früher Tod hat wohl die Auszeichnung mit dem Nobelpreis verhindert.

\section{Literatur}

Berthold HK (2003) Rudolf Schönheimer (1898-1941): Leben und Werk, 2. Aufl. Falk Foundation, Freiburg i. Br

Guggenheim KY (1991) Rudolf Schoenheimer and the concept of the dynamic state of body constituents. J Nutr 121:1701-1704

\section{Schrader-Formel}

- Organophosphate

\section{Schraubverschluss}

- Verschlusskappe

\section{Schüffner-Tüpfelung}

H. Baum

Englischer Begriff Schüffner's dots; granules

Definition Leicht rötliche Punktierung der Erythrozyten bei einer Infektion mit Plasmodien.

Beschreibung Die Schüffner-Tüpfelung (W. Schüffner, 1867-1949, Tropenarzt) ist ein nicht immer nachweisbares Begleitphänomen bei der Infektion der $>$ Erythrozyten mit den Malariaerregern Plasmodium vivax und P. ovale ( $\triangleright$ Plasmodien). Es handelt sich dabei um Ablagerungen von Hämozoin, der nicht toxischen, hochmolekularen, parasitären Speicherform des nicht abgebauten, toxischen Häms aus dem Wirtzellshämoglobin in den befallenen Erythrozyten. Aber auch bei einer Infektion mit Plasmodium falciparum und P. malariae können der Schüffner-Tüpfelung analoge Hämozoinablagerungen gefunden werden. 


\section{Literatur}

Bench aids for the diagnosis of malaria, plates no 1-8. World Health Organization (2000) http://apps.who.int/iris/bitstream/10665/42195/ 1/9241545240.pdf

\section{Schuller-Sagar-IgG-Formel}

- Immunglobulinbestimmung, intrathekal empirisch

\section{Schütteltest}

Röhrchentest

\section{Schutzbehälter}

> Nadelschutzkappen

\section{Schuurs, Anton}

$\triangleright$ Engvall, Eva

\section{Schwangerschaftsassoziiertes}

Plasmaprotein A

> Pregnancy-Associated-Plasma-Protein A

\section{Schwangerschaftsdiagnostik}

- Pränataldiagnostik

- Schwangerschaftstest im Urin

\section{Schwangerschaftshormon}

$\triangleright$ Relaxin

\section{Schwangerschaftstest im Urin}

W. G. Guder

Synonym(e) Choriongonadotropintest im Urin; hCG-Test

Englischer Begriff gravidity test in urine; human chorionic gonadotropine test in urine

Definition Verfahren zum Nachweis von humanem Choriongonadotropin ( $\triangleright$ Choriongonadotropin, humanes) $>10 \mathrm{IE} / \mathrm{L}$.

Synthese - Verteilung - Abbau - Elimination Humanes Choriongonadotropin ( $\triangleright$ Choriongonadotropin, humanes) ist ein Glykoproteohomon mit einer Molmasse von 36-40 kDa, das wie die hypophysären Gonadotropine aus 2 Untereinheiten aufgebaut ist, von denen die $\alpha$-Einheit der des Lutropins ( $\triangleright$ Luteinisierendes Hormon) gleich ist und die $\beta$-Kette spezifisch für CG ist. Es wird in den Synzytiotrophoblasten der Plazenta gebildet und in das mütterliche Blut abgegeben. Dort wird es in der freien Form in den Primärharn filtriert, bei der Rückresorption abgebaut und nicht resorbiertes Hormon im Urin ausgeschieden, wo es ab der ersten Woche nach Konzeption nachweisbar wird.

Funktion - Pathophysiologie $>$ Choriongonadotropin, humanes.

Analytik $>$ Choriongonadotropin, humanes.

Konventionelle Einheit Qualitativ als ,,+“ oder ,--“.

Referenzbereich - Frauen Negativ, ab 2. Woche nach Empfängnis positiv. Quantitative Werte im Plasma \ Choriongonadotropin, humanes

Indikation $>$ Choriongonadotropin, humanes.

Interpretation $>$ Choriongonadotropin, humanes.

Diagnostische Wertigkeit $>$ Choriongonadotropin, humanes.

\section{Literatur}

Stieber P, Schalhorn A (2009) Malignes Wachstum. In: Guder WG, Nolte J (Hrsg) Das Laborbuch in Klinik und Praxis, 2. Aufl. Elsevier/Urban und Fischer, München 


\section{Schwangerschaftstest mit dem \\ Bitterling}

- Bitterlingstest zum Nachweis einer Schwangerschaft

\section{Schwangerschaftstest mit der Maus}

- Schwangerschaftstest nach Aschheim und Zondek

\section{Schwangerschaftstest nach Aschheim und Zondek}

T. Arndt

Synonym(e) Aschheim-Zondek-Schwangerschaftstest

Englischer Begriff Aschheim-Zondek pregnancy reaction; Aschheim-Zondek reaction

Definition Heute obsoleter biologischer Test zum Nachweis einer Schwangerschaft unter Einsatz von Mäusen.

Beschreibung Nach den Gynäkologen Selmar Aschheim (1878-1965) und Bernhard Zondek (1891-1966) benanntes, früher häufig verwendetes Verfahren zur Schwangerschaftsfrüherkennung. Infantilen weiblichen Mäusen wird subkutan Schwangerenharn injiziert. Wachstum der Ovarien und Ovulation nach 4-5 Tagen zeigten eine Schwangerschaft an. Die Genauigkeit der Vorhersage lag bei $98 \%$. Im Vergleich zum Bitterlingstest ( $\triangleright$ Bitterlingstest zum Nachweis einer Schwangerschaft) war der Maustest also zuverlässiger. Die längere Ansprechzeit und die Notwendigkeit der Tötung der Versuchstiere waren Nachteile der Methode.

Varianten des Tests unter Verwendung anderer Tierspezies wie Krallenfrosch (6 Stunden Ansprechzeit), männlichen Fröschen (Auftreten von spermahaltigem Urin 2-4 Stunden nach Harninjektion) und der Deutschen Kröte (Bufo vulgaris, zur Ablösung von Krallenfroschimporten) mit Vermeidung der Obduktion waren Entwicklungsstufen auf dem Weg zum heutigen Schwangerschaftstest mit der spezifischen Bestimmung von Choriongonadotropin (HCG; $>$ Choriongonadotropin, humanes) im Schwangerenharn.

Anmerkung: Vor 3000 Jahren sollen die Ägypter am beschleunigten Keimen/Wachstum von mit Schwangerenharn begossenem Getreide (Weizen, Gerste) mit $75 \%$ Treffsicherheit eine Schwangerschaftsfrühdiagnose erreicht haben.

\section{Literatur}

Aschheim S, Zondek B (1928) Die Schwangerschaftsdiagnose aus dem Harn durch Nachweis des Hypophysenvorderlappenhormons. Klin Wochenschrift 7(1404-1411):1453-1457

Schlögl HA (2006) Das alte Ägypten. Geschichte und Kultur von der Frühzeit bis zu Kleopatra. C. H. Beck, München, S 167

\section{Schwangerschaftstest nach Glaser und Haempel}

- Bitterlingstest zum Nachweis einer Schwangerschaft

\section{Schwartz-Formel}

W. G. Guder

Synonym(e) Berechnung der Creatinin Clearance nach Schwartz

Englischer Begriff calculation of creatinine clearance according to Schwartz; Schwartz formula

Definition Formel zur Berechnung der $\triangleright$ Kreatinin-Clearance bei Kindern.

Beschreibung $\mathrm{Da} \triangleright$ Kreatinin im Serum/Plasma während der kindlichen Entwicklung seine Konzentration verändert und Mädchen niedrigere Werte als Jungen aufweisen, schlugen Schwartz et al. im Jahr 1976 folgende Formel vor, um die glomeruläre Clearance altersabhängig zu ermitteln:

Neugeborene bis $1 \mathrm{Jahr}$ :

$$
\text { GFR }=0,43 \times \frac{\text { Körperlänge }[\mathrm{cm}]}{\text { Kreatinin }[\mathrm{mg} / \mathrm{dL}]}
$$

Kinder ab dem 1. Lebensjahr:

$$
\text { GFR }=0,55 \times \frac{\text { Körperlänge }[\mathrm{cm}]}{\text { Kreatinin }[\mathrm{mg} / \mathrm{dL}]}
$$

Bei auf Referenzmethode ( $\triangleright$ Referenzmethodenwert) bezogener Analytik von Kreatinin ist die Formel nicht mehr gültig, da sie 35-120 \% höhere Clearance-Werte liefert (teils durch Sekretion, teils durch Wegfall der $\gg$ Pseudokreatinine). Daher wird empfohlen, bei Kindern $\triangleright$ Cystatin $\mathrm{C}$ als Marker zu verwenden. 


\section{Literatur}

Delanghe JR (2008) How to establish glomerular filtration rate in children. Scand J Clin Lab Invest 68(Suppl 241):46-51

Schwartz GJ, Haycock GB, Edelmann CM, Spitzer A (1976) A simple estimate of glomerular filtration rate in children derived from body length and plasma creatinine. Pediatrics 58:259-263

\section{Schwartz-Watson-Test}

\section{A. M. Gressner und O. A. Gressner}

Synonym(e) Porphobilinogen-Nachweis im Urin; WatsonSchwartz-Test

\section{Englischer Begriff Watson-Schwartz-test}

Definition Qualitativer Farbtest/Screeningtest zum Nachweis von Porphobilinogen im Urin bei Verdacht auf akute Porphyrie.

Beschreibung Der von den beiden US-amerikanischen Ärzten Cecil J. Watson (1901-1983) und Samuel Schwartz (1916-1997) entwickelte qualitative, diagnostische Test der akuten Porphyrie weist im Urin der Erkrankten $>$ Porphobilinogen mit der Ehrlich-Aldehydreaktion nach. Neben der Ausscheidung von Uroporphyrin, Koproporphyrin und > 5-Aminolävulinsäure wird bei dieser Erkrankung in größeren Mengen $>$ Porphobilinogen ausgeschieden. Zur Durchführung des Nachweisverfahrens werden $5 \mathrm{~mL}$ Urin (frischer Urin oder Aliquot eines lichtgeschützt und kühl aufbewahrten Sammelurins) mit einigen Tropfen $>$ Ehrlich-Probe (Dimethylaminobenzaldehyd in Salzsäure) versetzt und nach Zusatz von $1 \mathrm{ml}$ Chloroform mehrmalig umgeschüttelt. Porphobilinogen bzw. sein rotes Kondensationsprodukt bleibt im Gegensatz zu anderen Chromogenen (z. B. Gallenfarbstoffe) in der wässrigen Phase. Ein positives Ergebnis mit Rotfärbung der wässrigen Phase weist auf eine akute Porphyrie bzw. Porphobilinogenausscheidung hin. Ein positiver Schnelltest sollte durch eine differenzierten und quantitativen Porphyrinanalyse ergänzt werden ( $>$ Hoesch-Test, $>$ Porphyrine).

\section{Literatur}

Gitter A, Heilmeyer L (1963) Taschenbuch klinischer Funktionsprüfungen, 8. Aufl. Gustav Fischer Verlag, Stuttgart

Pierach CA, Cardinal R, Bossenmaier I, Watson CJ (1977) Comparison of the Hoesch and the Watson-Schwartz Test for urinary porphobilinogen. Clin Chem 23:1666-1668

Watson CJ, Schwartz S (1941) A simple test for urinary porphobilinogen. Proc Soc Exp Biol Med 47:393

\section{Schwefelsäure-Aufschluss}

- Veraschung

\section{Schweiß}

T. Arndt

Synonym(e) Sudor

\section{Englischer Begriff sweat}

Definition Von den Schweißdrüsen der Haut zu $99 \%$ aus Wasser mit geringen Anteilen an $\mathrm{NaCl}$, > Harnstoff, flüchtigen $>$ Fettsäuren, $>$ Cholesterin und einem $\mathrm{pH}$ von ca. 4,5 produziertes Sekret.

Beschreibung. Die Schweißanalytik hat im klinischchemischen Labor eine untergeordnete Bedeutung, eine wichtige Ausnahme ist die Chloridbestimmung zur Diagnose einer zystischen Fibrose. Im toxikologischen Labor gewinnen Drogenuntersuchungen aus Schweiß an Bedeutung.

\section{Literatur}

Reuter P (2004) Springer Lexikon Medizin. Springer, Berlin/Heidelberg/ New York

\section{Schweiß und Drogen}

T. Arndt

\section{Synonym(e) Drogenscreening in Schweiß}

Englischer Begriff drug screening in sweat; drug wipe test

Definition Drogenscreening im Schweiß, zumeist als Vorortanalyse, z. B. bei Verkehrskontrollen.

Beschreibung Allgemein etablierte Matrices zum Nachweis eines Alkohol- oder Drogenkonsums sind Blut bzw. Serum/ Plasma zum Nachweis eines akuten Missbrauchs, z. B. zum Zeitpunkt eines Unfalls oder einer Straftat und Urin zum retrospektiven Nachweis eines Konsums bzw. zur Abstinenzkontrolle. 
Daneben sind sog. alternative Matrices $>$ Matrix, alternative wie Haare, \ Mundflüssigkeit (Speichel), \ Schweiß, Nägel, ggf. auch Knochen- und Zahnmaterial von Interesse, da sie Mengenanteile der aufgenommenen Muttersubstanz und ihrer In-vivo-Metabolite enthalten und damit prinzipiell ebenfalls zum Drogennachweis geeignet sind.

Der Drogennachweis im Schweiß (z. B. Achselschweiß, Stirnschweiß) kann als immunologisches Screening mit sog. Wischtests, zumeist Einzeltests auf eine Droge oder Drogengruppe, oder mit physiko-chemischen Methoden erfolgen. Bei letzteren wird der Vorteil einer spezifischen und deshalb beweissicheren Analyse mit dem Verlust einer schnellen, verfälschungssicheren, schamfreien, nicht invasiven, $d$. h. aus Sicht der Präanalytik unproblematischen, Vorortanalytik erkauft.

Derzeit verfügbare Systeme erfassen Cannabis, Amphetamine, Kokain und Opiate. Das Messprinzip entspricht dem von $>$ Teststreifen, wobei der Wischtest auf die zu prüfende Oberfläche (Haut) aufgelegt wird, um Schweiß aufzunehmen. Anschließend wird der Wischtest befeuchtet, um die im Wischer aufgenommen Stoffe zu den Antikörper-beladenen Reaktionszonen im integrierten Teststreifen zu transportieren. Positive Wischtestergebnisse sind durch eine physikochemischen Bestätigungsanalyse, zumeist mit Massenspektrometrie, zu überprüfen.

Einsatzgebiete können u. a. Verkehrskontrollen, arbeitsmedizinische Vororttests, suchtmedizinische Betreuung etc. sein. Siehe auch $>$ Wischtests zum Drogennachweis $>$ Drogenscreening sowie unter den einzelnen Drogengruppen.

\section{Literatur}

De Giovanni N, Fucci N (2013) The current status of sweat testing for drugs of abuse: a review. Curr Med Chem 20(4):545-561

\section{Schweißanalytik}

T. Arndt

Synonym(e) Chlorid im Schweiß

\section{Englischer Begriff sweat analysis}

Definition Qualitative und quantitative Analysen von Schweiß.

Beschreibung Schweißanalytik beschränkt sich im Wesentlichen auf die qualitative oder quantitative Chloridanalyse (zu Referenzwerten s. > Chlorid).
Im Finger-Schweißtest (nach Shwachman und Gahm) wird die Hand des Patienten 20-30 Minuten auf eine Silbernitrat- und Kaliumbicarbonat-haltige > Agar-Platte gelegt. Bei pathologisch erhöhtem Chloridgehalt des Schweißes zeigt sich an den Druckstellen ein deutlicher gelb-grüner Silberchlorid-Niederschlag.

Im Pilocarpin-Ion(t)ophorese-Test (nach Ritter) wird die Schweißsekretion durch elektrische Reize mittels Metallelektroden auf der Haut und gleichzeitiges Befeuchten mit $2 \%$ iger Pilocarpiniumnitratlösung (Pilocarpinlösung) angeregt. Der Schweiß wird gesammelt, gewogen, verdünnt und anschließend einer titrimetrischen ( $\triangleright$ Titration), flammenphotometrischen ( $\triangleright$ Flammenemissionsspektrometrie) oder coulometrischen ( $\triangleright$ Coulometrie) Analyse unterzogen.

Im Schweißtest werden Metallelektroden an der volaren Seite des Unterarms und ein unter der Anode fixierter, mit $20 \mathrm{mmol} / \mathrm{L}$ Pilocarpinlösung getränkter, Zellstofftupfer zur Schweißstimulation eingesetzt. Nach 10 Minuten Stromfluss bei $2 \mathrm{~mA}$ werden die Elektroden entfernt, die Hautpartie gereinigt und eine Zelluloseacetatfolie mit Polyethylenfolienabdeckung gegen Verdunstung aufgelegt. Nach 30-60 Minuten wird über elektrische Leitfähigkeitsmessung und entsprechende Kalibrationsfunktionen die Natriumchloridkonzentration im Schweiß ermittelt.

Der Ninhydrin-Schweißtest (nach Moberg) mit Schweißsammlung auf Schreibmaschinenpapier durch ca. 10-minütiges Auflegen der zu untersuchenden Körperstelle, zweimaliges Befeuchten des Papiers mit 1 \%iger Ninhydrinlösung in Aceton (mit wenigen Tropfen Eisessig) und Trocknung in Heißluft, dient der qualitativen Beurteilung der Schweißsekretion einzelner Hautgebiete. Schweißhaltige Papierstellen färben sich lila, anhidrotische Stellen bleiben weiß.

Neben der Chloridbestimmung gewinnt das $>$ Drogenscreening im Schweiß an Bedeutung, da es eine nicht invasive und für Patient und Prüfpersonal weniger peinliche Probenabgabe ermöglicht. Einzelheiten unter $>$ Wischtests zum Drogennachweis bzw $>$ Schweiß und Drogen.

\section{Literatur}

Hallmann L (1980) Klinische Chemie und Mikroskopie, 11. Aufl. Georg Thieme Verlag, Stuttgart/New York

Keil E, Fiedler H (2000) Klinische Chemie systematisch. UNI-MED Verlag, Bremen

\section{Schweißgewinnung}

T. Arndt

Englischer Begriff sweat sampling 
Definition Aufgrund der geringen Schweißsekretion je Hautsegment und der daraus resultierenden geringen Probenvolumina schwieriger präanalytischer Teilschritt der Schweißanalytik.

Beschreibung Neben der früher üblichen Schweißsammlung mit Filterpapier oder Agargel ( $\triangleright$ Schweißanalytik) erfolgen Schweißsammlung und Analyse heute zumeist in einem geschlossenen System. Moderne Armmanschetten oder spezielle, auf die Haut applizierbare Filterscheiben mit Kapillarsystem gewährleisten heute eine weitgehend fehlerfreie Schweißsammlung und bei bestimmten Systemen eine simultane und kontinuierliche Durchfluss-Leitfähigkeitsbestimmung.

Die Schweißgewinnung bei Neugeborenen, dem wichtigsten Patientenkollektiv für Untersuchungen zur zystischen Fibrose, gestaltet(e) sich besonders schwierig. Das Nanoduct-System erlaubt jetzt Schweißanalysen schon in den ersten Lebenstagen. Das Gerät vereinigt die klassische Methode der Pilocarpin-Ion(t)ophorese ( $\triangleright$ Schweißanalytik) mit verbesserter Pilocarpin-Applikation und direkter Durchfluss-Leitfähigkeitsmessung aus nativem Schweiß. Fehler durch die unter Stimulation anfänglich stets erhöhte Schweißproduktion und damit Verdünnungseffekte werden durch Ermittlung eines Leitfähigkeitsmittelwertes über die Messzeit eliminiert. Das System ermöglicht eine Schweißanalyse am Krankenbett aus $3 \mu \mathrm{L}$ Schweiß innerhalb weniger Minuten, d. h. ohne Einschaltung eines Labors.

Schweißtests im Rahmen der Drogenanalytik werden gewöhnlich mit sog. Wischtests durchgeführt. Hierbei wird das auf einem Träger befindliche Testfeld auf die Hautoberfläche (z. B. Stirn, Achselhöhle) gedrückt oder darüber gewischt. Eine Schweißgewinnung im o. g. Sinne ist also nicht nötig.

\section{Literatur}

http://www.elitechgroup.com/product/nanoduct-neonatal-sweat-analysissystem/. Zugegrieffen am 22.09.2017

Weissman N, Pileggi VJ (1974) Inorganic ions. In: Henry RJ, Cannon DC, Winkelman JW (Hrsg) Clinical chemistry - principles and technics. Harper \& Row, Hagerstown

\section{Schwellenwert}

$>$ Cut-off-Wert

\section{Schwellenwert der ROC}

\author{
R.-D. Hilgers, N. Heussen und S. Stanzel
}

Synonym(e) Cut-off-Wert der ROC
Englischer Begriff cut-off value; cut-off

Definition Der Schwellenwert der ROC ist ein Wert zur Klassifizierung von quantitativen Messergebnissen einer - Stichprobe in diagnostisch positive bzw. negative Fälle.

Beschreibung Um zu einer Klassifizierung der Messergebnisse eines diagnostischen Testverfahrens $(\triangleright$ Test, diagnostischer) in positiv, für nicht normale Werte, und negativ, für normale Werte, zu gelangen, wird der Wertebereich dichotomisiert. Dazu wird ein Schwellenwert gewählt, anhand dessen der Messbereich in 2 nicht überlappende Bereiche (positives/ negatives Testresultat) geteilt wird.

Im Rahmen diagnostischer Testverfahren besteht eines der Ziele der ROC-Analyse darin, einen geeigneten Schwellenwert zu ermitteln. Aufgrund der Eigenschaften der $>$ ROCKurve empfiehlt sich vor allem ein Wert nahe der linken oberen Ecke der grafischen Darstellung. Sollten nicht klinische oder praktische Gründe für einen bestimmten Schwellenwert sprechen, etwa ein Schwellenwert mit einer geringen falsch-positiv oder falsch-negativ Rate, so könnte man auch alternativ den Ausdruck [Sensitivität $-\mathrm{m} \times(1-$ Spezifität $)$ ] maximieren. Ist $\mathrm{m}=1$, so maximiert man lediglich die Summe aus Sensitivität ( $\triangleright$ Sensitivität, diagnostische) und Spezifität ( $\triangleright$ Spezifität, diagnostische). Dies entspricht der Minimierung der Wahrscheinlichkeiten möglicher Fehlentscheidungen, was in der Praxis nicht notwendigerweise die einzig zu bevorzugende Strategie darstellt. Bei der Wahl von m können daher auch Kostenargumente für Falschentscheidungen und A-priori-Wahrscheinlichkeiten ( $\triangleright$ A priori odds) Berücksichtigung finden.

\section{Literatur}

Hilgers R-D, Bauer P, Scheiber V (2002) Einführung in die Medizinische Statistik. Springer, Berlin/Heidelberg/New York

Zweig MH, Campbell G (1993) Receiver-operating characteristic (ROC) plots: a fundamental evaluation tool in clinical medicine. Clin Chem 39:561-577

Schweres-akutes-respiratorischesSyndrom-Corona-Viren

SARS-Corona-Viren

\section{Schwerketten}

H. Renz und B. Gierten

Synonym(e) H-Kette 
Englischer Begriff heavy chain

Definition Schwere Ketten der Immunglobuline (Ig), die die Ig-Klasse definieren. Nachgewiesen sind 5 Formen mit teilweise mehreren Subtypen: $\mu$-Kette für IgM, $\gamma$-Kette mit 4 Subtypen für $\operatorname{IgG}, \alpha$-Kette mit 2 Subtypen für $\operatorname{IgA}$, $\delta$-Kette für IgD, $\varepsilon$-Kette für $\operatorname{IgE}$.

Beschreibung Schwerketten haben eine Molmasse zwischen 51 und $71 \mathrm{kDa}$. Anhand des konstanten C-terminalen Teils werden die Immunglobulinklassen definiert. Er enthält 3 wichtige Domänen ( $\mathrm{CH} 1-3)$. $\mathrm{CH} 1$ und $\mathrm{CH} 2$ bilden die Hinge-Region, die die Molekülform in Lösung von T nach Y zur Antigenbindung verändert. Das Komplementprotein $\mathrm{C} 1 \mathrm{q}$ bindet an der CH1-Domäne. Die CH3-Domäne vermittelt die Bindung an zelluläre Fc-Rezeptoren. Die bei zellständigen $>$ Immunglobuline nachweisbare vierte Domäne (CH4) enthält die Transmembrankomponente.

Der variable N-terminale Teil ist analog dem der Leichtketten an der Bildung der Antigentasche beteiligt und wird in ähnlicher Weise genetisch variiert.

Im Rahmen maligner Entartung von B-Zell-Klonen können neben nahezu intakten Immunglobulinmolekülen (Schwer- und Leichtketten) auch isolierte Schwerketten den 4 genannten Typen $(\alpha, \beta, \gamma, \delta)$ oder Leichtketten (Typ к oder $\lambda$ ) gebildet werden.

\section{Schwermetalle}

- Spurenelemente

\section{Scienna-Blutgruppensystem}

K. Kleesiek, C. Götting, J. Diekmann, J. Dreier und M. Schmidt

Synonym(e) Human erythroblast membrane protein (HERMAP); Sc

Englischer Begriff Scianna blood group system

Beschreibung Die Antigene des Scienna-Blutgruppensystems sind Typ-I-Membranglykoproteine mit einer Molekularmasse von 60-68 kDa. Das Protein wird als „human erythroblast membrane protein“ (HERMAP) bezeichnet und gehört $\mathrm{zu}$ der Immunoglobulin-Superfamilie. Das ERMAP-Gen umfasst $19 \mathrm{~kb}$ und ist in 11 Exons organisiert. Zum SciennaBlutgruppensystem gehören 2 hochfrequente Antigene, Sc1 und Sc3, und 2 niedrigfrequente Antigene, Sc2 und Sc4 (Radin-Antigen).

Die Scienna-Antigene werden auf Erythrozyten und schwach auf anderen Zelltypen wie Leukozyten, Thymus, Lymphknoten und Milz exprimiert. Die transfusionsmedizinische Bedeutung ist gering. Es werden Fälle von Morbus haemolyticus neonatorum (Mhn; s. D Morbus haemolyticus fetalis/neonatorum) durch Anti-Radin(Rd)-Antikörper berichtet.

\section{Literatur}

Reid ME, Lomas-Francis C (2004) The blood group antigen facts book, 2. Aufl. Elsevier, New York

\section{Screening-Untersuchung}

C. Vidal und W.-R. Külpmann

\section{Synonym(e) Suchtest}

\section{Englischer Begriff screening}

Definition Orientierende Untersuchung.

Beschreibung Die Screening-Untersuchung wird durchgeführt, um rasch und mit möglichst geringem finanziellen Aufwand zu ermitteln, ob vermutlich ein bestimmter Zustand, z. B. Krankheit, vorliegt oder nicht. Es handelt sich meist um qualitative Untersuchungen mit geringer analytischer Spezifität. Die > Entscheidungsgrenze zwischen Befund „negativ“ und Befund ,positiv“" wird so gewählt, dass bezogen auf die Fragestellung ein optimales Verhältnis von falsch negativen und falsch positiven Befunden erhalten wird. Je nach Befund und Situation schließt sich ggf. an die Screening-Untersuchung eine spezifische quantitative Bestimmung oder eine spezifische qualitative Untersuchung ( $\triangleright$ Bestätigungsuntersuchungen) an ( $\triangleright$ Drogenscreening).

\section{Literatur}

DIN 58985 (2003) Entscheidungsgrenzen. Beuth-Verlag, Berlin

\section{SDA}

- Strand Displacement Amplifikation (SDA)

- Tamm-Horsfall-Protein 


\section{SDH}

- Sorbitdehydrogenase

\section{SDMA}

- Asymmetrisches Dimethylarginin

\section{SDS-Behandlung}

- SDS-Elektrophorese

\section{SDS-Elektrophorese}

\section{R. Westermeier}

Synonym(e) Sodiumdodecylsulfat-Elektrophorese

Englischer Begriff SDS electrophoresis

Definition SDS ist ein anionisches Detergenz. Bei der SDSElektrophorese werden SDS-Protein-Komplexe in einem restriktiven Polyacrylamidgel nach Molmassen getrennt.

Physikalisch-chemisches Prinzip Natriumdodecylsulfat (SDS) ist sehr starkes anionisches Detergenz, das fast alle Proteine in Lösung bringen kann, auch sehr hydrophobe. Es denaturiert die Proteine, indem es deren Wasserstoffbrückenbindungen ( $\triangleright$ Wasserstoffbrückenbindung) öffnet und die Sekundär- und Tertiärstrukturen auflöst. SDS und die Proteine bilden Komplexe mit einer halskettenartigen Struktur, die sich aus Mizellen, die mit Proteinen „dekoriert" sind, und kurzen, flexiblen Polypeptidsegmenten zusammensetzt. In einem solchem Komplex sind 1,4 g SDS pro g Protein enthalten. Die elektrophoretische Mobilität (Beweglichkeit) eines SDS-Protein-Komplexes ist ausschließlich abhängig von der Molekülgröße; die Eigenladungen der Proteine sind durch SDS abgedeckt. Die negative Ladung pro Masseneinheit ist konstant. Wenn zusätzlich noch die Disulfidbrücken zwischen den Cysteinen mit einem Reduktionsmittel, wie $\beta$-Mercaptoethanol oder Dithiothreitol, aufgelöst werden, wird die Molekülgröße direkt proportional zur Molmasse.

Bei einer Auftrennung einer Mischung von SDS-ProteinKomplexen in einem SDS-enthaltenden Polyacrylamidgel haben die Logarithmen der Molmassen der Polypeptide eine lineare Beziehung zu ihren relativen Wanderungsstrecken. Die Molmassen werden über eine Eichkurve bestimmt, die mithilfe von parallel aufgetrennten Molmassestandard-Proteinen für jedes SDS-Gel erstellt wird.

Molmassen von Proteinen können mit der SDS-Elektrophorese nur dann korrekt bestimmt werden, wenn die Probe reduziert worden ist. Allerdings zerfallen dann Proteine mit Quartärstrukturen in ihre Untereinheiten; z. B. findet man von IgG nur noch die leichten und schweren Ketten, nicht aber das intakte IgG-Molekül. Es gibt Anwendungen, in denen die Proben nichtreduziert aufgetrennt werden, um $\triangleright$ Immunglobuline als ganze Moleküle zu erhalten.

In der folgenden Abbildung sind Serumproteinspuren reduziert und nichtreduziert nebeneinander in einem $>$ SDS-Gel zu sehen. Auftrennung von (1) Humanserum nichtreduziert, (2) Humanserum reduziert, (3) Standard für niedrige Molmassen, (4) Standard für niedrige Molmassen mit Kollagenhydrolysaten versetzt, (5) Standard für hohe Molmassen. Das nichtreduzierte - Albumin ist nicht komplett aufgefaltet und wandert deshalb schneller als das Albumin in reduziertem Serum und Standard. In der nichtreduzierten Probe findet man die kompletten IgG, in der reduzierten ist es in leichte und schwere Ketten zerfallen (Coomassie-Färbung):

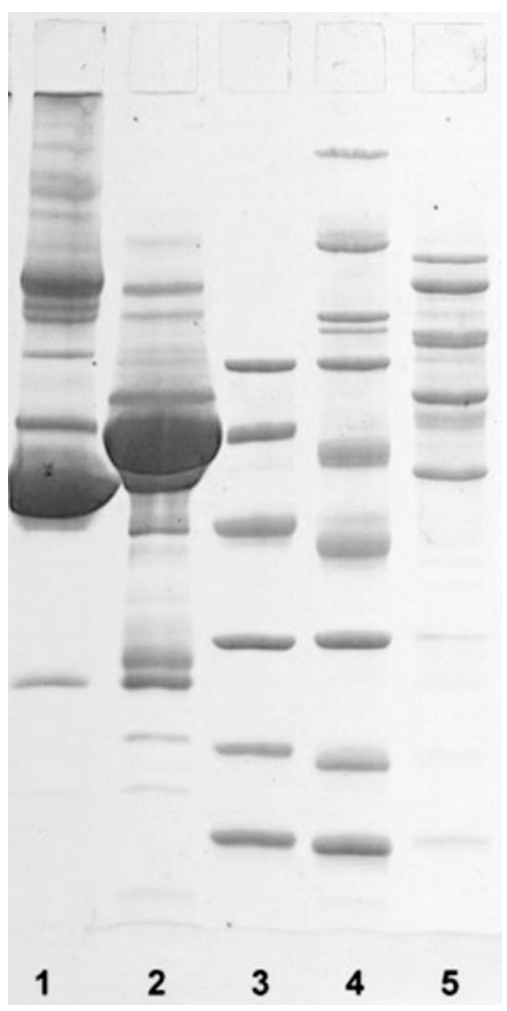

Die SDS-Elektrophorese wird in basischen Puffersystemen durchgeführt, weil dann die SDS-Protein-Komplexe stabil und negativ geladen sind. Normalerweise werden Polyacrylamidgele verwendet; nur in Ausnahmen, z. B. zur Auftrennung von $>$ Von-Willebrand-Faktor, kommen wegen 
der hohen Molmassen Agarosegele zum Einsatz. Die Trennungen können, wie bei der $>$ Polyacrylamid-Gel-Elektrophorese, in vertikalen oder horizontalen Systemen durchgeführt werden. In der SDS-Elektrophorese wandern alle Proteine, auch basische, in Richtung Anode. Im Gegensatz zu Nativelektrophoresen ( $\triangleright$ Elektrophorese) ergibt sich nur eine Bande pro Enzym. Die Trennungen sind aufgrund der hohen Ladungsdichte der SDS-Protein-Komplexe relativ schnell. Die Trennschärfe ist aufgrund der starken Siebeigenschaften der Polyacrylamidgele und der Auffaltung der Proteinmoleküle sehr hoch, wodurch sich zudem ein hohes Auflösungsvermögen ergibt.

Die Proteine werden entweder mit $>$ Coomassie-Färbung oder $\triangleright$ Silberfärbung visualisiert. Die SDS-Elektrophorese ist die Standardtrennmethode für Blotting-Techniken.

Interessante Anwendungen mit SDS-Substratgelen sind z. B. die zymographische Detektion von > Matrix-Metalloproteinasen in SDS-Gelen, die Gelatine oder Kollagen enthalten.

Einsatzgebiet $>$ Proteinuriediagnostik, Blotting-Techniken, Zweidimensional-Elektrophorese $>$ Elektrophorese, zweidimensionale.

Untersuchungsmaterial Sammelurin: aufkonzentriert (Coomassie-Färbung) oder nichtkonzentriert (Silberfärbung). Blotting: z. B. allergenenthaltende Proben, Borellioseerreger. Bronchiallavage.

\section{Instrumentierung}

- Elektrophoresekammer: vertikal oder horizontal (mit Umlaufkryostat)

- Gegebenenfalls einen Umlaufkryostat

- Stromversorger

- Färbeschalen oder einen Färbeautomaten

- Unter Umständen ein Densitometer

Spezifität Hohe Spezifität bei Blotting-Nachweisen und zymographischen Methoden.

Sensitivität Die Nachweisempfindlichkeit liegt bei ca. $50 \mathrm{pg}$ bei $\gg$ Silberfärbung und bei $5 \mathrm{ng}$ bei Coomassie-Färbung.

Fehlermöglichkeit Die meisten Fehler ergeben sich bei der Selbstherstellung von Gelen und Puffern. Diese können durch die Verwendung kommerzieller Fertiggele und Fertigpuffer weitgehend ausgeschlossen werden.

Praktikabilität - Automatisierung - Kosten Mit Fertiggelen und Färbeautomaten ist die Polyacrylamid-Gel-Elektrophorese einfach durchzuführen. Es gibt automatisierte Elektrophoresesysteme. Die Geräte selbst sind relativ preis- wert, während die Verbrauchsmaterialien wie Fertiggele, Puffer und Färbereagenzien die meisten Kosten verursachen.

\section{Literatur}

Lottspeich F, Engels JW (Hrsg) (2012) Bioanalytik, 3. Aufl. Heidelberg, Spektrum Akademischer Verlag Westermeier R (2016) Elektrophorese leicht gemacht. VCH, Weinheim

\section{SDS-Gel}

R. Westermeier

Synonym(e) Natriumdodecylsulfat-Gel

\section{Englischer Begriff SDS gel}

Definition Ein SDS-Gel ist ein Polyacrylamidgel, das $0,1 \%$ SDS enthält, zur Auftrennung von SDS-Protein-Komplexen nach den Molmassen.

Beschreibung $\triangleright$ SDS-Elektrophorese; $>$ PolyacrylamidGel-Elektrophorese.

\section{Literatur}

Westermeier R (2016) Elektrophorese leicht gemacht. VCH, Weinheim

\section{SDS-PAGE}

- SDS-Elektrophorese

- Selen

\section{Sebacinsäure}

G. F. Hoffmann, C.-D. Langhans und A. Schulze

Synonym(e) 1,10-Decandisäure 


\section{Englischer Begriff sebacic acid}

Struktur $\mathrm{C}_{10} \mathrm{H}_{18} \mathrm{O}_{4}$; Strukturformel:<smiles>O=C(O)CCCCCCCCC(=O)O</smiles>

Molmasse $202,25 \mathrm{~g}$.

Synthese - Verteilung - Abbau - Elimination Die im Verlauf der mitochondrialen $\beta$-Oxidation aus dem trifunktionellen Protein freigesetzten mittelkettigen Fettsäuren werden durch die mittelkettige Acyl-CoA-Dehydrogenase weiter verkürzt und im weiteren Verlauf zu Acetyl-CoA (geradzahlige Fettsäuren) bzw. zu Propionyl-CoA (ungeradzahlige Fettsäuren) abgebaut, die schließlich in den Citratzyklus einfließen.

Bei Defekten der mittelkettigen Acyl-CoA-Dehydrogenase (MCAD) und in geringerem Ausmaß der überlangkettigen Acyl-CoA-Dehydrogenase (VLCAD) werden die mittelkettigen Fettsäuren alternativ durch $\omega$-Oxidation zu mittelkettigen Dicarbonsäuren (Adipinsäure, Suberinsäure, Sebacinsäure) abgebaut. Diese werden entweder in freier Form oder als Glyzinkonjugate (Hexanoylglycin, Suberylglycin) im Urin ausgeschieden.

Funktion - Pathophysiologie Sebacinsäure hat keine bekannte Funktion im Intermediärstoffwechsel. Untersuchungen zur individuellen Toxizität der durch $\omega$-Oxidation entstandenen Dicarbonsäuren (Adipinsäure, Suberinsäure, Sebacinsäure) liegen erst in Ansätzen vor. In der Summe hemmen diese pathologischen Metabolite und/oder ihre Konjugate den mitochondrialen Energiestoffwechsel.

\section{Untersuchungsmaterial - Entnahmebedingungen Urin.}

\section{Präanalytik}

- Durch > Flüssig-Flüssig-Extraktion im sauren Medium mittels Ethylacetat oder Diethylether

- Mittels Gaschromatographie-Massenspektrometrie ( $\triangleright$ GCMS) als Di-Trimethylsilylester

Retentionsindex RI:1899

$\mathrm{M}+(\mathrm{m} / \mathrm{z}): 346$

Quant Ion (m/z): 331

Conf. Ion (m/z): 215

Internationale Einheit $\mathrm{mmol} / \mathrm{mol}$ Kreatinin (Urin).

Referenzbereich - Kinder $<2 \mathrm{mmol} / \mathrm{mol}$ Kreatinin.

Pathologischer Bereich: 0-5000 mmol/mol Kreatinin.

Indikation Hypoketotische Hypoglykämien, rezidivierende Hepatopathien und Enzephalopathien, insbesondere ReyeSyndrom, Myopathien, Rhabdomyolyse.
Interpretation Erhöhte Sebacinsäure-Ausscheidungen im Urin werden bei zahlreichen genetischen und sekundären Störungen der Fettsäureoxidation beobachtet. Entscheidend für die Beurteilung ist zuerst die Kenntnis des aktuellen Ernährungsstatus und -modus sowie des Abstandes von der letzten Nahrungsaufnahme. Die Differenzierung erfordert ferner Kenntnisse über die Konzentrationen anderer Fettsäureoxidationsprodukte. Die Sebacinsäure findet sich zusammen mit Adipinsäure und Suberinsäure als führender Metabolit beim MCAD-Mangel. Bei Ketosen und Formulanahrung auf der Basis von mittelkettigen Triglyzeriden (Alfaré) tritt Sebacinsäure auch bei Normalpersonen vermehrt auf.

Diagnostische Wertigkeit Stark erhöhte Urinausscheidungen von Sebacinsäure weisen auf eine gestörte Fettsäureoxidation hin. Die weitere Differenzierung erfordert Kenntnisse über die individuelle Stoffwechselsituation des Patienten, die Konzentrationen weiterer Metabolite und schließlich eine enzymatische oder molekularbiologische Bestätigungsdiagnostik.

\section{Literatur}

Blau N, Duran M, Gibson KM, Dionisi-Vici C (Hrsg) (2014) Physician's guide to the diagnosis, treatment, and follow-up of inherited metabolic diseases. Springer, Berlin/Heidelberg

Secreted protein acidic and rich in cysteine

- Osteonectin

\section{Sediment}

- Harnsediment

\section{Sediment des Harns}

> Harnsediment

\section{Sedimentum lateritium}

- Ziegelmehlsediment 


\section{Segmentkernige Granulozyten}

- Granulozyten, segmentkernige

\section{Segregationsanalyse}

- Kopplungsanalyse

\section{${ }^{75}$ SeHCAT-Test}

- Selenium-Homotaurocholsäure-Retentionstest

\section{${ }^{75}$ Se-Homotaurocholat-Test}

R. Tauber und F. H. Perschel

Englischer Begriff ${ }^{75} \mathrm{Se}$-homocholic acid taurine test

Definition Funktionsuntersuchung zur Diagnostik bei Malabsorption bzw. eines Gallensäureverlustsyndroms.

Durchführung Nach oraler Zufuhr der radioaktiv markierten Gallensäure ${ }^{75} \mathrm{Se}$-Homotaurocholsäure wird deren Resorption im terminalen Ileum durch Messung der Ganzkörperaktivität bestimmt.

Funktion - Pathophysiologie Die Gallensäure ( $\triangleright$ Gallensäuren) Homotaurocholsäure wird physiologischerweise im terminalen Ileum resorbiert. Bei gestörter Resorption wird die als Testsubstanz oral zugeführte radioaktiv markierte Gallensäure ${ }^{75} \mathrm{Se}$-Homotaurocholsäure mit den Fäzes ausgeschieden. Hieraus resultiert ein verminderter Anstieg der Ganzkörperaktivität.

Indikation Maldigestion, Malabsorption, Störungen des enterohepatischen Kreislaufs, Gallensäureverlustsyndrom.

\section{Literatur}

Thaysen EH, Pedersen L (1976) Idiopathic bile acid catharsis. Gut 17:965-970

\section{Sekretin}

A. M. Gressner und O. A. Gressner

\section{Englischer Begriff secretin}

Definition Von duodenalen und jejunalen Mukosazellen bei Kontakt mit Magensäure sezerniertes Polypeptidhormon, das die Produktion und Sekretion von Wasser und Bicarbonat im exokrinen Pankreas stimuliert und damit den $\mathrm{pH}$ im Duodenum für die optimale Wirkung digestiver pankreatogener Enzyme alkalisiert.

Beschreibung Lineares, aus 27 Aminosäuren bestehendes Polypeptid mit ausgeprägten Sequenzhomologien zu $\triangleright$ Glukagon, - Vasoaktives intestinales Polypeptid wird von den Mukosa-S-Zellen des Duodenums und Jejunums als Präprohormon synthetisiert und bei Kontakt der S-Zellen mit Magensäure $(\mathrm{pH}<4,5)$ sezerniert. \ Somatostatin ist der einzige physiologische Inhibitor der Sekretinfreisetzung. Nüchternplasmakonzentration 12-75 ng/L (methodenabhängig). Transiente Erhöhungen und Erniedrigungen in Abhängigkeit von der Nahrungsaufnahme: Anstieg im Blut innerhalb von 3 Minuten nach duodenaler Acidifizierung, Rückkehr zu Basalkonzentrationen innerhalb von 60 Minuten. Halbwertszeit ca. 4 Minuten. Degradation erfolgt vorwiegend (50\%) in der Niere. Die über einen G-Protein-gekoppelten Rezeptor ausgeübten Wirkungen sind: Stimulation der Bicarbonat- und Wassersekretion des Pankreas, der Leber und Brunner-Drüsen, Gallenblasenkontraktion und Cholerese, Parathyreoidhormonsekretion, Hemmung der Magen- und Duodenummotilität, der Gastrinfreisetzung und Magensäuresekretion ( $\triangleright$ Magensekretionsanalyse; $\triangleright$ Magensaft). Klinischer Einsatz im Rahmen des Sekretin-Gastrin-Testes ( $\triangleright$ SekretinGastrin-Test) bei Verdacht auf Zollinger-Ellison-Syndrom (Gastrinom): Sekretininfusion erhöht die Serumgastrinkonzentration ( $\triangleright$ Gastrin) und den Magensäureausstoß nur bei Zollinger-Ellison-Patienten (nicht bei gesunden Probanden). Erkrankungen mit Über- oder Unterschuss von Sekretin sind nicht bekannt.

Analyt sehr instabil (eisgekühltes Aprotinin-enthaltendes Heparin-Plasma).

Konzentrationsbestimmung mit kompetitiven $\triangleright$ Radioimmunoassay.

\section{Literatur}

Alfaro Cruz L, Parniczky A, Mayhew A et al (2017) Utility of direct pancreatic function testing in children. Pancreas 46(2):177-182 


\section{Sekretin-Caerulein-Test}

- Sekretin-Pankreozymin-Test

\section{Sekretin-Cholecystokinin-Test}

- Sekretin-Pankreozymin-Test

\section{Sekretin-Gastrin-Test}

M. Bidlingmaier

Synonym(e) Gastrin-Stimulationstest, Sekretin-Provokationstest

Englischer Begriff secretin stimulation test

Definition Stimulationstest zur Diagnostik des ZollingerEllison-Syndroms, bei dem auf Sekretin (und andere Reize) eine überschießende Freisetzung von Gastrin aus den G-Zellen im Antrum erfolgt.

Durchführung Durchführung vormittags nüchtern. Nach Legen einer Verweilkanüle ein- bis zweimalige Blutentnahme zur Bestimmung der Ausgangskonzentration von Gastrin. Danach erfolgt die intravenöse Gabe von 2 IE Sekretin pro $\mathrm{kg}$ Körpermasse. Weitere Blutentnahmen nach 2, 5, 10, (15) und 30 Minuten.

Struktur > Gastrin.

Molmasse - Gastrin.

Synthese - Verteilung - Abbau - Elimination $>$ Gastrin.

Halbwertszeit $>$ Gastrin.

Pathophysiologie Bei gastrinsezernierenden neuroendokrinen Tumoren (Zollinger-Ellison-Syndrom) kommt es zu einem im Verhältnis zur Azidität des Magensaftes inadäquat hohen Sekretion von Gastrin. Diagnostisch ist oft die Unterscheidung zwischen einer physiologischen Hypergastrinämie, die durch verschiedenste Faktoren hervorgerufen werden kann, und einer pathologischen, tumorbedingten Sekretion von Gastrin allein anhand der basalen Gastrinsekretion schwierig. In bis zu $60 \%$ der Fälle wird daher ein Stimulationstest durchgeführt, bei dem die Patienten mit tumorbedingter Hypergastrinämie überschießend reagieren.

Untersuchungsmaterial $>$ Gastrin.

\section{Präanalytik - Gastrin.}

Protonenpumpeninhibitoren können das Testergebnis verfälschen und sollten idealerweise eine Woche pausiert werden. Das Absetzen ist jedoch nicht immer unproblematisch.

Auch Anticholinergika, Antazida und H2-Rezeptorantagonisten müssen 24 Stunden vor dem Test abgesetzt werden.

Der Test darf nicht bei akuter Pankreatitis oder im Schub einer chronischen Pankreatitis durchgeführt werden.

Probenstabilität $>$ Gastrin.

Analytik $>$ Gastrin.

Konventionelle Einheit $>$ Gastrin.

Internationale Einheit $>$ Gastrin.

Umrechnungsfaktor zw. konv. u. int. Einheit $>$ Gastrin.

Referenzbereich - Erwachsene Wegen der großen Unterschiede in den Werten, die bei Verwendung verschiedener Gastrinassays erhalten werden, müssen assayspezifische Entscheidungsgrenzen gefordert werden. Oft wurden eine Verdoppelung der basalen Werte als beweisend für ein ZollingerEllison-Syndrom angesehen.

\section{Indikation}

- Diagnose des Zollinger-Ellison-Syndroms

- Überprüfung des Operationserfolgs und Therapiekontrolle bei Zollinger-Ellison-Syndrom

- Differenzialdiagnose erhöhter basaler Gastrinkonzentrationen

Interpretation S. Referenzbereiche und Pathophysiologie.

Diagnostische Wertigkeit Bei dem Test ist auf Einflussfaktoren zu achten, insbesondere ist eine Medikamentenanamnese unabdingbar. Tritt die Erkrankung in Zusammenhang mit einer multiplen endokrinen Neoplasie auf, ist ggf. der Einfluss einer Medikation mit Somatostatinanaloga zu beachten.

Bei bis zu $10 \%$ der Patienten mit Zollinger-EllisonSyndrom fällt der Test falsch negativ aus.

\section{Literatur}

Ito T, Cadiot G, Jensen RT (2012) Diagnosis of Zollinger-Ellison syndrome: increasingly difficult. World J Gastroenterol 18(39):5495-5503

Poitras P, Gingras MH, Rehfeld JF (2013) Secretin stimulation test for gastrin release in Zollinger-Ellison syndrome: to do or not to do? Pancreas 42(6):903-904

Rehfeld JF, Gingras MH, Bardram L, Hilsted L, Goetze JP, Poitras P (2011) The Zollinger-Ellison syndrome and mismeasurement of gastrin. Gastroenterology 140(5):1444-1453 


\section{Sekretin-Pankreozymin-Test}

\section{A. M. Gressner und O. A. Gressner}

Synonym(e) S-CCK-Test; Sekretin-Caerulein-Test; SekretinCholecystokinin-Test; Sekretin-Takus-Test; SPT

Englischer Begriff secretin-pancreozymin test; secretinCCK test

Definition Invasiver Sondentest zur Diagnostik der exkretorischen (digestiven) Pankreasinsuffizienz, bei dem nach sequenzieller intravenöser Gabe von $>$ Sekretin und Pankreozymin (Caerulein) ( $\triangleright$ Cholecystokinin) der Sekretionsausstoß von Bicarbonat und einiger repräsentativer Pankreasenzymaktivitäten im aspirierten Pankreas- bzw. Duodenalsaft quantitativ bestimmt wird. Aufgrund seiner hohen Spezifität und Sensitivität gilt der SPT als Referenzmethode.

Durchführung Nach 12-stündiger Nahrungskarenz Einführung einer doppelläufigen Lagerlöf-Sonde in Rechtsseitenlage unter Röntgenkontrolle, Positionierung im Duodenum auf Höhe des Sphinkter Oddi (s. Abbildung im Stichwort > LundhTest). Absaugen und Verwerfen des 1. Aspirates. Es schließen sich an: 30-minütige Basalphase mit Messung des sezernierten Volumens, der Bicarbonat- und Enzymsekretion, 30- bis 60-minütige > Sekretin-Infusionsphase $(1 \mathrm{CU} / \mathrm{kg} \mathrm{KG/h})$, Messung von sezerniertem Volumen, Bicarbonat- und Enzymsekretion, 30-minütige Phase zusätzlicher Caerulein-( $\triangleright$ Cholecystokinin) Infusion (75 ng/kg KG/h): Duodenalsaftaspiration in 15-minütigen Intervallen und Messung von sezerniertem Volumen, Bicarbonat- und Enzymsekretion ( $\triangleright$ Trypsin, $\triangleright$ Chymotrypsin, - Amylase, pankreasspezifische, $>$ Lipase, pankreatische). Aspirat muss eisgekühlt gesammelt und gelagert werden.

Funktion - Pathophysiologie Unter Sekretininfusion erhöht sich der Volumen- und Bicarbonatausstoß, unter zusätzlicher CCK(Caerulein)-Infusion wird die Enzymsekretion stimuliert. Erniedrigungen der gesamten Messwerte gelten als empfindlichste Indikatoren einer exkretorischen Pankreasinsuffizienz.

Untersuchungsmaterial - Entnahmebedingungen Aspirierter Duodenalsaft bzw. Pankreassekret nach Sondierung des Ductus pancreaticus. Probensammlung in eisgekühlten Messzylindern.

Präanalytik Absetzen oraler Enzymsubstitutionspräparate mindestens 3 Tage und 12-stündige Nahrungskarenz vor Testdurchführung. Eisgekühlte Asservierung des Duodenalsafts bis zu 8 Stunden.
Analytik Messung von sezerniertem Volumen/30 Minuten, Bicarbonatmenge/30 Minuten, Bicarbonatkonzentration sowie Amylase- $(\triangleright$ Amylase, pankreasspezifische), Lipase- $(\triangleright$ Lipase, pankreatische), $>$ Trypsin- und $>$ Chymotrypsin-Aktivitätsmengen/30 Minuten.

Referenzbereich - Erwachsene Testdurchführung ist nicht standardisiert, weshalb keine allgemein verbindlichen Referenzbereiche existieren.

Richtwerte:

\begin{tabular}{l|l}
$\begin{array}{l}\text { Referenzbereiche } 30 \mathrm{~min} \text { nach Sekretin } \\
\text { Volumen }\end{array}$ & $>67 \mathrm{~mL} / 30 \mathrm{~min}$ \\
\hline $\begin{array}{l}\text { Bicarbonatkonzentration } \\
\text { Bicarbonatsekretion }\end{array}$ & $>70 \mathrm{mmol} / \mathrm{L}$ \\
\hline Referenzbereiche $30 \mathrm{~min}$ nach Caerulein & $12.000 \mathrm{U} / 30 \mathrm{~min}$ \\
\hline Lipase & $>65.000 \mathrm{U} / 30 \mathrm{~min}$ \\
\hline Trypsin & $>30 \mathrm{U} / 30 \mathrm{~min}$ \\
\hline Chymotrypsin & $1200-6000 \mathrm{U} / 30 \mathrm{~min}$ \\
\hline Amylase & $>12.000 \mathrm{U} / 30 \mathrm{~min}$
\end{tabular}

Indikation Diagnostik der exokrinen Pankreasinsuffizienz.

Interpretation Der aufwendige, invasive Funktionstest gilt als Goldstandard (Referenztest) der exokrinen Pankreasinsuffizienz. Nachteil besteht in der fehlenden Standardisierung der Testdurchführung.

Entsprechend dem Testergebnis des S-CCK-Tests lässt sich die Pankreasinsuffizienz in folgende Schweregrade einteilen:

- Leichte Pankreasinsuffizienz:

- Bicarbonatkonzentration normal

- Sekretion eines oder mehrerer Enzyme erniedrigt

- Stuhlfettausscheidung normal

- Mittelschwere Pankreasinsuffizienz:

- Bicarbonatkonzentration erniedrigt

- Sekretion aller Enzyme erniedrigt

- Stuhlfettausscheidung normal.

- Schwere Pankreasinsuffizienz:

- Bicarbonatkonzentration erniedrigt

- Sekretion aller Enzyme erniedrigt

- Steatorrhoe

Diagnostische Wertigkeit Sensitivität beträgt im Mittel $92 \%(80-90 \%)$, Spezifität $94 \%$. Damit ist der S-CCKSondentest sensitiver als indirekte Pankreasfunktionsteste wie $>$ Pankreolauryltest, $>$ PABA-Test, $>$ Stuhlfett, Stuhlgewicht ( $\triangleright$ Stuhltrockengewicht) und Chymotrypsin im Stuhl. Die fäkale Elastase-1-Ausscheidung ( $\triangleright$ Elastase, pankreasspezifische, PE) soll ähnliche Sensitivitäten und Spezifitäten wie der S-CCK-Test haben. 


\section{Literatur}

Otte M (1979) Pankreasfunktionsdiagnostik. Internist 20:331-340 Stein J, Wehrmann T (Hrsg.) (2006) Funktionsdiagnostik in der Gastroenterologie, 2. Aufl. Springer Medizin Verlag, Heidelberg

\section{Sekretin-Provokationstest}

- Sekretin-Gastrin-Test

\section{Sekretin-Takus-Test}

- Sekretin-Pankreozymin-Test

\section{Sekretoreigenschaft}

- Sekretorstatus

\section{Sekretorstatus}

K. Kleesiek, C. Götting, J. Diekmann, J. Dreier und M. Schmidt

Synonym(e) Sekretoreigenschaft; Sekretorsystem

Englischer Begriff secretor system; secretor status

Definition Klassifizierung der Enzymaktivität der Se-Transferase, die entscheidend ist für die Fähigkeit, lösliche H-Antigene zu synthetisieren.

Beschreibung Der Sekretorstatus ist ein Begriff aus der Transfusionsmedizin, der dadurch bestimmt wird, ob bei einer Person H-Antigene sowohl auf der Erythrozytenmembran als auch lösliche H-Antigene in Saliva und Körperflüssigkeiten nachweisbar sind (Sekretoren) oder ob H-Antigene $(\triangleright$ H-Substanz) ausschließlich in der Erythrozytenmembran verankert vorkommen (Non-Sekretoren). Der Sekretorstatus einer Person wird bestimmt über die Aktivität der Fucosyltransferase 2 (Se-Transferase), die vom FUT2-Gen auf Chromosom 19q13.3 kodiert und in sekretorischen Drüsen exprimiert wird. Dieses Enzym katalysiert die Addition einer Fucose auf ein terminales Galaktosemolekül einer Oligosaccharidstruktur unter Ausbildung einer $\alpha 1,2$-glykosidischen
Bindung. Durch die Aktivität der Se-Transferase wird ein lösliches H-Antigen synthetisiert, das in Saliva und anderen Körperflüssigkeiten nachweisbar ist ( $\triangleright$ Salivatestung). Personen, die mindestens eine funktionsfähige Kopie des FUT2Gens aufweisen, können die lösliche Form des H-Antigens bilden und werden als Sekretoren (Se/Se oder Se/se) bezeichnet. Non-Sekretoren (se/se) hingegen produzieren kein lösliches H-Antigen, da sie aufgrund von Mutationen im FUT2Gen keine aktive Se-Transferase bilden können. Der Anteil der Non-Sekretoren in der europäischen Bevölkerung beträgt ca. $20 \%$. Der Sekretorstatus einer Person beeinflusst auch dessen Lewis-Phänotyp > Lewis-(Le-)Blutgruppensystem, da die Se-Transferase neben der Le-Transferase an der Synthese der unterschiedlichen Lewis-Antigenstrukturen beteiligt ist. Die Zugehörigkeit zu den Blutgruppen A, B, 0 oder $\mathrm{AB}$ ist unabhängig vom Sekretorstatus.

\section{Literatur}

Dean L (2005) Blood groups and red cell antigens. National Library of Medicine, NCBI

Mueller-Eckhardt C, Kiefel V (Hrsg) (2004) Transfusionsmedizin: Grundlagen - Therapie - Methodik, 3. Aufl. Springer, Berlin/Heidelberg/New York

\section{Sekretorsystem}

- Sekretorstatus

\section{Sektorfeldgeräte}

- Massenspektrometrie

\section{Sekundärelektronenvervielfacher}

- Photomultiplier

\section{Sekundärfollikel}

H. Baum

Englischer Begriff secondary follicle 
Definition Ansammlung von B-Lymphozyten mit Zonen aktiver Proliferation im Kortex von Lymphknoten und anderen lymphatischen Geweben.

Beschreibung Im Kortex des Lymphknotens sind Ansammlungen von reifen B-Lymphozyten ( $\triangleright$ B-Lymphozyt) nachweisbar, die als Primärfollikel bezeichnet werden. Nach Antigenstimulation werden in den Primärfollikeln aktivierte B-Lymphozyten nachweisbar, die morphologisch in Zentrozyten ( $\triangleright$ Zentrozyt) und Zentroblasten ( $\triangleright$ Zentroblast) differenziert werden können. Diese Zone aktiver Proliferation wird als $>$ Keimzentrum bezeichnet, die Follikel dann als Sekundärfollikel.

\section{Literatur}

Sagaert X, De Wolf-Peeters C (2003) Classification of B-cells according to their differentiation status, their micro-anatomical localisation and their development lineage. Immunol Lett 90:179-186

\section{Sekundärgefäß}

O. Colhoun

Englischer Begriff secondary specimen container

Definition Bezeichnung des Probengefäßes ( $\triangleright$ Probenröhrchen), das im medizinischen Laboratorium mit einem Aliquot der $\triangleright$ Primärprobe befüllt und identifiziert wurde.

Beschreibung Sekundärgefäße finden z. B. bei der Probenverteilung eines Primärgefäßes ( $\triangleright$ Primärgefäß) in einer zentralen Laborannahme an verschiedene Laborbereiche Anwendung.

\section{Sekundärmessnormal}

\Sekundärnormal

\section{Sekundärmetabolite}

> Sekundärstoffwechsel

\section{Sekundärnormal}

C. Vidal und W.-R. Külpmann

Synonym(e) Sekundärmessnormal

Englischer Begriff secondary measurement standard; secondary standard

Definition Normal, das durch Kalibrierung gegen ein Primärnormal für eine Größe gleicher Art geschaffen ist (Brinkmann 2012). Für Anmerkungen s. Literatur.

\section{Literatur}

Brinkmann B (2012) ) Internationales Wörterbuch der Metrologie (VIM) Deutsch-englische Fassung. ISO/IEC-Leitfaden 99:2007, 4. Aufl. Beuth-Verlag, Berlin

\section{Sekundärprobe}

W. G. Guder

Synonym(e) Analytische Probe

\section{Englischer Begriff analytical sample}

Definition In allen Fällen, bei denen die Patientenprobe ( $\triangleright$ Probe, z. B. Blut) aufgearbeitet oder geteilt wird, spricht man von einer Sekundärprobe oder sekundären Probe, aus der dann die Analyse mit der analytischen Portion entnommen wird (z. B. Serum oder Plasma).

Beschreibung Sekundärproben (s. a. \ Sekundärgefäß) werden immer dann benötigt, wenn die Analyse nicht aus dem vom Patienten gewonnenen Material ( $\vee$ Primärprobe, $\checkmark$ Patientenprobe), sondern aus daraus hergestellten Anteilen oder Extrakten durchgeführt wird. Beispiele für Sekundärproben dieser Art stellen Serum, Plasma, aber auch Blutausstrich, Harnsediment oder Extrakte dar. Diese werden als analytische Proben bezeichnet, aus denen die Analyse (und auf die sich die Konzentrationsangabe bezieht) durchgeführt wird. Auch eine Verteilung des primären Materials auf mehrere Labors oder Adressen kann als Sekundärprobe bezeichnet werden. 


\section{Literatur}

Dybkaer R (1997) Vocabulary for use in measurement procedures and description of reference materials in laboratory medicine. Eur J Clin Chem Clin Biochem 35:141-173

\section{Sekundärstoffwechsel}

T. Arndt

Synonym(e) Phytamine; Sekundärmetabolite

Englischer Begriff secondary metabolites

Definition Sekundäre Metabolite sind Substanzen, die auf anderen als den normalen Stoffwechselwegen zumeist nach der Phase des aktiven Wachstums und unter Bedingungen des Mangels hergestellt werden. Die biologische Bedeutung vieler sekundärer Metabolite ist noch unklar (IUPAC-Definition).

Beschreibung Das Verständnis o. g. Definition wird bei Kenntnis der Definition des Primärstoffwechsels (normaler Stoffwechsel) bzw. primärer Metabolite (normaler Metabolite) einfacher: Nach IUPAC-Definition umfasst der (normale) Stoffwechsel die Gesamtheit der physikalischen und chemischen Prozesse, die zu Erhalt und Reproduktion des Lebens erforderlich sind. In diesen Prozessen werden Nahrungsstoffe zur Energiegewinnung und zur Bildung einfacherer Moleküle abgebaut (Katabolismus), wobei letztere wiederum Ausgangsstoffe zur Synthese komplexerer Moleküle (Anabolismus) sind.

Stoffe des Sekundärstoffwechsels sind also für die Zelle selbst entbehrlich. Sie können für den Organismus als Ganzes jedoch nützlich sein. Beispiele für Sekundärstoffe wären u. a. Farb- und Duftstoffe oder Stoffe mit pharmakologischer Wirkung wie z. B. > Alkaloide. Tatsächlich sind die Grenzen zwischen Primär- und Sekundärstoffen fließend. Neuere Überlegungen bewerten deshalb die Trennung zwischen Primär- und Sekundärstoffwechsel als eher historisch und schlagen andere Systematiken vor.

\section{Literatur}

Firn DR, Jones CG (2009) A Darwinian view of metabolism: molecular properties determine fitness. J Exp Bot 60:719-726

Nagel B, Dellweg H, Gierasch LM (1992) Glossary for chemists of terms used in biotechnology (IUPAC Recommendations 1992). Pure Appl Chem 64:143-168

\section{SELDI}

- Ionisationsmethoden (Massenspektrometrie)

\section{SELDI-TOF}

T. Arndt

Synonym(e) Surface-Enhanced-Laser/DesorptionIonization-Time-of-Flight-Massenspektrometrie

Englischer Begriff SELDI-TOF; surface enhanced laser/ desorption ionization time of flight mass spectrometry

Beschreibung Ist eine Variante der MALDI-TOF ( $\triangleright$ Massenspektrometrie). Es werden sog. Chips mit funktionalisierten Oberflächen (unpolares, sog. ,,reversed phase material“" oder Ionenaustauscher) zur Proteinanreicherung und -reinigung eingesetzt. Diese adsorbieren jeweils eine bestimmte Klasse von Proteinen. Daneben finden auch spezifischere, biochemische, z. B. mit Antikörpern behandelte Oberflächen, welche nur mit dem Target-Protein reagieren, Anwendung. Typischerweise werden die zu analysierenden Gemische auf die Chips aufgetragen und verschiedenen Waschschritten unterzogen. Nach dem Trocknen des Chips wird eine Matrix (EAM, „energy absorbing molecule“) zugesetzt. Diese soll die Laserenergie gleichmäßig verteilen und überschüssige Laserenergie aufnehmen, um die Analyte vor Zerstörung zu schützen. Nach Laser-induzierter Desorption der Proteine aus dem Chip wird deren Molekülmasse anhand ihrer Flugzeit im TOFMassenspektrometer ermittelt (s. MALDI-TOF unter $>$ Massenspektrometrie). Anwendung findet SELDI-TOF z. B. bei der Identifikation von Markern für bestimmte Tumorarten oder der Alzheimer-Krankheit.

\section{Literatur}

Issaq HJ, Veenstra TD, Conrads TP, Felschow D (2002) The SELDITOF MS Approach to proteomics: protein profiling and biomarker identification. Biochem Biophys Res Commun 292:587-592

\section{Selected Ion Monitoring}

$>$ SIM 


\section{Selegilin (Amphetaminnachweis)}

- Methamphetamin

\section{Selektivität}

T. Arndt

$\operatorname{Synonym(e)}$ selektiv

Englischer Begriff selectivity

Definition Maß für die Eignung einer Analysenmethode zur Bestimmung von bestimmten Analyten in Substanzgemischen oder Probenmatrizes ohne Interferenzen durch andere Komponenten mit ähnlichen (physikochemischen) Eigenschaften (IUPAC-Definition).

Beschreibung Häufig werden die Begriffe Selektivität und Spezifität irrtümlich synonym verwandt. Spezifität ist jedoch ein absoluter Begriff, der keiner Graduierung im Sinne von z. B. „spezifisch“, „,besonders spezifisch“ oder „,spezifischer“ und ,am spezifischsten“ unterliegt und auch nicht in Zahlenwerten ausgedrückt werden kann. Selektivität ist dagegen ein $\mathrm{Ma}$ für die o. g. Eigenschaft eines Analysenverfahrens, das als verbale Graduierung, z. B. „weniger selektiv“ oder „sehr selektiv“" oder unter bestimmten Bedingungen auch als Zahlenwert angegeben werden kann.

Danach erfassen spezifische Reaktionen oder Analysenverfahren nur die interessierenden Analyte. Selektive Reaktionen oder Analysenverfahren bevorzugen die interessierenden Analyte, andere Komponenten mit ähnlichen Eigenschaften können jedoch interferieren. Das Maß für die Bevorzugung der Analyte ist die Selektivität. Spezifität ist also das höchste, nicht zu übertreffende Maß an Selektivität. Nach dieser Definition sind nur wenige Reaktionen oder Analysenverfahren spezifisch, während viele ein bestimmtes Maß an Selektivität besitzen. Für Aussagen bezüglich der Leistungsfähigkeit eines Analysensystems ist deshalb der Begriff Selektivität exakter und anstelle von Spezifität zu verwenden.

Anmerkung: Von der analytischen Spezifität ist die diagnostische Spezifität ( $\triangleright$ Spezifität, diagnostische) als ein Maß für die diagnostische Leistungsfähigkeit eines Laborparameters klar abzutrennen. Diese unterliegt gewöhnlich einer Graduierung, z. B. in \% von 100 (als Bestwert).

\section{Literatur}

Vessman $J$ et al (2001) Selectivity in analytical chemistry (IUPAC Recommendations 2001). Pure Appl Chem 73:1381-1386

\section{Selen}

D. Meißner und T. Arndt

Englischer Begriff selenium

Definition Selen (chemisches Symbol: Se) ist ein Halbmetall mit der Ordnungszahl 34. Es gehört zu den essenziellen Spurenelementen. In hohen Konzentrationen ist es toxisch.

Struktur Selen tritt in den Oxidationsstufen $-2,+2,+4$ und +6 auf. Die biologisch wirksamen Formen sind $\mathrm{Se}(\mathrm{VI})$ und $\mathrm{Se}$ (IV), wobei letztere die stabile Form ist. Im Organismus ist Selen vorwiegend an Proteine oder Aminosäuren gebunden.

Molmasse Relative Atommasse: 78,96.

Synthese - Verteilung - Abbau - Elimination Die Zufuhr von Selen und infolge dessen der Versorgungsgrad, der Körperbestand und die Normalwerte sind in Abhängigkeit vom Selengehalt des Bodens und damit vom Selengehalt des Trinkwassers und der pflanzlichen und tierischen Kost regional sehr unterschiedlich verteilt. Der Selengehalt des Bodens nimmt von Süden nach Norden deutlich ab. Die Bundesrepublik Deutschland gehört zu den Regionen, in denen die Selenversorgung nicht ausreichend gesichert ist.

Die Zufuhr des Selens erfolgt hauptsächlich über die Nahrung, die intestinale Absorption liegt bei durchschnittlich 80 \%. Im Plasma liegt Selen an die Plasmaproteine Albumin, Selenoprotein $\mathrm{P}$ und $\triangleright$ Glutathionperoxidase gebunden oder als Selenoaminosäure (Selenomethionin, Selenocystein), als Selenit oder Selenat vor. Speicherorte sind Schilddrüse, Niere, Leber, Milz, Herz. Absolut gesehen ist auch der Skelettmuskel selenreich. Der Selenhaushalt wird über die renale Ausscheidung geregelt, 50-60\% der zugeführten Menge werden mit dem Urin ausgeschieden.

Körperbestand: 10-15 mg. Bedarf: Männer $25 \mu \mathrm{g} / \mathrm{Tag}$, Frauen $20 \mu \mathrm{g} / \mathrm{Tag}$. Empfohlene Zufuhr: 30-50 $\mu \mathrm{g} / \mathrm{Tag}$, zusätzlich am Ende der Schwangerschaft $18 \mu \mathrm{g} / \mathrm{Tag}$ und in der Stillzeit $16 \mu \mathrm{g} / \mathrm{Tag}$. Tolerierbare Aufnahme pro Tag: $6 \mu \mathrm{g} / \mathrm{kg}$ KG. Selenreich sind Fleisch, Leber, Eier, Meerestiere, Nüsse. Pflanzliche Nahrungsmittel und Hefen enthalten Selenomethionin. 
Funktion - Pathophysiologie Aus klinischer Sicht hat die ausreichende Selenzufuhr Priorität, da dieses Element an wichtigen biochemischen Prozessen beteiligt ist, u. a. im Lipidstoffwechsel, in der Kardiologie, in der Intensivmedizin oder im Tumorgeschehen. Als Ursachen für einen Selenmangel kommen die nutritive Unterversorgung (Nahrungsmittel in selenarmen Gegenden), ungeeignete Angebotsformen, Selenantagonisten (Schwermetalle), erhöhter Bedarf, erhöhte Verluste, intensivmedizinische Therapien (totale parenterale Ernährung) oder angeborene Fehler in Betracht.

Selen übt seine physiologische Funktion als Bestandteil von etwa 30 Enzymen oder anderen Selenoproteinen aus. Am besten studiert sind die 4 Glutathionperoxidasen (Schutz vor Radikalen, Abbau von Lipidperoxiden), die 3 Deiodasen Typ I-III (Aktivierung und Inaktivierung von Schilddrüsenhormonen), Thioredoxinreduktasen (Regulation des zellulären Redoxstatus), Selenophosphatsynthetase (Selenoproteinsynthese), die Selenoproteine $\mathrm{P}$ und $\mathrm{W}$ und weitere Selenoproteine, die $\mathrm{u}$. a. in Reproduktion, Spermatogenese und Tumorgenese eine Rolle spielen und deren Funktion noch untersucht wird. Weitere Funktionen: Entgiftung von Schwermetallen $(\mathrm{Cd}, \mathrm{Hg}$ u. a.) durch Bildung und Ausscheidung schwerlöslicher Selenide und die Stärkung der Immunabwehr durch Stimulierung von Makrophagen.

Bei schwerem Selendefizit treten Kardiomyopathien, Leberschädigungen und Myopathien der Skelettmuskulatur auf. Als Selenmangelkrankheiten sind die Keshan-Krankheit, eine in China endemisch auftretende Kardiomyopathie und die Kashin-Beck-Krankheit, eine ebenfalls endemisch auftretende Osteoarthropathie mit starker Verformung der Gelenke beschrieben.

Die Gefahr einer Selenvergiftung ist gering, jedoch sind akute und chronische Intoxikationen bei erhöhter Selenzufuhr bekannt. Als Belastungsquellen kommen neben dem Arbeitsplatz die falsche Dosierung oder versehentliche Zufuhr von selenhaltigen Medikamenten sowie der Genuss von extrem selenreichen Nahrungsmitteln oder Trinkwasser (z. B. Venezuela) in Betracht.

Untersuchungsmaterial - Entnahmebedingungen Blut, Plasma, Urin.

Probenstabilität Blut: $20{ }^{\circ} \mathrm{C} 2$ Tage. Plasma, Urin: $20{ }^{\circ} \mathrm{C}$ 7 Tage, $4-8{ }^{\circ} \mathrm{C} 14$ Tage, $-20{ }^{\circ} \mathrm{C} 1 \mathrm{Jahr}$.

Präanalytik Besonders gereinigte Abnahmegeräte und Aufbewahrungsgefäße verwenden. Als Antikoagulans sind LiHeparin oder EDTA geeignet. Kontamination vermeiden. Zertifizierte Referenzmaterialien verwenden. Vermeidung von Matrixeinflüssen durch Matrixmodifier.
Analytik Atomabsortionsspektrometrie mit Graphitrohroder Hydridtechnik, Fluorometrie, Neutronenaktivierungsanalyse (NAA).

Konventionelle Einheit $\mu \mathrm{g} / \mathrm{L}, \mu \mathrm{g} / \mathrm{d}$.

Internationale Einheit $\mu \mathrm{mol} / \mathrm{L}, \mu \mathrm{mol} / \mathrm{d}$.

Umrechnungsfaktor zw. konv. u. int. Einheit $\mu \mathrm{mol} / \mathrm{L}$ (d) $=0,01266 \times \mu \mathrm{g} / \mathrm{L}(\mathrm{d}) ; \mu \mathrm{g} / \mathrm{L}(\mathrm{d})=78,96 \times \mu \mathrm{mol} / \mathrm{L}(\mathrm{d})$.

Referenzbereich - Erwachsene Einen Referenzbereich für Selen festzulegen, ist - anders als für andere Elemente - aus den unter Interpretation genannten Gründen schwierig. Für Gesunde in Deutschland findet man folgende Werte: Vollblut: zwischen $0,8-1,7 \mu \mathrm{mol} / \mathrm{L}(63-134 \mu \mathrm{g} / \mathrm{L})$; Serum/Plasma: zwischen $0,5-1,5 \mu \mathrm{mol} / \mathrm{L}(39-118 \mu \mathrm{g} / \mathrm{L})$; Urin: zwischen $0,18-0,95 \mu \mathrm{mol} / 24$ Stunden (14-75 $\mu \mathrm{g} / 24$ Stunden); Haare/ Nägel: $0,3-1,8 \mathrm{mg} / \mathrm{kg}$ TG $(4-23 \mu \mathrm{mol} / \mathrm{kg} \mathrm{TG}$ ) (Rükgauer und Kruse-Jarres 2002; Meißner 1997; Brätter 1992)

Referenzbereich - Kinder Altersabhängige Referenzbereiche in Serum (nach Rükgauer und Kruse-Jarres 2002):

\begin{tabular}{|l|l|l|}
\hline Alter (Jahre) & $\mu \mathrm{mol} / \mathrm{L}$ & $\mu \mathrm{g} / \mathrm{L}$ \\
\hline $0-1$ & $0,20-0,61$ & $16-48$ \\
$1-2$ & $0,29-0,78$ & $23-62$ \\
$2-4$ & $0,37-1,25$ & $29-99$ \\
\hline $4-6$ & $0,35-1,45$ & $28-114$ \\
\hline $6-10$ & $0,46-1,42$ & $36-112$ \\
\hline $10-14$ & $0,46-1,36$ & $36-107$ \\
\hline $14-18$ & $0,56-1,24$ & $44-98$ \\
\hline
\end{tabular}

Indikation Verdacht auf Unterversorgung oder Überladung, intensivmedizinische Behandlung, Kontrolle der Selentherapie, Niereninsuffizienz, arbeitsmedizinische Überwachung.

Interpretation Kurzzeitparameter: Urin, Plasma; mittelfristiger Parameter: Blut (bester Parameter zur Statusbestimmung); Langzeitparameter: Haare, Nägel. Die Referenzwerte sind regional stark unterschiedlich und hauptsächlich von der Bodenbeschaffenheit in der Region, den Verzehr- und Trinkgewohnheiten (Aufnahme über Speisen und Getränke) und darüber hinaus von der unkontrollierten Zufuhr über Nahrungsergänzungsmittel abhängig. Es ist sinnvoll, dass sich jedes Labor an eigenen Referenzwerten orientiert. Zusätzliche Informationen sind durch die Selenbestimmung in Erythrozyten (Langzeitparameter) zu erhalten. Niedrige Selenwerte sind bei einer großen Zahl von Krankheiten beobachtet worden. Bei Unterversorgung wird Substitution empfohlen. 
BAT-Wert (Serum): $150 \mu \mathrm{g} / \mathrm{L}$ (BAT-Werte-Liste 2017).

Grenzkonzentration im Trinkwasser: $10 \mu \mathrm{g} \quad \mathrm{Se} / \mathrm{L}$ (Trinkwasser-VO 2016).

Diagnostische Wertigkeit Bestimmung des Selenstatus, Diagnose des Selenmangels, der Selenexposition oder der Selenintoxikation.

\section{Literatur}

Brätter P und Wissenschaftlicher Beirat (1992) Mineralstoffe und Spurenelemente, Leitfaden für die ärztliche Praxis. Bertelsmann Stiftung, Güterloh

DFG (2017) Ständige Senatskommission zur Prüfung gesundheitsschädlicher Arbeitsstoffe. Mitteilung 53. MAK- und BAT-Werte-Liste 2017. Wiley-VCH, Weinheim

Köhrle J (2002) Selen. In: Biesalski HK, Köhrle J, Schümann K (Hrsg) Vitamine, Spurenelemente und Mineralstoffe. Georg Thieme Verlag, Stuttgart/New York, S 161-172

Köhrle J (2004) Selenium in biology and medicine - further progress and increasing interest. J Trace Elem Med Biol 18:61-63

Meißner D (1997) Referenzwerte von Selen in Blut und Serum im Raum Dresden. Med Klin 92(Suppl III):41-42

Rükgauer M, Kruse-Jarres JD (2002) Normalwerte für Mengen- und Spurenelemente. In: Biesalski HK, Köhrle J, Schümann K (Hrsg) Vitamine, Spurenelemente und Mineralstoffe. Georg Thieme Verlag, Stuttgart/New York, S 704

Trinkwasser-VO (2016) Trinkwasserverordnung in der Fassung der Bekanntmachung vom 10. März 2016. https://www.gesetze-iminternet.de/bundesrecht/trinkwv_2001/gesamt.pdf. Zugegrieffen am 04.09 .2017

\section{Selenium-Homotaurocholsäure- Retentionstest}

\section{A. M. Gressner und O. A. Gressner}

\section{Synonym(e) ${ }^{75}$ SeHCAT-Test}

Definition Der zur Diagnostik der Gallensäuremalabsorption eingesetzte nuklearmedizinische Funktionstest beruht auf der oralen Aufnahme der ${ }^{75}$ Selenium- $\left({ }^{75} \mathrm{Se}\right.$-)markierten konjugierten Gallensäure Homotaurocholsäure, die im terminalen Ileum aktiv resorbiert und mit der $\triangleright$ Galle sezerniert wird, deren Menge an festgelegten Zeitpunkten mit einem Ganzkörper-Counter oder einer Gamma-Kamera quantitativ bestimmt wird.

Beschreibung Die synthetische, in Position 24-C mit ${ }^{75} \triangleright$ Selen-markierte konjugierte Gallensäure ( $\vee$ Gallensäuren) wird nach Ermittlung des Nüchternnullwerts oral appliziert
(37 kBq bzw. $10 \mu \mathrm{Ci}$ ). Nach 6 Stunden wird die Ausgangsaktivität über dem Abdomen mit einer Gamma-Kamera bestimmt. Weitere Messungen erfolgen an den nachfolgenden Tagen (Tage 1, 2, 4 und 7). Die radioaktive Gallensäure wird aktiv im Ileum resorbiert und durchläuft etwa drei- bis zwölfmal pro Tag den enterohepatischen Kreislauf. Die Gallensäureausscheidung wird somit mehrfach reproduziert. Eine Quantifizierung ihrer Ausscheidung im Stuhl ist nicht notwendig.

Retentionsnormwerte in der Gallenblase sind in der folgenden Tabelle zusammengefasst:

\begin{tabular}{|l|l|}
\hline Zeitpunkt (Tag) & Retention (\%) \\
\hline 1 & $>80$ \\
\hline 2 & $>65$ \\
\hline 3 & $>50$ \\
\hline 7 & $>19$
\end{tabular}

Der ${ }^{75}$ SeHCAT-Test stellt ein sehr sensitives Verfahren zur Diagnostik ( $\triangleright$ Sensitivität, diagnostische) einer Gallensäuremalabsorption, z. B. bei Ileumresektionen von $20 \mathrm{~cm}$, dar und ist dem ${ }^{13} \mathrm{C}$-Glykocholat-Atemtest überlegen.

\section{Literatur}

Stein J, Wehrmann T (Hrsg) (2006) Funktionsdiagnostik in der Gastroenterologie. 2., vollst. überarb. und erweit. Aufl., Springer Medizin Verlag, Berlin/Heidelberg/New York

\section{Selenoprotein P}

$\checkmark$ Hepatokine

\section{Seliwanoff-Probe}

- Seliwanoff-Test

\section{Seliwanoff-Test}

A. M. Gressner und O. A. Gressner

Synonym(e) Fruktosenachweis nach Seliwanoff; ResorzinProbe; Seliwanoff-Probe; Seliwanow-Test

Englischer Begriff Seliwanoff's test 
Definition Heute obsoleter, semiquantitativer Nachweis von Fruktose im Urin.

Beschreibung Der von dem russischen Chemiker Theodor Seliwanoff (1859-1939) beschriebene Test beruht darauf, dass sich aus $>$ Fruktose bei Erhitzen mit konzentrierter Salzsäure Oxymethylfurfurol bildet, das mit Resorzin eine Rotfärbung ergibt. Eine sofortige Rotfärbung mit Niederschlag, der sich nach Zusatz von Methanol löst und verstärkt wird positiv bewertet. Wegen fehlender Spezifität heute nicht mehr zur Diagnostik der Fruktosurie in Gebrauch.

\section{Literatur}

Hallmann L (1980) Klinische Chemie und Mikroskopie, 11. Aufl. Georg Thieme Verlag, Stuttgart/New York

\section{Seliwanow-Test}

$>$ Seliwanoff-Test

\section{Seltene Antigene, erythrozytäre}

K. Kleesiek, C. Götting, J. Diekmann, J. Dreier und M. Schmidt

Synonym(e) Niedrigfrequente Antigene; Private Antigene

Englischer Begriff private antigens; low incidence antigens; low frequency antigens

Definition Die Häufigkeit eines seltenen Antigens liegt unter $1 \%$ (meist $<0,01 \%$ ) und wird auch bei nicht verwandten Individuen gefunden. Solche niedrigfrequente Antigene, die bisher nicht bekannten Blutgruppensystemen zugeordnet werden konnten, wurden $\mathrm{zu}$ der numerischen 700er-Serie zusammengestellt.

Einige Beispiele für seltene erythrozytäre Antigene sind die Antigene Ahonen (Ana), Swann (Swa), Batty (By), Biles (Bi), Box (Bxa), Christiansen (Chra), HJK, HOFM, JFV, JONES, Jensen (Jea), Katagiri (Kg), Livesay (Lia), Milne, Oldeide (Ola), Peters (Pta), Rasmussen (RASM), Reid (Rea), REIT, SARA, Torkildsen (Toa) oder Wulfsberg (Wu). Das Vorliegen von Anti-private-Antikörpern ist aufgrund der Vielzahl kompatibler Blutkonserven transfusionsmedizinisch nicht von Bedeutung. In seltenen Fällen können diese Antikörper einen Morbus haemolyticus neonatorum (Mhn; s. Morbus haemolyticus fetalis/neonatorum) verursachen.
Wenn ein seltenes Antigen nur in einer Familie gefunden wird, spricht man von Familienantigen.

\section{Literatur}

American Association of Blood Banks (1999) Technical manual, 13. Aufl. S. Karger, Basel

Reid ME, Lomas-Francis C (2004) The blood group antigen facts book, 2. Aufl. Elsevier, New York

\section{SEM}

> Standardfehler des Mittelwertes

\section{Seminalflüssigkeit}

A. M. Gressner und O. A. Gressner

Synonym(e) Seminalplasma

Englischer Begriff seminal fluid; seminal plasma

Definition Von den Samenblasen des Mannes sezernierte Flüssigkeit spezifischer chemischer Zusammensetzung, die der Aufnahme und Ernährung der Spermien dient und mit diesen das Ejakulat bildet, das ein wichtiges Untersuchungsmaterial für die männliche Fertilitätsdiagnostik darstellt.

Beschreibung Die nach Abzentrifugation der Spermien/ Spermatozyten aus dem milchig-trüben Ejakulat gewonnene zähflüssige, schwach alkalische Seminalflüssigkeit ist mit ihrem relativ hohen Fruktosegehalt ein wichtiger Energielieferant für die Motilität der Spermien. Neben $>$ Fruktose sind Citrat, Zink, Magnesium, Inositol ( $\triangleright$ Inosin), saure Prostata-Phosphatase ( $\triangleright$ Phosphatase, prostataspezifische saure), Glukosidase, $>$ Prostaglandine E1, E2, Geruchsstoffe u. a. in ihren jeweiligen Konzentrationen typische, diagnostisch teilweise relevante Bestandteile (s. Tabelle).

Referenzwerte wichtiger Kenngrößen der Seminalflüssigkeit (nach WHO-Angaben):

\begin{tabular}{l|l} 
Kenngröße & Referenzwert \\
\hline Volumen & $\geq 2,0 \mathrm{~mL}$ \\
\hline $\mathrm{pH}$ & $7,2-8,0$ \\
\hline Spermienkonzentration & $\geq 20 \mathrm{Millionen} / \mathrm{mL}$ \\
\hline Spermiengesamtzahl & $\geq 40 \mathrm{Millionen} /$ Ejakulat
\end{tabular}

(Fortsetzung) 


\begin{tabular}{|c|c|}
\hline Kenngröße & Referenzwert \\
\hline Motilität & $\begin{array}{l}\geq 50 \% \text { mit Vorwärtsprogression oder } 25 \% \\
\text { mit schneller Progression innerhalb von } \\
60 \text { min }\end{array}$ \\
\hline Morphologie & $\geq 30 \%$ mit normaler Gestalt \\
\hline Vitalität & $\geq 75 \%$ lebensfähig (Farbstoffausschluss) \\
\hline Leukozyten & $<1,0$ Million $/ \mathrm{mL}$ \\
\hline MAR-Test & $\begin{array}{l}\text { Zum Nachweis von IgG-Antikörpern auf } \\
\text { den Spermatozyten mittels IgG- } \\
\text { beschichteter Latexpartikel; <10 \% der } \\
\text { Zellen sind adhärent }\end{array}$ \\
\hline Alpha-Glukosidase & $\geq 20 \mathrm{mU} /$ Ejakulat \\
\hline Zink & $\geq 2,4 \mu \mathrm{mol} / /$ Ejakulat \\
\hline Citrat & $\geq 52 \mu \mathrm{mol} /$ Ejakulat \\
\hline Saure Phosphatase & $\geq 200 \mathrm{U} /$ Ejakulat \\
\hline Fruktose & $\geq 13 \mu \mathrm{mol} /$ Ejakulat \\
\hline
\end{tabular}

Zur Nomenklatur, Analytik und Bewertung der Veränderungen der Spermatozytenzahl, -morphologie und -motilität wird auf die andrologische Spezialliteratur und auf das aktuelle WHO-Laborhandbuch (2010) verwiesen. Die darin genannten Richtlinien mussten bis 2013 verbindlich eingeführt sein. Pathologische Ergebnisse des immunologischen MAR-Testes (mixed antiglobulin reaction) weisen auf das Vorliegen von Antikörpern gegen Spermatozyten hin.

\section{Literatur}

(WHO) (2003) WHO laboratory manual for the examination of human semen and sperm-cervical mucus interactions, 4. Aufl. Churchill Livingstone, S 285-315

(WHO) (2010) WHO laboratory manual for the examination and processing of human semen, 5. Aufl. ISBN 9789241547789 (deutsche Übersetzung liegt vor)

\section{Seminalplasma}

> Seminalflüssigkeit

\section{Senkspindel}

Urometer

\section{Sense-Strang}

J. Arnemann

Synonym(e) Codogener Strang

\section{Englischer Begriff sense string}

Definition Der codogene oder Sense-Strang entspricht demjenigen DNA-Strang in der doppelsträngigen DNA, der bei proteinkodierenden Genen den offenen Leserahmen enthält, als Matrizenstrang für die Transkription dient und komplementär zu der mRNA ist.

Beschreibung Die Frage, welcher der beiden antiparallelen, d. h. gegenläufigen DNA-Einzelstränge als codogener Strang fungiert, wird im Wesentlichen durch die Lage der Promotorbereiche bestimmt. Innerhalb eines Chromosoms ist der codogene Strang nicht durchgängig einem bestimmten DNAEinzelstrang zugeordnet, sondern variiert ohne erkennbare Systematik zwischen den beiden Strängen und damit auch in der Leserichtung.

\section{Literatur}

Strachan T, Read AP (2005) Molekulare Humangenetik. Elsevier $\mathrm{GmbH}$, München

\section{Sensitivitåt, analytische}

Messempfindlichkeit

\section{Sensitivität, diagnostische}

\section{R.-D. Hilgers, N. Heussen und S. Stanzel}

Synonym(e) Diagnostische Sensitivität

Englischer Begriff diagnostic sensitivity

Definition Die diagnostische Sensitivität (Sensitivität eines diagnostischen Tests) bezeichnet die (bedingte) Wahrscheinlichkeit für ein positives Testergebnis unter den tatsächlich Kranken ( $\triangleright$ Testergebnis, richtig-positives).

Beschreibung Die diagnostische Sensitivität lässt sich verstehen als Empfindlichkeit des Testverfahrens, da sie die Wahrscheinlichkeit für die richtige Testentscheidung unter den Kranken angibt. Die Sensitivität ist ein Maß für die diagnostische Accuracy ( $\triangleright$ Accuracy, diagnostische) eines Tests bzw. für die Validität ( $\vee$ Validität, diagnostische) eines dia- 
gnostischen Tests ( $\triangleright$ Test, diagnostischer), wenn als Referenz ein $\triangleright$ Goldstandard verwendet wird. Die Sensitivität wird geschätzt durch den Quotienten aus der Zahl der Erkrankten mit positivem Test dividiert durch die Gesamtheit der Erkrankten [d. h. der Quotient a / $(\mathrm{a}+\mathrm{c})$; s. Tabelle im Stichwort $>$ Vierfeldertafel]. Ist die Sensitivität des Tests hoch, so wird der Test kaum Kranke übersehen. Ein hoch sensitiver Test ist besonders dann hilfreich, wenn ein negatives Testresultat beobachtet wird.

\section{Literatur}

Hilgers R-D, Bauer P, Scheiber V (2002) Einführung in die Medizinische Statistik. Springer, Berlin/Heidelberg/New York

年

\section{Sensitivitäts-Spezifitäts-Diagramm}

$>$ ROC-Kurve

\section{Sensoren, biologische}

$>$ Biosensoren

\section{Sepsiskenngrößen}

\section{A. M. Gressner und O. A. Gressner}

Synonym(e) Biomarker der Sepsis; Kenngrößen der Sepsis

Englischer Begriff sepsis (bio)marker

Definition Laborkenngrößen mit den relativ besten Kriterien für die Diagnostik, Phasendifferenzierung, Verlaufskontrolle und Prognosebeurteilung der Sepsis.

Synthese - Verteilung - Abbau - Elimination Laborkenngrößen siehe Tab. 1 und 2.

Aktuelle Definitionen der Sepsis und des septischen Schocks (Singer et al. 2016): Sepsis ist eine lebensbedrohende Organdysfunktion, die als Folge einer fehlregulierten Antwort des Körpers auf eine Infektion auftritt. Ein septischer Schock ist definiert als eine besonders schwere Verlaufsform der Sepsis, bei der besonders gravierende Störungen der Zir-
Sepsiskenngrößen, Tab. 1 Laboratoriumsuntersuchungen bei Sepsis

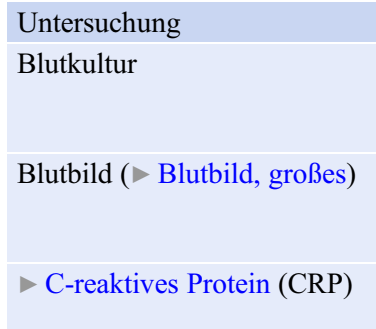

Interleukin-6 (IL-6)

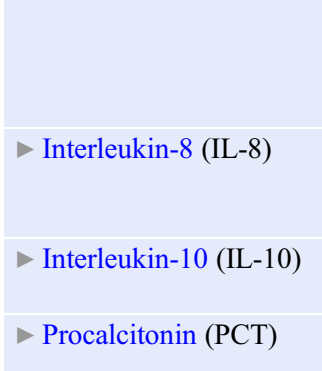

- Lipopolysaccharidbindendes Protein (LBP)

> HLA-DR auf CD 14(+) Monozyten

Ex-vivo-LPS-

Vollblutstimulation und

TNF- $\alpha$-Bestimmung

\section{Hinweis}

Mindestens zweimal innerhalb von 24 Stunden unter aeroben und anaeroben Bedingungen

Leukozyten $>12$ oder $<4 \mathrm{G} / \mathrm{L}$ und $>10 \%$ Vorstufenleukozyten $>12$ oder $<4 \mathrm{G} / \mathrm{L}$ und $>10 \%$ Vorstufen Anstieg nach 6 Stunden, Maximum bei ca. 48 Stunden, Halbwertszeit ca. 48 Stunden, kein Hinweis auf Sepsisgrad, aktiviert klassischen Komplementweg

Frühmarker (3-4 Stunden), besonders bei CRP-negativer Neonatalsepsis (Sensitivität 60-97\%), Abfall innerhalb von 48 Stunden

Bei CRP-negativer Neonatalsepsis (Sensitivität 83-91\%), alternativ zu IL-6

Fakultativ, erhöht bei Immunparalyse Hoher und plötzlicher Anstieg bei bakterieller Sepsis (Spezifität 80-100 \%, Sensitivität 70-100 \%), guter Verlaufsparameter (Halbwertszeit ca. 24 Stunden), Prognoseparameter

Hoher Anstieg bei bakterieller Infektion (in Verbindung mit IL-6 bewerten)

Nachweis der Immunparalyse (späte Sepsisphase) bei Abnahme

Funktionsreserve der Monozyten, Nachweis der Immunparalyse (späte Sepsisphase)
Sepsiskenngrößen, Tab. 2 Frühdiagnostik der Sepsis mittels Interleukin-6 (IL-6) und Lipopolysaccharid-bindendem Protein (LBP)

\begin{tabular}{|l|l|l|}
\hline IL-6 & LBP & Interpretation \\
\hline$\uparrow-\uparrow \uparrow \uparrow$ & \pm & $\begin{array}{l}\text { Systemische Entzündungsreaktion, ohne } \\
\text { bakterielle Infektion (Endotoxinämie [SIRS], } \\
\text { z. B. Hypoxie, Gewebeuntergang) }\end{array}$ \\
\hline$\uparrow-\uparrow \uparrow \uparrow$ & $\uparrow-\uparrow \uparrow \uparrow$ & $\begin{array}{l}\text { Systemische Entzündungsreaktion, mit } \\
\text { bakterieller Infektion/Endotoxinämie (Sepsis) }\end{array}$ \\
\hline \pm & $\uparrow-\uparrow \uparrow \uparrow$ & $\begin{array}{l}\text { Schwere lokale bakterielle Infektion } \\
\text { (z. B. Pneumonie, Pyelonephritis) }\end{array}$ \\
\hline
\end{tabular}

kulation, des Stoffwechsels und der zellulären Integrität vorhanden sind, die zu einem höheren Mortalitätsrisiko als für die Sepsis alleine führen. Die früher verwendeten Begriffe wie Sepsis-Syndrom und Septikämie sollten nicht mehr verwendet werden.

Pathophysiologie Die Sepsis ist eine systemische, entzündliche Reaktion des Organismus auf eine Infektion, die eine 
Folge der Invasion von obligat oder fakultativ pathogenen Keimen in normalerweise sterile Gewebe oder Körperflüssigkeiten darstellt. Der Nachweis einer Infektion ist obligat. Sie ist eine lebensbedrohliche Erkrankung, die sich auf der Grundlage einer teilweise unerkannten, okkulten Infektion entwickelt und zu multiplem Organversagen mit Todesfolge führen kann. Alternativ können spezifische Infektionen auch zu lokalen Organdysfunktionen ohne Generalisation führen. Der Schweregrad der Organschädigungen wird mit dem - SOFA-Score (,sequential organ failure assessment") erfasst.

Der klinische Schweregrad der systemischen Entzündung SIRS (,systemic inflammatory response syndrome“) kann auch mit folgenden Kenngrößen erfasst werden: Körpertemperatur $>38{ }^{\circ} \mathrm{C}$ oder $<36{ }^{\circ} \mathrm{C}$, Herzfrequenz $>90 /$ Minute, erhöhte Atemfrequenz $>20 /$ Minute, Leukozytenzahl $>12 \mathrm{G} / \mathrm{L}$ oder $<4 \mathrm{G} / \mathrm{L}$ oder $>10 \%$ Unreife. Für die Diagnose eines SIRS müssen 2 oder mehr pathologische Parameter gegeben sein (Seymour et al. 2016).

Pathogenese Im Zentrum einer generalisierten, überschießenden Entzündungsreaktion im Rahmen der Sepsis steht die Aktivierung entzündungs- und immunkompetenter Zellen wie Granulozyten, \Monozyten, Lymphozyten ( $\triangleright$ Lymphozyt), - Makrophagen und Endothelzellen, die im aktivierten Zustand eine Vielzahl von Mediatoren freisetzen. Auslösend sind Infektionen mit gramnegativen Keimen in 57-64 \%, mit grampositiven Keimen in 35-40 \%, mit Pilzen in 3-10\%. Wichtige Mediatoren sind Interleukine (IL) wie > Interleukin-1, - Interleukin-6, > Interleukin-8, > Tumornekrosefaktor- $\alpha$, - Interleukin-10, > Transforming Growth Factor $\beta$, Gerinnungsmediatoren wie $>$ Antithrombin-3, aktiviertes $>$ Protein C, - D-Dimer, Plasminogen-Aktivator-Inhibitor 1 (PAI-1), systemisches Thrombin u. a. (Tab. 1 und 2).

Stadien der Sepsis Im Sepsisverlauf kann sich eine Phase der generellen Hyperinflammation durch Ausschüttung mehrerer proinflammatorischer $>$ Zytokine mit einer Phase der ausgeprägten Immunparalyse durch Überschusssekretion antiinflammatorischer und immunsuppressiver Zytokine abwechseln (Abb. 1). Die pathogenetisch relevanten Zytokine können im Serum bestimmt und als phasenabhängige Kenngrößen eingesetzt werden. Neueste (Limulus-System-basierte) Biomarker wie plasmatische LPS-Reaktivität oder plasmatische $\beta$-Glukan-Reaktivität diagnostizieren eine schwere Sepsis sehr frühzeitig und kontrollieren den Therapieerfolg.

Untersuchungsmaterial Serum, Plasma.

Analytik S. Einzelkenngrößen.

Referenzbereich S. Einzelkenngrößen.

Bewertung Tab. 1 und 2.
Sepsiskenngrößen,

Abb. 1 Biphasischer

Sepsisverlauf mit Angabe beteiligter Zytokine. (Modifiziert nach: Grimminger et al. 1997)

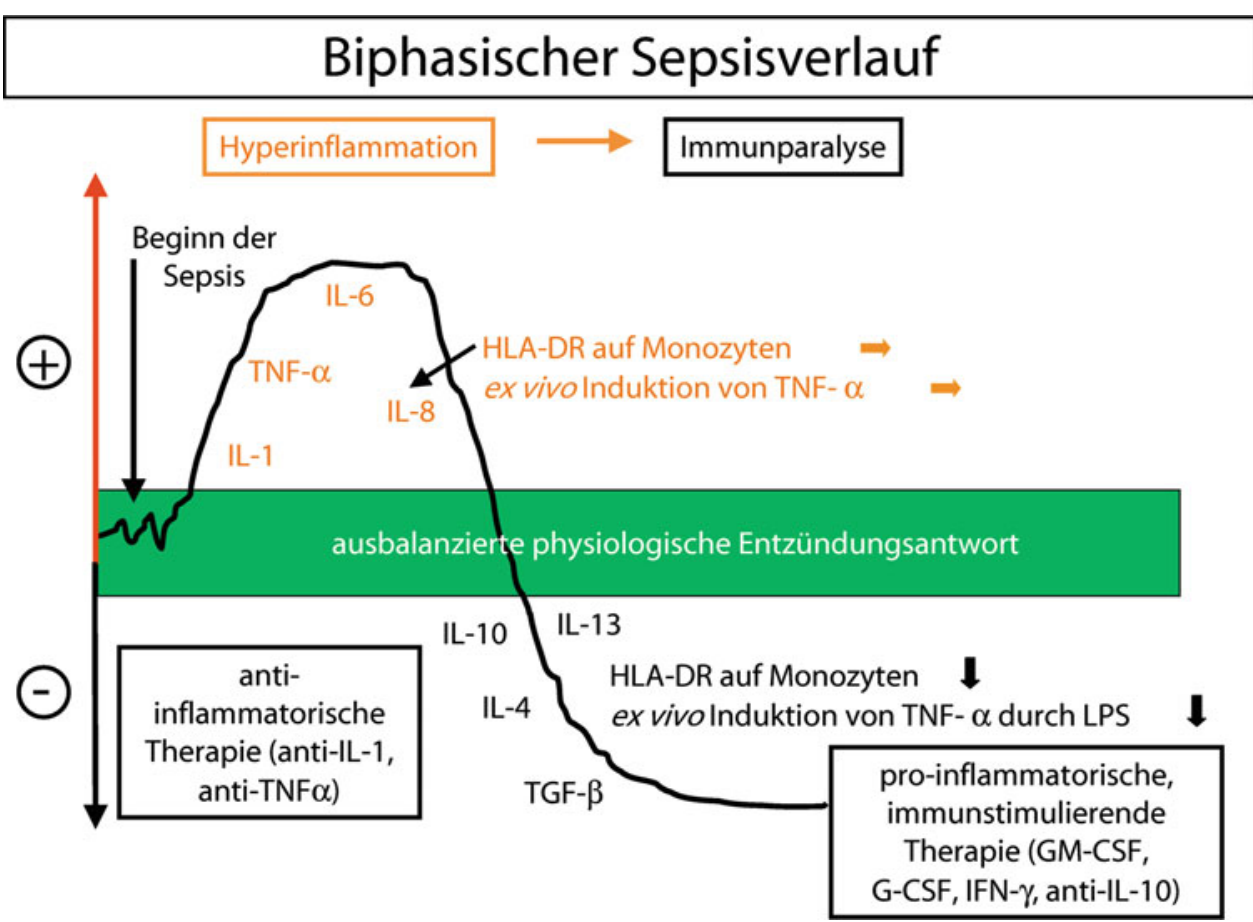




\section{Literatur}

Center for Sepsis Control and Care. www.cscc.uniklinikum-jena.de

Grimminger F, Mayer K, Seeger W (1997) Gibt es eine gesicherte Immuntherapie bei der Sepsis? Internist 38:541-552

Remick DG (2007) Biological perspectives - pathophysiology of sepsis. Am J Pathol 170:1435-1444

Seymour CW, Liu VX, Iwashyna TJ et al (2016) Assessment of clinical criteria for sepsis. For the third international consensus definition for sepsis and septic shock (sepsis-3). J Am Med Assoc 315(8):762-774

Singer M, Deutschman CS, Seymour CW et al (2016) The third international consensus definitions for sepsis and septic shock (sepsis-3). J Am Med Assoc 315(8):801-810

\section{Septin-9-Hypermethylierung}

- Septin-9-Test

\section{Septin-9-Test}

A. M. Gressner, S. Holdenrieder und O. A. Gressner

Synonym(e) Septin-9-Hypermethylierung

Englischer Begriff septin9-(gene)-test/assay

Definition Im Plasma nach DNA-Isolierung und PCR-Amplifikation geführter Nachweis auf zellfreie, zirkulierende, methylierte Sequenzen des Septin-9-Gens, der als spezifische und sensitive diagnostische Kenngröße für Dickdarm(adeno) karzinom gilt.

Beschreibung Im Rahmen von Tumorerkrankungen wurden einerseits Fusionen des Septin-9 mit dem Protoonkogen MLL, andererseits ein vermehrter Verlust der Heterozygozität der Genregion von Septin-9 z. B. beim Ovarialkarzinom beschrieben. Somit ist eine Funktion von Septin-9-Isoformen als Onkogen oder Suppressorgen vorstellbar.

Einige Septin-9-Subtpyen, wie z. B. v2 beim kolorektalen Karzinom und v4 beim Ovarialkarzinom, sind durch Hypermethylierung der Promotorregion reguliert. Assays zur Detektion der Septin-9-Hypermethylierung des v2-Transkripts wurden zur frühzeitigen Diagnose des kolorektalen Karzinoms entwickelt und in mehreren Fallkontrollstudien ausgetestet. Hierbei wurden diagnostische Sensitivitäten $(\triangleright$ Sensitivität, diagnostische) von etwa $70 \%$ bei einer diagnostischen Spezifität ( $\triangleright$ Spezifität, diagnostische) von $90 \%$ erzielt. Da aufgrund der geringen Prävalenz kolorektaler Karzinome bei asymptomatischen Personen zahlreiche falsch positive Befunde zu erwarten sind, wird derzeit geprüft, ob der Septin-9-Test im Präscreening von Risikogruppen vor der Koloskopie einen diagnostischen Stellenwert erhalten wird.

\section{Literatur}

Grützmann R et al (2008) Sensitive detection of colorectal cancer in peripheral blood by septin-9 DNA methylation assay. PLoS One 3:e3759

Song LL, Li YM (2016) Current noninvasive tests for colorectal cancer screening: an overview of colorectal cancer screening tests. World J Gastroenterol 8(11):793-800

Vos T de et al (2009) Circulating methylated SEPT9 DNA in plasma is a biomarker for colorectal cancer. Clin Chem 55:1337-1346

\section{Sequentieller Organfehlfunktion-}

\section{Score}

- SOFA-Score

\section{Sequenz, intervenierende}

$>$ Intron

\section{Sequenz, lytische}

- Membran-Attack-Komplex

\section{Sequenzier-PCR}

- Cycle-Sequencing

\section{Ser}

$>$ Serin

\section{Serie}

- Analysenserie 


\section{Serielle Datenübertragung}

- Analysegeräte-Anschluss

\section{Serieller diagnostischer Test}

- Test, serieller diagnostischer

\section{Serin}

A. C. Sewell

Synonym(e) Ser

Englischer Begriff serine

Definition Eine nicht essenzielle, proteinogene $\alpha$-Aminosäure, die erstmals im Jahr 1865 aus Seidenleim (Sericum) isoliert wurde.

Struktur $>$ Aminosäuren.

Molmasse $105,1 \mathrm{~g}$

Synthese - Verteilung - Abbau - Elimination Serin wird ausgehend von 3-Phosphoglyzerat durch Reduktion mit nachfolgender $>$ Transaminierung synthetisiert. Im Körper wird Serin zu $\triangleright$ Glyzin abgebaut und durch Transaminierung zu $\checkmark$ Pyruvat umgewandelt.

Funktion - Pathophysiologie Ser ist Bestandteil der Synthese von $\triangleright$ Purinen und $\triangleright$ Pyrimidinen und Präkursor in der Sphingolipidsynthese. Darüber hinaus spielt Ser eine wichtige Rolle in der katalytischen Funktion verschiedener Enzyme (z. B. \ Chymotrypsin, \rypsin). Nervengase und einige Insektizide wirken erst durch Kombination mit Ser mit Hemmung der Acetylcholinesterase.

Untersuchungsmaterial - Entnahmebedingungen Plasma, Serum, Urin, Liquor, Trockenblut.

Analytik $>$ Aminosäuren.

Referenzbereiche $>$ Aminosäuren.
Diagnostische Wertigkeit Niedrige Serinkonzentrationen in Plasma und Liquor weisen auf einen 3-PhosphoglyzeratDehydrogenasemangel oder Phosphoserin-Phosphatasemangel hin.

\section{Literatur}

Duran M (2008) Amino acids. In: Blau N, Duran M, Gibson KM (Hrsg) Laboratory guide to the methods in biochemical genetics. Springer, Berlin, S 53-90

Jaeken J, Detheux M, Van Maldergem L et al (1996) 3-phosphoglycerate dehydrogenase deficiency: an inborn error of serine biosynthesis. Arch Dis Child 74:542-545

\section{Serologische Verträglichkeitsprobe}

K. Kleesiek, C. Götting, J. Diekmann, J. Dreier und M. Schmidt

Synonym(e) Kälteabhängige Kreuzprobe; Kreuzprobe; Major-/Minorkreuzprobe

Englischer Begriff cross-matching; major or minor crossmatch

Definition Die serologische Verträglichkeitsprobe (Kreuzprobe) ist eine In-vitro-Prüfung der blutgruppenserologischen Verträglichkeit von Spender- und Empfängerblut vor jeder Transfusion von Erythrozytenpräparaten ( $\triangleright$ AB0-Kompatibilität-Inkompatibilität). Sie wird nach den Richtlinien der Bundesärztekammer rechtlich gefordert. Nur in Notfallsituationen zur Abwendung einer Lebensgefahr oder eines ernsten Schadens des Empfängers kann davon abgewichen werden.

Beschreibung Funktion und Methode: In einer serologischen Verträglichkeitsprobe wird das Serum des Transfusionsempfängers mit den Erythrozyten des Blutspenders inkubiert (Majorkreuzprobe). Eine Minorkreuzprobe (Verträglichkeit zwischen Spenderserum und Empfängererythrozyten) erfolgt aufgrund der in der Regel weitgehenden Plasmafreiheit transfundierter Erythrozytenkonzentrate nur in seltenen Einzelfällen und ist nach den Richtlinien der Bundesärztekammer nicht erforderlich.

Ein wesentlicher Bestandteil der Kreuzprobe ist der indirekte Antihumanglobulitest (indirekter Coombs-Test) als empfindliche Methode zum Nachweis von Antikörpern gegen Erythrozytenantigene ( $\triangleright$ Alloantikörper). Alle benutzten methodischen Verfahren müssen rechtlich hinsichtlich analytischer Spezifität und Sensitivität den Stand der Wissenschaft und Technik aufweisen. 
Eine wesentliche Aufgabe der Kreuzprobe ist es auch, vorausgegangene Fehlbestimmungen und Verwechslungen zu erkennen. So erfolgt bei jeder neu entnommenen Blutprobe des Probanden eine Kontrolle der AB0-Merkmale. Um transfusionsrelevante Antikörper infolge einer Sensibilisierung (z. B. durch Transfusionen, Schwangerschaften) innerhalb der letzten 3 Monate auch in anamnestisch fraglichen Fällen zu erfassen, ist nach spätestens 3 Tagen erneut eine Kreuzprobe für weitere Transfusionen mit einer frisch entnommenen Empfängerprobe durchzuführen. Das Ergebnis der serologischen Verträglichkeitsprobe ist zu dokumentieren.

Eine Sonderform stellt die kälteabhängige Kreuzprobe dar, die indiziert eingesetzt wird. Sie ist dann erforderlich, wenn beim Transfusionsempfänger therapeutische Maßnahmen unter systemischer Hypothermie notwendig sind, z. B. bei Herzoperationen, die Temperaturen von $<28{ }^{\circ} \mathrm{C}$ erfordern können. Um eine Agglutination der Spendererythrozyten oder patienteneigenen Erythrozyten aufgrund des Vorliegens von kältereaktiven Antikörpern ( $\vee$ Kälteantikörper) oder Autoantikörpern ( $\vee$ Autoantikörper) zu verhindern, wird ein Temperaturschwellenwert ermittelt, der im Rahmen der Hypothermiemaßnahme nicht unterschritten werden darf. Dazu wird in der kältereaktiven Kreuzprobe ein direkter Agglutinationstest in physiologischer NaCl-Lösung durchgeführt. Ausgehend von $37{ }^{\circ} \mathrm{C}$ wird in $2-3{ }^{\circ} \mathrm{C}$ Abstufungen die Temperatur in der Kreuzprobe schrittweise bis zu jener Temperatur erniedrigt, bei der die ersten Anzeichen einer Agglutination nachweisbar sind. Die Einhaltung der Temperaturbedingungen ist sowohl beim Abkühlen des Patienten als auch bei der Transfusion der Blutprodukte geboten.

\section{Literatur}

Bundesärztekammer (2005) Richtlinien zur Gewinnung von Blut und Blutbestandteilen und zur Anwendung von Blutprodukten (Hämotherapie), Aufgestellt gemäß Transfusionsgesetz von der Bundesärztekammer im Einvernehmen mit dem Paul-Ehrlich-Institut. Gesamtnovelle, Zweite Richtlinienanpassung 2010, Deutscher Ärzteverlag, Köln

Eckstein R, Zimmermann R (2015) Immunhämatologie und klinische Transfusionsmedizin, 7. Aufl. Urban \& Fischer/Elsevier Verlag, München

Kiefel V (Hrsg) (2010) Transfusionsmedizin: Grundlagen - Therapie - Methodik, 4. Aufl. Springer, Berlin/Heidelberg/New York

\section{Serotonin}

M. Bidlingmaier

Synonym(e) 3-(2-Aminoethyl)-1H-indol-5-ol; 5-Hydroxytryptamin; Enteramin
Englischer Begriff 5-HT; 5-hydroxytryptamine; enteramine; 3-( $\beta$-aminoethyl)-5-hydroxyindole; thrombocytin; thrombotonin

Definition Als Gewebshormon und als Neurotransmitter wirksames biogenes Amin mit Effekten auf gastrointestinale Motilität, Zentralnervensystem, Thrombozytenfunktion und Gefäßtomus.

Struktur Vom L-Tryptophan abgeleitetes biogenes Amin, Summenformel $\mathrm{C}_{10} \mathrm{H}_{12} \mathrm{~N}_{2} \mathrm{O}$.

Molmasse $176,22 \mathrm{Da}$.

Synthese - Verteilung - Abbau - Elimination Beim Menschen wird Serotonin aus L-Tryptophan unter Mitwirkung der Enzyme Tryptophanhydroxylase und Aromatische-L-Aminosäure-Decarboxylase (auch DOPA-Decarboxylase) synthetisiert. Hauptsyntheseort sind die enterochromaffinen Zellen des Gastrointestinaltrakts, aus denen über $90 \%$ der zirkulierenden Serotoninkonzentration stammt. Außerdem entsteht Serotonin in enteralen Neuronen. Stimuliert wird die Freisetzung durch erhöhten Druck im Darmlumen, aber auch durch bestimmte Aromastoffe. Neben einer luminalen erfolgt auch eine basolaterale Sekretion. Serotonin wirkt in der Darmschleimhaut sowohl parakrin als auch als Neurotransmitter. In den Blutgefäßen wird es von Thrombozyten aufgenommen. Eine Passage der Blut-Hirn-Schranke ist nicht möglich, das zentralnervös als Neurotransmitter wirksame Serotonin wird lokal in serotonergen Neuronen gebildet.

Die Wirkung des Serotonins wird beim Menschen über mindestens 14 verschiedene, fast ausschließlich G-Proteingekoppelte Serotonin- oder 5-HT-Rezeptoren vermittelt, die gewebsspezifisch exprimiert sind.

Der Abbau des Serotonins erfolgt ebenfalls gewebsspezifisch: Während als Neurotransmitter fungierendes Serotonin aus den synaptischen Spalten im Wesentlichen rückresorbiert und wiederverwendet wird, erfolgt der Abbau des zirkulierenden Serotonins rasch durch die Monoaminooxidase A (in geringem Umfang auch B). Das Hauptprodukt des Serotoninabbaus ist die $>5$-Hydroxyindolessigsäure, die renal ausgeschieden wird.

Ein alternativer Stoffwechselweg verwendet Serotonin als Ausgangssubstanz für die Synthese des $\triangleright$ Melatonins.

Pathophysiologie Serotonin hat aufgrund der in vielen Geweben vorhandenen Rezeptoren sowie der verschiedenen Rezeptorsubtypen ein breites Spektrum von Wirkungen. Pathophysiologisch ist eine Beteiligung von Serotonin u. a. in folgenden Bereichen beschrieben:

- Kardiovaskuläre Effekte: Die je nach Rezeptorsubtyp unterschiedlichen Effekte auf das Gefäßsystem - Kontraktion (Lunge, Niere) bzw. Relaxation (Skelettmuskulatur) - erklä- 
ren die mehrphasige Reaktion des Blutdrucks nach Serotoninexposition.

- Direkte Effekte auf Thrombozyten: Thrombozytenaggregation, insgesamt Förderung der Blutgerinnung.

- Gastrointestinaltrakt: motorische (Stimulierung der Peristaltik) und sensorische Effekte (Signalweiterleitung an das Zentralnervensystem, Übelkeit, Erbrechen).

- Im Zentralnervensystem wird Serotonin u. a. mit der Regulation von Stimmung, Appetit, Sexualverhalten, Schmerzempfindung und der Pathogenese der Migräne in Verbindung gebracht. Peripher messbare Serotoninkonzentrationen entstammen jedoch wie beschrieben überwiegend dem Gastrointestinaltrakt und haben daher im Kontext zentralnervöser Funktionen wenig Bedeutung.

Klinisch-diagnostisch ist die Serotonin- bzw. 5-Hydroxyindolessigsäure-Bestimmung jedoch fast ausschließlich bei der Diagnostik serotoninproduzierender Tumoren relevant. Karzinoide sind neuroendokrine Tumoren, die meist im Gastrointestinaltrakt, seltener auch ektop, z. B. in der Lunge, gefunden werden. Sie sezernieren - oft schubweise - hohe Konzentrationen von Serotonin, was zur typischen Symptomatik mit Flushreaktion, krampfartigen Bauchschmerzen, Diarrhoen, Bronchospasmen, Hypertonie und Tachykardie führt.

Untersuchungsmaterial Vollblut, Plasma (bevorzugt thrombozytenarm), Serum, Urin.

Wegen der raschen Metabolisierung von Serotonin zu 5-Hydroxyindolessigsäure in der Niere hat die Bestimmung von Serotonin im Urin wenig Aussagekraft, hier ist die direkte Bestimmung von 5-Hydroxyindolessigsäure sinnvoll.

Probenstabilität Insgesamt ist die Präanalytik für die Serotoninbestimmung im Blut kritisch. Nachdem $>95 \%$ des Serotonins in Blutproben in Vesikeln in den Thrombozyten vorliegt, ist eine Bestimmung des freien Serotonins nach Hämolyse sinnlos.

Präanalytik Serotonin kommt auch im Pflanzenreich vor. Einige Lebensmittel, wie z. B. Walnüsse oder Bananen, enthalten besonders viel Serotonin. Relevanten Einfluss auf die Serotoninkonzentration können aber auch andere Nüsse, Tomaten, Ananas, Auberginen, Avocados, Melonen, Mirabellen, Pflaumen, Johannisbeeren, Stachelbeeren, Auberginen, Kiwis und auch Alkohol, Nikotin, Kaffee, Tee und Schokolade haben. Die empfohlene Karenz von 2-3 Tagen ist praktisch oft schwer umzusetzen bzw. zu kontrollieren.

Auch eine Vielzahl von Medikamenten beeinflussen die Serotoninkonzentrationen. Falsch hohe Serotoninwerte werden u. a. beobachtet unter Paracetamol, Phenobarbital, Ephedrin und Amphetaminen, falsch niedrige Werte hingegen unter Acetylsalicylsäure, Levodopa und Isoniazid. Die Liste potenziell interferierender Medikamente ist jedoch sehr viel länger.

Analytik Hochleistungs-Flüssigkeitschromatographie, Immunoassay, Flüssigchromatographie-Massenspektormetrie.

Konventionelle Einheit $\mathrm{ng} / \mathrm{mL}$.

Internationale Einheit $\mathrm{nmol} / \mathrm{L}$.

Umrechnungsfaktor zw. konv. u. int. Einheit $1 \mathrm{ng} / \mathrm{mL}$ $=5,7 \mathrm{nmol} / \mathrm{L}$.

Referenzbereich - Erwachsene Die Referenzbereiche für Serotonin im thrombozytenarmen Plasma differieren stark je nach Abnahmeprotokoll, Probenaufarbeitung und Messmethode. In der Literatur berichteten Mittelwerte gesunder Probanden schwankten zwischen 0,6 und $179 \mathrm{nmol} / \mathrm{L}$, wobei im Durchschnitt aller Methoden 31,6 nmol/L angegeben werden. 5-Hydroxyindolessigsäure im Urin: bis $9,0 \mathrm{mg} / 24$ Stunden.

Indikation Verdacht auf neuroendokrine Tumoren (NET, Karzinoid).

Interpretation Beim Karzinoid finden sich besonders bei akuter Symptomatik deutlich erhöhte Werte der 5-Hydroxyindolessigsäure im Urin. Im symptomfreien Intervall können die Konzentrationen bei der Erkrankung jedoch normal sein.

Die Interpretation von Serotoninkonzentrationen im Blut kann nur in Kenntnis von Abnahmeprotokoll, Probenaufarbeitung und Messmethode erfolgen.

Diagnostische Wertigkeit 5-Hydroxyindolessigsäure-Werte über $40 \mathrm{mg} / 24$ Stunden gelten als beweisend für ein Karzinoid.

\section{Literatur}

Brand T, Anderson GM (2011) The measurement of platelet-poor plasma serotonin: a systematic review of prior reports and recommendations for improved analysis. Clin Chem 57(10):1376-1386

\section{Serotonin Release Assay}

T. Stief und P. Kiefer

Synonym(e) SRA

Englischer Begriff serotonin release assay 
Definition SRA misst die Aktivierung von Thrombozyten durch Antikörper, die gegen einen Komplex von Heparin und Plättchenfaktor 4 gerichtet sind. Der SRA wird mit Spenderthrombozyten durchgeführt und gilt als Goldstandard der Heparin-induzierten Thrombozytopenie(HIT)-2Testung. Der SRA ist wegen seiner Komplexität Speziallaboren vorbehalten.

Beschreibung Die Aktivierung der Plättchen durch Antikörper im Blut des Probanden ist der Freisetzung des $\triangleright$ Serotonin aus den Granula der Thrombozyten proportional. Das aus den Granula freigesetzte Serotonin wird durch einen > Enzymimmunoassay (EIA-SRA) oder durch $>$ Hochleistungs-Flüssigkeitschromatographie (HPLC-SRA) bestimmt.

Der SRA gilt als > Goldstandard zur Erfassung von HIT2-induzierenden Antikörpern. Sensitivität ( $\vee$ Sensitivität, diagnostische) und Spezifität ( $\triangleright$ Spezifität, diagnostische) werden mit $90 \%$ bzw. mit bis zu $100 \%$ angegeben. Häufig wird der Test auch eingesetzt, um schwache Ergebnisse des hochsensitiven Screeningtests (PF4/ELISA) zu bestätigen. HLA-Klasse-I-Autoantikörper oder Antikörper gegen Plättchen-spezifische Antigene können zu einer Heparin-unabhängigen Freisetzung von Serotonin führen. Bei allen HIT-2Messungen sollte auch die systemische Thrombinaktivität im Plasma ( $\alpha 2 \mathrm{M}-\mathrm{F} 2 \mathrm{a})$ gemessen werden, da Thrombin ein starker Thrombozytenaktivator ist.

Normbereich 19-62 ng/mL (jeweils 2,5-97,5 Perzentile; HIT-2-Patienten: $244-7987$ ng/ml).

\section{Literatur}

Harenberg J, Huhle G, Giese C, Wang LC, Feuring M, Song XH, Hoffmann U (2000) Determination of serotonin release from platelets by enzyme immunoassay in the diagnosis of heparin-induced thrombocytopenia. Br J Haematol 109:182-186

\section{Serpin A5}

Protein-C-Inhibitor

\section{Serum}

W. G. Guder

Synonym(e) Blutserum

\section{Englischer Begriff serum}

Definition Partikelfreier Überstand des Vollblutes nach vollständiger Gerinnung.

Beschreibung Serum stellt das traditionell am meisten verwendete Untersuchungsmaterial für Blutuntersuchungen in der Medizin dar. Es wird aus $>$ Vollblut durch Zentrifugation über 10 Minuten bei $2000 \mathrm{~g}$ gewonnen, nachdem die Gerinnung zu einer Retraktion des Blutkuchens geführt hat, der neben den Blutzellen alle > Gerinnungsfaktoren enthält, die mit Fibrin bei der Zentrifugation ausfallen. Bei diesem Vorgang werden $>$ Thrombozyten aktiviert und verlieren den größten Teil ihrer Inhalte in das Serum.

Unterschiede zwischen $>$ Plasma und Serum sind überwiegend durch den natürlichen Gerinnungsvorgang bedingt. So nehmen Gesamtprotein ab und > Phosphat, > Kalium, - Laktatdehydrogenase und andere Bestandteile der Thrombozyten (z. B. neuronenspezifische Enolase, saure Phosphatase, Dopamin, Serotonin) im Serum gegenüber Plasma zu.

\section{Literatur}

Guder WG, Narayanan S (2015) Plasma or serum? which anticoagulant to use? In: Guder WG, Narayanan S (Hrsg) Pre-examination procedures in laboratory diagnostics. Walter de Gruyter, Berlin/Boston, S 64-68

Guder WG, Ehret W, daFonseca-Wollheim F, Heil W, Müller-Plathe O, Töpfer G et al (1998) Serum, plasma or whole blood? which anticoagulant to use? J Lab Med 22:297-312

\section{Serum-Amyloid A}

G. Töpfer

$\operatorname{Synonym(e)~SAA~}$

Englischer Begriff serum amyloid A

\section{Serpin E1}

- Plasminogen-Aktivator-Inhibitor 1 
Definition Wird bei einer $>$ Akute-Phase-Reaktion wie Entzündungen und Abstoßreaktionen schneller gebildet und langsamer abgebaut als $>$ C-reaktives Protein (CRP), ist strukturell bei einer Molmasse von $12 \mathrm{kDa}$ an HDL gebunden und stellt das Vorläuferprotein des Gewebe-Amyloid-AAProteins dar, das bei chronischen Entzündungen abgelagert werden kann.

Struktur SAA enthält 104 Aminosäuren, wobei N-terminal die $\triangleright$ Aminosäuren 45-83 mit jenen des Protein-AA extrahiert aus den Fibrillen von Amyloid A identisch sind. Die Aminosäuren 38-58 sind in allen Spezies, in denen es vorkommt, gleich. Ratten haben kein messbares SAA wegen Fehlens der genetischen Kodierung von Teilen des Gens, sodass sich bei Entzündungen Teilstücke in der Leber ansammeln. Eine andere Form des SAA, die auch bei Tieren vorkommt, hat ein zusätzliches Oktapeptid zwischen den Aminosäuren 70 und 77, es verhält sich nicht als Akute-Phase-Protein ( $\triangleright$ Akute-PhaseProteine). Im Blutserum des Menschen kommen SAA1 und SAA2 vor mit zu $93 \%$ identischer Aminosäuresequenz. Der Anteil der SAA1-Isoform beträgt gleichbleibend bei Gesunden und bei der Akute-Phase-Reaktion $75 \%$. Stimuli durch IL-1 $\beta$ am Promotorgen sind bei der SAA-Synthese stärker und Stimuli von IL-6 gleich stark wirksam auf die Synthese von SAA und CRP. Nach seiner Sekretion aus der Bildungszelle assoziieren alle Formen des SAA auf der hydrophoben N-terminalen Seite mit HDL. Der Hauptträger für SAA ist HDL-3, auch andere HDL-Fraktionen sowie LDL und VLDL binden SAA. Während der Akute-Phase-Reaktion kann SAA in der HDLFraktion um das 1000-Fache ansteigen, wobei Apolipoprotein A-I, Apolipoprotein A-II und Apolipoprotein C-III aus dem Komplex verdrängt werden.

Molmasse $12 \mathrm{kDa}$.

Synthese - Verteilung - Abbau - Elimination Die Leber ist der Hauptsyntheseort, extrahepatische Synthese erfolgt noch in Fibroblasten und Makrophagen. Interleukin-1, - Interleukin-6 und Tumornekrosefaktoren ( $\downarrow$ Tumornekrosefaktor- $\alpha$ ) induzieren die Synthese, wobei Kortikosteroide diesen Effekt auf zellulärer Ebene verstärken. Bei Gesunden ist SAA nur in sehr geringen Konzentrationen im - Plasma vorhanden $(<10 \mathrm{mg} / \mathrm{L})$. Der Abbau geschieht in der Leber möglicherweise durch die Aufnahme der HDLPartikel von den Hepatozyten. Während der Akute-PhaseReaktion ist der Abbau um etwa 30 \% reduziert. Das könnte die Ursache für die Steigerung der Konzentration bei der Akute-Phase-Reaktion um das 2000-Fache sein (CRP-Steigerung dabei nur um das 1000-Fache bei verstärktem Abbau des CRP in der akuten Phase). Peak-Werte werden für SAA etwa 50 Stunden nach dem akuten Ereignis erreicht.
Funktion - Pathophysiologie Chronisch erhöhte Serumkonzentrationen des SAA sind eine der notwendigen Voraussetzungen zur Bildung von AA-Amyloid. Bei Tieren gibt es Isoformen des SAA, die mehr zur Amyloidablagerung neigen, dies ist beim Menschen nicht der Fall. Die Prävalenz einer derartigen Amyloidose beträgt bei Autopsien 0,5-0,7 \%. Bei Patienten mit rheumatischen Erkrankungen beträgt die Prävalenz der Amyloidose 4,5 \%. Die bisherigen Erkenntnisse zur Funktion und Pathophysiologie des Lipidstoffwechsels und der Abwehrfunktion im Zusammenhang mit SAA befinden sich überwiegend noch im Stadium des Tierexperiments. IL-18 stimuliert die SAA-Bildung von rheumatoiden Synovialzellen. SAA löst Apo E aus der HDL-Mizelle des Liquors bei Entzündungen. Damit wird Amyloid- $\beta-(\mathrm{AB}-)$ Fragment (1-42) nicht mehr an HDL gebunden. Die $A \beta$-Clearance ist gestört. SAA von Maus und Mensch binden das fettlösliche Retinol. Wie gegen CRP wurden auch Autoantikörper gegen SAA nachgewiesen.

\section{Untersuchungsmaterial - Entnahmebedingungen Serum} aus Vollblut.

Probenstabilität Proben möglichst frisch analysieren.

Serum bei $2-8{ }^{\circ} \mathrm{C} 8$ Tage stabil, bei $-20{ }^{\circ} \mathrm{C} 3$ Monate stabil.

Präanalytik Trübungen in den Proben stören bei $>$ Immunnephelometrie/ $\triangleright$ Immunturbidimetrie. Entfernung von Partikeln oder Lipidtrübungen bei $15.000 \times g$ über 10 Minuten, dann noch trübe Proben werden nicht analysiert. Frier-TauZyklen sind zu vermeiden.

Analytik $>$ Radioimmunoassay (RIA), latexverstärkte Immunnephelometrie, $>$ Enzyme-linked Immunosorbent Assay (ELISA), Dot-Blot. Internationaler (WHO-)Standard ist seit 1998 verfügbar. Bei der latexverstärkten Immunnephelometrie beträgt der Messbereich 3-200 mg/L (Verdünnung 1/400) bzw. bis $1000 \mathrm{mg} / \mathrm{L}$ bei Verdünnung des Serum von 1/2000.

\section{Konventionelle Einheit $\mathrm{mg} / \mathrm{dL}$.}

Internationale Einheit $\mathrm{mg} / \mathrm{L}$.

Umrechnungsfaktor zw. konv. u. int. Einheit $\mathrm{mg} /$ $\mathrm{dL} \times 10=\mathrm{mg} / \mathrm{L}$.

Referenzbereich - Erwachsene Latexverstärkte Immunnephelometrie: $<6,4 \mathrm{mg} / \mathrm{L}$ oder nach Whicher und Chir (1996) $<8-10 \mathrm{mg} / \mathrm{L}$ (Median: 1-2 mg/L) (methodenunabhängig).

Referenzbereich - Kinder Latexverstärkte Immunnephelometrie $(\mathrm{n}=35)$ : Nabelschnurblut $<3 \mathrm{mg} / \mathrm{L}$ (Median 
0,76 mg/L), Neugeborene (3-7 Tage) $>10,6 \mathrm{mg} / \mathrm{L}$ (Median $1,5 \mathrm{mg} / \mathrm{L})$ (Lannergard et al. 2005).

\section{Indikation}

- Entzündungsmarker, Aktivitätsmarker bei rheumatoider Arthritis

- Marker für Transplantatabstoßung

- Abklärung einer Amyloidose

- Indikationen ähnlich dem CRP wie Diagnostik von Herzattacken, Neugeboreneninfektionen.

Interpretation SAA zeigt auch bei Virusinfektionen in der Regel Anstiege über den Referenzbereich, beispielsweise bei zwei Drittel der gewöhnlichen Erkältungskrankheiten, während das bei CRP nur in etwa der Hälfte der Virusinfektionen beobachtet wird. Allerdings fehlen diese Anstiege des SAA bei Hepatitis-B- und -C-Infektionen. Auch Lupus erythematodes und ulzerative Kolitis zeigen keine SAA-Erhöhungen.

Bei malignen Tumoren steigt SAA an, wobei metastasierende Tumoren höhere Konzentrationen aufweisen.

Besondere Bedeutung weist SAA bei der Beurteilung des Aktivitätsgrades der rheumatoiden Arthritis (RA) auf, wo es den anderen Akute-Phase-Proteinen überlegen scheint, auch im Hinblick auf die Abschätzung des Risikos, bei hohen SAA-Serumkonzentrationen Amyloid A abzulagern. Allerdings ist die hohe Konzentration nur eine Voraussetzung für die Amyloidablagerung. Bei Frauen mit RA sind hohe SAASpiegel mit Symptomen einer fortgeschrittenen Atherosklerose verbunden.

Etabliert hat sich SAA zur Erkennung von Abstoßungsreaktionen von transplantierter Niere, Leber, Pankreas. Bedeutung kommt dem SAA auch für die Erkennung der Abstoßung transplantierter Herzen zu, allerdings nur mit einer diagnostischen Sensitivität ( $\triangleright$ Sensitivität, diagnostische) von $<70 \%$.

Zur Differenzialdiagnostik von Virusinfektionen und Rejektionskrisen wird vielfach $>$ Neopterin im Urin und/oder Serum empfohlen. Gleichzeitig mögliche bakterielle Infektionen stellen zusätzlich weiterhin ein differenzialdiagnostisches Problem dar, das allerdings möglicherweise über die $>$ Procalcitonin abklärbar ist (allerdings fehlen bisher dazu Publikationen).

Bei stabiler Angina pectoris und Herzinfarkt weist SAA eine ähnliche, wenn nicht bessere Empfindlichkeit wie CRP (im unteren Messbereich) auf. Arbeiten über die Bedeutung bei Neugeboreneninfektionen sollten den diagnostischen Wert von SAA für diese Fragestellung klären, zumal der Parameter SAA nunmehr besser verfügbar und seit der Einführung eines internationalen Standards 1998 gut vergleichbar zu messen ist. Bei nekrotisierender Enterokolitis von Frühgeborenen zeigte sich SAA in gleicher Weise wie Procalcitonin und CRP zur Erstdiagnostik und Verlaufskontrolle geeignet, SAA war aber gegenüber dem CRP für die Erkennung nosokomialer Infektionen von Frühgeborenen unterlegen.

Diagnostische Wertigkeit Die Hoffnung, dass sowohl virale als auch bakterielle Infektionen vollständig erfassbar sind, hat sich nicht erfüllt. Da der Anstieg bei Virusinfektionen, Abstoßungskrisen und chronischen Entzündungen besser diagnostisch nutzbar erscheint als der des CRP, sollte ein breiterer Einsatz an der Stelle oder zusätzlich zu CRP (und u. a. von $>$ Zytokine) erfolgen. Weiterhin ist die Bestimmung von SAA bei der Fragestellung „Amyloidose“ sinnvoll. Eine SAA-Konzentration von $>10 \mathrm{mg} / \mathrm{L}$ kann bei Ausschluss anderer Ursachen auf eine koronare Herzerkrankung hinweisen.

\section{Literatur}

Lannergard A, Friman G, Ewald U, Lind L, Larsson A (2005) Serum amyloid A (SAA) protein and high -sensitivity C-reactive protein (hsCRP) in healthy newborn infants and healthy young through elderly adults. Acta Paediatr 94:1198-1202

Whicher JT, Chir B (1996) Serum amyloid A. In: Ritchie RF, Navolotskaia O (Hrsg) Serum proteins in clinical medicine. Band 1: Laboratory section, 1. Aufl., Foundation for Blood Research, Scarborough, S $1-5$

\section{Serumcholinesterasen}

- Pseudocholinesterase

\section{Serum-/Plasmatrenngel}

- Trenngel

\section{Serum-Pool}

C. Vidal und W.-R. Külpmann

Synonym(e) Poolserum

Englischer Begriff serum pool

Definition Serum, das durch homogene Mischung von Serum verschiedener Probanden erhalten wird.

Beschreibung Serum-Pools werden hergestellt z. B. als Ausgangsmaterial für Kontrollseren. 


\section{Serumprotein-Elektrophorese}

\section{R. Westermeier, A. M. Gressner und O. A. Gressner}

Englischer Begriff serum protein electrophoresis

Definition Spezielle Anwendung der Zonenelektrophorese in nicht restriktiven Medien, wie Celluloseacetatfolien oder Agarosegelen, zur Trennung von Serumproteinen in die 5 Fraktionen Albumin, $\alpha_{1^{-}}, \alpha_{2^{-}}, \beta$ - und $\gamma$-Globuline.

Physikalisch-chemisches Prinzip Für die Trennung von Serumprotein wird meist die $>$ Celluloseacetatfolien-Elektrophorese oder die etwas höher auflösende $>$ Agarosegelelektrophorese eingesetzt. In vielen Laboratorien wird bereits mit der $\triangleright$ Kapillarelektrophorese experimentiert, weil diese besser zu automatisieren ist.

Im Verlauf von Erkrankungen ergeben sich Konzentrationsänderungen von Serumproteinen ( $\triangleright$ Akute-Phase-Proteine), die bei der Serumproteinelektrophorese zu qualitativen und quantitativen Abweichungen im $>$ Elektropherogramm und $>$ Densitogramm vom normalen Proteinmuster führen. Die Patientenseren werden mit Probenstempeln auf eine puffergetränkte Celluloseacetatfolie oder ein Agarosegel appliziert, im elektrischen Feld getrennt ( $\triangleright$ Elektrophorese) und - je nach Medium - mit Ponceaurot-Färbung oder Amidoschwarz-Färbung nachgewiesen. Die Elektropherogramme werden mit einem $>$ Densitometer ausgewertet und z. B. mithilfe von geeigneten Programmen in einen Befund integriert.

Einsatzgebiet Serumproteintrennungen zum Nachweis der Akute-Phase-Reaktion ( $\triangleright$ Akute-Phase-Proteine), Hypoglobulinämien, monoklonalen Gammopathien ( $\triangleright$ Immunglobulin, monoklonales), Bisalbuminämie ( $\triangleright$ Albumin).

Es handelt sich lediglich um eine Übersichtsanalyse, die bei abnormalem Befund durch diagnostisch validere Untersuchungen, z. B. Einzelproteinbestimmungen, ergänzt werden muss.

\section{Untersuchungsmaterial Serum}

\section{Instrumentierung}

- Elektrophoresekammer

- Stromversorger

- Färbeschalen

- Densitometer

Sensitivität Die Empfindlichkeit liegt im $\mu$ g-Bereich.
Referenzbereiche Die Angaben gelten für die Serumproteinelektrophorese auf Celluloseacetatfolie. In Abhängigkeit von der Färbemethode ( $\triangleright$ Amidoschwarz-Färbung, \ Ponceaurot-Färbung) der Proteinfraktionen ergeben sich im Einzelnen etwas unterschiedliche relative Verteilungen. Da es sich nicht um eine streng quantitative Methode handelt, sind die Angaben der absoluten Konzentrationen (g/L) als Richtbereiche zu verstehen (s. Tabellen).

Prozentuale Verteilung der getrennten Proteinfraktionen im Serum (\%) für Erwachsene:

\begin{tabular}{l|l|l|l|l|l|}
\hline Anfärbung & $\begin{array}{l}\text { Globuline } \\
\text { Albumin }\end{array}$ & $\alpha_{1}$ & $\alpha_{2}$ & $\beta$ & $\gamma$ \\
\hline $\begin{array}{l}\text { Amidoschwarz* } \\
\text { (Thomas 1981) }\end{array}$ & $60,6-68,6$ & $1,4-3,4$ & $4,2-7,6$ & $7,0-10,4$ & $12,1-17,7$ \\
\hline $\begin{array}{l}\text { Ponceaurot s* } \\
\text { (Grabner et al. }\end{array}$ & $55,3-68,9$ & $1,6-5,8$ & $5,9-11,1$ & $7,9-13,9$ & $11,4-18,2$ \\
1970) & & & & & \\
*Angaben der 5.- und 97,5.-Perzentile & & &
\end{tabular}

Konzentrationsverteilungen der getrennten Ponceaurotgefärbten Proteinfraktionen $(\mathrm{g} / \mathrm{L})$ für Kinder und Erwachsene (Gressner und Thomas 1995)

\begin{tabular}{|c|c|c|c|c|c|}
\hline & Neugeborene & $\begin{array}{l}\text { Säuglinge } \\
\leq 1 \mathrm{Jahr}\end{array}$ & $\begin{array}{l}\text { Kleinkinder } \\
<6 \text { Jahren }\end{array}$ & Schulkinder & Erwachsene \\
\hline Albumine & $32,7-45,3$ & $35,7-51,3$ & $33,1-52,2$ & $40,0-52,5$ & $35,2-50,4$ \\
\hline $\begin{array}{l}\alpha_{1^{-}} \\
\text {Globuline }\end{array}$ & $1,1-2,5$ & $1,3-2,5$ & $0,9-2,9$ & $1,2-2,5$ & $1,3-3,9$ \\
\hline $\begin{array}{l}\alpha_{2^{-}} \\
\text {Globuline }\end{array}$ & $2,6-5,7$ & $3,8-10,8$ & $4,3-9,5$ & $4,3-8,6$ & $5,4-11,3$ \\
\hline$\beta$-Globuline & $2,5-5,6$ & $3,5-7,1$ & $3,5-7,6$ & $4,1-7,9$ & $5,9-12,4$ \\
\hline$\gamma$-Globuline & $3,9-11,0$ & $2,9-11,0$ & $4,5-12,1$ & $5,9-13,7$ & $5,8-15,2$ \\
\hline
\end{tabular}

Fehlermöglichkeit Vielfältige Fehlerquellen beim Selbstgießen von Agarosegelen wie z. B. falsches Einwiegen von Agarosepulver, Verwenden von Agarose mit falscher Elektroendosmose oder zu hohem Wasseranteil, zu kurzes Aufkochen, mechanische Belastung der Agarosemoleküle durch Mischer, ungleichmäßige Gelschicht, falsche Pufferzusammensetzung.

Kommerzielle Systeme schließen diese Fehlerursachen weitgehend aus.

Celluloseacetatfolien müssen durch planes Auflegen („Floaten“) auf die Pufferoberfläche gleichmäßig mit Puffer getränkt werden und sind nur mit Pinzette und Gummihandschuhen zu berühren.

Praktikabilität - Automatisierung - Kosten Es werden von mehreren Firmen Fertiggele und -folien, Färbekits, und automatisierte Elektrophoresesysteme für die klinischen Anwendungen angeboten. Daneben stehen bedienungsfreundliche Densitometer-Steuerungsprogramme und Auswertungsprogramme zur Verfügung. 


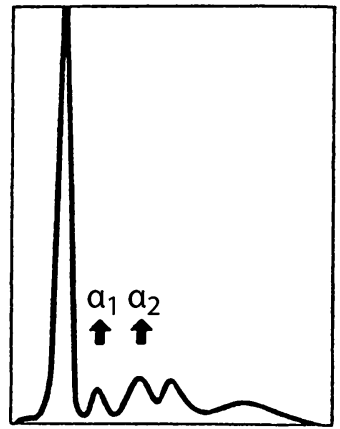

Akute Entzündung

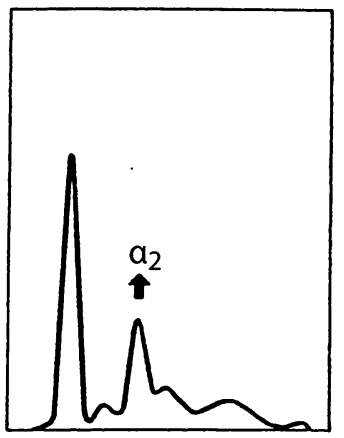

Nephrotisches Syndrom

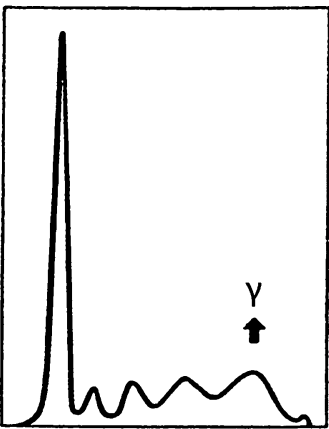

Chronische Entzündung

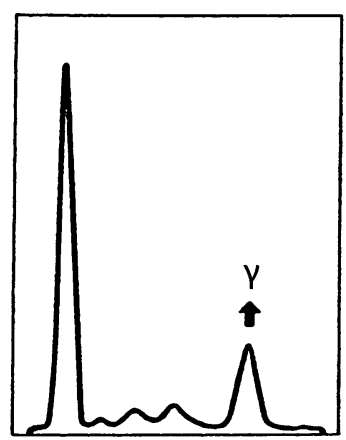

Monoklonale Gammopathie

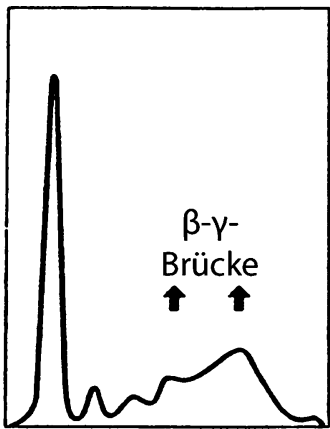

Leberzirrhose

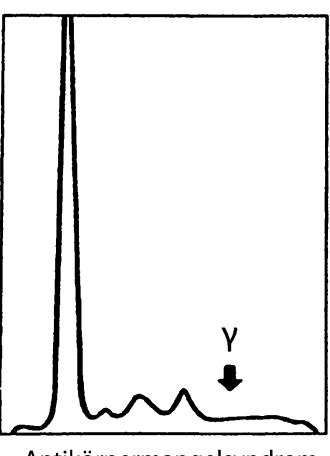

Antikörpermangelsyndrom

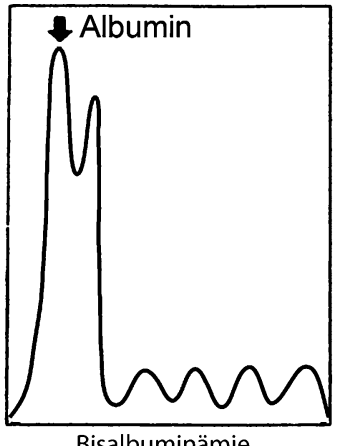

Bisalbuminämie

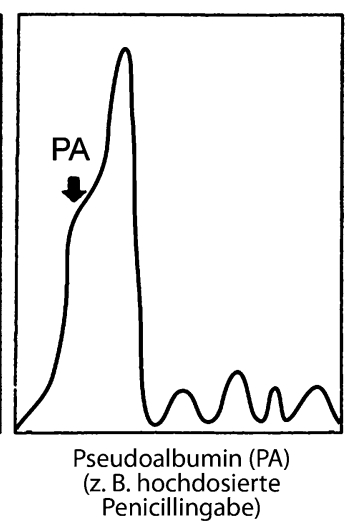

Serumprotein-Elektrophorese, Abb. 1 Typische elektrophoretische Konstellationen bei erworbenen oder genetischen Dysproteinämien. (Modifiziert nach Thomas 1981)

Interpretation Die Serumproteinelektrophorese ist eine wenig sensitive, semiquantitative Methode, die nur starke Veränderungen innerhalb der einzelnen elektrophoretisch trennbaren Fraktionen zu erfassen erlaubt. In manchen Fällen liefert ein ausgewähltes Proteinprofil ergänzende diagnostische Aussagen (Abb. 1).

\section{Literatur}

Grabner W, Bergner D, Wermuth G (1970) Mikrozonenelektrophorese auf Membranfolien. Ärzt Lab 16:193-201

Gressner AM, Thomas L (1995) Proteinstoffwechsel. In: Greiling H, Gressner AM (Hrsg) Lehrbuch der Klinischen Chemie und Pathobiochemie, 3. Aufl. Schattauer, Stuttgart

Thomas L (1981) Serumeiweißelektrophorese. Urban \& Schwarzenberg, München

\section{Serumprotein-Labilitätsreaktionen}

\section{A. M. Gressner und O. A. Gressner}

Synonym(e) Labilitätsreaktionen der Serumproteine; Trübungsteste
Englischer Begriff serum protein flocculation (turbidity) tests

Definition Heute obsolete chemische Fällungsreaktionen der Proteine im Serum durch Zugabe von Salzen oder Säuren zum Nachweis von Verschiebungen des Globulin-Albumin(G/A-)Verhältnisses im Rahmen von akuten und chronischen Entzündungen, Leber-, Lungen-, Nierenerkrankungen und multiplen Myelomen.

Beschreibung Verschiebungen des G/A-Verhältnisses bei chronischen Erkrankungen der genannten Organe und bei multiplem Myelom (Plasmozytom) werden je nach Test durch definierte Zugabe von Quecksilberchlorid ( $\triangleright$ TakataReaktion), einer Thymollösung ( $\triangleright$ Thymol-Trübungstest) oder Aqua bidest ( $\triangleright$ Sia-Waldenström-Test, EuglobulinLysezeit) und damit einsetzender Trübungsreaktion visuell qualitativ nachgewiesen. Eine semiquantitative (Stufen-) Bewertung der Trübung kann vorgenommen werden.

\section{Literatur}

MacLagan NF, Martin NH, Lunnon JB (1952) The mechanism and interrelationships of the flocculation tests. J Clin Pathol 5:1-9 


\section{Server}

O. Colhoun

\section{Englischer Begriff server}

Definition Computer, der in einem Netzwerk seine Dienste anderen Computern (den sog. Clients) zur Verfügung stellt.

Beschreibung In Netzwerken unterscheidet man File-Server zum Speichern von Daten und Application-Server, die Anwendungsprogramme zur Verfügung stellen; ferner werden oft Druck-Server und Fax-Server verwendet. In Weitbereichsnetzen oder einem Verbund von Netzen wie dem Internet werden Server i. d. R. als Mail-Server zum Versenden, Empfangen und Speichern von Emails, Web-Server für die Bereitstellung von Content via Internet sowie als File-Server zum Download von Daten eingesetzt.

Ein Computer, der als Server dient, muss i. d. R. sehr große Datenmengen speichern, verwalten und übertragen. Daher benötigt er eine Hardware-Ausstattung, die auf seine besonderen Aufgaben zugeschnitten ist:

- Hohe Ausfall- und Datensicherheit (redundante Hardware, Spiegeln von Festplatten, USV)

- Schnelle Festplatten hoher Speicherkapazität, häufig als RAID-System ausgeführt

- Großer Arbeitsspeicher

- Leistungsfähige Prozessoren

\section{Severe Acute Respiratory Syndrome Corona Viruses}

- SARS-Corona-Viren

\section{Severinghaus-Elektrode}

- Kohlendioxidpartialdruck

\section{SEWPROF}

$>$ Abwasser-Epidemiologie

\section{Sexualhormon-bindendes Globulin}

M. Bidlingmaier

Synonym(e) SHBG

Englischer Begriff sex hormone-binding globulin; SHBG

Definition Im Blut zirkulierendes Glykoprotein, das - Androgene und $>$ Estrogene mit hoher Spezifität und Affinität bindet und damit deren biologische Aktivität mit reguliert.

Struktur Homodimer aus 2 identischen Ketten, jeweils aus 373 Aminosäureresten. Das Molekül enthält verschiedene Ound N-verknüpfte Glykosilierungen. Das testikulär produzierte androgenbindende Protein (ABP) besitzt bei identischer Aminosäuresequenz ein unterschiedliches Glykosilierungsmuster.

Molmasse $43.700 \mathrm{Da}$ (Monomer).

Synthese - Verteilung - Abbau - Elimination Die Synthese des SHBG erfolgt in der Leber. Eine Vielzahl von Polymorphismen sind im Gen und in der Promotorregion beschrieben. In Zirkulation kommt es spontan zur Dimerisierung über die N-terminalen Abschnitte zweier identischer SHBG-Moleküle. Die Dimerisierung wird durch gebundene Sexualsteroide und zweiwertige Kationen wie Zink und Kalzium befördert.

In Zirkulation bindet SHBG Androgene und Estrogene mit Assoziationskonstanten von $1,5-55 \times 10^{8} \mathrm{M}^{-1}$. Hierbei ist die Affinität der Bindung am höchsten für das $>$ Dihydrotestosteron, gefolgt von Testosteronen ( $\triangleright$ Testosteron), Androstendiol, $\triangleright$ Estradiol und $\triangleright$ Estron. Viele synthetische Sexualsteroide und Gestagene werden ebenfalls an SHBG gebunden. DHEA hat eine schwache Affinität, DHEAS und $>$ Androstendion werden fast nicht gebunden. Die Bindung erfolgt im Verhältnis 1:1, ein SHBG-Dimer trägt also 2 Steroidmoleküle. Die Metabolisierung von SHBG erfolgt in 2 Phasen: Einer raschen initialen Verteilung in den extravaskulären Raum innerhalb weniger Stunden folgen die langsame Degradation und renale Elimination über mehrere Tage.

Halbwertszeit Mehrere Tage.

Pathophysiologie Die hepatische Synthese und Sekretion wird durch endokrine und nicht endokrine Faktoren reguliert, letztere scheinen nach neueren Daten bedeutsamer. Die SHBG- 
Konzentrationen korrelieren negativ mit Körpergewicht, Körperfett sowie speziell dem hepatischen Fett. Erniedrigte SHBGKonzentrationen sind auch mit dem metabolischen Syndrom und dem Auftreten von Typ-2-Diabetes - insbesondere bei der Frau - assoziiert. Androgene inhibieren, Estrogene stimulieren die Synthese und Sekretion. Ferner beeinflussen auch andere Hormone wie Thyroxin, Insulin, IGF-I ( $\triangleright$ Insulin-like growth factor I) und $\triangleright$ Prolaktin die SHBGSynthese. Bei Kindern sind die SHBG-Konzentrationen vor der Pubertät relativ hoch, fallen mit Einsetzen des Wachstumsschubs und der pubertären Reifung ab. Beim Erwachsenen sind die Konzentrationen - bei großer interindividueller Variabilität - bei der Frau tendenziell höher als beim Mann. Aufgrund des starken Estrogeneinflusses finden sich in der Schwangerschaft sowie unter oraler Kontrazeption die höchsten Werte. In der Menopause kommt es zum Abfall der SHBGSpiegel, bei älteren Männern wird hingegen ein Anstieg beobachtet.

Die physiologische und pathophysiologische Bedeutung des SHBG ergibt sich aus der Regulation des freien und damit biologisch aktiven Anteils der Sexualsteroide. Hier kommt ihm zusammen mit vor allem Albumin eine Speicher- und Pufferfunktion zu. SHBG interagiert auch direkt mit Proteinen auf der Membran androgen- und estrogensensitiver Zellen, wobei Mechanismus und Funktion dieser Interaktion noch weitgehend unklar sind. Dauerhaft erhöhte SHBGKonzentrationen finden sich unter Estrogeneinfluss, supprimierte SHBG-Konzentrationen können auf exzessive Androgenexposition hindeuten.

\section{Untersuchungsmaterial Serum.}

Probenstabilität Bei Raumtemperatur 12 Stunden, bei $4{ }^{\circ} \mathrm{C}$ bis 3 Tage, bei $-20^{\circ} \mathrm{C}$ mehrere Monate.

Analytik Immunoassay.

Konventionelle Einheit $\mu \mathrm{g} / \mathrm{mL}$.

Internationale Einheit $\mathrm{nmol} / \mathrm{L}$.

Umrechnungsfaktor zw. konv. u. int. Einheit $1 \mu \mathrm{g} / \mathrm{mL}$ $=10,53 \mathrm{nmol} / \mathrm{L}$.

Referenzbereich - Erwachsene Folgende Angaben können als grobe Orientierung gelten:

- Frauen: $18-144 \mathrm{nmol} / \mathrm{L}$

- Männer: 10-57 nmol/L

Referenzbereich - Kinder Präpubertär ca. 40-190 nmol/L. Pubertätsentwicklung beachten!

\section{Indikation}

- Zur Abschätzung der freien Androgenkonzentration (freier Androgenindex)

- Zustände, bei denen mit exzessiven freien Androgenen gerechnet werden muss

- Therapie mit Sexualhormonen oder Antiandrogenen (Monitoring)

- Verdacht auf Anabolikaabusus

- Störungen der Pubertätsentwicklung

- Verlaufskontrolle der Anorexia nervosa

- Thyreotoxikose

- Aufgrund epidemiologischer Daten ggf. ergänzend zur Abschätzung des Diabetesrisikos

Interpretation Erhöhte Konzentrationen von SHBG u. a. bei:

- Estrogengabe (z. B. Ovulationshemmer, Hormonersatztherapie)

- Hoden- und Ovarialtumoren

- Schwangerschaft

- Männlicher Hypogonadismus

- Anorexia nervosa

- Medikamentengabe (z. B. Antiepileptika)

- Leberzirrhose

Erniedrigte SHBG-Konzentrationen bei:

- Alle Zuständen, die mit einem Androgenexzess einhergehen

- Polyzystische Ovarien

- Hyperprolaktinämie

- Hypothyreose

- Ausgeprägte Adipositas

- Medikamentengabe (z. B. Ketoconazol)

- Glukokortikoidgabe, Cushing-Syndrom

Diagnostische Wertigkeit Insbesondere bei der Verwendung von potenziell störanfälligen Immunoassays zur Messung von $>$ Testosteron bietet die parallele Messung von SHBG eine Möglichkeit zur Abschätzung der freien Androgene. Die Richtigkeit der Abschätzung ist jedoch umstritten.

Supprimierte SHBG-Konzentrationen sind ein starker Hinweis auf einen Androgenexzess.

\section{Literatur}

Bukowski C, Grigg MA, Longcope C (2000) Sex hormone-binding globulin concentration: differences among commercially available methods. Clin Chem 46(9):1415-1416

Selva DM, Hogeveen KN, Innis SM, Hammond GL (2007) Monosaccharide-induced lipogenesis regulates the human hepatic sex hormone-binding globulin gene. J Clin Invest 117(12):3979-3987 
Thaler MA, Seifert-Klauss V, Luppa PB (2015) The biomarker sex hormone-binding globulin - from established applications to emerging trends in clinical medicine. Best Pract Res Clin Endocrinol Metab 29(5):749-760

\section{sFlt-1}

- fms-like tyrosine kinase 1, lösliche

\section{SGOT}

Aspartat-Aminotransaminase

\section{S-G-Qu}

> Szent-Györgyi-Quotient

\section{S-Hb}

• Sulfhämoglobin

\section{SHBG}

- Sexualhormon-bindendes Globulin

\section{Sheddase}

- Disintegrin-Metalloproteinasen

\section{Shewhart-Kontrollkarte}

R.-D. Hilgers, N. Heussen und S. Stanzel

Englischer Begriff Shewhart chart; Shewhart control chart,

Definition Die Shewhart-Kontrollkarte stellt den Zeitverlauf (z. B. in Stunden, Tagen oder Arbeitsschichten) der für die Präzisionskontrolle ermittelten Messwerte dar (s. Abbildung).
Schematische Darstellung einer Shewhart-Kontrollkarte:

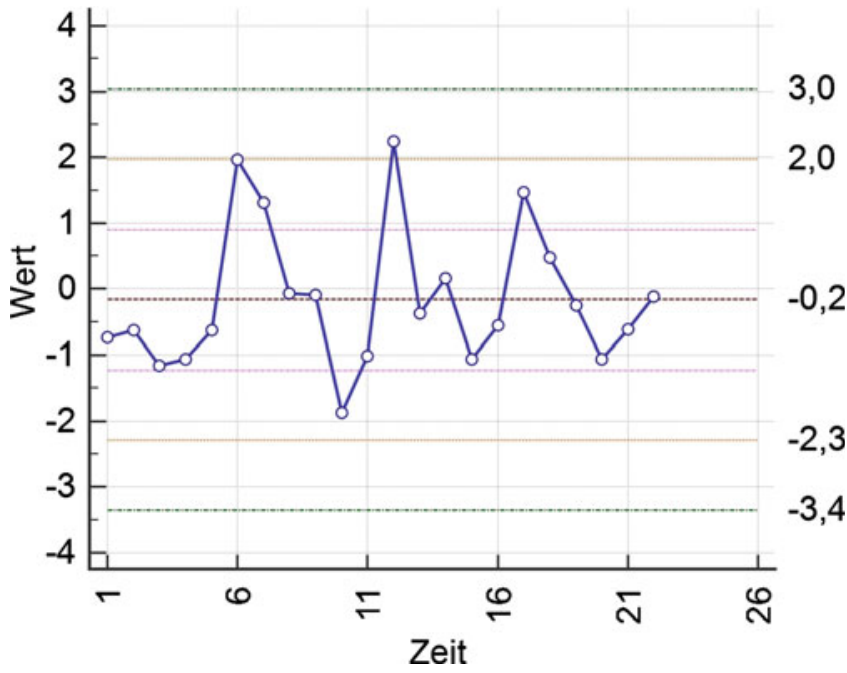

Beschreibung Die Shewhart-Kontrollkarte ist die im Rahmen der $>$ Präzisionskontrolle am häufigsten eingesetzte Kontrollkarte. Die mittlere horizontale Linie dieser grafischen Darstellung fasst die im Zeitverlauf beobachteten Messergebnisse durch den arithmetischen Mittelwert ( $\triangleright$ Mittelwert, arithmetischer) zusammen. Im Allgemeinen werden 4 zusätzliche horizontale Linien als Warn- bzw. Kontrollgrenzen in die Shewhart-Kontrollkarte eingezeichnet. Die Berechnung dieser Warn- und Kontrollgrenzen basiert dabei auf der - Standardabweichung der im Zeitverlauf beobachteten Messwerte. Die untere Warngrenze liegt um die zweifache Standardabweichung unterhalb, die obere Warngrenze um die zweifache Standardabweichung oberhalb der Mittellinie, während die beiden Kontrollgrenzen 3 Standardabweichungen von der Mittellinie entfernt liegen.

\section{Literatur}

Nebel C (1969) Statistische Qualitätskontrolle - das Handbuch der Western-Electric-Company für den Praktiker. Berliner Union, Stuttgart

\section{Shielded twisted pair}

O. Colhoun

Synonym(e) Twisted-Pair-Kabel

Englischer Begriff STP; shielded twisted pair

Definition Netzwerkkabel zur Verbindung von Computern.

Beschreibung Deutsch ,abgeschirmtes verdrilltes Kabelpaar": Das Kabel besteht aus mindestens zwei verdrillten 
Leitungen und ähnelt dem einer Telefonleitung. Beim STPKabel ist jede Ader einzeln abgeschirmt; dies im Gegensatz zum UTP (Unshielded-twisted-pair-Kabel).

\section{Shine- und Lal-Index}

\section{A. M. Gressner und O. A. Gressner}

\section{Synonym(e) S\&L-Index}

Englischer Begriff Shine-Lal index; S\&L index

Definition Der S\&L-Index dient der ätiologischen Differenzierung einer Mikrozytose in Eisen-Mangel und $\beta$-Thalassaemia minor und wird berechnet aus den beiden Erythrozyten-Indizes „mean corpuscular volume“ (MCV) und „mean corpuscular hemoglobin“ (MCH).

Beschreibung Das Blutbild der heterozygoten Thalassaemia minor ist gekennzeichnet durch eine leichte Anämie mit Hämoglobinerniedrigung meist nicht unter $100 \mathrm{~g} / \mathrm{L}(10 \mathrm{~g} / \mathrm{dL})$ bei erniedrigtem MCV $(<80 \mathrm{fL}$, Mikrozytose) und $\mathrm{MCH}$ $(<28 \mathrm{pg})$ ( $\triangleright$ Erythrozyten-Indices). Ein MCV im Referenzbereich (80 und $96 \mathrm{fL}$ ) schließt eine Thalassaemia minor aus. Die diagnostische Abgrenzung der Mikrozytose von einer durch Eisenmangel bedingten Anämie kann durch die Berechnung des S\&L-Index vorgenommen werden, der aus dem Quadrat des MCV multipliziert mit der mittleren korpuskulären Hämoglobinmenge ( $\mathrm{MCH})$, dividiert durch 100, nach folgender Formel berechnet wird: S\&L-Index = $(\mathrm{MCV} \times \mathrm{MCV}) \times(\mathrm{MCH} / \mathrm{100})$. Für Eisenmangelanämie werden eine diagnostische Sensitivität von $100 \%$ und Spezifität von $91 \%$, für $\beta$-Thalassämie diagnostische Sensitivität von $91 \%$ und Spezifität von $100 \%$ berichtet. Mehrere Studien widmen sich dem Vergleich der diagnostischen Kriterien modifizierter Indizes des roten Blutbildes, wie $>$ MentzerIndex, Huber-Herklotz-Index ( $\triangleright$ Huber-Herklotz-Formel), Green-King-Index, England-Fraser-Index, Ricerca-Index, Srivastava u. a., die zu teilweise unterschiedlichen Bewertungen der Leistungsfähigkeit dieser Indizes für die Zuordnung einer mikrozytären Anämie zu $\beta$-Thalassämie oder Fe-Mange kommen.

\section{Literatur}

Bordbar E, Taghipour S, Zucconu BE (2015) Reliability of different $\mathrm{RBC}$ indices and formulas in discriminating between $\beta$-Thalassaemia minor and other microcytic hypochromic cases. Mediterr J Hematol Infect Dis 7(1):e2015022
Niazi M, Tahir M, Raziq F et al (2010) Usefulness of red cell indices in differentiating microcytic hypochromic anemia. Gomal J Med Sci $8(2): 125-129$

Shine I, Lal S (1977) A strategy to detect beta-thalassaemia minor. Lancet 1:692-694

\section{Short Tandem Repeat (STR)}

\section{J. Arnemann}

Synonym(e) Mikrosatelliten; STR

Englischer Begriff short tandem repeat; STR

Definition Mikrosatelliten oder Short Tandem Repeats (STR) definieren kurze, sich hintereinander wiederholende Basenpaarabfolgen in nicht kodierenden Abschnitten der DNA, die aufgrund einer oft variablen Anzahl zur individuellen Typisierung menschlicher DNA eingesetzt werden.

Beschreibung In den nicht kodierenden Abschnitten der genomischen DNA finden sich Abschnitte mit kurzen, sich wiederholenden konstanten Basenpaarabfolgen, wie z. B. $(\mathrm{CA})_{\mathrm{n}}$ oder $(\mathrm{GATA})_{\mathrm{n}}$. Aufgrund der zahlreichen Wiederholungen in der Einzelanordnung, aber auch in der Verteilung im Genom werden diese Abschnitte als repetitive Elemente oder auch Mikrosatelliten bezeichnet. Der Begriff Mikrosatellit ist darauf zurückzuführen, dass in der früher durchgeführten DNA-Gradientenzentrifugation diese repetitiven Sequenzen oftmals als eigenständiger, kleiner Satellit dargestellt werden konnten.

In der aktuellen Diagnostik werden STR durch PCR mit Primern aus den flankierenden DNA-Sequenzen amplifiziert und die Produkte entweder gelelektrophoretisch oder meist fluoreszenzmarkiert mittels Kapillarelektrophorese aufgetrennt und dokumentiert. In der Vaterschaftsdiagnostik, aber auch in der Forensik werden speziell festgelegte STR als Basis des DNA-Fingerprints eingesetzt, wobei die ermittelten Fragmentgrößen in Datenbanken, z. B. des Bundeskriminalamtes, abgespeichert werden und weltweit aufgrund der angepassten Laborstandards auch mit den Mustern anderer Individuen abgeglichen werden können.

\section{Literatur}

Fregeau CL, Fourney RM (1993) DNA typing with fluorescently tagged short tandem repeats: a sensitive and accurate approach to human identification. BioTechniques 15:100-119 


\section{SHOX2-Test}

A. M. Gressner und O. A. Gressner

Synonym(e) SOX2-Gen-Test

Englischer Begriff SOX2(-gene)-test/assay

Definition Ein mittels PCR in der bronchoalveolären Spülflüssigkeit bzw. im Bronchialaspirat geführter Nachweis von methylierter SHOX2-DNA, die als spezifische diagnostische Kenngröße für Lungenkarzinom gilt.

Beschreibung In der Lungenspülflüssigkeit wird die isolierte DNA nach Bisulfitkonvertierung und Amplifikation des methylierten SHOX2-Gens mittels PCR nachgewiesen. Ein positives Testergebnis besitzt im Mittel eine diagnostische Sensitivität ( Sensitivität, diagnostische) von bis zu $78 \%$ und diagnostische Spezifität ( $\triangleright$ Spezifität, diagnostische) von $95 \%$ für maligne Lungentumoren, wobei für die einzelnen Tumortypen geringe Unterschiede bestehen (am höchsten für kleinzelliges Lungenkarzinom und Plattenepithelkarzinom). Ein positives Ergebnis ( $\triangleright$ Testergebnis, richtig-positives) verlangt weitere Bestätigungsdiagnostik.

\section{Literatur}

Ferone G, Song JY, Sutherland KD (2016) Sox2 is the determining oncogenic switch in promoting lung squamous cell carcinoma. Cancer Cell 30(4):519-532

Schmidt B, Lieberberg V, Dietrich D et al (2010) SHOX2 DNA methylation is a biomarker for the diagnosis of lung cancer based on bronchial aspirates. BMC Cancer 10:600

\section{Shunt-Bilirubin}

Bilirubin

SI

$>$ SI-Einheiten

- Silicium

\section{Sia-Ib-Antigen}

K. Kleesiek, C. Götting, J. Diekmann, J. Dreier und M. Schmidt

Synonym(e) Gd-Antigen

Englischer Begriff sialo-linear-branched antigen

Definition Die antigene Determinante stellt eine NeuNAcAlpha2-3Gal-Domäne dar, wie sie in Sialyllactose, sLewis $(\mathrm{Le})(\mathrm{x})$ und sLe(a), Sialyllactosamin, Sialyl-Fucosyllactose vorkommt. Diese sialysierten Kohlehydrate kommen auf adulten und neonatalen Erythrozyten, kernhaltige Zellen und in löslichen krebsassoziierten Mucinen vor. Sie werden von Kälteautoantikörpern (๖ Kälteagglutinin; \ Kälteautoantikörper) erkannt. Durch Sialidasebehandlung werden die Antigene zerstört. Zu den sialysierten Kohlenhydratantigenen, die durch Kälteagglutinine erkannt werden, gehören Sia-11- (früher Vo) und Sia-b1-Antigene (früher F1).

\section{Literatur}

Gallart T, Roelcke D, Blay M, Pereira A, Martínez A, Massó O, Viñas O, Cid M, Esparza J, Molina R, Barceló J (1997) Anti-Sia-lb (anti-Gd) cold agglutinins bind the domain NeuNAc alpha2-3Gal in sialyl Lewis(x), sialyl Lewis(a), and related carbohydrates on nucleated cells and in soluble cancer-associated mucins. Blood 90:1576-1587

König AL, Kreft H, Hengge U, Braun RW, Roelcke D (1988) Coexisting anti-I and anti-F1/Gd cold agglutinins in infections by Mycoplasma pneumoniae. Vox Sang 55:176-180

\section{Sialidase}

- Neuraminidase

\section{Sialinsäure, lipidgebundene}

A. M. Gressner und O. A. Gressner

Synonym(e) LASA; Lipid-assoziierte Sialinsäure; LSA; $N$-Acetylneuraminsäure, lipidgebundene

Englischer Begriff lipid-bound sialic acid; lipid-associated sialic acid; lipid-associated sialate; lipid-bound neuraminic acid 
Definition Glykosidisch gebundener, endständiger Bestandteil von Glykolipiden (und Glykoproteinen), die u. a. als Komponenten der Zellmembran wesentliche zelluläre Funktionen übernehmen und deren Serumkonzentration bei malignen (und einigen benignen) Erkrankungen oftmals signifikant erhöht ist.

Beschreibung Unter den Sialinsäuren ist die $N$-Acetylneuraminsäure am weitesten verbreitet. Sie ist endständiger Bestandteil von Glykolipiden und Glykoproteinen (> Glykoproteine), u. a. auf der Zellmembran und reguliert Zell-Zell-, Zell-Virus- oder Zell-Wirkstoff-Interaktionen. Neuraminidasen führen zur hydrolytischen Abspaltung. Konzentrationserhöhungen im Serum finden sich bei Mamma(63\%), gastroenterologischen $(65 \%)$, pulmonalen $(79 \%)$ und ovariellen (94\%) Neoplasien. Leukämien (86 \%), Lymphome (87\%), Melanome (84\%), Sarkome (97\%) und Hodgkin-Lymphom (91\%) weisen ebenfalls erhöhte LSAKonzentrationen auf, die sich jedoch auch bei benignen Erkrankungen, z. B. akuten Entzündungsreaktionen, finden. Spezifität ( $\triangleright$ Spezifität, diagnostische) und/oder Sensitivität ( $>$ Sensitivität, diagnostische) als alleiniger Tumormarker sind unzureichend, jedoch wurden Konzentrationsbestimmungen früher zum Nachweis einer therapeutischen Ansprechbarkeit empfohlen (Abfall unter Therapie). Heute ist LSA als Tumormarker nicht mehr im Gebrauch. Die Bestimmung erfolgt nach Extraktion der Sialo-Lipid-Fraktion des Serums oder Plasmas mit organischem Lösungsmittel und Fällung mit Phosphorwolframsäure photometrisch mit der > Bial-Probe: Sialinsäure bildet beim Erhitzen mit Salzsäure und Resorcinol bzw. Orcinol sowie $\mathrm{Fe}^{3+}$-Ionen einen violetten, photometrisch bei $580 \mathrm{~nm}$ quantifizierbaren Farbstoff.

\section{Literatur}

Dnistrian AM, Schwartz MK (1983) Lipid-bound sialic acid as a tumor marker. Ann Clin Lab Sci 13:137-142

\section{Sialinsäure-defizientes Apolipoprotein J}

$>$ Apolipoprotein J, Sialinsäure-defizientes

\section{Sialinsäure-defizientes Transferrin}

- Carbohydrate-deficient transferrin

\section{Sialinsäuren, freie und gebundene}

\section{F. Bürger}

Synonym(e) N-Acetylneuraminsäure

Englischer Begriff sialic acid; N-acetyl-neuraminic acid

Definition Die Sialinsäure (griech.: sialon für Speichel) ist ein Oberbegriff für N- bzw. O-acylierte Neuraminsäurederivate. Die im Menschen überwiegend vorkommende N-Acetylneuraminsäure (NANA) wird häufig als Sialinsäure bezeichnet.

Struktur 5-Acetamido-3,5-didesoxy-D-glycero-D-galactononulosonsäure, $\mathrm{C}_{11} \mathrm{H}_{19} \mathrm{NO}_{9}$. Strukturformel:<smiles>CC(=O)N[C@H]1[C@@H](O)CC(O)(C(=O)O)O[C@H]1[C@H](O)[C@H](O)CO</smiles>

Molmasse 309,27.

Synthese - Verteilung - Abbau - Elimination NANA wird aus N-Acetyl-Mannosamin und Phosphoenolpyruvat in einer Kondensationsreaktion unter Wasserabspaltung gebildet. Nur ein kleiner Teil liegt als freie NANA in Geweben und Körperflüssigkeiten vor, der Hauptteil gebunden an Oligosacchariden von Glykoproteinen oder Glykolipiden. Glykolipide kommen vor allem in Membranen und Oberflächen von Nervenzellen vor. Zusätzlich ist die NANA auch Bestandteil in den Oligosacchariden der Muttermilch. Die endständige NANA von Glykokonjugaten wird in Lysosomen durch saure Neuraminidasen abgespalten. Die frei gewordene NANA kann dann entweder wiederverwendet werden oder im Zytoplasma durch N-Acetylneuraminat-Lyasen abgebaut werden.

Pathophysiologie Die endständige NANA der Oligosaccharidketten von Glykoproteinen schützt letztere vor dem Abbau durch Proteasen und ist somit für deren Stabilität gegenüber Proteolyse und Denaturierung verantwortlich. Sie spielt auch eine Rolle bei Zell-Zell-Interaktionen, beim Transport positiv geladener Stoffe aufgrund ihrer negativen Ladung und bei Antigendeterminanten (z. B. Blutgruppendeterminanten).

Defekte im Abbau (1.), Transport (2.) oder FeedbackHemmung bei der Synthese (3.) von NANA führen zu lysosomalen Speichererkrankungen: 
1. Sialidose und Galaktosialidose. Die saure Neuraminidase bildet zusammen mit Cathepsin A und der $\beta$-Galaktosidase einen Enzymkomplex. Ein Defekt der sauren Neuraminidase (Sialidose) oder von Cathepsin A (Galaktosialidose) führt zu einer abnormen Speicherung von gebundener NANA in den Lysosomen verschiedener Organe und in Körperflüssigkeiten.

2. Infantile Sialinsäurespeichererkrankung (ISSD) und M. Salla. Defekt des „Anion and Sugar"-Transporters (AST), der für den Eflux von NANA aus den Lysosomen verantwortlich ist, führt zu einer abnormen Speicherung von freier NANA in Lysosomen verschiedener Organe und in Körperflüssigkeiten.

3. Sialurie. Defekt bei der Hemmung der UDP-GlcNAc-2Epimerase durch CMP-Neu5Ac führt zu einer unkontrollierten Synthese von NANA im Zytosol.

\section{Untersuchungsmaterial}

- Spontanurin, Morgenurin oder 24-Stunden-Sammelurin

- Hautfibroblasten

- Zellfreies Fruchtwasser

\section{Probenstabilität}

- Urin: bei Raumtemperatur (RT) $<5$ Tage; bei $4{ }^{\circ} \mathrm{C}$ 4 Wochen, bei $-20^{\circ} \mathrm{C}$ ca. 6 Monate

- Fibroblasten: pelletierte Zellen bei $-20^{\circ} \mathrm{C}$ ca. 6 Monate

- Zellfreies Fruchtwasser: bei RT: $<5$ Tage, bei $4{ }^{\circ} \mathrm{C}$ 4 Wochen, bei $-20^{\circ} \mathrm{C}$ ca. 6 Monate

\section{Präanalytik}

- Urin: Konservierung mit 3-6 Tropfen Dichlormethan pro $10 \mathrm{~mL}$ Urin, Versand bei Raumtemperatur oder ohne Konservierung Versand gefroren auf Trockeneis.

- Fibroblasten: mit Medium aufgefüllt; Versand bei RT innerhalb von 24 Stunden. Hautbiopsie: in steriler $0,9 \%$ $\mathrm{NaCl}$-Lösung, Versand bei RT innerhalb von 24 Stunden.

- Zellfreies Fruchtwasser: Versand bei RT innerhalb von 24 Stunden.

Analytik Photometrischer Nachweis der NANA durch Komplexbildung mit Thiobarbitursäure. Alternative Methoden sind HPLC und NMR-Spektroskopie.

\section{Internationale Einheit}

- Urin: $\mathrm{nmol} / \mu \mathrm{mol}$ Kreatinin

- Fibroblasten: $\mathrm{nmol} / \mathrm{mg}$ Protein

- Zellfreies Fruchtwasser: nmol/ml

Referenzbereich - Erwachsene Labor- und altersabhängig. Urin: Referenzwerte des Stoffwechsellabors Heidelberg 2016:

\begin{tabular}{|c|c|c|}
\hline \multirow[b]{2}{*}{ Alter } & \multicolumn{2}{|c|}{ Norm (mmol NANA/mol Kreatinin) } \\
\hline & Gebundene NANA & Freie NANA \\
\hline 6-199 Jahre & $11,7-29,4$ & $12,0-31,0$ \\
\hline
\end{tabular}

Referenzbereich - Kinder Labor- und altersabhängig. Urin: Referenzwerte des Stoffwechsellabors Heidelberg 2016:

\begin{tabular}{l|ll}
$\begin{array}{l}\text { Alter } \\
0-30\end{array}$ & $\begin{array}{l}\text { Norm (mmol NANA/mol Kreatinin) } \\
\text { Gebundene NANA }\end{array}$ & Freie NANA \\
\hline $\begin{array}{l}\text { Tage } \\
\text { Tage }\end{array}$ & $75,2-198,3$ & $72,5-174,7$ \\
\hline $\begin{array}{l}1-<2 \\
\text { Jahre }\end{array}$ & $39,0-116,8$ & $41,0-99,8$ \\
\hline 2-5 Jahre & 19,8-48,6 & $23,4-83,5$ \\
\hline 5 Jahre & S. Referenzbereich - Erwachsene & $\begin{array}{l}\text { S. Referenzbereich } \\
\text { - Erwachsene }\end{array}$ \\
\hline
\end{tabular}

\section{Indikation}

- Verdacht auf Sialidose, Galaktosialidose, Sialinsäurespeichererkrankung, M. Salla, Sialurie, Mukolipidose II/III

- Ausschluss GM1-Gangliosidose bei unklarem Oligosaccharid-Dünnschichtmuster

\section{Interpretation Urin:}

Betrachtet werden zum einen die Ausscheidung von freier und gebundener NANA für sich sowie und zum anderen der Faktor von gebundener zu freier NANA. Sind die gebundene NANA erhöht und der Faktor $>2,0$, ist an folgende Erkrankungen zu denken:

- Sialidose

- Galaktosialidose

- Mukolipidose Typ II/III

Sind die freie NANA erhöht und der Faktor $<0,5$, ist an folgende Erkrankungen zu denken:

- Infantile Sialinspeichererkrankung (freie NANA ca. 10-fach erhöht)

- Salla-Erkrankung (freie NANA ca. 1,5-2,5-fach erhöht)

- Sialurie (freie NANA ca. 100-fach erhöht)

Diagnostische Wertigkeit Urin - insbesondere Morgenurin und 24-Stunden-Sammelurin - ist bei der Fragestellung einer infantilen Sialinsäurespeichererkrankung, M. Salla und Sialurie dem Material Fibroblasten zu bevorzugen, da letzteres auch falsch negative Werte ergeben kann. Bei auffälligem Urinbefund und negativem Fibroblastenbefund sollte immer die Molekulargenetik angeschlossen werden. 


\section{Literatur}

Janas T, Janas T (2011) Membrane oligo- and polysialic acids. Biochim Biophys Acta 1808:2923-2932

Wang B, Brand-Miller J (2003) The role and potential of sialic acid in human nutrition. Eur J Clin Nutr 57:1351-1369

Warren L (1959) The thiobarbituric acid assay of sialic acids. J Biol Chem 234(8):1971-1975

\section{Sialoadhesin}

$>$ Siglec-1

\section{Sia-Waldenström-Test}

\section{A. M. Gressner und O. A. Gressner}

\section{Synonym(e) Euglobulin-Test}

\section{Englischer Begriff Sia-test}

Definition Heute obsoleter Suchtest auf hochmolekulare Paraproteine im Serum, die im elektrolytarmen Wasser zur Präzipitation gebracht werden.

Beschreibung Bei dem von R.H. Sia (1895-1970) und Jan Waldenström (1906-1996) 1924 entwickelten Test lässt man in einem Reagenzglas zu Aqua bidest (!) 1-2 Tropfen des zu untersuchenden Serums hineintropfen, wobei sich bei positivem Ergebnis ein deutliches weißes, schlierenförmig und schnell absinkendes Präzipitat unter leichter Trübung des Wassers bildet („Sia“ $=$,Serum in Aqua“). Schlierenbildung ohne Eintrübung des Wassers bedeutet negatives Ergebnis ( $\triangleright$ Testergebnis, richtig-negatives). Da der Test ( $\triangleright$ Test, diagnostischer) weder spezifisch noch empfindlich ist, hat er seine Bedeutung als Suchtest bei Verdacht auf Makroglobulinämie Waldenström (IgM-Plasmozytom) verloren und wird heute nicht mehr eingesetzt.

\section{Literatur}

Hallmann L (1980) Klinische Chemie und Mikroskopie, 11. Aufl. Georg Thieme Verlag, Stuttgart/New York

\section{Sichelzelle}

\section{H. Baum}

Englischer Begriff sickle cell
Definition Morphologisch sichelförmiger Erythrozyt ( $\triangleright$ Erythrozyten) bei der Sichelzellanämie.

In der folgenden Abbildung ist eine Sichelzelle dargestellt (Pfeil; 1000×, May-Giemsa-Grünwald-Färbung):

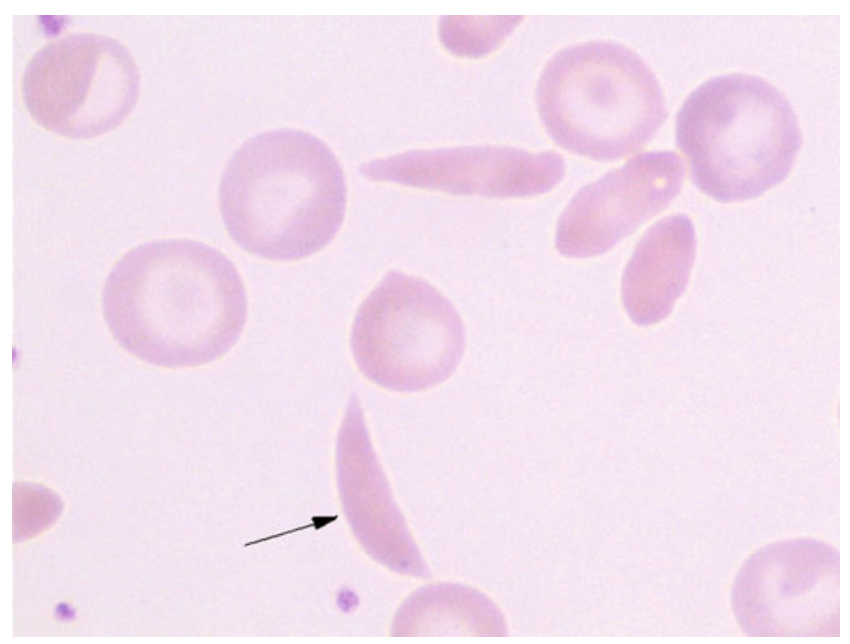

Beschreibung Der Nachweis von Sichelzellen im $>$ Blutausstrich ist ein spezieller Hinweis auf das Vorliegen einer Sichelzellanämie. Die Sichelzellanämie ist eine angeborene, autosomal dominant vererbte hämolytische Anämie, wobei die $\beta$-Kette des Hämoglobins den Strukturdefekt $\beta 6$ Glu $\rightarrow$ Val aufweist (Sichelzellhämoglobin). Unter Sauerstoffentzug zeigt $\mathrm{HbS}$ eine Aggregationsneigung, wobei die Erythrozyten dann die typische Sichelform annehmen. Der Nachweis der Sichelzellen gelingt bei heterozygoten Merkmalsträgern häufig erst bei Auswertung eines unter Sauerstoffabschluss angefertigten Blutausstrichs, wie nachfolgende Abbildung zeigt $(1000 \times$, Phasenkontrastaufnahme):

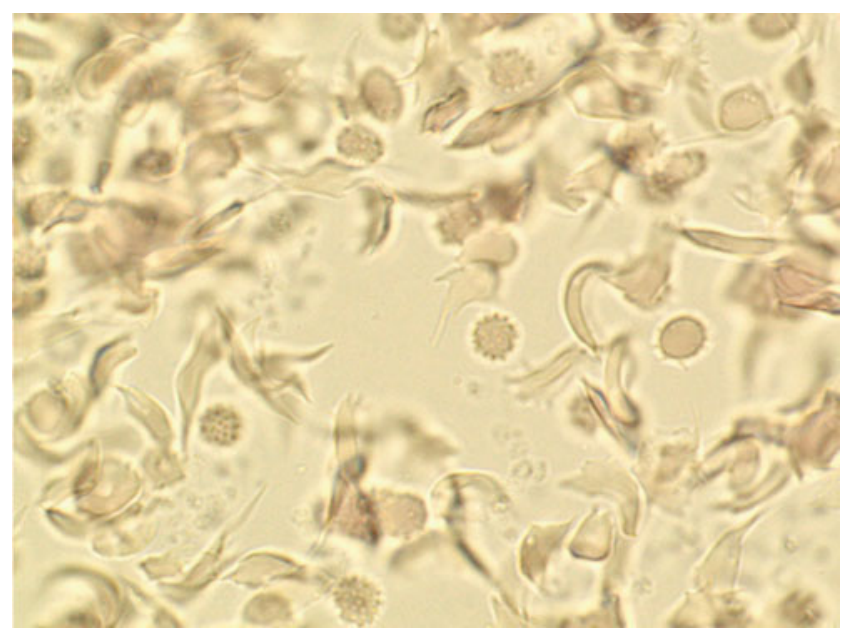

Neben dem direkten Nachweis der Sichelzellen im Blutausstrich kann das mutierte Hämoglobin $\mathrm{S}$ in der $>$ Hämoglobinelektrophorese oder auch mithilfe einer HPLC ( $\triangleright$ Hochleistungs-Flüssigkeitschromatographie) nachgewiesen werden. 


\section{Literatur}

Huber H, Nachbaur D, Pohl P, Pastner D (1991) Diagnose und Differentialdiagnose hämolytischer Anämien - Hämoglobin S. In: Huber H, Löffler H, Pastner D (Hrsg) Diagnostische Hämatologie. Springer, Berlin/Heidelberg/New York, S 49-54

\section{Sicherheitsbehälter}

W. G. Guder

Synonym(e) Entsorgungsbox für Nadeln und andere scharfe und infektiöse Gegenstände

Englischer Begriff sharps container; sharps disposal box; safety-box

Definition Behälter, die eine sichere Entsorgung von Nadeln und anderen scharfen Gegenständen (Lanzetten, Injektionskanülen, aber auch infektiös verunreinigten Haltern, Spritzen und Röhrchen) erlauben.

Beschreibung Sicherheitsbehälter sind für die Entsorgung von verletzenden und infektiösen Materialien aus dem medizinischen Bereich vorgeschrieben. Diese müssen einen leichten Einwurf erlauben, verschließbar sein und eine nicht penetrierbare Wand haben, sodass die darin gesammelten Gegenstände sicher entsorgt werden können.

\section{Literatur}

Von Meyer A, Cadamuro J, Streichert T, Gurr E, Fiedler GM, Leichtle A, Petersmann A, Pick K-H, Orth M, Riesch L, Sonntag O, Schmitt Y, WiegelB, Töpfer G, Guder WG (2017) Standard - Arbeitsanleitung zur peripher venösen Blutentnahme für die laboratoriumsmedizinische Diagnostik. J Lab Med 41:333-340

\section{Sicherheitsnadeln}

- Nadelschutzkappen

\section{Sicherheitszeichen}

- Gefahrstoffpiktogramme

\section{SID}

Säure-Basen-Modell nach Stewart

\section{Sid-Antigen}

$>$ Tamm-Horsfall-Protein

\section{Sideroblast}

H. Baum

\section{Englischer Begriff sideroblast}

Definition Normoblast mit in der Berlinerblau-Färbung ( $\triangleright$ Eisenfärbung) nachweisbaren eisenhaltigen Granula.

Beschreibung Sideroblasten sind reife Erythroblasten ( $\triangleright$ Normoblast), bei denen mit o. g. Färbung wenige (1-4) blaue Granula darstellbar sind. Dabei handelt es sich um nicht an \ Hämoglobin gebundene Eiseneinlagerungen. Der Anteil der Sideroblasten im Knochenmark ist stark von der Eisenkonzentration im Serum abhängig. Normalerweise sind 20-40 \% der Normoblasten im Knochenmark Sideroblasten. Verminderungen sind auf einen Eisenmangel zurückzuführen, Vermehrungen sind ein Hinweis auf eine Eisenverwertungsstörung.

\section{Literatur}

Enne W (1993) Zellen der Erythropoese. In: Begemann H, Rastetter J (Hrsg) Klinische Hämatologie, 4. Aufl. Georg Thieme Verlag, Stuttgart, S 36-37

\section{Siderocalin}

\ Neutrophilen-Gelatinase-assoziiertes Lipocalin

\section{Siderophagen}

H. Baum

Synonym(e) Erythrosiderophage

Englischer Begriff siderophage

Definition Aktivierter Makrophage, der Hämosiderin aus zerfallenen oder phagozytierten Erythrozyten enthält. 
Beschreibung Siderophagen sind aktivierte gewebeständige > Makrophagen, die aus > Erythrozyten stammendes > Hämosiderin enthalten. Sie sind ein Hinweis auf eine schon längere Zeit zurückliegende Blutung in ein Gewebe oder eine Körperhöhle. Häufig sind jedoch in den Siderophagen auch Erythrozyten oder Erythrozytenfragmente nachweisbar. Diese Makrophagen werden dann als Erythrosiderophagen bezeichnet. Nachgewiesen werden kann das intrazelluläre Hämosiderin mit der $\triangleright$ Berlinerblau-Reaktion.

Die Abbildung zeigt Erythrosiderophagen in einer Pleuraflüssigkeit (1000×, May-Giemsa-Grünwald-Färbung):

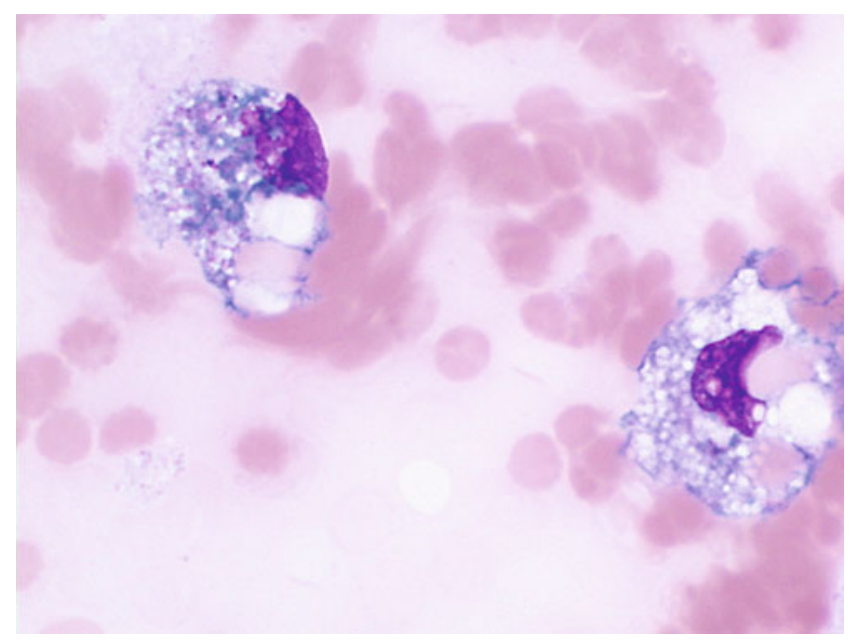

\section{Siderophilin}

$\checkmark$ Transferrin

\section{Siderosom}

> Pappenheim-Körper

\section{Siderozyten}

H. Baum

\section{Englischer Begriff siderocyte}

Definition Erythrozyten mit in der Berlinerblau-Reaktion nachweisbaren eisenhaltigen Granula.
Die Abbildung zeigt 2 Siderozyten (Pfeile) im peripheren Blut $(1000 \times$, Berlinerblau-Färbung):

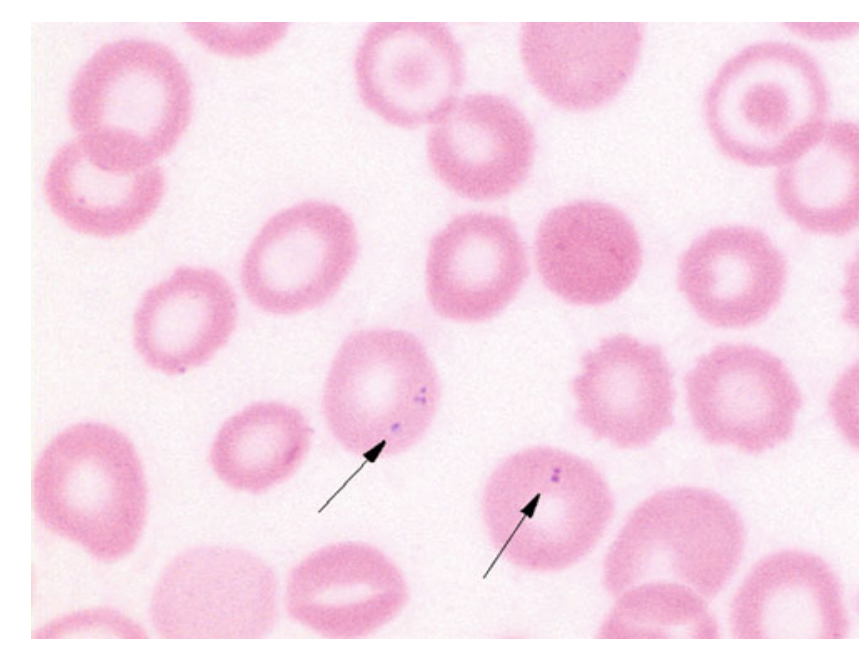

Beschreibung Siderozyten sind $>$ Erythrozyten, in denen mit der $>$ Berlinerblau-Reaktion meist 1-4 kleine Granula ( $\triangleright$ Pappenheim-Körper) nachweisbar sind. Es handelt sich dabei um nicht an $>$ Hämoglobin gebundenes $>$ Eisen (Siderosome). Der Nachweis einer Vermehrung der Siderozyten im peripheren Blut $>3$ \% deutet auf eine Eisenverwertungsstörung hin und kann vor allem bei Alkoholikern, schweren Infekten, nach Milzexstirpation und bei einer refraktären Anämie mit Ringsideroblasten (RARS) gefunden werden.

\section{Literatur}

Enne W (1993) Zellen der Erythropoese. In: Begemann H, Rastetter J (Hrsg) Klinische Hämatologie, 4. Aufl. Georg Thieme Verlag, Stuttgart, S 36-37

\section{Siedepunktserhöhung}

T. Arndt

Synonym(e) Ebullioskopie

Englischer Begriff boiling point elevation; ebulioscopy

Definition In Abhängigkeit von der Konzentration der gelösten Stoffe in einer Lösung wird deren Siedepunkt gegenüber jenem des reinen Lösungsmittels erhöht (z. B. um $0,51^{\circ} \mathrm{C}$ je 1 mol osmotisch wirksamer Substanz in $1 \mathrm{~kg}$ reinem Wasser). 
Beschreibung Bei vollständig dissoziierten Substanzen in einer verdünnten Lösung hängt die Siedepunktserhöhung allein von der $>$ Molalität des Gelösten und nicht von dessen chemischer Natur ab. Sie ist also ein Maß für die Molalität einer Lösung. Verfahren zur Ermittlung der Molalität einer Lösung über die Bestimmung der Siedepunktserhöhung werden unter dem Begriff Ebullioskopie zusammengefasst. Im Vergleich zur Kryoskopie ( $\triangleright$ Gefrierpunktserniedrigung) oder $\triangleright$ Osmometrie hat die Ebullioskopie im klinischchemischen Labor keine Bedeutung.

Die Ebullioskopie kann genutzt werden, um aus bekannten Einwaagen einer Substanz in eine definierte Menge Lösungsmittel die Molmasse ( $\triangleright$ Masse, molare) der Substanz zu ermitteln.

\section{Literatur}

Näser KH, Peschel G (1986) Physikalisch-chemische Meßmethoden. Deutscher Verlag für Grundstoffindustrie, Leipzig

\section{SI-Einheiten}

\section{Vidal und W.-R. Külpmann}

Synonym(e) Internationales Einheitensystem; SI; SI-System; Système international d'unités

\section{Englischer Begriff SI units}

Definition Das von der Generalkonferenz für Maße und Gewichte (Conférence Générale des Poids et Mesures, CGPM) angenommene und empfohlene kohärente Einheitensystem.

Beschreibung Aus den 7 Basiseinheiten (Tab. 1) werden alle anderen Einheiten des SI-Systems abgeleitet.

Bei abgeleiteten, kohärenten SI-Einheiten tritt kein von 1 verschiedener Umrechnungsfaktor auf. Die folgende Tabelle fasst abgeleitete kohärente Messgrößen und -einheiten (Auswahl) zusammen:

\begin{tabular}{l|l|l|} 
Messgröße & $\begin{array}{l}\text { Name der } \\
\text { Maßeinheit }\end{array}$ & $\begin{array}{l}\text { Symbol der } \\
\text { Maßeinheit }\end{array}$ \\
\hline Fläche & Quadratmeter & $\mathrm{m}^{2}$ \\
\hline Volumen & Kubikmeter & $\mathrm{m}^{3}$ \\
\hline Stoffmengenkonzentration & Mol/Kubikmeter & $\mathrm{mol} / \mathrm{m}^{3}$
\end{tabular}

Für bestimmte abgeleitete kohärente Einheiten werden eigene Namen benutzt. Die folgende Tabelle fasst abgeleitete
SI-Einheiten, Tab. 1 Basiseinheiten und deren Definition

\begin{tabular}{|c|c|c|c|}
\hline Basisgröße & Basiseinheit & Symbol & Definition \\
\hline Länge & Meter & $\mathrm{m}$ & $\begin{array}{l}\text { Ein Meter: Das } \\
1.650 .763,73-F a c h e ~ d e r \\
\text { Wellenlänge der von } \\
\text { Atomen des Nuklids }{ }^{86} \mathrm{Kr} \\
\text { beim Übergang vom } \\
\text { Zustand } 5 \mathrm{~d} 5 \text { zum Zustand } \\
\text { 2p10 ausgesandten, sich im } \\
\text { Vakuum ausbreitenden } \\
\text { Strahlung. }\end{array}$ \\
\hline Masse & Kilogramm & $\mathrm{kg}$ & $\begin{array}{l}\text { Ein Kilogramm: Die Masse } \\
\text { des Internationalen } \\
\text { Kilogrammprototyps. }\end{array}$ \\
\hline Zeit & Sekunde & $\mathrm{s}$ & $\begin{array}{l}\text { Eine Sekunde: Das } \\
\text { 9.192.631.770-Fache der } \\
\text { Periodendauer der dem } \\
\text { Übergang zwischen den } \\
\text { beiden } \\
\text { Hyperfeinstrukturniveaus } \\
\text { des Grundzustandes von } \\
\text { Atomen des Nuklids }{ }^{133} \mathrm{Cs} \\
\text { entsprechenden Strahlung. }\end{array}$ \\
\hline $\begin{array}{l}\text { Elektrische } \\
\text { Stromstärke }\end{array}$ & Ampère & A & $\begin{array}{l}\text { Ein Ampère: Die Stärke } \\
\text { eines zeitlich } \\
\text { unveränderlichen } \\
\text { elektrischen Stromes, der, } \\
\text { durch } 2 \text { im Vakuum parallel } \\
\text { im Abstand } 1 \text { Meter } \\
\text { voneinander angeordnete, } \\
\text { geradlinige, unendlich lange } \\
\text { Leiter von vernachlässigbar } \\
\text { kleinem, kreisförmigem } \\
\text { Querschnitt fließend, } \\
\text { zwischen diesen Leitern je } \\
1 \text { Meter Leiterlänge die } \\
\text { Kraft } 2 \times 10^{-7} \text { Newton } \\
\text { hervorrufen würde. }\end{array}$ \\
\hline $\begin{array}{l}\text { Thermodynamische } \\
\text { Temperatur }\end{array}$ & Kelvin & K & $\begin{array}{l}\text { Ein Kelvin: Der 273,16te } \\
\text { Teil der thermodynamischen } \\
\text { Temperatur des } \\
\text { Tripelpunktes des Wassers. }\end{array}$ \\
\hline Lichtstärke & Candela & $\mathrm{cd}$ & $\begin{array}{l}\text { Ein Candela: Die } \\
\text { Lichtstärke, mit der } \\
\text { 1/600.000 Quadratmeter der } \\
\text { Oberfläche eines Schwarzen } \\
\text { Strahlers bei der Temperatur } \\
\text { des beim Druck } \\
\text { 101.325 Newton durch } \\
\text { Quadratmeter erstarrenden } \\
\text { Platins senkrecht zu seiner } \\
\text { Oberfläche leuchtet. }\end{array}$ \\
\hline Stoffmenge & Mol & $\mathrm{mol}$ & $\begin{array}{l}\text { Ein Mol: Die Stoffmenge } \\
\text { eines Systems, das aus } \\
\text { ebenso viel Einzelteilchen } \\
\text { besteht, wie Atome in } \\
12 / 1000 \text { Kilogramm des } \\
\text { Kohlenstoffnuklids }{ }^{12} \mathrm{C} \\
\text { enthalten sind. Bei } \\
\text { Verwendung des Mols } \\
\text { müssen die Einzelteilchen } \\
\text { des Systems spezifiziert sein } \\
\text { und können Atome, } \\
\text { Moleküle, Ionen, } \\
\text { Elektronen sowie andere } \\
\text { Teilchen oder Gruppen } \\
\text { solcher Teilchen genau } \\
\text { angegebener } \\
\text { Zusammensetzung sein. Ein } \\
\text { Mol enthält stets } \\
6,0221367 \times 10^{23} \text { Teilchen } \\
\text { (Avogadro-Konstante). }\end{array}$ \\
\hline
\end{tabular}


kohärente SI-Messgrößen und -einheiten mit eigenem Namen (Auswahl) zusammen:

\begin{tabular}{|c|c|c|c|}
\hline Messgröße & $\begin{array}{l}\text { Name der } \\
\text { Maßeinheit }\end{array}$ & $\begin{array}{l}\text { Symbol der } \\
\text { Maßeinheit }\end{array}$ & $\begin{array}{l}\text { Ableitung der } \\
\text { Maßeinheit }\end{array}$ \\
\hline Frequenz & Hertz & $\mathrm{Hz}$ & $\mathrm{s}^{-1}$ \\
\hline Kraft & Newton & $\mathrm{N}$ & $\mathrm{m} \times \mathrm{kg} \times \mathrm{s}^{-2}$ \\
\hline Druck & Pascal & $\mathrm{Pa}$ & $\mathrm{N} / \mathrm{m}^{2}$ \\
\hline Energie/Arbeit & Joule & $\mathrm{J}$ & $\mathrm{N} \times \mathrm{m}$ \\
\hline Leistung & Watt & W & $\mathrm{J} / \mathrm{s}$ \\
\hline $\begin{array}{l}\text { Elektrische } \\
\text { Ladung }\end{array}$ & Coulomb & $\mathrm{C}$ & $\mathrm{A} \times \mathrm{s}$ \\
\hline $\begin{array}{l}\text { Elektrische } \\
\text { Kapazität }\end{array}$ & Farad & $\mathrm{F}$ & $\mathrm{C} / \mathrm{V}$ \\
\hline $\begin{array}{l}\text { Elektrischer } \\
\text { Widerstand }\end{array}$ & Ohm & W & V/A \\
\hline $\begin{array}{l}\text { Elektrische } \\
\text { Leitfähigkeit }\end{array}$ & Siemens & $\mathrm{S}$ & $\mathrm{A} / \mathrm{V}$ \\
\hline $\begin{array}{l}\text { Aktivität eines } \\
\text { Radionuklids }\end{array}$ & Becquerel & $\mathrm{Bq}$ & $\mathrm{s}^{-1}$ \\
\hline Enzymaktivität & Katal & kat & $\mathrm{mol} \times \mathrm{s}^{\times 1}$ \\
\hline $\begin{array}{l}\text { Celsius- } \\
\text { Temperatur }\end{array}$ & Grad Celsius & ${ }^{\circ} \mathrm{C}^{1)}$ & K \\
\hline $\begin{array}{l}\text { Absorbierte } \\
\text { Dosis }\end{array}$ & Gray & Gy & $\mathrm{J} \times \mathrm{kg}^{-1}$ \\
\hline
\end{tabular}

${ }^{1)}$ Umrechnung: $\left({ }^{\circ} \mathrm{C}\right)$ in $(\mathrm{K}): \times\left({ }^{\circ} \mathrm{C}\right)+273,15$

Zur Neudefinition der Stoffmenge Mol und zu den aktuellen Entwicklungen zu den 7 Grundgrößen im SI-System siehe $>$ Mol.

Zur einfacheren Darstellung von extremen Wertebereichen sind bestimmte Vorsilben zugelassen. Die folgende Tabelle fasst zulässige SI-Präfixe zusammen:

\begin{tabular}{|l|l|l|}
\hline Faktor & Präfix & Symbol für Präfix \\
\hline $10^{18}$ & Exa & E \\
\hline $10^{15}$ & Peta & P \\
$10^{12}$ & Tera & T \\
\hline $10^{9}$ & Giga & G \\
\hline $10^{6}$ & Mega & M \\
$10^{3}$ & Kilo & k \\
\hline $10^{2}$ & Hekto & h \\
\hline $10^{1}$ & Deca & da \\
\hline $10^{-1}$ & Dezi & d \\
\hline $10^{-2}$ & Centi & $\mathrm{c}$ \\
\hline $10^{-3}$ & Milli & $\mathrm{m}$ \\
\hline $10^{-6}$ & Mikro & $\mu$ \\
\hline $10^{-9}$ & Nano & $\mathrm{n}$ \\
\hline $10^{-12}$ & Pico & $\mathrm{p}$ \\
\hline $10^{-15}$ & Femto & $\mathrm{f}$ \\
\hline $10^{-18}$ & Atto & $\mathrm{a}$ \\
\hline
\end{tabular}

Bei Umrechnung von Nicht-SI-Einheiten in SI-Einheiten ergeben sich in der Regel von 1 verschiedene Faktoren. fol- gende Tabelle fasst nicht SI-kohärente Messgrößen und -einheiten zusammen:

\begin{tabular}{|c|c|c|c|}
\hline Messgröße & Maßeinheit & $\begin{array}{l}\text { Symbol der } \\
\text { Maßeinheit }\end{array}$ & $\begin{array}{l}\text { Angabe in } \\
\text { SI-Einheiten }\end{array}$ \\
\hline \multirow[t]{3}{*}{ Zeit $^{1)}$} & Minute & $\min$ & $60 \mathrm{~s}$ \\
\hline & Stunde & $\mathrm{h}$ & $3600 \mathrm{~s}$ \\
\hline & Tag & d & $86400 \mathrm{~s}$ \\
\hline Volumen ${ }^{1)}$ & Liter & $\mathrm{L}$ & $\begin{array}{l}10^{-3} \mathrm{~m}^{3} \text { oder } \\
1 \mathrm{dm}^{3}\end{array}$ \\
\hline $\begin{array}{l}\text { Katalytische } \\
\text { Aktivität }{ }^{2)}\end{array}$ & $\begin{array}{l}\text { Int. } \\
\text { Enzymeinheit }\end{array}$ & $\mathrm{U}$ & 16,67 nkat \\
\hline Masse $^{1)}$ & Tonne & $t$ & $1000 \mathrm{~kg}$ \\
\hline \multirow{3}{*}{ Druck $^{2)}$} & Bar & bar & $100000 \mathrm{~Pa}$ \\
\hline & Bar & bar & $100 \mathrm{kPa}$ \\
\hline & $\begin{array}{l}\text { Phys. } \\
\text { Atmosphäre }\end{array}$ & $\mathrm{atm}$ & $101325 \mathrm{~Pa}$ \\
\hline \multirow[t]{3}{*}{ Druck $^{3)}$} & $\mathrm{mmHg}$ & Torr & $133,222 \mathrm{~Pa}$ \\
\hline & mmWS & $\mathrm{mmH}_{2} \mathrm{O}$ & $9,80665 \mathrm{~Pa}$ \\
\hline & $\begin{array}{l}\text { Techn. } \\
\text { Atmosphäre }\end{array}$ & at & $98066,5 \mathrm{~Pa}$ \\
\hline \multirow[t]{2}{*}{ Länge $^{2)}$} & Ångström & $\AA$ & $10^{-10} \mathrm{~m} ; 0,1 \mathrm{~nm}$ \\
\hline & $\begin{array}{l}\text { Nautische } \\
\text { Meile }\end{array}$ & sm, NM & $1852 \mathrm{~m}$ \\
\hline \multirow[t]{3}{*}{ Fläche ${ }^{2)}$} & $\mathrm{Ar}$ & $\mathrm{a}$ & $100 \mathrm{~m}^{2}$ \\
\hline & Hektar & ha & $10000 \mathrm{~m}^{2}$ \\
\hline & Barn & $\mathrm{b}$ & $\begin{array}{l}10^{-28} \mathrm{~m}^{2} \\
100 \mathrm{fm}^{2}\end{array}$ \\
\hline${\left.\text { Geschwindigkeit }{ }^{2}\right)}^{2}$ & Knoten & kn & $0,514 \mathrm{~m} \times \mathrm{s}^{-1}$ \\
\hline Beschleunigung $^{2)}$ & $\mathrm{Gal}$ & $\mathrm{Gal}$ & $10^{-2} \mathrm{~m} \times \mathrm{s}^{-2}$ \\
\hline Radionuklidaktivität $^{2}$ ) & Curie & $\mathrm{Ci}$ & $\begin{array}{l}3,7 \times 10^{10} \mathrm{~Bq} \\
\left(3,7 \times 10^{10} \mathrm{~s}^{-1)}\right.\end{array}$ \\
\hline Absorbierte Dosis ${ }^{2)}$ & $\operatorname{Rad}$ & $\mathrm{rad} / \mathrm{rd}$ & $\begin{array}{l}10^{-2} \text { Gy }\left(10^{-2} \mathrm{~J} /\right. \\
\mathrm{kg})\end{array}$ \\
\hline Strahlenexposition ${ }^{2)}$ & Röntgen & $\mathrm{R}$ & $2,58 \times 10^{-4} \mathrm{C} / \mathrm{kg}$ \\
\hline
\end{tabular}

${ }^{1)}$ Zeitlich unbefristet neben den SI-Einheiten verwendbare Nicht-SIEinheiten

${ }^{2)}$ Zeitlich befristet neben den SI-Einheiten verwendbare Nicht-SIEinheiten

${ }^{3)}$ Nicht-SI-Einheit, die nicht verwendet soll; darf nur in Klammern in Ergänzung zur SI-Einheit zur Erleichterung deren Einführung angegeben werden

\section{Literatur}

Bureau international des poids et mesures (2014) The International System of Units (SI), 8 Aufl. www.bipm.org

IEC 80.000 series. "Quantities and Units“

ISO 80.000 series. „Quantities and Units“

WHO (1977) The SI for the health professions. WHO, Geneva

SIG

> Säure-Basen-Modell nach Stewart 


\section{Siggaard-Andersen-Nomogramm}

O. Müller-Plathe

Synonym(e) Kurvennomogramm; Säure-Basen-Nomogramm

Englischer Begriff Acid-base nomogram; curve nomogram
Definition Nomogramm zur Berechnung von $p \mathrm{CO}_{2}$ und $\mathrm{Ba}-$ senparametern aus zwei pH-Bestimmungen im Rahmen der „Äquilibriermethode“.

Beschreibung Bei der von P. Astrup ( $\triangleright$ Astrup, Poul) beschriebenen Äquilibriermethode werden die pH-Werte von zwei auf $p \mathrm{CO}_{2}$-Werte um 20 und $60 \mathrm{mmHg}$ äquilibrierten Blutproben ( $\triangleright$ Partialdruck) in ein Koordinatensystem mit $\mathrm{pH}$ auf der Abszisse und $\lg \mathrm{pCO}_{2}$ auf der Ordinate eingetra-

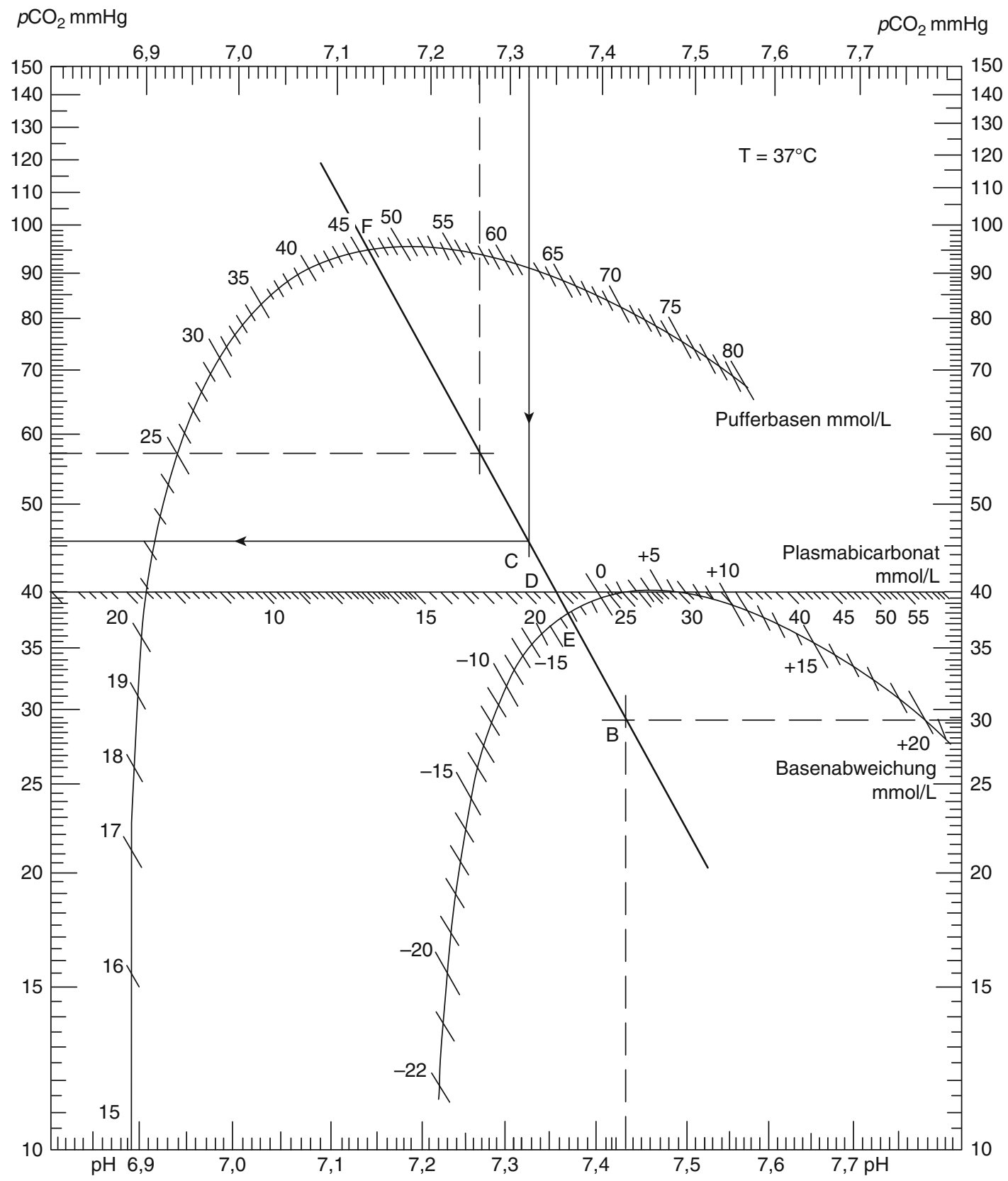

Siggaard-Andersen-Nomogramm, Abb. 1 Kurvennomogramm mit Beispielen. $A, B$, pH-Werte der äquilibrierten Blutproben; $C$, aktueller pH mit interpoliertem $p \mathrm{CO}_{2} ; D$, Standardbicarbonat; $E$, Basenabweichung; $F$, Pufferbasen 
gen, die Punkte durch eine Gerade verbunden und $p \mathrm{CO}_{2}$ aus dem aktuellen $\mathrm{pH}$ der Blutprobe durch Interpolation abgelesen. Die Position der Geraden hängt von der Bicarbonatkonzentration, ihre Steilheit vom Hämoglobingehalt ab. Ihr Schnittpunkt mit der Ordinate $\mathrm{pCO}_{2} 40 \mathrm{mmHg}$ entspricht dem > Standardbicarbonat. Der Schnittpunkt mit zwei von Siggaard-Andersen (Ole Siggaard-Andersen, geboren am 10. Dezember 1932, Professor für Klinische Chemie an der Universität Kopenhagen) konstruierten Kurven (Abb. 1) gestattet die Ablesung der Basenabweichung des Blutes und der Gesamtkonzentration der Pufferbasen im Blut.

Das Kurvennomogramm hat keine messtechnische Bedeutung mehr, da $p \mathrm{CO}_{2}$ inzwischen nicht mehr durch Interpolation, sondern mit einer spezifischen Elektrode gemessen wird und die Basenparameter im Blutgasgerät elektronisch berechnet werden. Außerdem wird heute dem Bezug der $>$ Basenabweichung auf die Extrazellularflüssigkeit anstelle von Blut der Vorzug gegeben. Das Kurvennomogramm (wie auch das ebenfalls von Siggaard-Andersen publizierte Leiternomogramm C2) hat aber weiterhin einen hohen didaktischen Wert, da es die Zusammenhänge zwischen den einzelnen Größen des Säure-Basen-Status ( $\triangleright$ Säure-Basen-Stoffwechsel) sehr gut veranschaulicht.

\section{Literatur}

Siggaard-Andersen O (1963) Blood acid-base alignment nomogram: scales for $\mathrm{pH}, \mathrm{pCO}_{2}$, base excess of whole blood of different hemoglobin concentrations, plasma bicarbonate, and plasma total $\mathrm{CO}_{2}$. Scand J Clin Lab Invest 15:211-217

Siggaard-Andersen O, Engel K (1960) A new acid-base nomogram. An improved method for the calculation of the relevant blood acid-base data. Scand J Clin Lab Invest 12:177-186

\section{Siglec-1}

A. M. Gressner und O. A. Gressner

Synonym(e) CD169; Sialoadhesin

Englischer Begriff sialic acid-binding immunoglobulin-like lectin; sialoadhesin

Definition Siglec-1 ist ein auf Monozyten, Makrophagen und Immunzellen begrenztes, transmembranäres Zelloberflächenglykoprotein mit Funktionen im Immunsystem, bei der Antigenpräsentation, Zell-Zell-Interaktion und Zelladhärenz, dem frühzeitige diagnostische und prognostische Bedeutung für das primäre Sjögren-Syndrom und dessen Verlauf sowie für das Therapiemonitoring von Autoimmunerkrankungen (z. B. SLE) zukommt.

Beschreibung Die Diagnose des primären Sjögren-Syndroms (pSS) basiert bei bis zu 83 \% der Patienten auf einem positiven Nachweis antinukleärer Antikörper (ANA, > Autoantikörper gegen Zellkerne) mit einem feingranulierten Fluoreszenzmuster, auf dem Nachweis von Anti-Ro/SSA- (bei 40-75 \%, Autoantikörper gegen SS-A) bzw. Anti-La/ SSB-Antikörper (bei 23-52 \%, > Autoantikörper gegen SS-B), oft in Verbindung mit positivem Nachweis von Rheumafaktor (ca. $70 \%$, $>$ Rheumafaktoren) und polyklonaler Hypergammaglobulinämie. Ein positiver Nachweis von Anti-Ro/SSA-Antikörpern ist auch bei weiteren Kollagenosen $\mathrm{zu}$ finden und kann der klinischen Manifestation der Erkrankung um bis zu 20 Jahre vorausgehen.

Siglec-1 ist ein von Typ-I-Interferon induziertes und reguliertes Adhäsionsmolekül mit einem Molekulargewicht von 175-185 kDa, das Sialinsäure-Glykane bindet. Strukturell gehört es zur Immunglobulin-Superfamilie mit 3 Domänen, die sich auf ein extra-, trans- und intrazelluläres Segment verteilen. Die quantitative, durchflusszytometrisch gemessene ( $>$ Durchflusszytometrie) Expressionsstärke von Siglec-1 auf Monozyten lässt eine Differenzierung der glandulären von der extraglandulären (signifikant häufiger positiv) Form des Sjögren-Syndroms zu und gibt Hinweise auf Krankheitsaktivität und systemische Ausbreitung der Erkrankung (Rose et al. 2016).

\section{Literatur}

Eakin AJ, Bustard MJ, McGeough CM et al (2016) Siglec-1 and-2 as potential biomarkers in autoimmune disease. Proteomics Clin Appl 10(6):635-644

Rose T, Szelinski F, Lisney A et al (2016) SIGLEC1 is a biomarker of disease activity and indicates extraglandular manifestation in primary Sjögren's syndrome. RMD Open 2(2):e000292

Stefanski A-L, Tomiak C, Pleyer U et al (2017) Diagnostik und Therapie des Sjögren-Syndroms. Dtsch Ärztebl 114(20):354-361

\section{Signalauflösung}

$>$ Auflösungsvermögen

\section{Signal/Rausch-Verhältnis}

- Grundrauschen 


\section{Signifikanzniveau}

> Irrtumswahrscheinlichkeit $\alpha$

\section{Silber}

D. Meißner und T. Arndt

Synonym(e) Argentum

\section{Englischer Begriff silver}

Definition Silber (chemisches Symbol: Ag) ist ein Edelmetall mit der Ordnungszahl 47 und der relativen Atommasse von 107,8682 . Es ist ein nicht essenzielles Spurenelement.

Beschreibung Silber hat keine bekannte physiologische Funktion. Die tägliche Silberaufnahme aus der Umgebung und durch die Nahrung betrug für einen erwachsenen US-Bürger im Mittel $70 \mu \mathrm{g}$. Es sollen mehr als die Hälfte inhalierten metallischen Silbers über die Lunge absorbiert werden, weniger als $10 \%$ einer oralen Dosis im Gastrointestinaltrakt und weniger als $1 \%$ bei Hautkontakt. Nicht exponierte Deutsche hatten eine mittlere Silberblutkonzentration von $0,07 \mu \mathrm{g} / \mathrm{L}$ (Bereich $<0,02-0,4 \mu \mathrm{g} / \mathrm{L}$ ). Intensiver Kontakt mit Silberverbindungen führt zur (möglicherweise irreversiblen) Ablagerung von Silbersalzen in Haut (schiefergraue Verfärbung), Schleimhäuten und Organen $($ Argyrie $=$ Argyrose $)$. Man geht davon aus, dass der überwiegende Anteil absorbierten Silbers über den Stuhl (85-90\%) und nur $10 \%$ über den Urin ausgeschieden werden. Nicht exponierte Deutsche zeigten eine Silberurinausscheidung von $0,08 \mu \mathrm{g} / \mathrm{L}$ oder weniger (Heitland und Koster 2006a), Italiener von 0,06-2,5 $\mu \mathrm{g} / \mathrm{L}$ (Baselt 2014).

In der Medizin findet Silber Anwendung in Dentallegierungen und zur Desinfektion, auch als Bakteriostatikum, z. B. in Form topischer Cremes bei Verbrennungen. Kolloidales Silber wird als Nahrungsergänzungsstoff zur Behandlung vielfältiger Krankheiten und Gebrechen angeboten. Akute Intoxikationen mit großen Mengen oral aufgenommenen Silbers äußern sich in Bauchschmerzen, Erbrechen bis ggf. Schock, chronische Intoxikationen können zu Argyrose sowie Nieren- und Leberschäden führen.

Indikationen zur Bestimmung von Silber bestehen in der Toxikologie, um den Missbrauch von Silbersalzen nachzuweisen, und in der Arbeitsmedizin. Silber wird in großen Mengen in der Schmuckindustrie, in Legierungen, Lötmaterial und bei der Münzherstellung eingesetzt.
Die o. g. Konzentrationsangaben für Deutsche stammen aus Heitland und Koster (zitiert in Baselt 2014). Sie sollen in Ermangelung validierter Referenzbereiche einer ersten Orientierung bei der Interpretation von Silberanalyseergebnissen dienen.

\section{Literatur}

Baselt RC (2014) Disposition of toxic drugs and chemicals in man, 10. Aufl. Biomedical Publications, Seal Beach, S 1848-1849

Doherty PJ, Williams DF (1994) Silver. In: Seiler G, Sigel A, Sigel $\mathrm{H}$ (Hrsg) Handbook on metals in clinical and analytical chemistry. Marcel Dekker, New York/Basel/Hong Kong, S 563-569

Heitland P, Koster HD (2006a) Biomonitoring of 37 trace elements in blood samples from inhabitants of northern Germany by ICP-MS. J Trace Elem Med Biol 20:253-262

Heitland P, Koster HD (2006b) Biomonitoring of 30 trace elements in urine of children and adults by ICP-MS. Clin Chim Acta $365: 310-318$

\section{Silberfårbung}

R. Westermeier

Englischer Begriff silver staining

Definition Hochempfindliche Nachweismethode für Proteine oder Nukleinsäuren nach ihrer Auftrennung in einem Elektrophoresegel oder in einem Gewebeschnitt.

Beschreibung Bei der Silberfärbung wird Silbernitrat oder - alternativ - Silberdiamin in metallisches Silber überführt. Dabei bildet das Silber mit Proteinen, Nukleinsäuren, Polysacchariden und Lipopolysacchariden unlösliche Komplexe. Die Entwicklung wird mit Formaldehyd ausgelöst. Die gesamte Prozedur ist dem photographischen Entwicklungsprozess sehr ähnlich. Die Elektrophoresemuster zeigen dann dunkelbraune Banden oder Flecken auf transparentem bis hellgelbem Hintergrund. Silberfärbung funktioniert besonders gut in Polyacrylamidgelen; es gibt aber Varianten für Agarosegele. Auch für Polyacrylamidgele gibt es eine hohe Anzahl von unterschiedlichen Varianten, die optimiert sind für unterschiedliche Anwendungen für Proteine und Nukleinsäuren.

Die Technik benötigt viele Schritte, die Zeiten sind exakt einzuhalten. Alle Varianten beinhalten im Prinzip all diese Schritte:

- Fixierung

- Sensibilisierung

- Mehrere Waschschritte 
- Silberbad

- Entwicklung

- Stoppbad

- Mehrere Waschschritte

Für diese Methode sind Färbeautomaten sehr praktisch.

Mit Silberfärbung erreicht man sehr hohe Nachweisempfindlichkeit, leider sind die Färbekurven nicht linear, der dynamische Bereich ist sehr eng, wodurch sich die Methode nicht gut zu Quantifizierungen eignet.

\section{Literatur}

Kerenyi L, Gallyas F (1972) A highly sensitive method for demonstrating proteins in electrophoretic, immunoelectrophoretic and immunodiffusion preparations. Clin Chim Acta 38:465-467

Westermeier R (2016) Elektrophorese leicht gemacht. VCH, Weinheim

\section{Silberimprägnierung nach Gomori}

$>$ Gomori-Färbung

\section{Silber/Silberchlorid-Elektrode}

- Referenzelektrode

\section{Silicium}

D. Meißner und T. Arndt

\section{Englischer Begriff silicon}

Definition Silicium (chemisches Symbol: Si) ist das zweithäufigste Element der Erdkruste. Es ist ein Element der IV. Hauptgruppe des Periodensystems der Elemente mit der Atomnummer 14 und gehört zu den essenziellen $>$ Ultraspurenelementen.

Struktur Silicium liegt in der Oxidationsstufe +4 als Silikat oder Monokieselsäure vor. Es kann an organische Verbindungen, speziell an $>$ Glykosaminoglykane, gebunden sein. Es bildet stabile Ringstrukturen, wobei die Si-O- und Si-CBindungen stabil, die Si-Si- und die Si-H-Bindungen weniger stabil sind.
Molmasse Relative Atommasse: 28,0855.

Synthese - Verteilung - Abbau - Elimination Man nimmt an, dass der Mensch aus Nahrungsmitteln, Getränken und Atemluft 9-14 mg Silicium pro Tag resorbiert, den größten Teil des aufgenommenen Siliciums jedoch unverändert über den Stuhl wieder ausscheidet. Über das Blut wird das Silicium in die Gewebe verteilt, wobei es sich besonders im Bindegewebe, in Blutgefäßen, Trachea, Sehnen, Haut und Knochen, u. U. auch in Lunge und Lymphknoten anreichert. Die Ausscheidung erfolgt über den Urin und die Muttermilch.

Bedarf: 3-4 mg/Tag. Empfohlene Zufuhr: $>10 \mathrm{mg} / \mathrm{Tag}$. Siliciumreich sind Muskelfleisch, Leber, Lunge, Hirn, Hafer, Hirse.

Funktion - Pathophysiologie Silicium kommt in allen Lebewesen vor. Siliciummangel ist beim Menschen nicht bekannt, jedoch nimmt der Siliciumgehalt in Körperflüssigkeiten und Organen mit dem Alter ab. Wichtige Funktionen sind die Förderung des Wachstums (nur im Tierversuch nachgewiesen), die Verbesserung der Struktur von Epithelien und Bindegewebe (Einbau von Silicium in Mukopolysaccharide von Haut, Haaren, Nägeln), die Förderung der Knochenbildung und -reifung (Wirkung an den Epiphysenenden des Knochens, Quervernetzung der Proteine und Mukopolysaccharide) und die Förderung von Elastizität und Stabilität der Arterienwände. Möglicherweise wird der Stoffwechsel der Lipoproteine durch organische Siliciumverbindungen günstig beeinflusst. In der ersten Hälfte des 20. Jh. wurden anorganische und einfache organische Siliciumverbindungen in der Tuberkulose-, Arteriosklerose- und Tumortherapie verwendet. An die damaligen Ergebnisse wurden große Hoffnungen geknüpft, die sich bis heute nicht erfüllt haben.

Die Toxizität von Silicium ist gering. Gefährlich ist das Einatmen von Siliciumverbindungen, besonders Asbest, oder von $\mathrm{SiO}_{2}$-haltigem Staub (Silikose bei exponierten Arbeitern).

Untersuchungsmaterial - Entnahmebedingungen Serum, Urin.

Probenstabilität $20{ }^{\circ} \mathrm{C} 7$ Tage, $4-8{ }^{\circ} \mathrm{C} 14$ Tage, $-20{ }^{\circ} \mathrm{C}$ 1 Jahr.

Präanalytik Spurenelementfreie Abnahmegeräte und Gefäße verwenden. Jeglicher Kontakt mit Glas ist zu vermeiden, auch bei der Reagenzien- und Wasserherstellung.

Analytik Atomabsorptionsspektrometrie (Zeeman-Technik), - Inductively Coupled Plasma, Neutronenaktivierungsanalyse.

Konventionelle Einheit $\mu \mathrm{g} / \mathrm{L}$ (d). 
Internationale Einheit $\mu \mathrm{mol} / \mathrm{L}(\mathrm{d})$.

Umrechnungsfaktor zw. konv. u. int. Einheit $\mu \mathrm{mol} / \mathrm{L}$ $(\mathrm{d})=0,0356 \times \mu \mathrm{g} / \mathrm{L}(\mathrm{d}) ; \mu \mathrm{g} / \mathrm{L}(\mathrm{d})=28,0855 \times \mu \mathrm{mol} / \mathrm{L}(\mathrm{d})$.

Referenzbereich - Erwachsene Standardisierte Referenzwerte sind nicht bekannt. Serum: $500 \mu \mathrm{g} / \mathrm{L}(17,8 \mu \mathrm{mol} / \mathrm{L})$; Urin: $9000 \mu \mathrm{g} / \mathrm{Tag}(320 \mu \mathrm{mol} / \mathrm{Tag})$ (Anke 2002).

Referenzbereich - Kinder s. Erwachsene.

Indikation Verdacht auf unzureichende Zufuhr oder verminderte Versorgung.

Interpretation Der Gehalt in Körperflüssigkeiten ist von der Art der zugeführten Siliciumverbindungen und der Nahrungszusammensetzung abhängig.

Diagnostische Wertigkeit Die Siliciumbestimmung spielt in der Diagnostik nur gelegentlich eine Rolle, wobei die Bedeutung einer ausreichenden Siliciumversorgung sicherlich unterschätzt wird.

\section{Literatur}

Anke M (2002) Silicium. In: Biesalski HK, Köhrle J, Schümann K (Hrsg) Vitamine, Spurenelemente und Mineralstoffe. Georg Thieme Verlag, Stuttgart/New York, S 237-238

sIL-2R

- Interleukin-2-Rezeptor, löslicher

\section{SIM}

B. Güssregen

Synonym(e) Selected Ion Monitoring

Englischer Begriff selected ion monitoring

Beschreibung SIM (selected ion monitoring) ist eine Technik in der $>$ Massenspektrometrie, durch welche die Empfindlichkeit bei einer $\triangleright$ GC-MS- oder $>$ LC-MS-Methode enorm gesteigert werden kann. Beim SIM werden nur bestimmte Ionen der Masse $\mathrm{m} / \mathrm{z}$ aufgezeichnet. Die Steigerung der Empfindlichkeit kommt dadurch zustande, dass die tatsächliche Messzeit und damit die Zahl der registrierten Ionen bei vorselektierten $\mathrm{m} / \mathrm{z}$-Werten erheblich erhöht wird.

\section{Simon, Johann Franz}

A. M. Gressner und O. A. Gressner

Lebensdaten Deutscher Pharmazeut, geboren am 25. August 1807 in Frankfurt/Oder, gestorben am 23. Oktober 1843 in Wien.

Verdienste Simon hatte ein zusätzliches Studium der Chemie absolviert und sich zunächst mit der toxikologischen Analytik befasste. Im Jahr 1840 erhielt er in der Klinik von Johann Lucas Schönlein (1793-1864) an der Charité in Berlin die Stelle eines „chemischen Assistenten“ in einem für chemisch-diagnostische Untersuchungen eigens eingerichteten Laboratorium. Simon gab als erster 1842 ein umfassendes zweibändiges Handbuch der angewandten medizinischen Chemie (1840-1842) mit einer umfassenden Darstellung der Klinischen Chemie ( $>$ Klinische Chemie) heraus sowie eine Zeitschrift (,Beiträge zur physiologischen und pathologischen Chemie und Mikroskopie") dieses neuen Fachgebietes. Seine Arbeiten beruhen auf einer Vielzahl eigener Beobachtungen und Analysen, die erstmalig eine systematische Darstellung der diagnostisch bedeutsamen pathologischen Veränderungen wiedergeben. Simon erarbeitete erfolgreich die Beziehungen zwischen chemischen und morphologischen Veränderungen des menschlichen Blutes und definierten Erkrankungen und stellte damit die medizinische Interpretation klinisch-chemischer Befunde auf eine wissenschaftliche Basis. Er organisierte einen „Verein für physiologische und pathologische Chemie" in Berlin, der als erste wissenschaftliche Vereinigung der Klinischen Chemie angesehen werden kann. Zusammen mit Scherer ( $>$ Scherer, Johann Joseph von) und Heller ( $\triangleright$ Heller, Johann Florian) gehört er zu den Begründern der Klinischen Chemie.

\section{Literatur}

Büttner J (1977) Geschichte der Klinischen Chemie. Med Welt 28:1238-1243

Büttner J (1985) Die Entwicklung der Klinischen Chemie im Spannungsfeld zwischen Medizin und Chemie. J Clin Chem Clin Biochem 23:797-804

\section{Simple Western}

- Simple Western Blotting 


\section{Simple Western Blotting}

\section{R. Westermeier}

Synonym(e) Simple Western

\section{Englischer Begriff Simple Western blotting}

Definition Patentierte Methode der Immundetektion von Antigenen nach elektrophoretischer Trennung und Immobilisierung der Proteinfraktionen in Kapillaren.

Physikalisch-chemisches Prinzip Beim Simple Western Blotting erfolgt die Trennung des Proteingemisches mittels einer Kapillarelektrophorese, bei der die innere Kapillarwand mit einer Substanz beschichtet ist, die bei Lichtaktivierung die getrennten Proteinfraktionen bindet. Anschließend folgt eine Immundetektion mit Primär- und Sekundärantikörpern durch Inkubieren und Waschen der Kapillare. Die Sekundärantikörper sind mit Meerrettichperoxidase konjugiert; die Detektion erfolgt über Chemilumineszenz. Alle Schritte sind automatisiert. Die Trennung kann nach 2 verschiedenen Prinzipien durchgeführt werden: entweder durch eine isoelektrische Fokussierung zur Trennung nach den isoelektrischen Punkten oder eine SDS-Elektrophorese zur Trennung nach Molekülgrößen.

Einsatzgebiet Proteinbestimmungen.

Untersuchungsmaterial Biologische Flüssigkeiten, Gewebeextrakte, Zelllysate.

Instrumentalisierung Vollautomatisierte Apparatur der Firma ProteinSimple.

Spezifizität Hoch, da die Methode auf Immunreaktion beruht.

Sensitivität Im Bereich niedriger Picogramm bis hoher Femtogramm.

Fehlermöglichkeit Diese Technik funktioniert vollautomatisch, der Aufwand für die Probenvorbereitung ist minimal. Dadurch wenig Fehler möglich.

Praktikabilität - Automatisierung - Kosten Gerät und Kapillarkits gibt es nur bei der Firma ProteinSimple, der Inhaberin der Patente.

Bewertung - Methodenhierarchie (allg.) Geeignet für klinisch-chemische Labore mit hohem Probendurchsatz.

\section{Literatur}

Nguyen U, Squaglia N, Boge A, Fung PA (2011) The Simple Western ${ }^{\text {TM: }}$ a gel-free, blot-free, hands-free Western blotting reinvention. Nat Methods 8:v-vi

Sindbis-Viren (SINV)

W. Stöcker

Englischer Begriff Sindbis virus

Beschreibung des Erregers Familie: Togaviridae; Gattung: Alphavirus; Art: Sindbis-Virus; Subtypen: Ockelbo-Virus, Babanki-Virus; Plusstrang-RNA-Genom, behüllt.

Erkrankungen Verbreitung: Südafrika, Ägypten, Indien, Philippinen, Südostasien, Zentralasien, Russland, Australien, Nordeuropa.

Übertragung: Stechmücken (ornithophile Culex ssp., vor allem $C$. pipiens und $C$. torrentium, Aedes ssp. u. a.); verschiedene Vogelarten, darunter Zugvögel, dienen als Reservoir.

Klinik: Sindbis-Fieber, febrile Erkrankung mit Kopfschmerzen, Arthritis/Arthralgie, Exanthem, die etwa eine Woche andauert. Nur bei einem kleinen Teil der Patienten persistieren Gelenkbeschwerden.

Analytik Kultur: Virusanzucht.

Serologie: Nachweis spezifischer Antikörper (IgA, IgG, IgM) im Serum durch indirekte Immunfluoreszenz ( $>$ Immunfluoreszenz, indirekte), $>$ Enzyme-linked Immunosorbent Assay, > Neutralisationstest, Hämagglutinations-Hemmtest.

Probenmaterial Direktnachweis: Blut oder Blutbestandteile. Das Material sollte bis zur Weiterverarbeitung bei +4 bis $+8{ }^{\circ} \mathrm{C}$ aufbewahrt werden.

Serologie: Serum oder Plasma für den Nachweis der Antikörper sind bei $+4{ }^{\circ} \mathrm{C}$ bis zu 2 Wochen lang beständig, bei $-20{ }^{\circ} \mathrm{C}$ über Monate und Jahre hinweg. Zur Tiefkühlkonservierung des IgM kann man den Proben 80 \% gepuffertes Glyzerin beifügen.

Diagnostische Wertigkeit Ursache für Fieber mit Hautausschlag und Gelenkschmerzen können auch in Deutschland Sindbis-Viren sein. Der direkte Virusnachweis aus dem Blut ist während der ersten Krankheitstage möglich. Ab dem 8.-10. Tag nach Einsetzen der Symptome können spezifische 
Antikörper (IgM, IgG) nachgewiesen werden. Kreuzreaktionen mit Antikörpern gegen verwandte Viren sind möglich.

Differenzialdiagnose: virale Infektionen mit Gelenkbeteiligung (z. B. Dengue- und Chikungunya-Fieber), die in den Infektionsgebieten parallel auftreten, ggf. rheumatoide Arthritis, reaktive Arthritis.

Durch die Verordnung zur Anpassung der Meldepflichten nach dem Infektionsschutzgesetz an die epidemische Lage (IfSG-Meldepflicht-Anpassungsverordnung), die am 01.05.2016 in Kraft getreten ist, wurde die Meldepflicht für Labore nach $\S 7$ Abs. 1 Satz 1 Infektionsschutzgesetz (IfSG) auf den direkten oder indirekten Nachweis von ChikungunyaViren, Dengue-Viren, West-Nil-Fieberviren, Zika-Viren und sonstige Arboviren ausgedehnt, soweit der Nachweis eine akute Infektion anzeigt. Darüber hinaus können allgemeine nicht erreger- oder krankheitsspezifische Meldepflichten bestehen.

\section{Literatur}

Robert Koch-Institut, Berlin (2011) Steckbriefe seltener und importierter Infektionskrankheiten. Robert-Koch-Institut, Berlin

\section{Single-Quadrupol}

\section{B. Güssregen}

Englischer Begriff single quadrupole

Beschreibung Bei einem Single-Quadrupol handelt es sich um ein Massenspektrometer mit einem Quadrupol (im Gegensatz zum Triple-Quadrupol, bei dem 3 Quadrupole nacheinander stehen; Massenspektrometrie).

\section{Singulett-Zustand}

$>$ Lumineszenz

SiRNA

J. Arnemann

Synonym(e) Small interfering RNA

\section{Englischer Begriff siRNA}

Definition Die siRNA-Moleküle (,small interfering RNA“) sind kleine doppelsträngige RNA-Moleküle von 20-25 Basenpaaren zur Hemmung der RNA-Expression.

Beschreibung siRNA-Moleküle inhibieren posttranskriptional die RNA-Expression durch Bindung an die mRNA in einem RNA-induzierten Silencing-Komplex (RISC) mit nachfolgender Degradation der mRNA.

Werden bei einem Gen zeitgleich mRNA (sense) und aRNA (antisense) transkribiert, können beide Transkripte zu einer doppelsträngigen RNA (dsRNA) paaren. Diese dsRNA wird dann durch die dsRNA-spezifische Endonuklease DICER-2 in kleine Abschnitte von 20-25 Basenparen gespalten, wobei die siRNA-Moleküle jeweils einem phosphorylierten 5'-Überhang besitzen. Die doppelsträngigen siRNAMoleküle binden an das Effektorprotein Ago-2 und werden entwunden, sodass das Effektormolekül sich an die komplementäre mRNA anlagern kann und zusammen mit einer spezifischen RNA-Endonuklease den RISC bilden kann, der die gebundenen mRNA-Moleküle durch eine Endonukleasespaltung vollständig abbaut und somit eine Translation verhindert. Dieser Prozess wird auch als posttranskriptionelles Gene-Silencing beschrieben.

Der Ursprung der siRNAs ist noch nicht abschließend geklärt, scheint aber vielfältig zu sein, wie z. B. exogen durch Viren im Zytoplasma oder auch endogen im Zellkern durch Zentromerfragmente, Transposons oder Pseudogene.

\section{Literatur}

Carthew RW, Sontheimer EJ (2009) Origins and mechanisms of miRNAs and siRNAs. Cell 136:642-655

Wittrup A, Lieberman J (2015) Knocking down disease: a progress report on siRNA therapeutics. Nat Rev Genet 16:543-552

\section{Sirolimus}

H.-D. Haubeck

Englischer Begriff sirolimus; rapamycin

Definition Sirolimus und sein Derivat $>$ Everolimus sind zyklische Makrolide mit potenter immunsuppressiver Wirkung, deren Mechanismus sich von dem der CalcineurinInhibitoren Ciclosporin und Tacrolimus unterscheidet. 
Strukturformel:<smiles>COC(CC1CCC(C)C(O)(C(=O)C(=O)N2CCCCC2C(=O)OC(CC(=O)C(C)C=C(C)C(O)C(OC)C(=O)C(C)CC(C)C=CC=CC=C(C)C(C)CC2CCC(O)C(OC)C2)C(C)CC2CCC(O)C(O)(OC)C2)O1)C(C)=CC=CC(C)CC(C)CC(C)C</smiles>

Molmasse $914,2 \mathrm{~g}$.

Halbwertszeit 57-63 Stunden.

Synthese - Verteilung - Abbau - Elimination Sirolimus ist ein zyklisches Makrolid, das aus Actinomyzeten (Streptomyces hygroscopicus) isoliert wurde. Sirolimus besitzt eine starke immunsuppressive Wirkung, deren Mechanismus sich von dem der Calcineurin-Inhibitoren $>$ Ciclosporin und $>$ Tacrolimus unterscheidet. Sirolimus hemmt die Aktivierung von T-Lymphozyten durch Antigene ( $>$ Antigen) und $>$ Zytokine und ihre Proliferation über eine Blockade von mTOR (,mammalian target of rapamycin"). Hierfür bindet Sirolimus zunächst an das zytosolische Immunophilin FKBP12. Dieser Komplex, der Calcineurin nicht inhibiert, wird dann an mTOR gebunden, das als Schlüsselkinase den Übergang von der G1in die S-Phase des Zellzyklus reguliert.

Immunsuppressive Wirkung Die immunsuppressive Wirkung von Sirolimus ist nach den vorliegenden Studien bezüglich der Rate akuter Abstoßungen, aber auch bezüglich des Patienten- bzw. Transplantatüberlebens, vergleichbar mit den Calcineurin-Inhibitoren. Als wichtigster Vorteil von Sirolimus, im Vergleich zu den Calcineurin-Inhibitoren, wird die fehlende Nephrotoxizität angesehen. Diese Nephrotoxizität bildet eine wichtige Ursache der chronischen Transplantatabstoßung und ist für die Langzeitergebnisse der Transplantation von entscheidender Bedeutung. Ein weiterer Vorteil von Sirolimus liegt in seiner ausgeprägten antiproliferativen Wirkung, durch die auch eine Hemmung der Tumorentstehung bzw. des Tumorwachstums (vor allem Lymphome und Hauttumoren) bei transplantierten Patienten zu erwarten ist. Daneben wird auch über die Hemmung der Proliferation von Endothelzellen und glatten Muskelzellen eine Verminderung atheroskerotischer Gefäßveränderungen erwartet. Bei den Nebenwirkungen von Sirolimus stehen die myelosup- pressive Wirkung mit einer Leukopenie und Thrombopenie und die Auswirkungen auf den Lipidstoffwechsel (Hypercholesterinämie und Hypertriglyzeridämie) im Vordergrund. Darüber hinaus führt die antiproliferative Wirkung häufig zu Wundheilungsstörungen.

Pharmakokinetik Sirolimus wird bei oraler Gabe schnell resorbiert, besitzt jedoch eine geringe Bioverfügbarkeit. Sirolimus hat mit ca. 60 Stunden eine sehr lange Halbwertszeit und zeigt große intra- und interindividuelle Schwankungen in der Pharmakokinetik. $95 \%$ des Sirolimus liegen intrazellulär vor. Die Metabolisierung erfolgt in der Leber über das Cytochrom-P450-3A-(CYP3A-)System. Außerdem ist Sirolimus ein Substrat des P-Glykoproteins, durch das Moleküle aus den Zellen heraustransportiert werden. Dementsprechend, aber auch wegen des relativ kleinen therapeutischen Bereichs, ist ein Drug-Monitoring notwendig.

Untersuchungsmaterial - Entnahmebedingungen EDTABlut; Probenstabilität bei $4{ }^{\circ} \mathrm{C} 7$ Tage, lichtempfindlich.

Präanalytik Inhibitoren und Induktoren des CYP3A-Systems beeinflussen die Sirolimus-Konzentration. Dementsprechend führen z. B. Ketoconazol und Ciclosporin zu deutlich erhöhten Sirolimus-Konzentrationen. Die Resorption von Sirolimus wird durch fettreiche Mahlzeiten beeinflusst, d. h. die Resorption wird verzögert und die Peak-Konzentration reduziert. Die resorbierte Sirolimus-Gesamtmenge (AUC, area under the curve) wird dagegen erhöht. Dementsprechend sollte die Sirolimus-Talkonzentration immer unter gleichen Bedingungen, entweder nüchtern oder postprandial, bestimmt werden.

Analytik $>$ LC-MS, LC-MS/MS, > Immunoassay.

Interpretation Therapeutischer Bereich: Die Konsensusempfehlung des (vorläufigen) therapeutischen Bereichs von Sirolimus bei Patienten nach Nierentransplantation liegt für die Kombination mit Steroiden und Mycophenolat-Mofetil (MMF) bei 5-10 ng/mL und ohne MMF bei 8-12 ng/mL.

\section{Literatur}

Armstrong VW, Streit F (2003) Drug monitoring of sirolimus and everolimus. J Lab Med 27:222-227

Flechner SM, Goldfarb D, Modlin D et al (2002) Kidney transplantation without calcineurin inhibitor drugs: a prospective, randomized trial of sirolimus versus cyclosporine. Transplantation 74:1070-1076

\section{SIRS}

Sepsiskenngrößen 


\section{SI-System}

- Einheitensystem

- SI-Einheiten

\section{Sitosterin}

K. J. Lackner und D. Peetz

Synonym(e) 22:23-Dihydrostigmasterol; $\beta$-Sitosterol

Englischer Begriff sitosterol

Beschreibung Sitosterin ist ein pflanzliches Sterol, das vom Menschen intestinal kaum resorbiert wird. Es unterscheidet sich vom $>$ Cholesterin durch eine Ethylgruppe am Kohlenstoff 24 der Seitenkette.

Strukturformel:

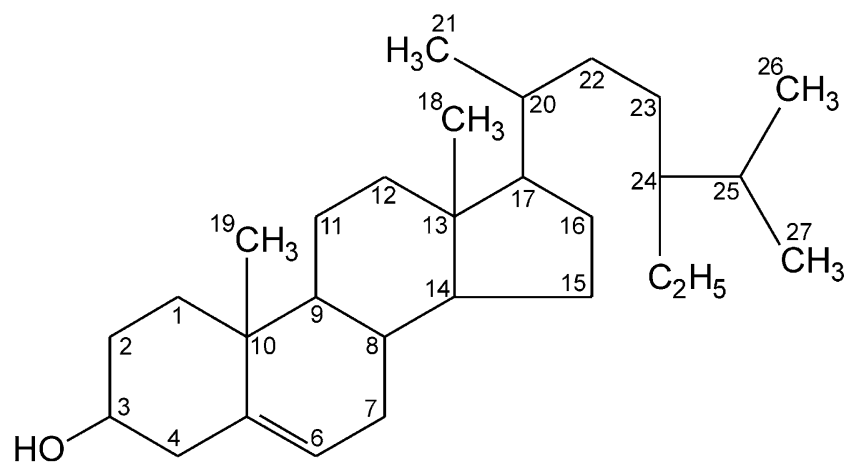

Für die selektive Resorption und Ausscheidung ist die normale Funktion der „ATP-binding cassette (ABC)“-Transporter G8 und/oder G5 erforderlich. Defekte eines dieser Gene führen zur Sitosterolämie, einer Erkrankung mit erhöhtem Serum- und Gewebegehalt von Sitosterin, Xanthomen und frühzeitiger Atherosklerose. Die Konzentrationsbestimmung von Sitosterin erfolgt meist mittels \ GC-MS oder LC-MS/MS. Da Sitosterin einerseits die Entstehung von Atherosklerose fördern kann, andererseits wie auch andere Pflanzensterole und -stanole die Resorption von Cholesterin und die Serumkonzentration von LDL-Cholesterin vermindert, ist die Bedeutung von Sitosterin in der Nahrung und insbesondere als Nahrungsergänzungsmittel momentan Gegenstand der Diskussion.

\section{Literatur}

Gylling H, Plat J, Turley S et al (2014) European Atherosclerosis Society Consensus Panel on Phytosterols. Plant sterols and plant stanols in the management of dyslipidaemia and prevention of cardiovascular disease. Atherosclerosis 232:346-360

\section{$\beta$-Sitosterol}

Sitosterin

\section{Skala, metrische}

C. Vidal und W.-R. Külpmann

Synonym(e) Kardinalskala

Englischer Begriff metric scale

Definition Oberbegriff für Differenzskala ( $\triangleright$ Intervallskala) und Ratio-Skala ( $\triangleright$ Verhältnis-Skala).

\section{Literatur}

DIN 55350, Teil 12 (1989) Begriffe der Qualitätssicherung und Statistik. Merkmalsbezogene Begriffe. Beuth-Verlag, Berlin

\section{Skala, topologische}

C. Vidal und W.-R. Külpmann

Englischer Begriff topological scale

Definition Oberbegriff für $\triangleright$ Nominalskala und $\triangleright$ Ordinalskala.

\section{Literatur}

DIN 55350, Teil 12 (1989) Begriffe der Qualitätssicherung und Statistik. Merkmalsbezogene Begriffe. Beuth-Verlag, Berlin

\section{Skeggs, Leonard Tucker Jr.}

O. A. Gressner und A. M. Gressner

Lebensdaten Amerikanischer Mediziner, geboren am 09. Juni 1918 in Fremont, Ohio/USA, gestorben am 04. Dezember 2002 in Cleveland, Ohio/USA. Studium an der Youngstown State 
University, OH. Master's Degree (1941) und Doktorand (1948) in Biochemie an der Western Reserve University, Cleveland (WRU). Direktor des Hypertensionslabors am Cleveland Veterans Affairs Hospital. 1992 Gründung der Leonard und Jean Skeggs Stiftungsprofessur für Biochemie. Im Jahr 1997 Aufnahme in die Cleveland Medical Hall of Fame.

Verdienste Skeggs und sein Kollege Jack Leonards entwickelten im Jahr 1948 den als ,künstliche Niere“ bezeichneten ersten Plattenhämodialysator. Ebenfalls wurde durch Skeggs der Grundstein für die Entwicklung der ACE-Hemmer im Jahr 1956 mit der bahnbrechenden Aufklärung der Funktion des ,,angiotensin-converting enzyme“ (ACE; $>$ Angiotensinkonvertierendes Enzym) gelegt, wofür er 1968 mit dem Vernon Stouffer Award ausgezeichnet wurde.

Skeggs ist jedoch v. a. für die erste Konzeption von einem teilautomatisierten $>$ Analysegerät für die Laboratoriumsdiagnostik Ende der 1940er-Jahre bekannt, durch dessen Schlauchsystem ein kontinuierlicher „Strom von Reagenzien“ geschickt wurde, die fotometrisch analysiert und über einen Rechner ausgewertet werden konnten. Dieses Verfahren wurde jedoch erst 1954 durch die New Yorker Firma Technicon Corp. weiter kommerzialisiert. Der hieraus hervorgegangene Prototyp des „Autoanalyzer Technicon“ konnte 12 Parameter des Blutserums bestimmen und war bis 1970 in zahlreichen Laboratorien in Gebrauch.

\section{Literatur}

Lewis L (1981) Leonard Tucker Skeggs-a multifaceted diamond. Clin Chem 27(10) 1465-1468

Skeggs LT (1957) An automatic method for colorimetric analysis. Amer J Cin Pathol 28:311-322

\section{Skleroproteine}

> Proteine, fibrilläre

\section{SLA-Antikörper}

Autoantikörper gegen SLA

\section{SLA-Autoantikörper}

- Autoantikörper gegen SLA

\section{SLC4A1}

D Diego-(DI-)Blutgruppensystem

\section{SLC14A1 (solute carrier family 14, member 1)}

- Kidd-Blutgruppensystem

\section{Slides}

- Analyse mit trägergebundenen Reagenzien

\section{S\&L-Index}

- Shine- und Lal-Index

SMA

- Autoantikörper gegen glatte Muskulatur

\section{Small interfering RNA}

- siRNA

\section{Sm-Antikörper}

- Autoantikörper gegen Sm

\section{Smart select}

Data-dependent acquisition

\section{Smooth muscle antibodies}

- Autoantikörper gegen glatte Muskulatur 


\section{SMRP}

- Mesothelin-related peptide

\section{Sn}

- Zinn

\section{Snellius-Brechungsgesetz}

- Refraktion

\section{SNP}

\section{J. Arnemann}

Synonym(e) Einzelnukleotid-Polymorphismus

Englischer Begriff single nucleotide polymorphism; SNP

Definition Mit dem Begriff Einzelnukleotid-Polymorphismus (SNP) wird die Variation eines einzelnen Basenpaares in einem definierten DNA-Abschnitt bezeichnet.

Beschreibung Die SNP-Varianten sind in der SNPDatenbank (dbSNP) unter definierten Referenznummern und mit zusätzlichen Informationen zu Häufigkeit, Allelverteilung und genomischen Kenngrößen gelistet. Die Nukleotid-Substitutionen sind Keimbahnvarianten und damit erblich und unterscheiden sich von somatischen Punktmutationen. In geschätzt zwei Drittel aller Fälle findet sich ein $\mathrm{C}>\mathrm{T}$ Austausch, der oftmals auf die Desaminierung eines methylierten Cytosins (5-Methylcytosin) zu Thymin zurückzuführen ist.

Die SNPs finden sich in kodierenden, wie auch nicht kodierenden intronischen Bereichen. Die Mehrzahl der SNPs sind funktionslos (,silent mutation“), dennoch können in bestimmten Fällen funktionelle Aminosäureaustausche damit einhergehen, bei SNPs in Promotor- oder regulatorischen Bereichen eine Modifikation der Transkriptionsaktivität oder bei SNPs in Intronbereichen in seltenen Fällen eine neue kryptische Spleißstelle. Eine funktionelle Auswirkung muss im Einzelfall und mithilfe der Datenbank überprüft werden.

Einsatzgebiete sind $u$. a. Tests auf krankheitsassoziierte Varianten, wie z. B. die adulte Laktoseintoleranz

\section{Literatur}

dbSNP.: https://www.ncbi.nlm.nih.gov/snp/. Zugegrieffen am 05.06.2018

\section{S/N-Ratio}

- Grundrauschen

\section{S/N-Verhältnis}

- Grundrauschen

$\mathrm{sO}_{2}$

> Sauerstoffsättigung

\section{Société Internationale de Transfusion Sanguine (SITS)}

- International Society of Blood Transfusion

\section{Society of Hair Testing}

A. M. Gressner und O. A. Gressner

Synonym(e) Gesellschaft für Haaranalytik; SoHT

Definition Internationale Gesellschaft zur Förderung der Technologie und Analytik von Haarproben sowie deren wissenschaftliche und klinische Bewertungen.

Beschreibung Die 1995 gegründete internationale Gesellschaft widmet sich der Förderung der Forschung und Entwicklung zur Analytik von Haaren für diagnostische, forensische und arbeitsmedizinische Zwecke. Damit verbunden sind entsprechende Analysen zum Nachweis von Dopingpharmaka und zur Drogenkonsumption. Zu diesem Zweck werden von der SoHT regelmäßig aktuelle ConsensusStatements publiziert und internationale Kongresse zur Präanalytik, Technologie, Materialgewinnung und Interpretation der Ergebnisse organisiert. 


\section{Literatur}

Cooper GAA, Kronstrand R, Kintz P (2012) Society of hair testing guidelines for drug testing in hair. Forensic Sci Int 218(1-3):20-24

Europ Workplace Drug Testing Society, edit. (2010) Drug and alcohol testing in hair, collection and analysis. Version 1.0

http://www.soht.org/

\section{SOD}

- Superoxiddismutase

\section{Sodiumdodecylsulfat-Elektrophorese}

> SDS-Elektrophorese

\section{SOFA-Score}

\section{A. M. Gressner und O. A. Gressner}

Synonym(e) Sequentieller Organfehlfunktion-Score

Englischer Begriff sequential organ failure assessment score

Definition Von der European Society for Intensive Care Medicine festgelegter klinisch-labordiagnostischer Konsens für die objektive Beurteilung des Schweregrads eines Multiorganversagens.
Beschreibung Der SOFA-Score erfasst die wichtigsten Organfunktionen mit jeweils einem Parameter und teilt den Schweregrad der Organdysfunktion entsprechend der Abweichung dieses Parameters von der Norm ein. Grundlage der täglichen Erhebung (24-Stunden-Zeiträume) sind die jeweils schlechtesten Werte für jedes Organsystem, wobei im Einzelnen die Organsysteme Niere, Leber, Lunge, zentrales Nervensystem, Herz, Kreislauf- und Gerinnungssystem in die Bewertung einbezogen werden (Tab. 1). Für jedes einzelne Organsystem werden zwischen 0 (normale Funktion) und 4 (deutlich eingeschränkte Funktion bzw. Einsatz eines Organersatzverfahrens) Punkte vergeben. Alle Organsysteme fließen zu gleichen Teilen in die Gesamtbewertung ein.

Bestimmt werden die Kenngrößen (Kenngröße, klinischchemische):

- Kreatinin oder Ausfuhrmenge
- B Bilirubin (gesamt)
- Blutdruck
- Katecholamine (semiquantitativ)

- Glasgow Coma Scale Score (Grad der Bewusstseinsstörung)

Zur Einschätzung der respiratorischen Leistung wird der Oxygenierungsindex nach Horovitz zur Quantifizierung der pulmonalen Gasaustauschstörung (Horovitz et al. 1974) verwendet. Die Berechnung dieses Oxygenierungsindexes erfolgt durch Bildung des Quotienten aus arteriellem $>$ Sauerstoffpartialdruck $\left(p \mathrm{O}_{2}\right)$ und inspiratorischem Sauerstoffanteil $\left(\mathrm{F}_{\mathrm{i}} \mathrm{O}_{2}\right)$.

Interpretation Studien konnten zeigen, dass eine Zunahme der Score-Werte für jedes einzelne Organsystem eine erhöhte Mortalität prognostiziert. Sowohl die an einem einzelnen Tag erreichte absolute Punktzahl als auch die Differenz zum Aufnahmewert erwies sich als prognostisch bedeutend.

SOFA-Score, Tab. 1 Bewertung des Schweregrads der Organdysfunktion mittels SOFA-Score

\begin{tabular}{|c|c|c|c|c|c|}
\hline Organ & Parameter & $\begin{array}{l}\text { Punkte } \\
1\end{array}$ & 2 & 3 & 4 \\
\hline Respiration & $p \mathrm{O}_{2} / \mathrm{F}_{\mathrm{i}} \mathrm{O}_{2}(\mathrm{mmHg})$ & $<400$ & $<300$ & $\begin{array}{l}\text { Maschinelle Beatmung } \\
<200\end{array}$ & $<100$ \\
\hline Niere & $\begin{array}{l}\text { Kreatinin }(\mathrm{mg} / \mathrm{dL}) \text { oder Urinmenge } \\
(\mathrm{mL} / \mathrm{Tag})\end{array}$ & $1,2-1,9$ & $2,0-3,4$ & $\begin{array}{l}3,5-4,9 \\
<500\end{array}$ & $\begin{array}{l}>5,0 \\
<200\end{array}$ \\
\hline Leber & Bilirubin (gesamt; mg/dL) & $1,2-1,9$ & $2,0-5,9$ & $6,0-11,9$ & $>12,0$ \\
\hline $\begin{array}{l}\text { Herz, } \\
\text { Kreislauf }\end{array}$ & $\begin{array}{l}\text { Blutdruck }(\mathrm{mmHg}) \\
\text { Katecholamine }(\mu \mathrm{g} / \mathrm{kg} \mathrm{KG} / \mathrm{min})\end{array}$ & $\begin{array}{l}\text { MAD } \\
<70 \mathrm{mmHg}\end{array}$ & $\begin{array}{l}\text { Dopamin } \\
\leq 5 \\
\text { Dobutamin }\end{array}$ & $\begin{array}{l}\text { Dopamin }>5 \\
\text { Adrenalin } \leq 0,1 \\
\text { Noradrenalin } \leq 0,1\end{array}$ & $\begin{array}{l}\text { Dopamin }>5 \\
\text { Adrenalin } \leq 0,1 \\
\text { Noradrenalin } \\
\leq 0,1\end{array}$ \\
\hline Gerinnung & Thrombozyten $\left(1000 / \mathrm{mm}^{3}\right)$ & $<150$ & $<100$ & $<50$ & $<20$ \\
\hline ZNS & Glasgow Coma Scale Score & $14-13$ & $12-10$ & $9-6$ & $<6$ \\
\hline
\end{tabular}

$\mathrm{F}_{i} \mathrm{O}_{2}$, inspiratorischer Sauerstoffanteil; $M A D$, mittlerer arterieller Druck; $\mathrm{pO}_{2}$, arterieller Sauerstoffpartialdruck; Glasgow Coma Scale Score, international verbreitetes Punktesystem zur Abschätzung einer Bewusstseinsstörung anhand von Augenöffnung, verbaler und motorischer Reaktion. 


\section{Literatur}

Horovitz JH et al (1974) Pulmonary response to major injury. Arch Surg 108:349-355

Vincent JL et al (1996) The SOFA (Sepsis-related Organ Failure Assessment) score to describe organ dysfunction/failure. Intensive Care Med 22:707-710

\section{Sofortdiagnostik, immunologische}

W. Stöcker und C. Krüger

Synonym(e) Immunschnelltests

Englischer Begriff rapid immunotests

Definition Patientennahe qualitative oder quantitative immunologische Einzelmessungen von Antigenen oder Antikörpern ohne aufwendige Probenvorbereitung, unter Verwendung gebrauchsfertiger Reagenzien.

Einsatzgebiete Patientennahe, von ungeschultem Personal oder vom Patienten selbst ausführbare immunologische Analytik, die innerhalb weniger Minuten zu leicht interpretierbaren Ergebnissen führt. Der Nachweis des humanen Choriogonadotropins (HCG; $>$ Choriongonadotropin, humanes) im Urin (Schwangerschaftstest) war einer der ersten verfügbaren kommerziellen Schnelltests. Mittlerweile gibt es in der Human- und Veterinärmedizin eine Vielzahl immunologischer Schnelltestsysteme. Zum direkten Nachweis von Viren (z. B. $>$ HIV-1 und -2, Influenza-Viren A, B und C und $\checkmark$ Hanta-Viren), Bakterien (Legionellen, Helicobacter, Streptokokken), Pilzen (Candida albicans) oder Parasiten (Plasmodium falciparum) oder zur Untersuchung von Antikörpern bei Autoimmun- und Infektionserkrankungen und Allergien (rheumatoide Arthritis, Zöliakie, Borreliose, allergische Diathese). In der Landwirtschaft weist man mit immunologischen Schnelltests Pestizide nach, bei Verkehrskontrollen Drogen, wie - Amphetamine und Tetrahydrocannabiol (\$Cannabinoide), in der Lebensmittelindustrie $>$ Histamin im Fisch.

Analytik Die Testsysteme für die immunologische Sofortdiagnostik basieren größtenteils auf den gleichen Prinzipien wie konventionelle Assays ( $\triangleright$ Enzyme-linked Immunosorbent Assay, $>$ Immunfluoreszenz, indirekte, $>$ Western blot etc.). Ein Beispiel ist das sogenannte Lateral-flow-Prinzip: Die zu untersuchende Probe wird durch Kapillarkräfte über eine Nitrocellulosemembran gezogen, um dort mit gebundenen Antikörpern (oder Antigenen) zu reagieren. Als Nachweisreagenzien dienen in der Regel mit Gold oder farbigen Latexpartikeln markierte Antigene (oder Antikörper), die in einem zweiten Inkubationsschritt eine visuell identifizierbare Reaktionsbande erzeugen.

Bei anderen Tests wird durch die immunologische Reaktion eine Enzymaktivität beeinflusst, was, über Biosensoren vermittelt, elektrochemische Signale hervorruft. Es gibt auch „homogene Immunschnelltests“, bei denen Probe, Konjugat und Substrat in einem Schritt gemeinsam inkubiert werden.

Probenmaterial Serum, Plasma, Vollblut, Kapillarblut, Speichel, Stuhl, Urin, Liquor.

Diagnostische Wertigkeit Für einige Analyte sind sehr empfindliche immunologische Schnelltests mit Sensitivitäten ( $\triangleright$ Sensitivität, diagnostische) über $98 \%$ verfügbar, z. B. Schwangerschaftstest, HIV-Nachweis. Oft leidet aber die entsprechende Spezifität aufgrund der sehr kurzen Reaktionszeiten, sodass positive Reaktionen nach Möglichkeit in etablierten kompetenten Laboratorien mit konventionellen Testsystemen bestätigt werden sollten. Unentbehrlich sind immunologische Schnelltests unter anderem bei Verdacht auf lebensbedrohliche Erkrankungen, die rasches Handeln erfordern, wie Myokardinfarkt oder Septikämie.

\section{Literatur}

Luppa PB, Schlebusch H (Hrsg) (2008) POCT - Patientennahe Labordiagnostik. Springer, Heidelberg/Berlin/New York, S 382

Stürenburg E, Junker R (2009) Point-of-care testing in microbiology: the advantages and disadvantages of immunochromatographic test strips. Dtsch Ärztebl Int 106:48-54

\section{Sofortdiagnostik, patientennahe}

- Patientennahe Sofortdiagnostik

\section{Software}

O. Colhoun

Synonym(e) Anwendung; Anwendungsprogramm

Englischer Begriff software

Definition Die ,immateriellen“ Komponenten eines Computersystems, im Unterschied zur ,greifbaren“ Hardware.

Beschreibung Nach DIN 44300 die „Gesamtheit oder Teil der Programme für Rechensysteme, wobei die Programme 
zusammen mit den Eigenschaften der Rechensysteme den Betrieb der Rechensysteme, die Nutzung der Rechensysteme zur Lösung gestellter Aufgaben oder zusätzliche Betriebsund Anwendungsarten der Rechensysteme ermöglicht".

\section{SoHT}

$>$ Society of Hair Testing

\section{Solid-phase Micro-Extraction}

C. Vidal und W.-R. Külpmann

Synonym(e) Festphasen-Mikroextraktion; SPME

Englischer Begriff solid phase micro-extraction

Definition Verfahren der Probenvorbereitung für gaschromatographische Analysen ( $\triangleright$ Gaschromatographie).

Beschreibung Bei der SPME handelt es sich um ein Extraktionsverfahren, bei dem eine dünne Faser, die mit speziellen Adsorbenzien belegt ist, Analytmoleküle aus einer Matrix aufnimmt. Anschließend wird die Faser über eine Kanüle in das Einlasssystem eines Gaschromatographen verbracht und die Analyse durchgeführt. Es gibt verschiedene Verfahrensweisen für die SPME. Die Faser kann direkt in eine $\mathrm{zu}$ analysierende Flüssigkeit eingetaucht werden. Beim Vorliegen flüchtiger Analyten kann die Extraktion auch aus dem Dampfraum (Headspace) über einer zu analysierenden Flüssigkeit oder einer festen Probe (z. B. eingedampfter Extrakt) geschehen. Bei letzterer wird ein gasdichtes Gefäß mit der Probe erhitzt. Über die Kanüle einer Spritze wird die SPMEFaser in den Dampfraum des Probengefäßes eingebracht, sodass flüchtige Verbindungen aufgenommen werden können. S. a. > Festphasenextraktion, \ Mikrosäulen.

\section{Literatur}

Pawliszyn J (1997) Solid phase microextraction. Wiley-VCH, New York

\section{Sollwert}

C. Vidal und W.-R. Külpmann

Englischer Begriff method dependent assigned value
Definition Ohne Anwendung eines Referenzmessverfahrens $(\triangleright$ Referenzmessverfahren) ermittelter Zielwert.

Anmerkung: Der Sollwert kann gegenüber dem wahren Wert ( $\triangleright$ wahrer Wert einer Größe) eine nicht vernachlässigbare systematische $>$ Messabweichung enthalten.

\section{Literatur}

Bundesärztekammer (2014) Richtlinie der Bundesärztekammer zur Qualitätssicherung laboratoriumsmedizinischer Untersuchungen. Dtsch Ärztebl 111:A1583-A1618

Qualitätsmanagement in der Laboratoriumsmedizin (2000) Teil 1: Grundbegriffe. DIN 58936-1, 3.1.9.2. Beuth-Verlag GmbH, Berlin

\section{Sollwertermittlung}

C. Vidal und W.-R. Külpmann

Englischer Begriff procedure for the determination of method dependent assigned values

Definition Verfahren zur Bestimmung von Sollwerten ( $>$ Sollwert) in $>$ Kontrollmaterial.

Beschreibung Für die Beurteilung der Richtigkeit im Rahmen der internen $>$ Qualitätssicherung werden Kontrollmaterialien ( $>$ Kontrollmaterial) benötigt, die vorgeben, welcher Messwert mit einem bestimmten Analyseverfahren gefunden werden sollte. Dieser Sollwert ist nur für das genau angegebene Analysenverfahren gültig, muss aber soweit als technisch möglich metrologisch rückführbar sein. Das Verfahren wird eingesetzt, wenn ein $>$ Referenzmethodenwert nicht zur Verfügung stehen.

\section{Literatur}

Bundesärztekammer (2014) Richtlinie der Bundesärztekammer zur Qualitätssicherung laboratoriumsmedizinischer Untersuchungen. Dtsch Ärztebl 111:A1583-A1618

\section{Somatische Mutation}

J. Arnemann

Synonym(e) Spontane Gewebemutation 


\section{Englischer Begriff somatic mutation}

Definition Im Gegensatz zu Keimbahnmutationen entstehen somatische Mutationen spontan und betreffen nur bestimmte Zellreihen, können also, mit Ausnahme von De-novo-Keimzellmutationen, nicht weiter vererbt werden.

Beschreibung Somatische Mutationen sind mehrheitlich Fehler bei der DNA-Replikation mitotisch aktiver Zellen und werden als Transläsionssynthese (TLS) beschrieben. Unter TLS versteht man einen Prozess, der in einem gewissen Rahmen einen DNA-Schaden toleriert und eine DNAReplikation über DNA-Läsionen, wie z. B. Thymindimere oder AP-Abschnitte, hinweg erlaubt. Unter AP-Abschnitte versteht man in diesem Zusammenhang ein abasisches Molekül, das aufgrund von chemischen Noxen weder eine Purinnoch eine Pyrimidinbase (,apurinic/apyrimidic site") besitzt. Ein wesentlicher Faktor sind dabei oxidative DNA-Schäden. Aber auch Fehler bei der DNA-Reparatur oder Mutationen aufgrund von mutagenen Agenzien können das Entstehen von somatischen Mutationen fördern.

Ein pathogener Effekt kann bevorzugt auftreten, wenn es sich um sehr teilungsaktive Zellen handelt und die Mutation zelluläre Funktionen, Regelkreise, Signalwege oder die DNAReparaturmechanismen grundlegend stört. Dies kann die zelluläre Differenzierung beeinträchtigen und zu einer Proliferation wenig differenzierter Zellen als möglichen Beginn einer Tumorerkrankung führen.

Bei erblichen Tumorerkrankungen, wie z. B. erblicher Brust- und Eierstockkrebs Typ BRCA1/2, bei denen bereits konstitutiv eine ererbte Mutation vorliegen, kann das Auftreten einer zweiten somatischen Mutation so die Krebsentstehung triggern, zumal es zu einem Komplettausfall der Funktion eines Tumorsuppressors kommt.

\section{Literatur}

Martincorena I, Campbell PJ (2015) Somatic mutation in cancer and normal cells. Science 349:1483-1489

\section{Somatokrinin}

- Wachstumshormon-Releasinghormon

\section{Somatomedin C}

$>$ Insulin-like growth factor I

\section{Somatorelin}

- Wachstumshormon-Releasinghormon

\section{Somatostatin}

A. M. Gressner und O. A. Gressner

Synonym(e) SRIF

Englischer Begriff somatostatin; somatotropin release inhibiting hormone (factors); SRIF

Definition Ein in mehreren Organen und Geweben (Magen, Duodenum, Pankreas, Darmtrakt, Hypothalamus, ZNS) synthetisiertes, lineares Peptidhormon mit breiter inhibitorischer Wirkung auf Hormon-, Magen- und exokrine Pankreassekretion.

Beschreibung Das in den D-Zellen des Magenantrums, in Duodenum, Langerhans-Inseln des Pankreas, Intestinaltrakt, Hypothalamus und ZNS als Präprosomatostatin synthetisierte, nachfolgend proteolytisch prozessierte Somatostatin kommt in 2 Formen mit 14 Aminosäuren (SS-14, SRIF ${ }_{14}$ ) und 28 Aminosäuren (SS-28, $\left.\mathrm{SRIF}_{28}\right)$ vor, deren relative Verteilung gewebeabhängig verschieden ist (s. Abbildung): SS-14 vorwiegend im ZNS und alleinig im Pankreas, SS-28 im Magen-Darm-Trakt.

Die Abbildung zeigt die Struktur und die Prozessierung von Somatostatin:

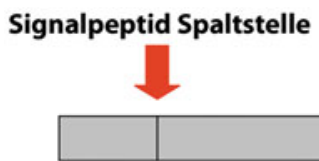

Proteolytische Spaltstellen

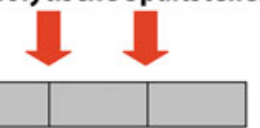

Präprosomatostatin

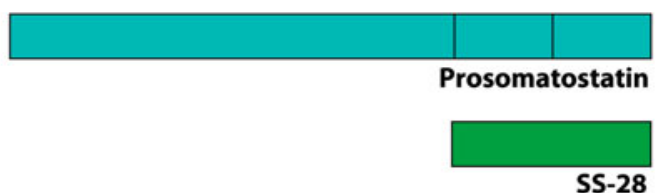

\section{Somatoliberin}

- Wachstumshormon-Releasinghormon 
Sekretionsstimuli sind Nahrungsaufnahme und Magensäure im Duodenallumen. Physiologische Effekte (antisekretorisch, antiproliferativ, antiangiogen) werden über 5 Subtypen G-Protein-gekoppelter Rezeptoren vermittelt und betreffen:

Hemmt die Sekretion von > Somatostatin, - Wachstumshormon, \ Thyreotropin, \ Insulin, \ Glukagon, \ Gastrin, - Cholecystokinin, > Sekretin, > Polypeptid, pankreatisches, - Vasoaktives intestinales Polypeptid, \ Gastrointestinales Peptid, Motilin, Calcitonin, Triiodthyronin ( $\triangleright$ Triiodthyronin, freies), Thyroxin ( $\triangleright$ Thyroxin, freies), - Aldosteron und anderen Hormonen. Damit Inhibitor der Magensäure-, Pankreassaft- und Gallesekretion. Zusätzlich neuromodulatorische Aktivität.

Halbwertszeit in der Zirkulation 1-3 Minute.

Nüchternkonzentration im EDTA-Plasma methodenabhängig verschieden, Richtwert für Normalpersonen $<25 \mathrm{ng} / \mathrm{L}$.

Analyt instabil (eisgekühltes Plasma mit Aprotininzusatz).

Konzentrationsbestimmung mit kompetitivem $>$ Radioimmunoassay oder $>$ Enzymimmunoassay nach Säulenextraktion.

Konzentrationserhöhungen: Somatostatin-produzierender Tumor (Somatostatinom), Phäochromozytom, alkoholische Lebererkrankungen, Colitis ulcerosa.

\section{Literatur}

Herrera-Martinez AD, Gahete MD, Pedraza-Arevalo S et al (2018) Clinical and functional implication of the components of somatostatin system in gastroenteropancreatic neuroendocrine tumors. Endocrine 59(2):426-437

Weckbecker G, Lewis I, Albert R, Schmidt HA, Hoyer D, Bruns C (2003) Opportunities in somatostatin research: biological, chemical and therapeutic aspects. Nat Rev Drug Discov 2:999-1017

\section{Somatotropes Hormon}

- Wachstumshormon

\section{Somatotropin}

- Wachstumshormon

\section{Somatropin}

- Wachstumshormon

\section{Sonata}

- Zaleplon

SOP

- Standardarbeitsanweisung

\section{Sorbens}

> Stationäre Phase

\section{Sorbitdehydrogenase}

A. M. Gressner und O. A. Gressner

Synonym(e) EC 1.1.1.14; Iditol-Dehydrogenase; SDH

Englischer Begriff sorbitol dehydrogenase; L-iditol dehydrogenase

Definition SDH ist ein für den Fruktosestoffwechsel der Leber wichtiges, rein zytoplasmatisch lokalisiertes und mit hoher spezifischer Aktivität nur in der Leber (Hepatozyten) vorkommendes Enzym, dessen Aktivitätsbestimmung im Serum früher zur Diagnose nekrotisierender Leberparenchymschäden eingesetzt wurde.

Synthese - Verteilung - Abbau - Elimination SDH katalysiert die reversible Umwandlung von D-Fruktose zu $\mathrm{D}$-Sorbit in Anwesenheit von NADH $+\mathrm{H}^{+}$. Die Organgehalte an SDH-Aktivität in Leber, Niere und Prostata verhalten sich wie 200:50:1, die mit Abstand höchste spezifische Aktivität besitzt die Leber. Muskel und Erythrozyten enthalten nur sehr geringe oder keine SDH-Aktivitäten.

Funktion - Pathophysiologie SDH im Serum ist ausschließlich hepatischen Ursprungs (hohe Organspezifität). Extrazellulär verliert SDH rasch an Aktivität.

Untersuchungsmaterial-Entnahmebedingungen Serum, Heparin-Plasma. 
Probenstabilität SDH ist sehr instabil. Bei Raumtemperatur $25 \%$ Aktivitätsabnahme pro Tag, bei $4-8{ }^{\circ} \mathrm{C}$ und bei $-20^{\circ} \mathrm{C}$ ebenfalls Aktivitätsverluste.

Analytik Die Aktivitätsbestimmung erfolgt im einfachen optischen Test gemäß folgender Reaktion:

$$
\text { D-Fruktose }+\mathrm{NADH}+\mathrm{H}^{+} \underset{\mathrm{pH} \mathrm{9,5}}{\stackrel{\mathrm{pH} \mathrm{7,5}}{\rightleftarrows}} \text { D-Sorbit }+\mathrm{NAD}^{+}
$$

Die Oxidationsrate von NADH $+\mathrm{H}^{+}$gemessen an der Absorptionsabnahme bei 334, 340 oder $366 \mathrm{~nm}$ pro Zeiteinheit entspricht der SDH-Aktivität.

Referenzbereich - Erwachsene $37{ }^{\circ} \mathrm{C}$ Messtemperatur: 0-2,6 U/L (44 nkat/L).

Im gesunden Serum ist (nahezu) keine SDH-Aktivität nachweisbar.

Indikation Diagnose und Verlaufskontrolle von Leberparenchymzellschädigungen.

Interpretation Aktivitätsanstiege sind spezifisch für Parenchymzellnekrosen im Rahmen akuter infektiöser Hepatitiden, toxischen Leberzellschädigungen, hypoxischer Leberschäden (z. B. akute Rechtsherzinsuffizienz nach Herzinfarkt), primärer und sekundärer Lebertumoren und Traumatisierungen. Die Verwendung des Enzyms ist heute obsolet, da Aktivitätsanstieg relativ flüchtig und inkonstant sind.

\section{Literatur}

El-Kabbani O, Darmanin C, Chung RP (2004) Sorbitdehydrogenase: structure, function and ligand design. Curr Med Chem 11(4):465-476

Greiling H, Gressner AM (Hrsg) (1995) Lehrbuch der Klinischen Chemie und Pathobiochemie, 3., neubearb. Aufl., Schattauer Verlag, Stuttgart, New York

\section{Sotalol}

$>\beta$-Rezeptorenblocker

\section{Southern, Edwin Mellor}

\section{A. M. Gressner und O. A. Gressner}

Lebensdaten Englischer Chemiker und Molekularbiologe, geboren am 7. Juni 1938 in Burnley, Lancashire, UK.
Verdienste Nach dem Studium der Chemie an der University of Manchester (1958) und Promotion an der University of Glasgow (1962) arbeitet Southern als Molekularbiologe am Medical Research Council (MRC) der University of Edinburgh, wo er sich methodisch mit der DNA-Sequenzanalyse beschäftigte. Dort entwickelte er auch die nach ihm benannte Methode des „Southern Blots“ zum Nachweis spezifischer DNA-Sequenzen, die er 1975 im Journal of Molecular Biology publizierte ( $\triangleright$ Southern-Blot-Analyse). Weitere Projekte in seiner Zeit als Direktor des Institutes of Biochemistry an der University of Oxford waren auf die Kartierung des humanen Genoms und auf die Entwicklung von DNA-Chips gerichtet.

\section{Literatur}

Harding A (2005) Sir Edwin Southern: scientist as problem solver. Lancet 366:1919

Southern EM (1975) Detection of specific sequences among DNA fragments separated by gel electrophoresis. J Mol Biol 98(3): $503-517$

\section{Southernblot}

- Southern-Blot-Analyse

\section{Southern-Blot-Analyse}

\section{J. Arnemann}

Synonym(e) Southernblot

Englischer Begriff Southern blot analysis

Definition Zweck der Southern-Blot-Analyse ist die Darstellung von spezifischen DNA-Fragmenten durch Hybridisierung mit definierten DNA-Sonden nach erfolgtem Transfer der restriktionsenzymatisch gespaltenen und im Agarosegel elektrophoretisch aufgetrennten DNA-Moleküle auf eine Trägerfolie.

Beschreibung Die in einer Agarosematrix gelelektrophoretisch aufgetrennten DNA-Fragmente werden in Spiegelung des photographisch dokumentierten Auftrennungsergebnisses in 
einem 1:1-Verhältnis auf eine Trägermembran übertragen und für weitergehende Anwendungen fixiert.

Die Übertragung erfolgt dabei im klassischen SouthernBlotting, einer Methode nach dem Biochemiker Southern ( $\triangleright$ Southern, Edwin Mellor). Hierbei werden die gefärbten und photographierten Agarosegele mit den längenmäßig aufgetrennten und als „Wolke“ nicht identifizierbaren DNA-Fragmenten durch Inkubationen in

- depurinierender Lösung (0,25 M HCl-Lösung) zur Fragmentierung,

- alkalischer Denaturierungslösung $(0,5 \mathrm{~N} \mathrm{NaOH}-1,5 \mathrm{M}$ NaCl-Lösung) zur Überführung vom DNA-Doppel- zum DNA-Einzelstrang und

- Neutralisierungspuffer (z. B. $1 \mathrm{M}$ Tris- $\mathrm{HCl}$ pH $5-3 \mathrm{M}$ $\mathrm{NaCl})$ zur Neutralisierung.

Das Gel wird anschließend auf den Southern-Blot-Apparat, einer Glasscheibe zwischen 2 Pufferbehältern $(20 \times$ SSC-Lösung) gelegt mit Verbindung über dickes Filterpapier. Das Agarosegel wird mittels Frischhaltefolie an den Seiten perfekt abgedeckt. Anschließend wird die eigentliche Trägermembran (Nylon- oder Nitrozellulosemembran) passgenau auf das Gel platziert und mit einem Stapel Filterpapiere und einem kleinen Gewicht $(250-500$ g) bedeckt. Die Kapillarkräfte lassen den Puffer durch das Agarosegel und die Trägermembran nach oben in den Filterpapierstapel steigen, wobei die einzelsträngigen DNA-Fragmente mitgeführt werden und in korrespondierender Position an die Trägermembran binden und nach abgeschlossenen Transfer fixiert werden (z. B. durch UV-Licht).

Die Trägermembranen werden anschließend in Hybridisierungsexperimenten eingesetzt, wo definierte einzelsträngige DNA-Sonden (z. B. Plasmide), radioaktiv mittels $\mathrm{P}^{32}$ markierte Nukleotide oder nicht radioaktiv mittels DIG oder Biotin markierte Nukleotide, mit der Trägerfolie inkubiert werden. Die Sonden hybridisieren dabei mit den komplementären DNA-Fragmenten (z. B. Patienten-DNA) auf der Trägerfolie und bilden ein stabiles Hybridmolekül, das entsprechend der Markierung durch Autoradiographie $\left(\mathrm{P}^{32}\right)$ oder Chemielumineszenz (DIG, Biotin) nachgewiesen wird. Die Größen der dargestellten DNA-Fragmente werden anhand von mitgeführten DNA-Markern bestimmt.

Die Southern-Blot-Analyse ermöglicht eine Kartierung und Zuordnung von DNA-Fragmenten im Rahmen einer RFLP-Analyse (Restriktionsfragmentlängenanalyse) und die Detektion pathologischer bzw. abweichender DNA-Fragmente im Krankheitsfall.

Die Methode hat in den vergangenen Jahren zugunsten der PCR-Techniken ( $\triangleright$ PCR (Polymerase-Kettenreaktion)) an Bedeutung verloren und wird diagnostisch nur noch selten, wie z. B. zur Methylierungsanalyse bei fraX-Patienten (FMR1) eingesetzt.

\section{Literatur}

Roche Molecular Biochemicals (2000) DIG application manual for filter hybridization. Roche Diagnostics $\mathrm{GmbH}$, Mannheim

Sambrook J, Fritsch EF, Maniatis T (1989) Molecular cloning - a laboratory manual. Cold Spring Harbor Laboratory Press, New York

Southern EM (1975) Detection of specific sequences among DNA fragments separated by gel electrophoresis. J Mol Biol 98:503-517

\section{SOX1-Autoantikörper 2}

- Autoantikörper gegen Gliazell-Nuclei

SOX2-Gen-Test

- SHOX2-Test

SP

- Phosphatase, Prostataspezifische Saure

- Phosphatase, Saure

- Phosphatase-Reaktion

\section{SP-2}

- Sexualhormon-bindendes Globulin

\section{Spannweite}

R.-D. Hilgers, N. Heussen und S. Stanzel

Synonym(e) Range

\section{Englischer Begriff range}

Definition Die Spannweite ist definiert als die Differenz zwischen dem kleinsten ( $\triangleright$ Minimum) und dem größten $(\triangleright$ Maximum $) \triangleright$ Messergebnis.

Beschreibung Die Spannweite ist ein ausreißerempfindliches Maß für die \ Variabilität der Messergebnisse. Während 
eine Addition bzw. Subtraktion einer Konstanten zu bzw. von allen Messwerte den Wert der Spannweite nicht beeinflusst, wirken sich eine Multiplikation bzw. Division aller Messwerte mit bzw. durch einen konstanten Faktor derart auf die Spannweite aus, dass sich dieser gemäß derselben mathematischen Operation ändert. Die letztgenannte Eigenschaft der Spannweite findet insbesondere bei einer Änderung der Skala, in der die Werte gemessen wurden, Verwendung.

\section{Literatur}

Hilgers R-D, Bauer P, Scheiber V (2002) Einführung in die Medizinische Statistik. Springer, Berlin/Heidelberg/New York

\section{SPARC}

$>$ Osteonectin

\section{SPE}

> Mikrosäulen

\section{Spearman- Rangkorrelationskoeffizient}

- Korrelationskoeffizient nach Spearman

\section{Spearman'scher Rangkorrelationskoeffizient}

Korrelationskoeffizient nach Spearman

\section{Specimen}

- Spezimen

\section{Speciociliatin}

Kratom

\section{Speciogynin}

Kratom

\section{Speed}

T. Arndt

Definition Straßenname/Deckname für Amphetamine ( $\triangleright$ Straßennamen von Drogen: Amphetamine).

\section{Speichel als Probe}

Speichelgewinnung

\section{Speichel und Drogen}

T. Arndt

Synonym(e) Drogenscreening in Speichel; Mundflüssigkeit und Drogen

Englischer Begriff saliva and drugs; oral fluid and drugs; drug screening in oral fluid/saliva

Definition Nachweis von Drogen in Speichel bzw. Mundflüssigkeit.

Beschreibung Drogen und deren Metabolite gelangen durch passive Diffusion aus dem Blut, Filtration, aktive Sekretion und orale Kontamination in die $>$ Mundflüssigkeit (s. Anmerkung unten) und können dort einen kurzzeitig zurückliegenden Drogenkonsums anzeigen.

Mit der Verfügbarkeit geeigneter Speichelsammelsysteme steigt das Interesse an Speichel bzw. Mundflüssigkeit als alternative Matrix zu Blut und Urin. Sie bietet z. B. Vorteile bei der Probennahme. Diese ist nicht invasiv (wie die Blutentnahme), nicht die Intimsphäre berührend (wie die Urinab- 
gabe unter Sichtkontrolle) und im Beisein einer Aufsichtsperson weitgehend manipulationssicher. Weitere Vorteile sind im Vergleich zu Urin die Nachweisbarkeit der Muttersubstanzen und eine einheitlichere Matrix und im Vergleich zu Blut die zumeist höheren Analytkonzentrationen.

Die Probensammlung kann über Adsorbentien wie Watte oder Zellstoff erfolgen ( $\triangleright$ Speichelgewinnung) oder über ein flüssigkeitsbasiertes Sammelsystem. Bei letzterem werden z. B. $4 \mathrm{~mL}$ einer mit Lebensmittelfarbstoff markierten, schwach sauren Pufferlösung 2 Minuten im Mund belassen und dann in einen Becher ausgespuckt. Das Gemisch wird anschließend in Probenröhrchen überführt und analysiert.

Bei diesem Verfahren dienen der saure $\mathrm{pH}$ einer forcierten Speichelsekretion und der Farbstoff der kolorimetrischen Bestimmung des Anteils an Mundflüssigkeit im Gemisch. Zusätzlich werden Kortisol und Amylaseaktivität als wichtige Speichelcharakteristika bestimmt, um Manipulationen durch ggf. in den Backentaschen abgelegte Flüssigkeiten zu erkennen. Drogenscreenings in Mundflüssigkeit ergaben z. B. im Vergleich zu Urinscreenings höhere Nachweisraten für Amphetamin- und Heroinkonsum.

Derzeit noch nicht abschließend geklärte Fragen betreffen alle Phasen der Erstellung eines analytischen Befundes:

Präanalytik Einfluss physiologischer und pathologischer Zustände (z. B. hoher Sympathikotonus oder generelle Mundtrockenheit), Stabilität der Analyte im Speichel.

Analytik Probenvorbereitung, Extraktionsverfahren, analytische Sensitivität im niedrigen $\mathrm{pg} / \mathrm{mL}$-Bereich (niedriger als im Urin), Qualitätskontroll- und Ringversuchsmaterial adäquater Matrix.

Postanalytik/Interpretation Standardisierung der Matrix (ähnlich zum Kreatininbezug für Urinanalysen), Wirkstoffkonzentrations-Wirkungs-Beziehungen, Speichel-Blut-Konzentrationsverhältnisse, Entscheidungsgrenzen (cut-offs).

Anmerkung Im Bereich der Klinischen Chemie wird zumeist der Begriff Speichel (engl. ,saliva“) benutzt, im Bereich der forensischen Toxikologie und Arbeitsmedizin, insbesondere im Drogenscreening, der Begriff Mundflüssigkeit, da er die tatsächlich im Mundraum gewonnene Probenmatrix, die kein reiner Speichel ist, besser beschreibt.

\section{Literatur}

Boettcher M (2014) Drogen- und Medikamententestung im Speichel. Trillium Diagnostik 2:82-83

Wille SM, Baumgartner MR, Fazio VD, Samyn N, Kraemer T (2014) Trends in drug testing in oral fluid and hair as alternative matrices. Bioanalysis 6:2193-2209

\section{Speichelanalytik}

T. Arndt

Synonym(e) Salivaanalytik

Englischer Begriff oral fluid analysis; saliva analysis

Definition Nachweis oder Quantifizierung von biochemischen Kenngrößen in Speichel bzw. Mundflüssigkeit.

Beschreibung Mit der Verfügbarkeit geeigneter Speichelsammelsysteme ( $\triangleright$ Speichelgewinnung) steigt das Interesse an Speichel bzw. Mundflüssigkeit als eine nicht invasiv zugängige Matrix für labormedizinische Untersuchungen. Speichelanalysen wurden u. a. bei Mund- und Rachenraum-, Autoimmun- und Infektionserkrankungen vorgeschlagen. Eine Übersicht findet sich bei Prasad et al. 2016.

Eine breitere Anwendung von Speichelanalysen im Routinelabor ist noch nicht zu erkennen. Die meisten Erfahrungen liegen derzeit im Bereich der Drogenanalytik vor $(\triangleright$ Speichel und Drogen).

\section{Literatur}

Prasad S, Tyagi AK, Aggarwal BB (2016) Detection of inflammatory biomarkers in saliva and urine: potential in diagnosis, prevention, and tretament for chronic diseases. Exp Biol Med 241:783-799

\section{Speicheldrüsengangepithel- Antikörper}

- Autoantikörper gegen Speicheldrüsenausführungsgänge

\section{Speichelgewinnung}

W. G. Guder

Synonym(e) Probengewinnung von Speichel; Speichel als Probe

Englischer Begriff saliva collection; collection of saliva as sample (specimen) 
Definition Alle Arten der Gewinnung von Speichel als Untersuchungsmaterial für diagnostische Zwecke.

Beschreibung Speichel als Untersuchungsmaterial hat die Vorteile der nichtinvasiven Gewinnung und zuweilen der spezifischeren Information über „freie“ Konzentrationen z. B. von Medikamenten und Drogen im Körper, verglichen mit Plasma. Die Gewinnung der Probe wird mit einer der kommerziell erhältlichen Speichelsammelvorrichtungen empfohlen, die auf folgenden Prinzipien beruhen:

- Watterollen, die in den Mund eingelegt werden (z. B. Sarstedt Salivette, Clin Rep Recipe)

- Polymerschaumstoff (Accu Sorb oder Oral Screen von Avitar Technologies)

- Kunstseide oder Baumwolltupfer am Stiel (Orapette, Fa. Trinity Biotech; Saliva Alcohol Test; Fa. STC-Technologies; Saliva Sampler, Fa. Stat Sure Diagnostic Systems, USA; Saliva Collection System (SCS) zum Sammeln von oraler Flüssigkeit („oral fluid“), Fa. Greiner-Bio One; Abusa-Stick; Fa. Chem Elec)

- Polster am Lollipop-Stiel (Ora Sure = Epi-Screen, Fa. Epitope, USA)

Die Speichelgewinnung erfolgt normalerweise aus gemischtem Speichel der Parotis und Submandibulardrüsen. Durch Einlegen von Absorbern unter die Ausführungsgänge der jeweiligen Speicheldrüsen können aber auch gezielt Speichelproben der seitlich getrennten und nach Drüsen getrennten Arten gewonnen werden. Die Absorber werden durch Zentrifugation in einem speziellen Probengefäß vom klaren Speichel befreit, der dann als Untersuchungsmaterial dient.

\section{Literatur}

Guder WG (2015) When are other other body fluids to be analyzed? In: Guder WG, Narayanan S (Hrsg) Pre-examination procedures in laboratory diagnostics. Walter de Gruyter, Berlin/Boston, S 81-89

Haeckel R, Colic D (1988) Verfahren zur Speichelgewinnung. In: Haeckel R (Hrsg) Speicheldiagnostik. GIT-Verlag, Darmstadt, S 1-8

\section{Speichermedium}

- Datenträger

\section{Spektralphotometer}

T. Arndt

Synonym(e) Spektrophotometer

Englischer Begriff spectrophotometer

Definition Umgangssprachliche Bezeichnung für ein Spektrometer zur bildlichen Darstellung eines Spektrums $(\triangleright$ Spektrum).

Beschreibung Nach den Empfehlungen der IUPAC soll der Begriff nicht mehr für spektrochemische Methoden und Verfahren verwendet werden, da $\triangleright$ Photometrie/ $\triangleright$ Photometer die rein visuelle Auswertung einer Strahlung beschreiben und nicht die Aufzeichnung von Intensitäten von Spektralbanden mithilfe eines oder mehrerer Detektoren, wie es in der analytischen Chemie heute üblich ist.

\section{Literatur}

Inczedy J, Lengyel T, Ure AM (1998) Compendium of analytical nomenclature (definitive rules 1997), 3. Aufl. Blackwell Science, Oxford.

\section{Spektralphotometrie}

T. Arndt

\section{Speicheltest}

- Kaugummitest

\section{Speicheltestung}

Salivatestung
Synonym(e) Spektrophotometrie

\section{Englischer Begriff spectrophotometry}

Definition Umgangssprachliche Bezeichnung für eine Analyse zur bildlichen Darstellung eines Spektrums ( $\triangleright$ Spektrum).

Beschreibung Heute unüblich, weil die aktuellen Methoden und Verfahren nicht auf einer visuellen Beobachtung und Auswertung beruhen, sondern gewöhnlich Intensitäten von Spektralbanden aufzeichnen und danach per definitionem zur - Spektrometrie/Spektroskopie gehören. 


\section{Spektrenbibliothek}

$\checkmark$ Bibliotheksuche

\section{Spektrenvergleich}

- Bibliotheksuche

\section{Spektrochemische Analyse}

- Spektrometrie/Spektroskopie

\section{Spektrograph}

T. Arndt

Englischer Begriff spectrograph

Definition Kombination von $>$ Spektroskop oder Spektrometer ( $\triangleright$ Spektrometrie/Spektroskopie) mit einer Kamera, die ein Bild eines Strahlungsspektrums ( $\triangleright$ Spektrum) auf ein Fotogel oder eine zweidimensionale Anordnung elektronischer Bildsensoren aufnimmt (IUPAC-Definition).

\section{Literatur}

Inczedy J, Lengyel T, Ure AM (1998) Compendium of Analytical Nomenclature (definitive rules 1997), 3. Aufl. Blackwell Science, Oxford.

\section{Spektrometrie/Spektroskopie}

T. Arndt

Synonym(e) Spektrochemische Analyse

Englischer Begriff spectrometry/spectroscopy; spectrochemical analysis

Definition Die Begriffe Spektrometrie und $\triangleright$ Spektroskopie sind Oberbegriffe für alle Messmethoden ( $\triangleright$ Messmethode) und Verfahren, bei denen Phänomene der Lichtabsorption und Lichtemission aufgenommen und ausgewertet werden.

Beide Begriffe werden zumeist synonym verwandt. Tatsächlich werden rein spektroskopische Methoden in der Analytik immer seltener angewandt. Der Begriff Spektrometrie setzt sich deshalb immer stärker durch. Nach der gültigen IUPAC-Definition ist der Begriff Spektrometrie zu verwenden, insbesondere dann, wenn die Lichtabsorptions- und Lichtemissionsphänomene durch einen Detektor aufgezeichnet (und nicht nur visuell beobachtet) werden. Danach sind praktisch alle im klinisch-chemischen Labor eingesetzten, auf Lichtabsorption bzw. Lichtemission beruhenden Analysenverfahren spektrometrische Verfahren.

Physikalisch-chemisches Prinzip Grundlage der Spektrometrie ist das $>$ Lambert-Beer-Gesetz. Zur Bestimmung der Konzentration (c) eines Analyten aus der Extinktion (E) wird das Gesetz in der Form $\mathrm{c}=\mathrm{E}_{\lambda, \mathrm{T}} / \varepsilon_{\lambda, \mathrm{T}} \times \mathrm{d}$ angewandt, wobei die Schichtdicke (d) und der Extinktionskoeffizient $\left(\varepsilon_{\lambda, T}\right)$ in Abhängigkeit von der Wellenlänge $(\lambda)$ und der Temperatur (T) durch die Messbedingungen festgelegt sind.

Einsatzgebiet Das Einsatzgebiet der Spektrometrie umfasst praktisch alle Bereiche des klinisch-chemischen Labors, also z. B. enzymatische, immunologische, elektrophoretische und chromatographische Analysen. Einige Methoden nutzen charakteristische physikochemische (spektrochemische) Eigenschaften des Analyten direkt zur Analyse (z. B. - Atomabsorptionsspektrometrie und $>$ Atomemissionsspektrometrie, Flammenatomabsorptionsspektrometrie ( $\triangleright$ Flammenatomabsorptionsspektrometrie/-spektroskopie), > Flammenemissionsspektrometrie, - UV/VIS-Spektrometrie mit > Photodioden-Array-Detektor). Andere werten die infolge von spezifischen Reaktionen eintretenden Veränderungen in den spektrochemischen Eigenschaften des Analysensystems aus. Diese Veränderungen können unmittelbares Ergebnis der Umsetzungsreaktion sein (z. B. im optischen Test nach Warburg [ $\triangleright$ Enzymaktivität], in der $\triangleright$ Immunnephelometrie und $>$ Immunturbidimetrie) oder aus mit der Umsetzung des Analyten gekoppelten Reaktionen resultieren (z. B. im gekoppelten optischen Test nach Warburg).

Untersuchungsmaterial Prinzipiell sind alle Untersuchungsmaterialien unabhängig vom Aggregatzustand (fest, flüssig, gasförmig) für spektrometrische Analysen geeignet. Im klinisch-chemischen Labor handelt es sich mehrheitlich um Analysen in ursprünglich flüssigen Proben (Blut, Plasma, Serum, Urin) oder durch Flüssigextraktion gewonnene Extrakte aus festen Proben (z. B. Fäzes).

Instrumentierung Ein spektrometrisches Analysensystem zur Lichtabsorptionsmessung besteht in seiner allgemeinen Form aus einer Strahlungsquelle, z. B. einer $>$ Deuterium- 
lampe oder $\triangleright$ Xenonlampe zur Erzeugung von Licht im ultravioletten oder einer $>$ Wolfram(faden)lampe ("Glühbirne“) für den visuellen Wellenlängenbereich. Der Strahlengang wird durch ein Dispersionssystem wie z. B. ein Prisma oder ein Gitter ( $\triangleright$ Monochromator) geführt, um aus dem originär polychromatischen Licht monochromatisches Licht, d. h. Licht einer bestimmten Wellenlänge (exakter eines sehr engen Wellenlängenbereiches), zu isolieren. Dieses wird durch die Messzelle ( $\triangleright$ Küvette) geleitet und in Abhängigkeit von der Farbe und Farbdichte der in der Messzelle vorliegenden Probe unterschiedlich stark absorbiert. Hierdurch erfolgt eine Abschwächung des Lichtes. Aus der Differenz der Intensitäten des in die Messzelle eintretenden und aus ihr austretenden Lichtes kann, unter Zugrundelegung vom > Lambert-BeerGesetz und geeigneter Kalibrationsfunktionen, auf die Konzentration des Analyten in der Messzelle bzw. der Probe geschlossen werden.

Als Strahlungsempfänger werden photoelektrische Empfänger wie $>$ Photoelement, $>$ Photozelle, $>$ Photomultiplier (Sekundärelektronenvervielfacher, SEV) und $>$ Photodiode, aber auch thermoelektrische Empfänger wie Thermoelemente und Widerstandsthermometer eingesetzt. Einzelheiten unten den jeweiligen Stichwörtern.

In der $>$ Atomabsorptionsspektrometrie (AAS) kann auf das Dispersionssystem zur Herstellung monochromatischen Lichts verzichtet werden, da dieses (elementspezifisch) direkt in einer sog. Hohlkathodenlampe generiert wird. Zu den Besonderheiten der $>$ Atomemissionsspektrometrie (AES) s. dort.

Spezifität Analytische Spezifität und Sensitivität spektrometrischer Methoden sind, in Abhängigkeit von der jeweiligen Fragestellung (Untersuchungsgut, Analyt, störende Begleitsubstanzen mit ähnlichen physiko-chemischen Eigenschaften) ausreichend bis hervorragend.

Fehlermöglichkeit Unter der Voraussetzung einer ausreichenden analytischen Validierung sind spektrometrische Analysenverfahren hinreichend richtig und präzise. Zu möglichen Fehlerquellen s. unter den speziellen Analysenverfahren.

Praktikabilität - Automatisierung - Kosten Die Spektrometrie ist die mit großem Abstand am häufigsten eingesetzte Analysenmethode des klinisch-chemischen Labors. Dementsprechend steht eine breite Auswahl an Spektrometern vom transportablen Handgerät bis zum vollmechanisierten Analysensystem zur Verfügung. Letztere sind geeignet, Analysenserien von mehreren Hundert Proben und diese bei fast gleichzeitiger Bestimmung von teilweise mehr als 50 verschiedenen Analyten aus einer Probe zu bewältigen. Die Reagenzienkosten betragen derzeit zwischen wenigen Cent für die klinisch-chemischen Basisparameter (klinisch-chemi- sches Profil) und ca. 5 Euro für Spezialanalyte. Der Personalaufwand ist gering, sodass sich trotz hoher Gerätekosten (bis zu 1 Million Euro) bei hohen Analysenzahlen kurze Amortisationszeiten realisieren lassen.

Bewertung - Methodenhierarchie (allg.) Spektrometrische Analysenverfahren sind bei richtiger Durchführung und hinreichender Validation (durch den Hersteller und/oder Anwender) richtig und präzise. Variationskoeffizienten in der Analysenserie (Intra-assay CV) und zwischen den Analysenserien (Inter-assay $\mathrm{CV}$ ) von $<10 \%$ sind problemlos erreichbar.

\section{Literatur}

Kortüm G (1962) Kolorimetrie, Photometrie und Spektrometrie. Eine Anleitung zur Ausführung von Absorptions-, Emissions-, Fluoreszenz-, Streuungs-, Trübungs- und Reflexionsmessungen. SpringerVerlag, Berlin/Göttingen/Heidelberg

Näser KH, Peschel G (1986) Physikalisch-chemische Meßmethoden. Deutscher Verlag für Grundstoffindustrie, Leipzig

\section{Spektrophotometer}

Spektralphotometer

\section{Spektrophotometrie}

Spektralphotometrie

\section{Spektroskop}

T. Arndt

Englischer Begriff spectroscope

Definition Gerät zur visuellen Beobachtung und Auswertung von Spektren im Bereich des sichtbaren Lichts (IUPAC-Definition).

Beschreibung Die Kombination eines Spektroskops mit einem oder mehreren Detektoren zur Aufzeichnung der Intensität von Spektralbanden ist ein Spektrometer. Im klinischchemischen Labor werden vor allem Spektrometer eingesetzt ( $\triangleright$ Spektrometrie/Spektroskopie). 


\section{Literatur}

Inczedy J, Lengyel T, Ure AM (1998) Compendium of analytical nomenclature (definitive rules 1997), 3. Aufl. Blackwell Science, Oxford.

\section{Spektroskopie}

\section{T. Arndt}

\section{Englischer Begriff spectroscopy}

Definition Analyse physikalischer Systeme unter Zuhilfenahme elektromagnetischer Strahlung, die mit dem System in Wechselwirkung steht oder von ihm generiert wird (IUPAC-Definition).

Beschreibung Dabei wird mithilfe eines Spektroskops ( $\triangleright$ Spektroskop) die Strahlung visuell beobachtet und visuell ausgewertet. In diesem Sinne könnte ein Mikroskop auch als Spektroskop und das Mikroskopieren als Spektroskopie bezeichnet werden.

Kombiniert man ein Spektroskop mit einem oder mehreren Detektoren zur Messung der Intensität spektraler Banden, spricht man von einem Spektrometer und Spektrometrie.

Die Begriffe Spektroskopie und Spektrometrie werden häufig synonym verwandt (besonders in der englischsprachigen Literatur und deshalb zunehmend auch in Deutschland). Tatsächlich werden rein spektroskopische Methoden in der Analytik immer seltener angewandt. Der Begriff Spektrometrie sollte sich deshalb als Oberbegriff für alle auf der Messung elektromagnetischer Strahlung beruhenden Analysenmethoden stärker durchsetzen. Die für das klinisch-chemische Labor wichtigen Begriffe und Methoden werden deshalb unter dem Stichwort $>$ Spektrometrie/Spektroskopie näher vorgestellt.

\section{Literatur}

Inczedy J, Lengyel T, Ure AM (1998) Compendium of analytical momenclature (definitive rules 1997), 3. Aufl. Blackwell Science, Oxford

\section{Spektrum}

T. Arndt

Synonym(e) Lichtspektrum

\section{Englischer Begriff spectrum}

Definition In der Optik Darstellung von Strahlungen in Abhängigkeit von der Wellenlänge, Wellenzahl oder Schwingungsfrequenz.

Beschreibung Das bekannteste Spektrum ist sicher das Spektrum des Sonnenlichts. Die Wellenlängenbereiche ultravioletten, sichtbaren und infraroten Lichts sowie des Spektrum des sichtbaren Lichts zeigt die folgende Abbildung:

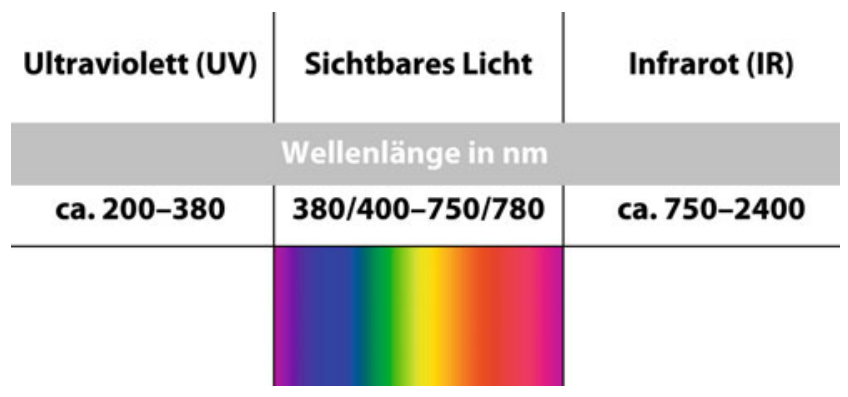

Im klinisch-chemischen Labor nutzt man die Aufzeichnung von Spektren in der $>$ Spektrometrie/Spektroskopie zur qualitativen und quantitativen Analyse auf der Grundlage charakteristischer Absorptionsspektren (z. B. InfrarotSpektrometrie, $>$ UV/VIS-Spektrometrie), Emissionspektren (z. B. Atomemissionsspektrometrie, Flammenatomemissionsspektrometrie) oder der Absorption von Licht bestimmter Wellenlängen (z. B. optischer Test nach Warburg, - Atomabsorptionsspektrometrie, Flammenatomabsorptionsspektrometrie/-spektroskopie) die substanzgruppenoder substanzspezifisch sind.

\section{Spektrum-Bias}

\section{R.-D. Hilgers, N. Heussen und S. Stanzel}

Englischer Begriff spectrum bias

Definition Spektrum-Bias tritt auf, wenn die Studienpopulation ein anderes klinisches Spektrum (etwa nur schwerere Fälle) aufweist als die Population, in welcher der Test ( $\vee$ Test, diagnostischer) angewandt werden soll.

Beschreibung Im Rahmen jeder klinischen Studie bezeichnet man den Sachverhalt, dass die Studienergebnisse systematisch, also durch bestimmte Ursachen, beeinflusst werden können, als Bias. Spezifisch für diagnostische Studien ( $>$ Studien, diagnostische) ist der Spektrum-Bias, besonders dann, wenn die Validität des diagnostischen Tests evaluiert werden soll. 
Darüber hinaus können jedoch auch andere Biasquellen die Ergebnisse eines diagnostischen Tests verzerren (Sackett 1979).

\section{Literatur}

Kramer MS (1988) Clinical epidemiology and biostatistics. Springer, Berlin/Heidelberg/New York

Sackett DL (1979) Bias in analytic research. J Chron Dis 32:51-63

\section{SPE-Mikrosäulen}

> Mikrosäulen

\section{Spermatozoen-Antikörper}

Antikörper gegen Spermatozoen

\section{Spermatozyten}

- Seminalflüssigkeit

\section{Spermien}

- Seminalflüssigkeit

\section{Sperrflag}

\section{O. Colhoun}

\section{Englischer Begriff blocking flag}

Definition Sperrflags des Analysegeräts bewirken die Blockierung eines gemessenen Werts in der technischen Validation.

Beschreibung Sie werden mit oder anstelle des Messwerts vom Analysegerät an die $>$ Labor-EDV übertragen. Für die Freigabe des Werts ist ein expliziter und sinnvollerweise protokollierter Benutzereingriff notwendig.

\section{Sperrung von Ergebnissen}

O. Colhoun

Englischer Begriff blocking of results

Definition Manuelle oder automatisierte Kennzeichnung von Messwerten vor oder während der Validation im > Labor-EDV-System, um deren Ausgabe auf den Laborbefund zu unterdrücken.

Beschreibung Anhand fester Kriterien (z. B. Über-/Unterschreitung vom Messbereich, \High-Dose-Hook-Effekt, Hämolyse in der Probenmatrix etc.; s. > Hämolyse, in vivo und in vitro) kann eine Sperrung des Ergebnisses bereits durch das Analysengerät erfolgen, das anstelle oder zusätzlich zum Messwert ein $>$ Sperrflag ausgibt oder überträgt. Unplausible, kontrollbedürftige Werte können durch manuelle Sperrung in der technischen oder medizinischen Validation in der Labor-EDV für die Befundausgabe unterdrückt werden.

\section{Spezialbefund}

O. Colhoun

\section{Englischer Begriff special interpretation}

Definition Der Spezialbefund ist eine Domäne der labormedizinischen Befundinterpretation; eine aktive, konstellations- und patientenbezogene medizinische Informationsaufbereitung mit Einbezug von klinischen Angaben und Fragestellungen, relevanten, laborintern verfügbaren Informationen und in der individuellen Konstellation enthaltenen Informationen.

Beschreibung Dient zur Unterstützung und Optimierung des diagnostischen Entscheidungsvorganges für den an das Labor einsendenden Kliniker. Besonders gilt dies für an sich seltene Befundkonstellationen, die vom einzelnen Stationsarzt kaum, vom befundenden Laborarzt jedoch relativ häufig beobachtet werden.

\section{Literatur}

Trendelenburg C, Colhoun O, Wormek A et al (1998) Knowledge-based test result interpretation in laboratory medicine. Clin Chim Acta 278(2):229-242 


\section{Speziationsanalyse}

D. Meißner und T. Arndt

Synonym(e) Spezies-Analytik

Englischer Begriff speciation analysis

Definition Speziationsanalyse bedeutet die eindeutige Identifizierung und Quantifizierung der Spezies (= Bindungsformen) in einer Probe mit analytischen Methoden.

Beschreibung Die Speziationsanalyse wird $u$. a. in der - Spurenelementanalytik angewendet. Mit der Bestimmung der Elemente nach Zerstörung der Matrix erhält man deren Gesamtkonzentration in der Probe, jedoch keine Aussage über die biochemische Wirkung dieser Elemente, die mit den verschiedenen Bindungsformen zusammen hängt. Spezies sind in diesem Fall z. B. Metall-Organo-Komplexe, Metall-Organyl-Verbindungen oder unterschiedliche Wertigkeitsstufen der Metalle. Die analytischen Methoden dürfen die Spezies während der Probengewinnung, Lagerung und Analyse nicht verändern. In der Regel besteht die Speziationsanalyse aus der speziesspezifischen Trennung und der elementselektiven Detektion. Zur Trennung werden Ultrafiltration sowie chromatographische und elektrophoretische Verfahren und zur Detektion die verschiedenen Methoden der $>$ Atomabsorptionsspektrometrie, des $>$ inductively coupled plasma und der Voltammetrie ( $>$ Voltammetrie, zyklische und inverse) angewendet. Zunehmende Bedeutung haben auch hier die Massenspektrometrie und molekularbiologische Methoden.

Die Speziationsanalytik gewinnt mit zunehmender Kenntnis der zum Teil stark differierenden physiologischen, pathobiochemischen und toxikologischen Wirkungen von anorganischen und organischen Verbindungen desselben Metalls (z. B. $>$ Arsen, $>$ Quecksilber), von unterschiedlichen Metalloxidationsstufen in seinen Verbindungen (z. B. Arsen, - Chrom) und/oder von verschiedenen Aufnahmewegen an diagnostischer und gutachterlicher Bedeutung.

\section{Literatur}

Michalke B, Schramel P (1999) Spezies-Analytik - Theorie und Praxis. In: Meißner D (Hrsg) Spurenelemente. Wissenschaftliche Verlagsgesellschaft, Stuttgart, S 3-18

Rükgauer M (Hrsg) (2003) Signalwirkung von Mineralstoffen und Spurenelementen. Wissenschaftliche Verlagsgesellschaft, Stuttgart

\section{Spezies-Analytik}

- Speziationsanalyse

\section{Spezifisches Gewicht (des Urins)}

- Dichte, spezifische und relative

$\checkmark$ Gewicht, spezifisches des Urins

\section{Spezifitåt, analytische}

G. Schumann

Englischer Begriff analytical specificity

Definition Fähigkeit eines Untersuchungsverfahrens, nur den gesuchten Analyten zu erfassen.

Beschreibung Ein Untersuchungsverfahren, das nur eine Messgröße erfasst, wird als sehr (,absolut") spezifisch bezeichnet. Je mehr analytische Einflussgrößen das - Messergebnis verfälschen, desto unspezifischer ist ein Verfahren. Die analytische Spezifität (Unspezifität) ist von der diagnostischen Spezifität zu unterscheiden (s. a. > Selektivität).

\section{Literatur}

Qualitätsmanagement in der Laboratoriumsmedizin (2001) Teil 2: Begriffe zur Qualität und Anwendung von Untersuchungsverfahren. Beuth-Verlag, Berlin. DIN 58936-2, 3.1.2.4

\section{Spezifität, diagnostische}

R.-D. Hilgers, N. Heussen und S. Stanzel

Synonym(e) Diagnostische Spezifität

Englischer Begriff specificity

Definition Die Spezifität eines diagnostischen Tests bezeichnet die (bedingte) Wahrscheinlichkeit für ein negatives Test- 
ergebnis ( $\triangleright$ Testergebnis, richtig-negatives) unter den tatsächlich Gesunden.

Beschreibung Die diagnostische Spezifität reflektiert die Treffsicherheit eines Tests ( $\triangleright$ Test, diagnostischer) insofern, als sie die Wahrscheinlichkeit für die richtige Testentscheidung unter den Gesunden quantifiziert. Dementsprechend ist die Spezifität ein Maß für die diagnostische Accuracy ( $\triangleright$ Accuracy, diagnostische) eines Tests. Die Spezifität wird geschätzt durch den Quotienten aus der Zahl der Gesunden mit negativem Test dividiert durch die Gesamtzahl der Gesunden [Quotient d / $(\mathrm{d}+\mathrm{b})$, s. Tabelle im Stichwort $>$ Vierfeldertafel]. Ein spezifischer Test wird Gesunde kaum als erkrankt fehlklassifizieren. Er ist besonders dann hilfreich, wenn ein positives Testresultat beobachtet wird.

\section{Literatur}

Hilgers R-D, Bauer P, Scheiber V (2002) Einführung in die Medizinische Statistik. Springer, Berlin/Heidelberg/New York

\section{Spezimen}

A. M. Gressner und O. A. Gressner

Synonym(e) Materialprobe (z.B. Blut, Urin, Liquor, Gewebe)

Englischer Begriff specimen

Definition Direktes, ohne weitere Vorbehandlung vom Patienten stammendes Untersuchungsmaterial.

Beschreibung Der im angelsächsischen Schrifttum häufiger, in Deutschland jedoch seltener verwendete Begriff des Spezimen steht für flüssiges, festes oder gasförmiges natives, d. h. direkt vom Patienten stammendes Material, das dem Labor zum Zwecke der Untersuchung zugeleitet wird. Der Begriff ist international nicht einheitlich und verbindlich definiert und entspricht am ehesten der Definition der $\triangleright$ Primärprobe. Gebräuchliche Spezimenarten sind $\triangleright$ Vollblut, $\triangleright$ Urin, - Liquor cerebrospinalis, \Magensaft, \ Speichelgewinnung, Synovialflüssigkeit ( $\triangleright$ Synovia-Analyse), $\triangleright$ Schweiß, Fruchtwasser, Pankreassekret, > Transsudat, \& Exsudat, > Körperflüssigkeiten, extravasale, Pleuraflüssigkeit, Zystenflüssigkeit, $\triangleright$ Seminalflüssigkeit, Konkremente (Gallen- und Nierensteine, $\triangleright$ Steinanalyse) und Fäzes. Aus dem Spezimen wird vor der Untersuchung die $>$ Probe hergestellt, die denjenigen Teil des Spezimens darstellt, der für die Charakterisierung oder Untersuchung verwendet wird.

\section{Literatur}

Dybkaer R (1997) Vocabulary for use in measurement procedures and description of reference materials in laboratory medicine. Eur J Clin Chem Clin Biochem 35:141-173

Richterich R, Colombo JP (1978) Klinische chemie: theorie, praxis, interpretation, 4. Aufl. S. Karger, Basel

\section{Sphärozyt}

H. Baum

\section{Synonym(e) Kugelzelle}

Englischer Begriff spherocyte

Definition Kleiner, kompakter, runder, stark angefärbter Erythrozyt ( $\triangleright$ Erythrozyten) ohne zentrale Aufhellung.

Die Abbildung zeigt Sphärozyten (Pfeile), zum Größenvergleich ist auch ein „Standardlymphozyt“ abgebildet (1000×, May-Giemsa-Grünwald-Färbung):

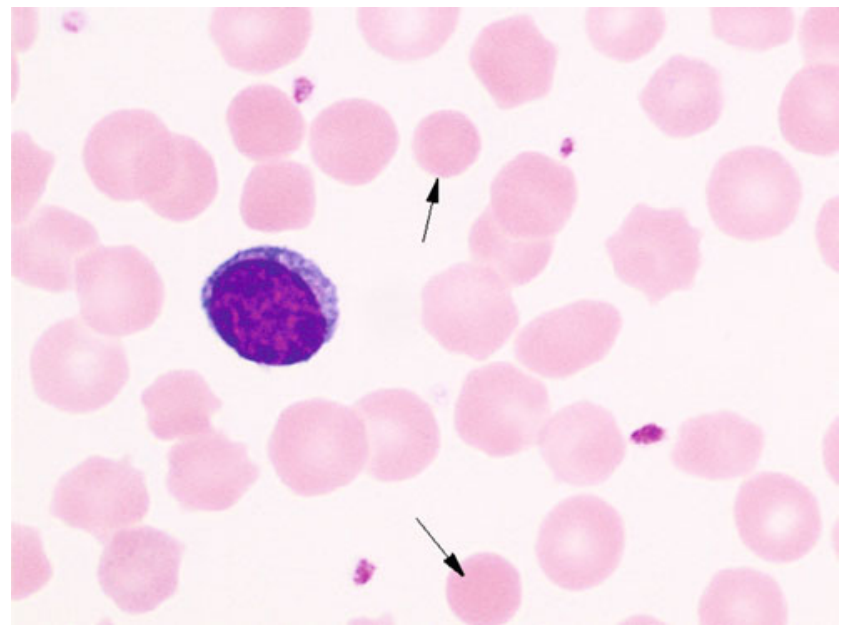

Beschreibung Der Sphärozyt ist die charakteristische Erythrozytenform bei der hereditären Sphärozytose (Kugelzellanämie). Der Sphärozyt ist klein $(5 \mu \mathrm{m})$, kompakt und rund. Er zeigt eine starke Anfärbbarkeit ohne zentrale Aufhellungszone. Angesichts seiner Kugelform ist das Verhältnis Oberfläche zu Volumen verändert, was mit einem erhöhten Hämoglobingehalt des Einzelerythrozyten $(\mathrm{MCH})$ einher- 
geht. Dies führt zu einer Erhöhung des MCHC ( $\triangleright$ Erythrozyten-Indices). Pathophysiologisch liegt ein Membrandefekt zugrunde, wobei verschiedene Mutationen im Ankyrin, in den Spectrin- $\alpha$ - und - $\beta$-Ketten, dem Band-3Protein, dem Protein 4.2 für die veränderten Membraneigenschaften verantwortlich sind. Allerdings kann es auch bei anderen hämolytischen Anämien zur Bildung von Kugelzellen kommen.

\section{Literatur}

Koeppen KM, Heller S (1991) Differentialblutbild (panoptische Färbung). In: Boll I, Heller S (Hrsg) Praktische Blutzelldiagnostik. Springer, Berlin/Heidelberg/New York, S 171

\section{Sphingomyelin}

\section{K. J. Lackner und D. Peetz}

\section{Englischer Begriff sphingomyelin}

Definition Phospholipid aus Ceramid und Phosphorylcholin.

Beschreibung Sphingomyelin kommt in Zellmembranen von Wirbeltieren vor. Die größten Mengen finden sich in den Myelinscheiden des Nervensystems, aus denen es auch ursprünglich isoliert wurde. Der Gehalt an Sphingomyelin ist lokal unterschiedlich und beeinflusst die Membraneigenschaften signifikant. Spezialisierte Membrandomänen, sog. Rafts, weisen einen hohen Anteil von Sphingomyelin und Cholesterin auf.

\section{Literatur}

Chakraborty M, Jiang XC (2013) Sphingomyelin and its role in cellular signaling. Adv Exp Med Biol 991:1-14

\section{Sphingomyelinase}

K. J. Lackner und D. Peetz

Englischer Begriff sphingomyelinase

Definition Enzyme, welche die Hydrolyse von Sphingomyelin zu Ceramid und Phosphorylcholin katalysieren.
Beschreibung Man kann 6 Typen von Sphingomyelinasen (SPM) unterscheiden: saure SPM (lysosomal), sekretorische SPM, neutrale SPM (Mg-abhängig und -unabhängig), alkalische SPM (intestinal), bakterielle SPM. Die SPM-Aktivität ist der $>$ Phospholipase C-Aktivität ähnlich. Da sowohl Ceramid als auch Phosphorylcholin Signale übertragen können, ist die SPM in die zelluläre Signaltransduktion involviert. AuBerdem sind SPM für die Membranstruktur der Zelle relevant.

\section{Literatur}

Bienias K, Fiedorowicz A, Sadowska A, Prokopiuk S, Car H (2016) Regulation of sphingomyelin metabolism. Pharmacol Rep 68:570-581

\section{Spice}

T. Arndt

\section{Englischer Begriff spice}

Definition Früherer Handelsname für eine das synthetische Cannabinoid JWH-018 enthaltende Kräutermischung, heute eher ein nicht näher definierter Sammelbegriff für in der Drogenszene gehandelte Kräutermischungen mit Zusatz von synthetischen psychoaktiven Substanzen, im Falle von „Spice"-Mischungen zumeist aber nicht zwingend synthetischen Cannabinoiden.

Beschreibung Die vielfältigen und in ihrer Benennung und Zusammensetzung ständig wechselnden Produkte entziehen sich jeder klaren Kategorisierung, weil immer wieder Mischungen auftauchen, die sowohl der einen als auch der anderen oder keiner der bekannten Kategorien zugeordnet werden können.

Mit der Kräutermischung „Spice“ wurde im Herbst 2008 das Phänomen der in der Drogenszene schon beliebten sog. Legal Highs erstmals einer breiteren Öffentlichkeit bekannt. Schnell wurde klar, dass das Wirkprinzip dieser zum Räuchern (nicht Rauchen!) angebotenen Produkte nicht vorgeblich legale psychoaktive Pflanzen(teile) sind, sondern gewöhnlichen Kräutermischungen zudotierte synthetische Stoffe mit psychoaktiver Wirkung. Seitdem wurden immer wieder sog. $>$ Neue Psychoaktive Substanzen (NPS) auf den Markt gebracht und in einer Art „Hase-und-Igel-Wettlauf“ zeitversetzt dem Betäubungsmittelgesetz (BtMG) unterstellt.

Der dafür erforderliche gutachterlich-juristische Prozess erwies sich für die Dynamik der Drogenszene als viel zu langsam. Mit dem am 26. November 2016 in Kraft getretenen Neue-psychoaktive-Stoffe-Gesetz (NpSG) wurde deshalb ein 
neues Verfahren implementiert, weg von der Unterstellung von Einzelsubstanzen unter das BtMG, hin zum Verbot ganzer Substanzgruppen, d. h. aller denkbaren Derivate und Abkömmlinge einer chemischen Leitstruktur. Die Auswirkungen auf den Drogenmarkt sind derzeit noch nicht zu beurteilen.

Siehe auch $\triangleright$ Neue Psychoaktive Substanzen (NPS).

\section{Literatur}

European Monitoring Centre for Drugs and Drug Addiction (2010) Thematic papers. Understanding the „Spice“ phenomenon. Toxichem Krimtech 77:29-45. www.emcdda.europa.eu

Europäische Beobachtungsstelle für Drogen und Drogensucht (2016) Europäischer Drogenbericht 2016: Trends und Entwicklungen. Amt für Veröffentlichungen der Europäischen Union, Luxemburg. http://www.emcdda.europa.eu. Zugegriffen am 30.12.2016

NpSG (2016) Gesetz zur Bekämpfung der Verbreitung neuer psychoaktiver Stoffe - Neue-psychoaktive-Stoffe-Gesetz (NpSG). Bundesgesetzblatt Teil 1 Nr. 55, 2615-2622

\section{Spiken}

- Standardaddition

\section{Spike-Versuch}

- Standardaddition

\section{SPINK1}

> Trypsinogen-Aktivierungspeptid

\section{Spiritus}

$>$ Ethanol

\section{Splanchnolith}

- Darmkonkremente

\section{Spleißmutation}

$>$ Splice-Mutation

\section{Splice-Mutation}

\section{J. Arnemann}

Synonym(e) Spleißmutation

Englischer Begriff splice mutation

Definition Eine Spleißmutation ist eine DNA-Sequenzmutation, die ein regelrechtes Spleißen der prä-mRNA verhindert.

Beschreibung Eine Spleißmutation liegt vor, wenn Spleißdonor- oder Spleißakzeptorstellen durch Mutationen, wie z. B. Basenaustausch, Insertion oder Deletion von Nukleotiden, so verändert sind, dass keine reguläre mRNA aus der prä-mRNA herausgespleißt wird.

Eine Mutation an den hochgradig konservierten Spleißstellen verhindert ein ordnungsgemäßes Binden der Spleißosomen und damit ein Herausschneiden der durch Mutation beeinträchtigten Intronsequenzen. So kann z. B. die reife mRNA nichtgespleißte Intronsequenzen enthalten, die bei einer Translation $\mathrm{zu}$ einem vorzeitigen Kettenabbruch der Proteinsynthese, zur Synthese eines fehlerhaften oder Nonsense-Proteins oder den allgemeinen Ausfall des Proteins führen. Spleißmutationen sind daher pathogene Mutationen für die Entwicklung oftmals schwerwiegender humangenetischer Erkrankungen.

\section{Literatur}

Ward AJ, Cooper TA (2010) The pathobiology of splicing. J Pathol 220:152-163

\section{Splicing}

J. Arnemann

Synonym(e) Spleißen

Englischer Begriff splicing

\section{Spleißen}

Splicing 
Definition Spleißen, mehrheitlich als Splicing gebraucht, bezeichnet den Prozess, aus einem RNA-Primärtranskript die funktionslosen Intronabschnitte herauszuschneiden und die relevanten Exonabschnitte miteinander zu verbinden.

Beschreibung Die mit Abstand meisten proteincodierenden humanen Gensequenzen sind in kodierende Exon- und nicht kodierende Intronabschnitte unterteilt, denen eine Promotorregion zur Regulation der Transkription vorgeschaltet ist. Bei der Transkription wird das gesamte Gen, die sog. Transkriptionseinheit, durch die RNA-Polymerase II in eine prä-mRNA transkribiert, die einen RNA-Strang intermittierend mit peptidcodierenden Exonabschnitten und nicht kodierenden, funktionslosen Intronabschnitten enthält. Der Spleißprozess, also das Herausschneiden der funktionslosen Abschnitte durch eine Endonuklease, ist durch Signalsequenzen in der RNA, den Spleißstellen, reguliert. Das Spleißen wird im Wesentlichen durch definierte Intronsequenzen reguliert.

Das Intron folgt dabei auf RNA-Ebene der GU-AG-Regel, wobei das Intron im $5^{\prime}$-Bereich überwiegend durch die Basenfolge GU (an der Spleißdonorstelle), der 3'-Bereich des Introns durch die Basenfolge AG (an der Spleißakzeptorstelle) charakterisiert ist. Die Spleißdonor- und Spleißakzeptorstellen sind jeweils durch eine teils variable Sequenzabfolge definiert, die auch die flankierenden Exonsequenzen mit einschließt. So folgt die exonische Donorsequenz der Abfolge (C/A)AG und flankiert unmittelbar die intronischen Abfolge $\boldsymbol{G U}(\mathrm{A} / \mathrm{G}) \mathrm{AGU}$, was die Consensus-Spleißdonorstelle insgesamt als Sequenzabfolge (C/A)AGGU(A/G)AGU definiert. Die intronische Akzeptorsequenz besteht aus einem Pyrimidinstretch von $(\mathrm{C} / \mathrm{U}) \times 11$ gefolgt von einer beliebigen Base, einem weiteren $(\mathrm{C} / \mathrm{U})$, sowie der Akzeptorsequenz $\mathrm{AG}$, während die exonische Akzeptorsequenz nur durch ein Purinmolekül $(\mathrm{A} / \mathrm{G})$ bestimmt ist, insgesamt die Consensus-Spleißakzeptorstelle durch die Sequenzfolge $(\mathrm{C} / \mathrm{U})(\mathrm{C} / \mathrm{U})(\mathrm{C} / \mathrm{U})(\mathrm{C} / \mathrm{U})$ $(\mathrm{C} / \mathrm{U})(\mathrm{C} / \mathrm{U})(\mathrm{C} / \mathrm{U})(\mathrm{C} / \mathrm{U})(\mathrm{C} / \mathrm{U})(\mathrm{C} / \mathrm{U})(\mathrm{C} / \mathrm{U}) \mathrm{N}(\mathrm{C} / \mathrm{U}) \boldsymbol{A} \boldsymbol{G}(\mathrm{A} / \mathrm{G})$ definiert ist. Eine weitere, für das Spleißen relevante intronische Sequenzabfolge ist die „branch site“, die durch die Consensus-Sequenzabfolge $(U / \mathrm{C} /) \mathrm{N}(\mathrm{C} / \mathrm{U})(U / \mathrm{C})(A / \mathrm{G}) \boldsymbol{A}(C / \mathrm{U})$ definiert ist.

Der eigentliche Spleißprozess setzt sich aus folgenden Schritten zusammen:

1. Spaltung am 5'-Ende der Donorstelle, wobei

2. das G-Nukleotid der intronischen Donorsequenz eine kovalente Verknüpfung mit dem obligaten A der „branch site" eingeht und die Sequenzabfolge so eine Lasso- oder Lariatstruktur ausbildet.

3. Spaltung am 3'-Ende der Akzeptorstelle mit nachfolgender Freisetzung des Intronlariats und gleichzeitiger kovalenter Verknüpfung der beiden Exons.
Funktionell wird das beschriebene Herausspleißen der Intronsequenz unter Ausbildung eines Spleißosoms erreicht, einem Komplex aus Proteinen und RNA. Verschiedene snRNAs (,small nuclear RNA“), wie z. B. U1- oder U2-snRNA, bilden zusammen mit Proteinen die snRNPKomplexe aus, die wiederum spezifische Wechselwirkungen mit der prä-mRNA eingehen und an der Spleißdonor- und Spleißakzeptorstelle das eigentliche Herausschneiden der RNA-Fragmente durchführen.

\section{Literatur}

Strachan T, Read AP (2005) Molekulare Humangenetik. Elsevier $\mathrm{GmbH}$, München

\section{SPME}

- Solid-phase Micro-Extraction

\section{Spontane Gewebemutation}

- Somatische Mutation

\section{Spontaner Mittelstrahlurin}

$\checkmark$ Spontanurin

\section{Spontanurin}

W. G. Guder

Synonym(e) Frei fließender Urin; Spontaner Mittelstrahlurin

Englischer Begriff spot urine; midstream urine

Definition Als Spontanurin wird jeder Urin bezeichnet, der ohne Katheter durch „spontanes“ Wasserlassen gewonnen werden kann.

Beschreibung Von den diagnostisch empfohlenen Spontanurinen werden folgende Urinproben definiert (in Klammer Beispiele für Ihre Verwendung): 
- Mittelstrahlurin: mittlere Portion eines spontan gelassenen Urins (Teststreifen, mikrobiologische Untersuchung, Drogen)

- Erster Morgenurin (als Mittelstrahlurin): erste spontane Urinprobe nach mindestens 8- bis 12-stündiger Ruhe und Harnkontinenz (Harnsediment, Teststreifen)

- Zweiter Morgenurin: Spontanurin als Mittelstrahlurin nach dem ersten Morgenurin während des Vormittags $=$ Spontanurin am Vormittag (Urinproteine und Ausscheidungsprodukte, wenn auf Konzentration, z. B. Kreatinin, bezogen)

- Sammelurin: Spontanurin als gesamte Portion über eine definierte Zeit gesammelt (quantitative Analyse von Ausscheidungsprodukten sowie Clearancemessungen).

\section{Literatur}

Kouri T, Fogazzi G, Gant V, Hallander H, Hofmann W, Guder WG (2000) European urinalysis guidelines. Scand J Clin Lab Invest 60(Suppl 231):1-96

\section{Spontanurin am Vormittag}

$>$ Morgenurin

SPP

- Phosphatase, Prostataspezifische Saure

\section{S100-Protein}

S. Holdenrieder und P. Stieber

Synonym(e) S100

\section{Englischer Begriff S100 protein}

Definition $\mathrm{S} 100$ ist ein $21 \mathrm{kDa}$ schweres, thermolabiles, saures Protein und gehört einer multigenen Familie calciumbindender Proteine an.

Struktur S100 besteht als Dimer aus 2 isomeren Untereinheiten $(\alpha: 10,4 \mathrm{kDa} ; \beta: 10,5 \mathrm{kDa})$ und kann in den Isoformen S100B $(\beta \beta)$, S100A $(\alpha \beta)$ und S100A1 $(\alpha \alpha)$ auftreten.
Molmasse $21 \mathrm{kDa}$.

Synthese - Verteilung - Abbau - Elimination S100B ist in hohen Konzentrationen in astroglialen Zellen des Zentralnervensystems (ZNS) lokalisiert; in geringerem Ausmaß wird es von Schwann-Zellen des peripheren Nervensystems (PNS), Chondrozyten, Adipozyten und Langerhans-Zellen produziert. S100A wird insbesondere auf malignen Melanomzellen exprimiert, wobei der Gehalt von S100A mit der Invasionstiefe und Tumordicke korreliert. Daneben ist S100A ebenfalls im ZNS vorhanden, trägt zum Gesamtanteil jedoch nur $5 \%$ bei. S100A1 ist in Keratinozyten, Melanozyten, in glatter Muskulatur, Kardiomyozyten und in der Niere zu finden.

Halbwertszeit 2-3 Stunden.

Funktion - Pathophysiologie Bisher sind insgesamt 21 Isoformen der S100-Familie bekannt ( $\$$ S100A12-Protein). Sie sind in ihrer Funktion als intrazelluläre Calciumrezeptormoleküle an der Regulation der Zellfunktion auf verschiedenen Ebenen beteiligt: So stehen sie einerseits mit zellulären Differenzierungs- und Proliferationsvorgängen in Beziehung. Darüber hinaus kann S100 in Interaktion mit dem Tumorsuppressorprotein $\mathrm{p} 53$ treten und dessen Phosphorylierung durch Proteinkinase C blockieren. Dadurch verliert p53 die Fähigkeit zur Oligomerisierung und kann seine Funktion bei der Regulierung des Zellzyklus, der DNA-Reparatur und der Apoptoseinduktion nicht mehr ausüben. S. a. > Autoantikörper gegen $\mathrm{p} 53$.

Neurodestruktion oder Neurodegeneration führen zu einer S100-Freisetzung aus astrozytären Gliazellen und zunächst zu einer Erhöhung der S100-Konzentration im Liquor, bei Schädigung der Blut-Hirn-Schranke später auch im Serum. Somit eignen sich S100-Bestimmungen im Serum insbesondere bei akuten Läsionen zur Beurteilung der Funktionsbeeinträchtigung der Blut-Hirn-Schranke.

Untersuchungsmaterial - Entnahmebedingungen Serum, Liquor.

Analytik $\triangleright$ Enzymimmunoassay (EIA), $\triangleright$ Radioimmunoassay (RIA), $\triangleright$ Immunradiometrischer Assay (IRMA), $\triangleright$ Lumineszenz-Immunoassay (LIA), > ElektrochemilumineszenzImmunoassay (ECLIA).

Die meisten der kommerziell erhältlichen S100-Assays verwenden gegen die $\beta$-Untereinheit des S100 gerichtete mono- oder polyklonale Antikörper und detektieren somit die Isoformen S100A und S100B. Darüber hinaus existieren Assays, die eine detailliertere Differenzierung der S100Subtypen erlauben. 


\section{Konventionelle Einheit $\mathrm{ng} / \mathrm{mL}(\mu \mathrm{g} / \mathrm{L})$.}

Referenzbereich - Erwachsene Serum: Median 0,04 $\mu \mathrm{g} / \mathrm{L}$; $95 \%$-Perzentile 0,1 $\mu \mathrm{g} / \mathrm{L}$ (methodenabhängig).

Interpretation Die meisten S100-Methoden sind für die Anwendung im Serum ausgetestet. Aufgrund der calciumbindenden Eigenschaft können bei Messung von S100 im EDTA-, Citrat- und Heparinplasma falsch positive oder negative Werte gemessen werden.

S100 weist eine hohe Tumorspezifität für das maligne Melanom auf. Bei sämtlichen anderen malignen Tumoren wurden vereinzelt allenfalls gering gradige Erhöhungen von S100 im Serum beobachtet. Ebenso verursachen viele differenzialdiagnostisch relevante benigne Erkrankungen keine oder nur gering erhöhte S100-Konzentrationen.

An klinischen Einflussgrößen sind jedoch bakterielle Infekte $\mathrm{zu}$ berücksichtigen, die S100-Werte von bis $\mathrm{zu}$ 2,0 $\mu \mathrm{g} / \mathrm{L}$ hervorrufen können. Beeinträchtigungen der Leberund/oder Nierenfunktion können zu leichten S100-Erhöhungen führen.

\section{Diagnostische Wertigkeit}

- Malignes Melanom: Differenzialdiagnose, Prognose, Therapiemonitoring

- Neurodestruktion und Neurodegeneration

\section{Literatur}

Holdenrieder S, Spelsberg F, Hatz R et al (2013) Pattern of S100-release in benign and malignant diseases beside malignant melanoma. J Lab Med 37:21-28

Jäckel A, Deichmann M, Waldmann V et al (1999) S-100b-Protein im Serum als Tumormarker beim malignen Melanom. Hautarzt 50:250-256

Stieber P (2008) S100. In: Thomas L (Hrsg) Labor und Diagnose, 7. Aufl. TH-Books, Frankfurt am Main, S 1355-1358

\section{Sprotte-Nadel}

W. G. Guder

Synonym(e) Atraumatische Kanüle; Kanüle nach Sprotte und Whitacre; Lumbalpunktionsnadel

Englischer Begriff atraumatic needle; canula according to Sprotte and Whitacre
Definition Von Sprotte und Whitacre entwickelte Nadel zur ,atraumatischen“ Gewinnung von Liquor cerebrospinalis.

Beschreibung Um eine schonende Einführung der Kanüle in den Liquorraum zu ermöglichen, entwickelten Sprotte (1987) und Hart und Whitacre (1951) eine Kanüle, die schonender (,atraumatisch“) in den punktierten Liquorraum ( $\triangleright$ Liquor-Gewinnung) eindringt. Sie zeichnet sich dadurch aus, das eine 22 G-Kanüle mit einem Aussendurchmesser von 0,7 $\mathrm{mm}$ einen seitlichen Eingang statt dem Eingang an der Spitze aufweist. Insbesondere wurden so Verletzungen von Gefäßen und die Blutkontamination des gewonnenen Liquors vermindert.

\section{Literatur}

Braune HJ, Huffmann G (1992) A prospective double blind clinical trial, comparing the sharp Quincke needle $(22 \mathrm{G})$ with an "atraumatic“ needle $(22 \mathrm{G})$ in the induction of post-lumbar puncture headache. Acta Neurol Scand 86:50-54

Hart JR (1951) Pencil point needle in prevention of postspinal headache. J Amer Med Ass 147:657-658

Sprotte G, Schedel R, Pajunk H (1987) Eine atraumatische Universalkanüle für einseitige Regionalanaestesien. Anaesthesie 10:104-108

\section{SPT}

> Sekretin-Pankreozymin-Test

\section{Spurenelementanalytik}

D. Meißner und T. Arndt

Englischer Begriff analysis of trace elements

Definition Bestimmung von Spurenelementen in verschiedenen Untersuchungsmaterialien, einschließlich Präanalytik.

Beschreibung Wegen der Allgegenwart der $>$ Spurenelemente und der z. T. äußerst geringen Konzentrationen sind bei der Bestimmung einige Besonderheiten zu beachten: das Untersuchungsmaterial muss für die Fragestellung repräsentativ sein, die Präanalytik bedarf höchster Aufmerksamkeit, an analytische Sensitivität und Spezifität sowie Nachweisgrenze der Messverfahren sind hohe Anforderungen zu stellen, die $>$ Interaktion ist $\mathrm{zu}$ beachten.

Untersuchungsmaterial - Entnahmebedingungen Es kommen Blut und seine Bestandteile - einschließlich Blutzellen - Urin, Faeces, Liquor, Schweiß, Speichel, Haare, 
Nägel, Gewebeproben und andere Körperflüssigkeiten oder -bestandteile in Betracht. Die Auswahl der Probe hängt von der klinischen Fragestellung ab. Bei festen Proben ist $\mathrm{zu}$ beachten, dass die Verteilung der Spurenelemente in der Matrix häufig nicht gleichmäßig ist. Besondere Kritikfähigkeit verlangt die Analyse von Haarproben.

Präanalytik Hauptproblem ist die Kontaminationsgefahr, die von der Vorbereitung des Patienten (Desinfektionsmittel) über Gewinnung (Entnahmegeräte und -gefäße), Transport und Lagerung der Proben bis zur Analyse (Reagenzien, Bezugslösungen, Wasser, Gefäße, Pipetten o. Ä.) und den Einflüssen aus der Umwelt (Luft, Staub) reicht. Zur Blutentnahme sind Kanülen, die keine Spurenelemente abgeben, und spurenelementfreie Gefäße zu verwenden. Gegebenenfalls sind die ersten 1-2 mL Blut nicht für die Spurenelementbestimmung zu verwenden. Die Ergebnisse sind weiterhin von den Entnahmebedingungen (Körperlage, Stauung, Entnahmestelle, Hämolyse) und von individuellen Einflussgrößen abhängig. Darüber hinaus haben die Haltbarkeit verdünnter Lösungen oder die Adsorption von Spurenelementen an den Gefäßwänden sowie Matrixeinflüsse eine große Bedeutung.

Messverfahren Im klinischen Labor ist die $>$ Atomabsorptionsspektrometrie (FAAS, ET-AAS oder Hydrid-AAS) die Methode der Wahl, gelegentlich werden Photometrie, Voltammetrie ( $\vee$ Voltammetrie, zyklische und inverse), $\triangleright$ potenziometrische Strippinganalyse oder die ICP-Technik angewendet. Spezielle Fragen können mittels Neutronenaktivierungsanalyse, Röntgenfluoreszenzspektrometrie, molekularbiologischer Methoden oder weiterer Spezialtechniken bearbeitet werden, z. B. „total reflection X-ray fluorescence (TXRF) spectroscopy“, die sich durch äußerst geringen Aufwand bei der Probenverarbeitung auszeichnet. Im klinisch-chemischen Routinelabor gewinnen Kopplungen aus Atomemissionstechniken (hier ICP - „,inductively coppled plasma“) mit einem massenspektrometrischen Detektor (MS) als ICP-MS bezeichnet immer mehr an Bedeutung.

Bei der Beurteilung der Ergebnisse müssen die genannten Einflussgrößen berücksichtigt werden. Besondere Beachtung verdient die > Interaktion, da ihr Einfluss zu erheblichen Fehlinterpretationen führen kann.

\section{Literatur}

Kruse-Jarres JD (1994) Möglichkeiten und Grenzen der Spurenelementbestimmung in biologischem Material. In: Anke M, Meißner D (Hrsg) Defizite und Überschüsse an Mengen- und Spurenelementen in der Ernährung. Verlag Harald Schubert, Leipzig, S 1-15

Seiler HG, Sigel A, Sigel H (Hrsg) (1994) Handbook on metals in clinical and analytical chemistry. Marcel Dekker, New York/Basel/ Hong Kong, Ch. 3-15

\section{Spurenelemente}

D. Meißner und T. Arndt

Synonym(e) Mikroelemente

Englischer Begriff trace elements

Definition Elemente, die in sehr geringen Mengen im Organismus vorhanden sind, wobei unterschiedliche Kriterien zugrunde gelegt werden, z. B. $<0,01 \%$ der Körpermasse oder Konzentration im ppm-Bereich $(\mu \mathrm{g} / \mathrm{g}$ bzw. $\mu \mathrm{g} / \mathrm{mL})$ und darunter.

Beschreibung Spurenelemente werden in essenzielle und nicht essenzielle Spurenelemente unterteilt. Eine Untergruppe sind die $>$ Ultraspurenelemente, bei denen ein klinisch signifikanter Mangel bisher nicht nachgewiesen werden konnte.

Essenzielle Spurenelemente sind lebensnotwendig, ihre Anwesenheit ist die Voraussetzung für den normalen Ablauf vieler biochemischer Vorgänge. Sie unterliegen einer homöostatischen Regulierung und sind nur in einem sehr begrenzten und für jedes Element typischen Konzentrationsbereich physiologisch wirksam. Sowohl Mangel als auch Überschuss können zu Störungen führen, die sich z. T. als charakteristische Krankheiten äußern.

Nicht essenzielle Spurenelemente haben keine physiologische Funktion, können aber - wenn in übermäßiger Menge aufgenommen - zu Intoxikationen führen. Für den Menschen sind $\mathrm{Co}, \mathrm{Cu}, \mathrm{Fe}, \mathrm{I}, \mathrm{Mn}, \mathrm{Mo}, \mathrm{Ni}$, Se und $\mathrm{Zn}$ sowie $\mathrm{Cr}$, F, Si und V (Ultraspurenelemente) essenziell. Zu den nicht essenziellen Elementen, die in der klinischen Praxis Bedeutung haben, zählen jene Elemente, die als Belastungen über die Umwelt, über Arbeitsprozesse oder als Therapeutika in den menschlichen Körper gelangen und - abhängig von der zugeführten Menge - toxische Wirkungen entfalten können: Ag, Al, As, $\mathrm{Au}, \mathrm{Bi}, \mathrm{Cd}, \mathrm{Ge}, \mathrm{Hg}, \mathrm{Li}, \mathrm{Pb}, \mathrm{Pd}, \mathrm{Pt}, \mathrm{Rb}, \mathrm{Sb}, \mathrm{Sn}, \mathrm{Sr}, \mathrm{Tl}$ und U.

Der Körperbestand ist das Ergebnis des Zusammenspiels von Zufuhr (Nahrung, Trinkwasser, Luft), Resorption (meist an Aminosäuren gebunden über Duodenum, oberes Jejunum), Transport (proteingebunden vorwiegend über die Blutbahn), Speicherung (proteingebunden in typischen Geweben/Organen) und Ausscheidung (Urin, Faeces und/ oder Schweiß).

Ihre biochemische Funktion üben Spurenelemente in erster Linie als Bestandteil biochemisch aktiver Substanzen (Spezies) aus: Metalloenzyme, durch Metallionen aktivierbare Enzyme, Hormone (Zn, I), Vitamine (Co). Weitere Funktionen: Stabilisierung von Membranen oder anderen Strukturen $(\mathrm{Zn})$, Wundheilung $(\mathrm{Zn})$, Elektronentransport $(\mathrm{Cu}, \mathrm{Fe})$, Schutz vor Radikalen ( $\mathrm{Se}, \mathrm{Mn}, \mathrm{Zn}, \mathrm{Cu}$ ), als Stimulator für 
immunologische (Zn, Se, Fe) und Inhibitor für neoplastische Prozesse (Pt, Se). Im Falle der Zufuhr als Substitution bei Spurenelementmangel oder wegen einer spezifischen therapeutischen Wirkung spielen zahlreiche Spurenelemente auch als Arzneimittel eine Rolle. Für das Verständnis der biochemischen und toxikologischen Prozesse ist die Identifizierung der Spezies, d. h. der exakten Erscheinungsform des Spurenelementes bzgl. Oxidationszahl und Verbindung im Organismus von großer Bedeutung. So wird die Toxizität eines Spurenelementes nicht selten vom Oxidationsstatus (z. B. Cd(III) vs. $\mathrm{Cd}(\mathrm{VI})$ ) und/oder der Substanzklasse (z. B. organische vs. anorganische Quecksilberverbindungen) geprägt. Die Differenzierung und Quantifizierung der sog. Spurenelementspezies erfolgt in einer $\triangleright$ Speziationsanalyse.

Erhöhte Zufuhr von Spurenelementen hat eine schädigende Wirkung. Oberhalb einer für jedes Element typischen zugeführten Menge bzw. typischen Konzentration in einzelnen Körperbestandteilen kommt es sowohl bei essenziellen als auch bei nicht essenziellen Spurenelementen zu akuten oder chronischen Vergiftungen. Darüber hinaus entfalten zahlreiche Spurenelemente eine mutagene, kanzerogene und/oder teratogene Wirkung.

Indikationen zur Bestimmung von Spurenelementen sind:

- Spurenelementmangel (s. Tab.): genetisch bedingte Fehler (Absorption, Transport, Speicherung, Exkretion), unzureichende Zufuhr, unzureichende biochemische Verfügbarkeit, erhöhter Bedarf oder übermäßige Verluste

- Störungen des Spurenelementgleichgewichts: Transportstörungen, schwere akute Situationen wie Verbrennungen, Polytrauma, Myokardinfarkt, Schock, Stress, schwere Infektionen

- Intensive Therapieverfahren: Hämodialyse, totale parenterale Ernährung, schwere Operationen

- Übermäßige Zufuhr und Vergiftungen

- Kontrolle der Therapie mit Spurenelementen oder spurenelementhaltigen Medikamenten.

Die folgende Tabelle zeigt die Bestimmung ausgewählter Spurenelemente bei Spurenelementmangelerscheinungen:

\begin{tabular}{|l|l|l|}
\hline $\begin{array}{l}\text { Indikation } \\
\text { Spurenelementmangel- } \\
\text { krankheiten }\end{array}$ & Element & Krankheit/klinische Symptome \\
\hline & $\mathrm{Zn}$ & Acrodermatitis enteropathica \\
\hline & $\mathrm{Cu}$ & Hypogonadismus \\
\hline & $\mathrm{Fe}$ & Menke-Syndrom \\
\hline & $\mathrm{Se}$ & Kisenmangelanämie \\
\hline $\begin{array}{l}\text { Primärer oder } \\
\text { sekundärer } \\
\text { Spurenelementmangel }\end{array}$ & $\mathrm{Zn}$ & $\begin{array}{l}\text { Schilddrüsenerkrankungen } \\
\text { Appetitlosigkeit, } \\
\text { Wachstumshemmung, } \\
\text { verminderte Wundheilung }\end{array}$ \\
\hline
\end{tabular}

(Fortsetzung)

\begin{tabular}{|c|c|c|}
\hline Indikation & Element & Krankheit/klinische Symptome \\
\hline & $\mathrm{Cu}$ & $\begin{array}{l}\text { Pigmentstörungen, Anämie bei } \\
\text { Kindern, Schädigung der } \\
\text { Arterienwände }\end{array}$ \\
\hline & $\mathrm{Se}$ & $\begin{array}{l}\text { Muskeldystrophie, verringerter } \\
\text { Schutz gegen Radikale }\end{array}$ \\
\hline & $\mathrm{Cr}$ & Verringerte Glukosetoleranz \\
\hline
\end{tabular}

Die Ermittlung von Referenzbereichen für Spurenelemente erweist sich häufig als äußerst schwierig, weil vielfältige Faktoren, wie z. B. Luftqualität, Trinkwasser, Bodenqualität, Nahrungsmittel, Ernährungszubereitung und Ernährungsgewohnheiten, die Spurenelementversorgung und damit den individuellen Spurenelementhaushalt gesunder Personen beeinflussen. Zusammenstellungen von Mittelwerten und Bereichen, inklusive $5 \%$-, 60 \%- und $95 \%$-Perzentilen, für 37 Spurenelemente im Blut Erwachsener aus den Großräumen Aachen, Erkelen und Bremen bzw. 30 Spurenelementen im Urin von Kindern und Erwachsenen aus dem Großraum Bremen finden sich bei Heitland und Köster (2006a, b).

\section{Literatur}

Geldmacher-von Mallinckrodt M, Meißner D (1994) General aspects of the role of metals in clinical chemistry. In: Seiler HG, Sigel A, Sigel $\mathrm{H}$ (Hrsg) Handbook on metals in clinical and analytical chemistry. Marcel Dekker, New York/Basel/Hong Kong, S 13-29

Heitland P, Köster HD (2006a) Biomonitoring of 37 trace elements in blood samples from inhabitants of northern Germany by ICP-MS. J Trace Elem Med Biol 20:253-262

Heitland P, Köster HD (2006b) Biomonitoring of 30 trace elements in urine of children and adults by ICP-MS. Clin Chim Acta 365:310-318

Rükgauer M (Hrsg) (2003) Signalwirkung von Mineralstoffen und Spurenelementen. Wissenschaftliche Verlagsgesellschaft, Stuttgart

\section{SQL-Abfrage}

\section{O. Colhoun}

\section{Englischer Begriff SQL query}

Definition Structured Query Language, ,strukturierte Abfragesprache“, enthält eine Reihe von Befehlen, mit denen komplette Datenbanken erstellt, ganz oder teilweise verändert oder gelöscht werden können.

Beschreibung Für die Datenmanipulation stehen ebenfalls einige Befehle zur Verfügung, mit denen Elemente in eine 
Datenbank eingefügt, bereits vorhandene aktualisiert und überflüssige gelöscht werden können. Außerdem sind mit dieser Befehlsgruppe Selektionen nach bestimmten Kriterien möglich. SQL wird häufig als Abfragesprache für Datenbanken im Internet eingesetzt.

\section{SQL-Server}

O. Colhoun

Englischer Begriff SQL server

Definition Als $>$ Server dienende Datenbank.

Beschreibung Es handelt sich um eine relationale Datenbank, die als Abfragesprache SQL verwendet.

\section{Squamous cell carcinoma antigen}

S. Holdenrieder und P. Stieber

$\operatorname{Synonym(e)~SCC;~SCCA~}$

Englischer Begriff squamous cell carcinoma antigen

Definition Das „squamous cell carcinoma antigen“ ist ein $42 \mathrm{kDa}$ schweres Protein und wurde durch polyklonale Antikörper aus Lebermetastasen eines Zervixkarzinoms isoliert.

Struktur Das „squamous cell carcinoma antigen“ ist ein hochreines Protein mit einem Kohlenhydratanteil von nur $0,6 \%$ und stellt eine von 14 Fraktionen des TA-4-Antigens dar. Es besteht eine enge Homologie der Aminosäurensequenz mit jener der Serinproteasen-Inhibitor-Familie, z. B. dem Plasminogen-Aktivator-Inhibitor ( $\triangleright$ Plasminogen-Aktivator-Inhibitor 1).

Molmasse $42 \mathrm{kDa}$.

Synthese - Verteilung - Abbau - Elimination TA-4 kommt in großzelligen Zervixkarzinomen, in normalen, dysplastischen und malignen Plattenepithelgeweben des aerodigestiven Trakts mit einer hohen Expression in der Oberfläche von normalem Plattenepithel und in gut differenzierten Plattenepithelkarzinomen vor. Es ist nicht in dysplastischen
Mundhöhlenepithelien und in schlecht differenzierten Plattenepithelkarzinomen nachweisbar. Subzellulär wird TA-4 im Zytosol gefunden und deshalb als Strukturprotein und Differenzierungsindex des Plattenepithelkarzinoms angesehen.

Die Ausscheidung von SCC erfolgt vorwiegend renal. Niereninsuffizienzen können die Elimination der Zytokeratine verzögern und zu erhöhten SCC-Konzentrationen führen.

\section{Halbwertszeit 1 Tag.}

Funktion - Pathophysiologie Die wesentliche klinische Bedeutung der SCC-Bestimmung liegt im Therapiemonitoring und der Rezidiverkennung von Plattenepithelkarzinomen der Zervix, der Lunge, des Ösophagus, des Kopf-NackenKarzinoms sowie des Analkanals.

Bei benignen Erkrankungen dieser Organe sowie bei dermatologischen Erkrankungen können die Werte ebenfalls erhöht sein. Gegenüber CYFRA 21-1 weist SCC eine noch höhere Spezifität für Plattenepithelkarzinome auf.

Untersuchungsmaterial - Entnahmebedingungen Serum, Plasma, Liquor, Aszites-, Pleuraflüssigkeit.

Analytik > Radioimmunoassay (RIA), $>$ Immunradiometrischer Assay (IRMA), > Enzymimmunoassay (EIA), > Elektrochemilumineszenz-Immunoassay (ECLIA).

Konventionelle Einheit $\mathrm{ng} / \mathrm{mL}(\mu \mathrm{g} / \mathrm{L})$.

Referenzbereich - Erwachsene Serum: Median 0,7 $\mu \mathrm{g} / \mathrm{L}$; $95 \%$-Perzentile $1,5 \mu \mathrm{g} / \mathrm{L}$ (methodenabhängig).

Indikation Therapiekontrolle und Nachsorge von Plattenepithelkarzinomen der Zervix, der Lunge, des Ösophagus, des Kopf-Nacken-Karzinoms sowie des Analkanals.

Interpretation Die meisten SCC-Assays sind für die Anwendung im Serum und Plasma ausgetestet und können auch für die Bestimmung von SCC-Fragmenten in anderen Körperflüssigkeiten eingesetzt werden.

SCC ist weder tumor- noch organspezifisch. Es wird in hohen Wertlagen $(>10 \mu \mathrm{g} / \mathrm{L})$ jedoch vornehmlich von Plattenepithelkarzinomen der Zervix, der Lunge, des Ösophagus, des Kopf-Nacken-Karzinoms sowie des Analkanals, seltener von anderen gynäkologischen und gastrointestinalen Karzinomen freigesetzt.

Wichtige \ Einflussgrößen für die SCC-Konzentrationen sind Niereninsuffizienzen (in Korrelation zur Höhe des Kreatininwertes) und Hauterkrankungen wie Psoriasis, Ekzeme und Pemphigus, die z. T. deutliche Erhöhungen hervorrufen können. Wegen des Vorkommens von SCC im Schweiß, 
Speichel und anderen Körperflüssigkeiten ist außerdem eine Kontamination bei der Pipettierung unbedingt zu vermeiden.

Diagnostische Wertigkeit Plattenepithelkarzinome der Zervix, der Lunge, des Ösophagus, des Kopf-Nacken-Karzinoms und des Analkanals: Therapiemonitoring, Rezidiverkennung.

\section{Literatur}

Lamerz R (2008) SCC. In: Thomas L (Hrsg) Labor und diagnose, 7. Aufl. TH-Books, Frankfurt am Main, S 1351-1355

Stieber P, Heinemann V (2008) Sinnvoller Einsatz von Tumormarkern. J Lab Med 32:339-360

\section{SRA}

- Serotonin Release Assay

\section{S-rDNA-Sequenzierung}

J. Arnemann

Englischer Begriff 16S rDNA sequencing

Definition Die 16S-rDNA-Sequenzierung dient der Identifizierung von Bakterienisolaten durch Amplifikation und Sequenzierung der speziesspezifischen variablen V2-V4und V6-V9-Regionen der 16S-rDNA.

Beschreibung In Verbindung mit $>$ Next-GenerationSequencing (NGS) lässt sich das Spektrum der Keime aus nativem Material, wie z. B. Wundabstrichen, Vaginalabstrichen oder Stuhlproben, als sog. $>$ Mikrobiom-Analyse identifizieren.

Das bakterielle Operon für rDNA ist organisiert in Spacer, 16S-rDNA-Gen, Spacer, 23S-rDNA-Gen, Spacer und 5S-rDNAGen. Während die transkribierten Gene für 16S-rDNA, 23S-rDNA und 5S-rDNA in ihrer Sequenzabfolge sehr stark konserviert sind, können die nicht transkribierten SpacerAbschnitte eine gewisse Variabilität in der DNA-Sequenz zeigen, die man für eine individuelle Typisierung von Bakterienkeimen einsetzen kann. Ausgehend von definierten Primer-Paaren im konservierten Abschnitt des Operons werden jeweils die variablen V2-V4- und V6-V9-Regionen der 16S-rDNA-Bereiche eines Bakterienisolates überbrückend amplifiziert und anschlieBend nach Sanger ( $\triangleright$ Sanger-Sequenzierung) sequenziert und ausgewertet. Die Sequenzen der variablen Bereiche sind für die diversen Bakterienspezies in Datenbanken, wie z. B. der 16S-rDNA Reference Library oder der Greengenes-Datenbank, gelistet und stehen zum Abgleich mit den erhobenen Sequenzdaten und zur Identifizierung der jeweiligen Bakterienspezies zur Verfügung.

Alternativ zur Sequenzierung von Isolaten kann mittels NGS auch ein Gemisch von Bakterienkeimen in nativem Material, wie z. B. Stuhlproben oder Abstrichen, analysiert werden. Der Amplifikationsschritt ist hierbei identisch zur Einzelprobe, die unterschiedlichen Amplifikate können jedoch durch die massive Parallelsequenzierung der NGS-Methode individuell hinsichtlich der DNA-Sequenz ausgewertet und mittels Bioinformatik die zugehörigen Bakterienkeime identifiziert werden. Dieser Prozess wird auch als Mikrobiom-Analyse bezeichnet und die diagnostische Bedeutung der MikrobiomAnalysen aus diversen Abstrichproben oder Stuhlproben ist zunehmend.

\section{Literatur}

Woo PCY et al (2008) Then and now: use of 16S rDNA gene sequencing for bacterial identification and discovery of novel bacteria in clinical microbiology laboratories. Clin Microbiol Infect 14:908-934

\section{SRIF}

- Somatostatin

SRM (selected reaction monitoring)

Massenspektrometrie

SS-A-Antikörper

- Autoantikörper gegen SS-A

\section{SS-B-Antikörper}

- Autoantikörper gegen SS-B

ssDNA-Antikörper

- Autoantikörper gegen Einzelstrang-DNA 


\section{St. Louis Enzephalitis-Viren (SLEV)}

W. Stöcker

Englischer Begriff St. Louis encephalitis virus

Beschreibung des Erregers Familie: Flaviviridae; Gattung: Flavivirus; Art: St. Louis Enzephalitis-Virus. PlusstrangRNA-Genom, ca. $40 \mathrm{~nm}$ Durchmesser.

Erkrankungen Vorkommen: Nordamerika, Karibik, Mittelund Südamerika.

Vektoren: Stechmücken (verschiedene Culex-Spezies).

Wirte: Vögel (Virusreservoir), Menschen (Endwirt).

Klinik: Über $99 \%$ der Patienten zeigen keine oder nur leichte Symptome. Kommt es zu einer Meningoenzephalitis (häufiger bei älteren Patienten) oder Enzephalitis, treten zunächst Fieber, Kopfschmerzen, Nackensteifigkeit, Verwirrung, Schläfrigkeit auf. Im späteren Verlauf kann es zu Tremor, Spontannystagmus, Myoklonien, Rigor, Paralysen, Ataxie bis hin zum Koma kommen. Weitere Komplikationen: Bronchopneumonie, gastrointestinale Blutungen. Die Letalitätsrate liegt bei jungen Patienten unter $5 \%$, steigt aber altersabhängig auf bis zu $15 \%$. Neuropsychiatrische Spätfolgen, wie Müdigkeit, Vergesslichkeit, Konzentrationsstörungen sind möglich.

Analytik Direktnachweis: Nachweis viraler RNA durch RT-PCR (Polymerase-Kettenreaktion), Virusanzucht.

Serologie: Nachweis spezifischer Antikörper (IgM, IgG) im Serum durch z. B. indirekte Immunfluoreszenz, $\checkmark$ Enzyme-linked Immunosorbent Assay.

Probenmaterial Direktnachweis: Blutplasma, Liquor oder Gewebe. Das Material sollte bis zur Weiterverarbeitung bei +4 bis $+8{ }^{\circ} \mathrm{C}$ aufbewahrt werden.

Serologie: Serum oder Plasma für den Nachweis der Antikörper sind bei $+4{ }^{\circ} \mathrm{C}$ bis zu 2 Wochen lang beständig, bei $-20^{\circ} \mathrm{C}$ über Monate und Jahre hinweg. Zur Tiefkühlkonservierung des IgM kann man den Proben 80 \% gepuffertes Glyzerin beifügen.

Diagnostische Wertigkeit In den USA zählen die SLEV zu den häufigsten Auslösern viraler Enzephalitis-Epidemien. Direktnachweise des Virus kurz nach der Infektion sind zwar möglich, aber schwierig. Der Nachweis spezifischer IgM-Antikörper ist etwa ab dem 3.-5. Krankheitstag möglich, zu beachten sind Kreuzreaktionen mit Antikörpern gegen andere Flaviviren (FSME-, Gelbfieber-, Dengue-, West-Nil-, Zika-, Powassan-Viren, u. a.). Ein vierfacher Anstieg des spezifischen Antikörpertiters in einer zweiten Serumprobe gilt als eindeutiger Nachweis der Infektion.
Differenzialdiagnose: West-Nil-Fieber, andere bakterielle oder virale ZNS-Infektionen mit Meningitis oder Enzephalitis.

\section{Literatur}

Center for Disease Control and Prevention (2010) Saint Louis encephalitis, Atlanta, 29 Jan. https://www.cdc.gov/sle/index.html. Zugegriffen am 02.08.2017

Robert-Koch-Institut, Berlin (2011) Steckbriefe seltener und importierter Infektionskrankheiten. Robert-Koch-Institut, Berlin

STA

- Analyse, systematische toxikologische

\section{Stabilisatoren}

W. G. Guder

Englischer Begriff stabilizers

Definition Zusätze in Probengefäßen, die der Stabilisierung der zu messenden Analyte in der Probe dienen ( $\triangleright$ Proteinaseinhibitoren als Stabilisatoren, $\triangleright$ Probenstabilität).

Beschreibung Wenn ein Analyt in der untersuchten - Matrix nicht stabil ist, sodass während der üblichen Transport- und Aufbewahrungszeit eine medizinisch relevante Veränderung der Konzentration zu erwarten ist, werden der $\triangleright$ Probe bei der Gewinnung Stabilisatoren zugesetzt, die eine ausreichende Stabilität der Analyte bis zur Analyse gewährleisten. Als Stabilisatoren dienen Basischemikalien (Ansäuern bis zum Enteiweißen mit scharfen Säuren), Inhibitoren des proteolytischen Abbaus (z. B. Aprotinin), Substanzen zur Bindung von Metallen (z. B. Citrat bei Gerinnungstests, EDTA zur Stabilisation von Blutzellen und zur Hemmung von Proteinasen bei labilen Peptidhormonen) sowie spezifische Hemmstoffe zur Vermeidung des Bakterienwachstums (Thymol/Borsäure, Formiat) oder Serin/Natriumborat zur Hemmung der $>\gamma$-Glutamyltransferase bei der Stabilisierung von Ammoniak.

Stabilisatoren müssen nicht nur auf die erwünschte Wirksamkeit und das Fehlen von Störungen analytischer Prozesse geprüft werden, sondern auch auf ihre Ungefährlichkeit beim Umgang durch medizinisches Personal und Patienten sowie 
bei der Entsorgung gemeinsam mit dem Untersuchungsmaterial (z. B. Sammelurin) in die normale Toilette oder den Verbrennungsmüll. So wurde Cäsium-Azid als Stabilisator für Urinproben erprobt und für sehr wirksam befunden. Wegen der Toxizität der Substanz und der unvorhersagbaren Folgen beim Ausgießen der Urine in die Abwässer kann dieser Stabilisator jedoch nicht empfohlen werden. Die jeweils zu jedem Analyten passenden Stabilisatoren finden sich in der jeweils neuesten Fassung von „Die Qualität diagnostischer Proben“"

\section{Literatur}

Die Qualität diagnostischer Proben (2012) 7. Aufl. BD Diagnostics/ Preanalytical Systems, Heidelberg ab 2018 als App

Hagemann P, Scholer A (2011) Aktuelle Urindiagnostik. Labolife, Rotkreuz

\section{Stabilisatoren, biologische}

- Proteinaseinhibitoren als Stabilisatoren

\section{Stabilität der Messgröße in der Probenmatrix}

> Probenstabilität

\section{Stabilität der Probe}

> Probenstabilität

- Stabilisatoren

\section{Stabilitätskonstante}

- Assoziationskonstante

\section{Stabkernige}

- Granulozyten, stabkernige

\section{Stahlblau}

- Berlinerblau-Reaktion

\section{Stammdaten}

O. Colhoun

\section{Synonym(e) EDV-Konfiguration}

Definition Hinterlegung der individuellen Arbeitsabläufe eines medizinischen Labors im gelieferten Standard-LaborEDV-System.

Beschreibung Die Arbeit im eigenen medizinischen Laboratorium richtet sich nach bestimmten Funktionsabläufen. Die angebotenen Messgrößen wurden individuell benannt und erhalten eigene Parameterbezeichnungen in der $>$ LaborEDV. Alle zu bearbeiteten Untersuchungsdaten und Arbeitsschritte, Materialien, Einsender und zugelassene Benutzer sind abzubilden. Diese Festlegung erfolgt in den Stammdaten und ermöglicht so eine optimale Anpassung des Standardsystems an die eigene Arbeitsumgebung und -weise. Damit werden die Stammdaten zum Gerüst des Systems. Sie müssen absolut korrekt und sorgfältig definiert und gepflegt werden, denn fehlerhafte Stammdaten führen unweigerlich zu fehlerhaften Befunden, Abrechnungen, statistischen Auswertungen etc. Änderungen an den Stammdaten werden protokolliert und sind nachvollziehbar in Bezug auf Zeitpunkt und Benutzer.

Die Hinterlegung der Stammdaten erfolgt nach Themenkreisen bzw. Bearbeitungsbereichen jeweils in Stammdateien:

Abrechnungsarten Definition der Rechnungsarten, mit denen Aufträge abgerechnet werden können und aller zugehörigen Abrechnungsmodalitäten und Ausnahmen. Beispiel: Definition der Abrechnungsart Gebührenordnung für Ärzte (GOÄ) mit Hinterlegung des Punktwerts, eines zugehörigen Regelwerks, evtl. fixer oder preisabhängiger Rabatte, Sonderpreise für bestimmte Analyten.

Analysen Definition aller im Labor durchgeführten Untersuchungen. Hierzu gehören ergebnistragende Analysen (Natrium, grampositive Kokken etc.), laborinterne Analysen (Berechnungszwischenergebnisse), Pseudoanalysen (Schwangerschaftswoche, Abnahmemenge etc.), Antibiotika, Befundüberschriften und -zwischenüberschriften. Diese Stammdatei enthält den Analysencode, verschieden ausführliche Analysenbezeichnungen für unterschiedliche Befundarten, laborinterne Erläuterungen, die Dimension, Ergebnisart, Zuordnung der 
Position bei Auftragserfassung, -bearbeitung und Befunddarstellung, Zuordnung zu Befundart und Zwischenüberschrift, Sortierkriterien, den Arbeitsplatz, statistische Zuordnungen, die Leistungsziffer, Festlegung sämtlicher Bearbeitungsoptionen (Erfassung in Auftragserfassung oder nur per Anforderungskarte, Darstellung in Befundauskunft oder/und Befund, Abrechenbarkeit etc.), Festlegung der Qualitätskontrollvorgaben, Kriterien zur Darstellung des Parameters in der medizinischen Validation, Standardmaterial und Referenzbereiche (Standard, alters-, geschlechts- und/oder zustandsabhängig, „Marcumar“.

Textbausteine Definition aller Arten von Texten wie Textergebnisse, Keimnamen, Befundkommentare, Zusatzkommentare.

Arbeitsplatz Definiert den Inhalt einer Arbeitsliste: Zuordnung zu Analysengerät, Layout der Arbeitsliste, Kontrollmaterialien.

Häuser Definiert die Organisationseinheiten, die an das Laboratorium einsenden, z. B. Krankenhäuser, Standorte, Praxen.

Einsender Definiert die Einsender an das Laboratorium, also alle Stellen, die Proben liefern, Befundempfänger und Rechnungsempfänger und ordnet diesen jeweils ein Befundlayout zu. Alle relevanten Daten des Einsenders (Anrede, Adresse, Ansprechpartner, Telefonnummer) werden hier hinterlegt.

Gebührenordnung Hinterlegung der Abrechnungsziffern der jeweiligen Gebührenordnung mit Voll-, Sach- und Substanzkosten. Angabe der Texte für die Ausgabe auf der Rechnung.

Geräte In der Analysengerätestammdatei werden die im Labor angeschlossenen Analysengeräte erfasst, die vom EDV-System angesprochen bzw. deren Daten an das System gesandt werden. Die Stammdatei enthält Informationen über die am Gerät durchgeführten Analysen, zugehörige Kontrollmaterialien und technische Daten zum Online-Anschluss.

Kommunikationsstrukturen Datenübertragungen an externe Anwender können nach unterschiedlichen Protokollen durchgeführt werden. Details der Übertragung (z. B. unterschiedliche „Dialekte“ eines Standardprotokolls) werden hier definiert.

Kontrollmaterialien Alle im Labor verwendeten Kontrollmaterialien sind mit ihren Daten hier zu erfassen (Bezeichnung, Hersteller, Analysen, Sollwerte, ID-Nummer, Chargennummer, Lot-Nummer, Gültigkeit, Art der Kontrolle, Vorperiode, Präzisionskontrollgrenzwerte).
Materialien Kurz- und Langbezeichnung, Lokalisationsbeschreibung erforderlich (z. B. Punktat), Zuordnung zu Laborbereich, Eingruppierung in Statistik.

\section{Standard, innerer}

- Standard, interner

\section{Standard, interner}

T. Arndt

Synonym(e) IS; Standard, innerer

Englischer Begriff internal standard

Definition Bezeichnung für jene Komponente, die der - Probe für die qualitative Identifizierung und/oder die Bestimmung der Analyte zugesetzt wird.

Beschreibung Die häufigsten Einsatzgebiete von internen Standards (IS) im klinisch-chemischen Labor sind die > Chromatographie, $>$ Elektrophorese und $>$ Massenspektrometrie. Hier werden durch Zugabe definierter Mengen eines internen Standards sowie Berechnung und Auswertung von Signalhöhen- oder Signalflächen-Quotienten Analyt/IS die durch die Probenvorbereitung, Dosierung und Trennung eintretenden Analytverluste kompensiert.

Die als interner Standard genutzte Verbindung sollte, auch unter pathologischen Bedingungen, nicht in der nativen Analysenprobe vorhanden sein. Weitere Voraussetzungen für die Eignung einer Verbindung als interner Standard sind: weitgehende strukturelle und physiko-chemische Ähnlichkeit mit dem oder den Analyten, ähnliches Verhalten im Analysensystem, Verfügbarkeit als Reinstsubstanz zur Einwaage. Eine definierte Menge an internem Standard wird unmittelbar vor Probenvorbereitung zur Analyse einem definierten Aliquot der Analysenprobe zugesetzt. Unter der Annahme vergleichbarer Verluste von Analyt und IS während der Probenvorbereitung heben sich diese durch Quotientenbildung von Analyt- und IS-Signalen auf und werden damit für die quantitative Analyse bedeutungslos.

Zur Kalibrierung werden Proben mit verschiedenen Konzentrationen der Analyte und konstanter Konzentration des internen Standards analysiert. Aus der Gegenüberstellung der Analytkonzentrationen (x-Achse) und der Signalhöhen- oder Signalflächen-Quotienten Analyt/IS (y-Achse) erhält man eine Kalibrierfunktion, mit deren Hilfe die Analytkonzentra- 
tion in den Patientenproben grafisch oder rechnerisch ermittelt werden kann. Man spricht auch von innerer oder interner „Eichung“ oder Kalibrierung (im Gegensatz zur äußeren „Eichung“ oder Kalibrierung anhand von Standardlösungen der Analyte).

Klassische Beispiele für den Einsatz eines internen Standards sind die Verwendung von Dihydroxybenzylamin bei der chromatographisch/elektrochemischen Bestimmung der - Katecholamine sowie von isotopenmarkierten Referenzsubstanzen in der Massenspektrometrie (z. B. mehrfach deuterierte Formen des Analyten).

\section{Literatur}

Unger KK (Hrsg) (1989) Handbuch der HPLC. Teil 1 - Leitfaden für Anfänger und Praktiker. GIT Verlag, Darmstadt

\section{Standard temperature and pressure, dry \\ O. Müller-Plathe}

\section{Synonym(e) STPD}

\section{Englischer Begriff STPD}

Definition Internationale Konvention für die Angabe von Gasvolumina.

Beschreibung Nach den Gesetzen von Boyle-Mariotte und Gay-Lussac hängt das Volumen einer Gasmenge vom Druck und der Temperatur ab. Um die Angaben über Gasvolumina vergleichbar zu machen, werden gemessene Gasvolumina mittels Tabellen auf folgende Standardbedingungen umgerechnet:

$\mathrm{t}=0{ }^{\circ} \mathrm{C}(273,16 \mathrm{~K})$ und $\mathrm{P}=760 \mathrm{mmHg}(101,3 \mathrm{kPa}) \mathrm{des}$ trockenen Gases.

$\mathrm{O}_{2}$-Aufnahme und $\mathrm{CO}_{2}$-Ausscheidung des Körpers werden in STPD angegeben.

\section{Standardabweichung}

R.-D. Hilgers, N. Heussen und S. Stanzel

Englischer Begriff standard deviation
Definition Die Standardabweichung ist definiert als die Wurzel aus der > Varianz:

$$
s_{x}=\sqrt{\frac{1}{n-1} \sum_{i=1}^{n}\left(x_{i}-\bar{x}\right)^{2}}
$$

Dabei bezeichnet $\bar{x}$ den arithmetischen Mittelwert ( $>$ Mittelwert, arithmetischer) der $n$ beobachteten Messwerte $\mathrm{x}_{\mathrm{i}}$.

Beschreibung Die Standardabweichung ist das am häufigsten verwendete Maß für die Stärke der $>$ Variabilität zwischen den Messergebnissen ( $\triangleright$ Messergebnis). Die Standardabweichung hat die gleiche Maßeinheit wie die ursprünglichen Messergebnisse und ist ausreißeranfällig. Während eine Addition bzw. Subtraktion einer Konstanten zu bzw. von allen Messwerten den Wert der Standardabweichung nicht beeinflusst, wirken sich eine Multiplikation bzw. Division aller Messwerte mit bzw. durch einen konstanten Faktor derart auf die Standardabweichung aus, dass sich diese gemäß derselben mathematischen Operation ändert. Die letztgenannte Eigenschaft der Standardabweichung findet insbesondere bei einer Änderung der Skala, in der die Werte gemessen wurden, Verwendung.

Der zweifache Standardabweichungsbereich um den arithmetischen Mittelwert überdeckt mindestens $75 \%$ der Messergebnisse, während der dreifache Standardabweichungsbereich um den arithmetischen Mittelwert etwa $90 \%$ der Messwerte enthält.

\section{Literatur}

Hilgers R-D, Bauer P, Scheiber V (2002) Einführung in die Medizinische Statistik. Springer, Berlin/Heidelberg/New York

\section{Standardabweichung, gepoolte}

\author{
R.-D. Hilgers, N. Heussen und S. Stanzel
}

Englischer Begriff pooled standard deviation

Definition Die gepoolte Standardabweichung ist definiert als die Wurzel aus der gepoolten Varianz ( $\triangleright$ Varianz, gepoolte).

Beschreibung Die gepoolte Standardabweichung misst die gemeinsame $>$ Variabilität innerhalb von 2 oder mehr Stichproben ( $\triangleright$ Stichprobe), deren Messergebnisse miteinander kombiniert werden sollen. Im allgemeinen Fall von k Stichproben mit Stichprobenumfängen $n_{l},(\ldots), n_{k}$ ergibt sich die 
gepoolte Standardabweichung als eine Art „fallzahlgewichtete Mittelung“ der Standardabweichungen $\mathrm{s}_{1},(\ldots), \mathrm{s}_{\mathrm{k}}$ der k einzelnen Stichproben:

$$
\mathrm{s}_{\mathrm{p}}=\sqrt{\frac{1}{\mathrm{~N}-\mathrm{k}} \sum_{\mathrm{i}=1}^{\mathrm{k}}\left(\mathrm{n}_{\mathrm{i}}-1\right) \times \mathrm{s}_{\mathrm{i}}^{2}} ; \mathrm{N}=\sum_{\mathrm{i}=1}^{\mathrm{k}} \mathrm{n}_{\mathrm{i}}
$$

\section{Literatur}

Glantz SA (1992) Primer of biostatistics, 3. Aufl. McGraw-Hill, New York

\section{Standardabweichung, residuale}

R.-D. Hilgers, N. Heussen und S. Stanzel

Englischer Begriff standard deviation of the residuals; residual standard deviation

Definition Die residuale Standardabweichung beschreibt die > Variabilität der geschätzten $>$ Residuen.

\section{Literatur}

Hartung J, Elpelt B, Klösener KH (1995) Statistik, Lehr- und Handbuch der angewandten Statistik. Oldenbourg Verlag, München

\section{Standardaddition}

T. Arndt

Synonym(e) Spiken; Spike-Versuch

Englischer Begriff spiking

Definition Häufig genutzte Form der Standardisierung einer Analysenmethode, wenn die Methode des internen Standards ( $\triangleright$ Standard, interner) nicht anwendbar ist.

Beschreibung Die Standardisierung/Quantifizierung erfolgt durch die Zugabe einer definierten Analytmenge zu einem Aliquot des Untersuchungsmaterials, Analyse der nativen und der aufgestockten (gespikten) Probe sowie Auswertung der Analyt-Signalhöhenverhältnisse aus nativer und aufgestockter Probe unter Hinzuziehung geeigneter Kalibrierfunktionen.
Ein häufiger Anwendungsbereich im klinisch-chemischen Labor ist die $>$ Atomabsorptionsspektrometrie.

Durch Spiken können in der $\triangleright$ Chromatographie zunächst unbekannte Signale identifiziert werden, indem man die Probe vor und nach Zugabe der vermuteten Substanz analysiert. Ist das Signal im Chromatogramm nach dem Spiken größer als vorher, kann mit hoher Sicherheit darauf geschlossen werden, dass das Signal (zumindest maßgeblich) von der Verdachtssubstanz herrührt.

\section{Standardarbeitsanweisung}

U. Zimmermann und A. Steinhorst

Synonym(e) Arbeitsanweisung; SAA; SOP

Englischer Begriff operating procedure; standard operating procedure; SOP

Definition Dokumentierte Verfahrensweise über die Durchführung bestimmter Tätigkeiten (z. B. Untersuchungsverfahren).

Beschreibung Eine spezielle Form der Arbeitsanweisung ist die Standardarbeitsanweisung (SAA oder SOP). SAAs sollen bestimmte, immer wiederkehrende Aktivitäten, Arbeitsverfahren bzw. Laboruntersuchungen beschreiben. Sie sind Beschreibungen von standardisierten Arbeitsverfahren, die es ermöglichen sollen, dass das jeweils beschriebene Untersuchungsverfahren jederzeit und von verschiedenen Personen definiert durchgeführt wird und dass später die jeweilige Vorgehensweise jederzeit rekonstruiert werden kann.

Für die SAAs gelten bestimmte formale Anforderungen. Diese müssen schriftlich genehmigt, geeignet und am Arbeitsplatz verfügbar sein. Eine gelenkte Verteilung muss sichergestellt sein.

Die formalen Anforderungen an die Dokumentation eines (medizinischen) Untersuchungsverfahrens - bzw. einer SAA für ein Untersuchungsverfahren - sind in der ISO 15189 niedergelegt. Danach soll die Verfahrensdokumentation außer den Identifikationsangaben für die Dokumentenlenkung - falls für das Untersuchungsverfahren zutreffend - folgendes enthalten:

- Zweck der Untersuchung

- Grundlage und Methode des für die Untersuchungen angewendeten Verfahrens

- Leistungsmerkmale

- Art der Probe (z. B. Plasma, Serum, Urin)

- Vorbereitung des Patienten

- Art des Behälters und der Zusatzstoffe 
- Erforderliche Ausrüstung und Reagenzien

- Umwelt- und Sicherheitsmaßnahmen

- Kalibrierverfahren (metrologische Rückführbarkeit)

- Schritte im Arbeitsablauf

- Verfahren der Qualitätssicherung

- Störungen (z. B. Lipämie, Hämolyse, Bilirubinämie, Drogen) und Kreuzreaktionen

- Kurzbeschreibung des Verfahrens zur Ergebnisberechnung einschließlich der Messunsicherheit der gemessenen Größenwerte, falls zutreffend

- Biologische Referenzbereiche oder klinische Entscheidungswerte

- Berichtspflichtiges Intervall für die Untersuchungsergebnisse

- Anweisungen zur Bestimmung quantitativer Ergebnisse, wenn ein Ergebnis nicht innerhalb des Messbereichs liegt

- Falls zutreffend, alarmierende oder kritische Werte

- Befundinterpretation durch das Laboratorium

- Mögliche Ursachen von Abweichungen

- Verweise

\section{Literatur}

Hocheimer N (2002) Das kleine QM-Lexikon. Wiley-VCH, Weinheim DIN EN ISO 15189:2014 „Medizinische Laboratorien - Anforderungen an die Qualität und Kompetenz“"

\section{Standardbicarbonat}

O. Müller-Plathe

\section{Englischer Begriff standard bicarbonate}

Definition Standardbicarbonat (StBK) ist die Plasmabicarbonatkonzentration nach Äquilibrierung des Vollbluts mit einem Gasgemisch von $p \mathrm{CO}_{2}=40 \mathrm{mmHg}(5,33 \mathrm{kPa})$ und $p \mathrm{O}_{2}>100 \mathrm{mmHg}(13,33 \mathrm{kPa})$ bei $37^{\circ} \mathrm{C}$ und stellt somit ein $\mathrm{Maß}$ für die nicht respiratorische Seite des Säure-BasenGleichgewichts ( $\triangleright$ Säure-Basen-Stoffwechsel) dar.

Beschreibung Eine $\mathrm{pH}-\mathrm{Messung}$ nach vorangehender Äquilibrierung ( $\triangleright$ Partialdruck) erlaubt bei konstantem $p \mathrm{CO}_{2}$ die Berechnung von StBK aufgrund der Henderson-HasselbalchBeziehung ( $>$ Säure-Basen-Stoffwechsel) nach der Formel: $\lg \mathrm{CHCO}_{3}{ }^{-}$(stand $)=\mathrm{pH}-6,015$.

Die meisten Analysatoren berechnen StBK im Rahmen der Blutgasanalyse ohne zusätzlichen Aufwand. StBK löste die - Alkalireserve als Ausdruck der nicht respiratorischen („metabolischen“) Komponente des Säure-Basen-Gleichge- wichts $\mathrm{ab}$, ist aber inzwischen durch die $>$ Basenabweichung überholt, die diese Komponente in korrekterer Weise wiedergibt.

\section{Literatur}

Jörgensen K, Astrup P (1957) Standard bicarbonate, its significance, and a new method for its determination. Scand J Clin Lab Invest 9:122-132

\section{Standardfehler des Achsenabschnitts}

\section{R.-D. Hilgers, N. Heussen und S. Stanzel}

Englischer Begriff standard error of the intercept

Definition Der Standardfehler des Achsenabschnitts ist ein Maß für die $>$ Variabilität des Schätzers ( $>$ Schätzer) für den - Achsenabschnitt.

Beschreibung Der Standardfehler des Achsenabschnittes wird benötigt, um die Präzision der Schätzung des Achsenabschnittes beurteilen zu können, etwa anhand eines statistischen Tests ( $\triangleright$ Test, statistischer) oder eines Konfidenzintervalls ( $\triangleright$ Konfidenzintervall).

\section{Literatur}

Hartung J, Elpelt B, Klösener KH (1995) Statistik, Lehr- und Handbuch der angewandten Statistik. Oldenbourg Verlag, München

\section{Standardfehler des Mittelwertes}

R.-D. Hilgers, N. Heussen und S. Stanzel

Synonym(e) SEM

Englischer Begriff standard error of the mean; SEM

Definition Der Standardfehler des Mittelwertes ist definiert als Quotient von $>$ Standardabweichung $\left(s_{\mathrm{x}}\right)$ und der Wurzel aus der Anzahl der $n$ beobachteten Messergebnisse:

$$
\mathrm{SEM}=\frac{\mathrm{s}_{\mathrm{x}}}{\sqrt{\mathrm{n}}}
$$


Beschreibung Der Standardfehler des Mittelwerts (SEM) beurteilt die Stärke der Variabilität des arithmetischen Mittelwertes ( $\triangleright$ Mittelwert, arithmetischer) der Messreihe. Der SEM ist kein Maß zur Beschreibung der > Variabilität der Einzelbeobachtungen ( $\triangleright$ Beobachtung). Während eine Addition bzw. Subtraktion aller Messwerte den Wert des Standardfehlers nicht beeinflusst, wirken sich eine Multiplikation bzw. Division aller Messwerte mit bzw. durch einen konstanten Faktor derart auf den Standardfehler aus, dass sich diese gemäß derselben mathematischen Operation ändert. Die letztgenannte Eigenschaft des Standardfehlers findet insbesondere bei einer Änderung der Skala, in der die Werte ( $>$ Messwert) gemessen wurden, Verwendung.

Der SEM nimmt bei gleicher Variabilität der Messwerte mit zunehmendem Stichprobenumfang ( $>$ Stichprobe) ab.

\section{Literatur}

Glantz SA (1992) Primer of biostatistics, 3. Aufl. McGraw-Hill, New York

\section{Standardfehler des Regressionskoeffizienten}

\section{R.-D. Hilgers, N. Heussen und S. Stanzel}

Englischer Begriff standard error of the regression coefficient

Definition Der Standardfehler des Regressionskoeffizienten ist ein Maß für die $>$ Variabilität des Schätzers ( $>$ Schätzer) für den Regressionskoeffizienten ( $\vee$ Regressionskoeffizient).

Beschreibung Der Standardfehler des Regressionskoeffizienten wird benötigt, um die Präzision der Schätzung des Regressionskoeffizienten beurteilen zu können, etwa anhand eines statistischen Tests ( $\vee$ Test, statistischer) oder eines Konfidenzintervalls (s. $>$ Konfidenzintervall).

\section{Literatur}

Hartung J, Elpelt B, Klösener KH (1995) Statistik, Lehr- und Handbuch der angewandten Statistik. Oldenbourg Verlag, München

\section{Standardisiertes Probenarchiv}

Biobanken

\section{Standardmessunsicherheit}

C. Vidal und W.-R. Külpmann

Synonym(e) Standardunsicherheit

Englischer Begriff Standard measurement uncertainty; standard uncertainty of measurement; standard uncertainty

Definition Messunsicherheit, ausgedrückt als seine $>$ Standardabweichung (Brinkmann 2012).

\section{Literatur}

Brinkmann B (2012) Internationales Wörterbuch der Metrologie (VIM) Deutsch-englische Fassung. ISO/IEC-Leitfaden 99:2007, 4. Aufl. Beuth-Verlag, Berlin

\section{Standardmessunsicherheit, kombinierte}

C. Vidal und W.-R. Külpmann

Synonym(e) Standardunsicherheit, kombinierte

Englischer Begriff combined standard measurement uncertainty; combined standard uncertainty

Definition - Standardmessunsicherheit, die man erhält, indem man die einzelnen Standardmessunsicherheiten verwendet, die den Eingangsgrößen des Modells der Messung beigeordnet werden (Brinkmann 2012). Für Anmerkungen s. Literatur.

\section{Literatur}

Brinkmann B (2012) Internationales Wörterbuch der Metrologie (VIM) Deutsch-englische Fassung. ISO/IEC-Leitfaden 99:2007, 4. Aufl. Beuth-Verlag, Berlin

\section{Standardunsicherheit}

- Standardmessunsicherheit 


\section{Standardunsicherheit, kombinierte}

- Standardmessunsicherheit, kombinierte

\section{Standzeit}

C. Vidal und W.-R. Külpmann

Definition Längere Zeitintervalle (z. B. Zentrifugieren, Inkubieren) während einer $>$ Analyse, die für andere, nicht mit der betreffenden Analyse zusammenhängende Tätigkeiten genutzt werden können.

\section{Literatur}

Haeckel R, Fischer G, Fischer M et al (1984) Vorschläge zur Definition von Zeitbegriffen. Dt Ges Klin Chem Mitteilungen 14:187-192

\section{Stannum}

$>$ Zinn

\section{Stansfeld-Webb-Methode}

A. M Gressner und O. A Gressner

Englischer Begriff Stansfeld count

Definition Zellzahlbestimmung im $>$ Urin.

Beschreibung Früher zur quantitativen Bestimmung der renalen Ausscheidung von $>$ Leukozyten und $\triangleright$ Erythrozyten eingesetzte Methode der Zellzahlbestimmung im unzentrifugierten, frischen, gut durchmischten Urin unter Benutzung einer $\triangleright$ Zählkammer nach Neubauer oder Bürker.

Pathologisch: > 5 Erythrozyten $/ \mathrm{mL},>5$ Leukozyten $/ \mathrm{mL}$

\section{Literatur}

Rothkopf M (1965) Erfahrungen mit der quantitativen Urinuntersuchung nach Stansfeld-Webb. Z Urol 58:121-124

\section{Stärkegelelektrophorese}

R. Westermeier

Englischer Begriff starch gel electrophoresis

Definition In der Stärkegelelektrophorese verwendet man teilweise hydrolysierte Kartoffelstärke als stabilisierendes Medium zur Auftrennung von Proteinen im elektrischen Feld. Wegen der unterschiedlichen Ladungen und/oder Molekülgrößen ergeben sich unterschiedliche Wanderungsgeschwindigkeiten; es bilden sich Zonen der Einzelsubstanzen aus.

Beschreibung Das Trennprinzip ist das gleiche wie bei - Agarosegelelektrophorese und $>$ Polyacrylamid-Gel-Elektrophorese. Meist werden Serumproteine auf ca. $1 \mathrm{~cm}$ dicke Gele aufgetragen, die nach der $>$ Elektrophorese für verschiedene Enzymnachweise in mehrere Schichten aufgeschnitten werden. Die einzelnen Schichten werden dann mit unterschiedlichen Zymogramm-Techniken ( $\triangleright$ Zymogramm-Technik) angefärbt, sodass man verschiedene Muster aus einer Trennung erhält.

Die Stärkegelelektrophorese ist fast vollständig von Agarosegel- und Polyacrylamid-Gel-Elektrophoresen verdrängt worden, weil die beiden letzteren Techniken einfacher durchzuführen sind und ihre Reproduzierbarkeit besser ist.

\section{Literatur}

Smithies O (1955) Zone electrophoresis in starch gels: group variations in the serum proteins of normal human adults. Biochem J 61:629-641

\section{STAT}

C. Vidal und W.-R. Külpmann

\section{$\operatorname{Synonym(e)~Eilanalyse~}$}

Englischer Begriff short turn around time (STAT)

Beschreibung Analysen, die besonders schnell durchgeführt werden müssen. Moderne Analysegeräte besitzen in der Regel eine STAT-Funktion. Sie erlaubt, während des Betriebs umgehend eine STAT-Probe vor allen anderen bereits im Gerät befindlichen Proben ( $\triangleright$ Probe) zu messen ( $\triangleright$ STAT-Labor). 


\section{Stat-Analytik}

- Notfall-Analytik

\section{State-Marker}

T. Arndt

Definition Sammelbegriff für zustands- und zeitabhängige Kenngrößen eines bestimmten physiologischen oder pathologischen Prozesses.

Beschreibung Der Begriff findet innerhalb der Klinischen Chemie vor allem im Rahmen der Alkoholmissbrauchsdiagnostik Anwendung. Er umfasst, in Abgrenzung zum sog. - Trait-Marker, all jene klinisch-chemischen Kenngrößen ( $\triangleright$ Kenngröße, klinisch-chemische), die einen akuten, kürzlich zurückliegenden oder chronischen Alkoholkonsum anzeigen, z. B. \ Ethanol in Blut, $>\gamma$-Glutamyltransferase, - Carbohydrate-deficient transferrin in Serum und $>$ Ethylglukuronid in Urin und Haaren. S. auch - Alkoholmissbrauchskenngrößen. State-Marker sind für alle physiologischen und pathobiochemischen Zustände definierbar. Für den Diabetes mellitus sind z. B. die Glukosekonzentration in NaF-Serum oder das $>$ Hämoglobin A1C im EDTA-Blut State-Marker.

\section{Literatur}

Arndt T (2011) Biomarker des Alkoholkonsums - eine Übersicht. Toxichem Krimtech 78:419-430

\section{Stationäre Phase}

T. Arndt

Synonym(e) Festphase; Packungsmaterial; Sorbens; Trennflüssigkeit

Englischer Begriff stationary phase

Definition Neben der mobilen Phase eine der beiden Phasen, aus denen das chromatographische oder elektrophoretische System besteht ( $\triangleright$ Chromatographie, $\triangleright$ Elektrophorese). Die stationäre Phase ist auf einer planaren Fläche ( $\triangleright$ Dünnschichtchromatographie, $\triangleright$ Flachbett-Elektrophorese) oder in einer Säule (Säulenchromatographie) fixiert. Sie kann aus einem Feststoff (Sorbens), einer Flüssigkeit (Trennflüssigkeit) oder einem Gel bestehen.

Beschreibung Die Trennflüssigkeit ist auf einen Festkörper (Träger) aufgezogen, der auch am Trennprozess beteiligt sein kann.

Die am häufigsten eingesetzten festen Packungsmaterialien sind kugelförmige, poröse anorganische Oxide (z. B. Kieselgel, $\mathrm{Al}_{2} \mathrm{O}_{3}$ ) oder organische Polymere (z. B. vernetzte Agarose, Copolymere von Styrol-Divinylbenzol, Methylmethacrylate) oder eine Kombination aus beiden (Verbundpackungsmaterialien). Die Partikeldurchmesser betragen zumeist 3-10 $\mu \mathrm{m}$ für analytische und $10-100 \mu \mathrm{m}$ für präparative Anwendungen.

Durch Modifikation der Porengröße und Oberfläche der Packungsmaterialien lässt sich eine enorme Vielzahl von stationären Phasen mit speziellen Trenneigenschaften herstellen. Ein wichtiges Unterscheidungsmerkmal ist die Hydrophobizität der stationären Phase. Eine polare stationäre Phase hat funktionelle Gruppen auf der Sorbensoberfläche. Diese Materialien werden als Normalphasen bezeichnet und die mit ihnen durchgeführte Chromatographie als NormalphasenChromatographie. Durch chemische Modifikation der polaren Gruppen, z. B. durch Bindung von Alkylgruppen mit 8 oder 18 C-Atomen, erhält man unpolare Oberflächen. Man bezeichnet diese stationären Phasen als Umkehrphasen (RP: „reversed phase") und die mit ihnen durchgeführte Chromatographie als Umkehrphasen-Chromatographie (,reversedphase chromatography“).

\section{Literatur}

Ettre LS (1993) Nomenclature for chromatography. Pure Appl Chem 65:819-872

Unger KK (Hrsg) (1989) Handbuch der HPLC. Teil 1 Leitfaden für Anfänger und Praktiker. GIT Verlag, Darmstadt

\section{Statistik}

O. Colhoun

\section{Englischer Begriff statistics}

Definition Als Funktion des Labor-EDV-Systems: Zählen und Zusammenfassen von Ereignissen.

Beschreibung Die Statistikfunktionen der $>$ Labor-EDV sind neben der Mengenauswertung vor allem für die Grup- 
pierung nach bestimmten Regeln notwendig. Die Systeme unterscheiden zwischen medizinischen Statistiken (Auswertung der Analytik nach Ergebnissen, Ergebniskonstellationen) und Leistungsstatistiken (Anzahl der durchgeführten Leistungen mit preislicher Bewertung).

\section{Statistik, deskriptive}

R.-D. Hilgers, N. Heussen und S. Stanzel

Synonym(e) Beschreibende Statistik

Englischer Begriff descriptive statistics

Definition Unter dem Begriff ,deskriptive Statistik“ werden die Verfahren der beschreibenden Statistik zusammengefasst.

Beschreibung Das Ziel der deskriptiven Statistik besteht darin, die im Rahmen medizinischer Erhebungen gesammelten Daten so aufzubereiten, dass sie überschaubar und interpretierbar werden. In der univariaten deskriptiven Statistik werden die erhobenen Werte einzelner Merkmale ( $\triangleright$ Merkmal) durch die Auszählung und grafische Darstellung absoluter bzw. relativer Häufigkeiten der einzelnen Merkmalsausprägungen sowie die Berechnung von Lagemaßen (z. B. \ Mittelwert, arithmetischer, $\checkmark$ Median, $>$ Minimum, $>$ Maximum) und Streuungsmaßen (z. B. \ Varianz, \ Spannweite, \ Standardabweichung) zusammengefasst. Die Verfahren der bivariaten bzw. multivariaten deskriptiven Statistik hingegen werden zu Beschreibung und Quantifizierung der Art von Zusammenhängen zwischen jeweils 2 bzw. mehreren Merkmalen verwendet. Beispiele hierfür sind die $\triangleright$ Punktwolke, die lineare Regression $(\triangleright$ Regression, lineare) sowie diverse Korrelationskoeffizienten (z. B. \ Korrelationskoeffizient nach Pearson, \ Korrelationskoeffizient nach Spearman).

\section{Literatur}

Weiß C (1999) Basiswissen Medizinische Statistik. Springer, Berlin/ Heidelberg/New York

Statistik, induktive

R.-D. Hilgers, N. Heussen und S. Stanzel

Synonym(e) Inferenzstatistik; Schließende Statistik
Englischer Begriff inductive statistics; statistical inference

Definition Verfahren der schließenden Statistik

Beschreibung Ziel der induktiven Statistik ist die Verallgemeinerung von Sachverhalten, die in einer $>$ Stichprobe beobachtet wurden, auf die zugehörige > Grundgesamtheit. Verfahren der induktiven Statistik sind insbesondere statistische Tests ( $\triangleright$ Test, statistischer) oder Konfidenzintervalle ( $\triangleright$ Konfidenzintervall).

\section{Literatur}

Weiß C (1999) Basiswissen Medizinische Statistik. Springer, Berlin/ Heidelberg/New York

\section{Statistik, medizinische}

O. Colhoun

Englischer Begriff medical statistics

Definition > Labor-EDV-gestützte statistische Auswertung der Laboraufträge nach medizinischen Kriterien.

Beschreibung Hierzu zählen vor allem die Auswertung der Analytik nach Ergebnissen (z. B. „Alle Hämoglobin-Anforderungen der Chirurgischen Klinik des vergangenen Jahres, deren Ergebnis kleiner als $9 \mathrm{mg} / \mathrm{dL}_{\text {betrug }}$ ") sowie die statistische Aufbereitung des generellen Einsendeverhaltens (z. B. Anzahl der Patienten, Anzahl der Patienten pro Klinik, Anzahl der Patienten pro Station, Anforderungsverhalten pro Einsender, Anforderungsverhalten pro Einsendergruppe in definiertem Zeitintervall, Anforderungsverhalten gesamt).

\section{Statistische Korrelation}

- Korrelation, statistische

\section{Statistische Qualitätskontrolle}

> Qualitätskontrolle, statistische 


\section{Statistische Verteilung}

- Verteilung, statistische

\section{Statistischer Ausreißer}

- Ausreißer, statistischer

\section{Statistischer Effekt}

Effekt, statistischer

\section{Statistischer Signifikanztest}

- Test, statistischer

\section{Statistischer Test}

- Test, statistischer

\section{Statistisches Modell}

> Modell, statistisches

\section{STAT-Labor}

\section{A. M. Gressner und O. A. Gressner}

Synonym(e) Notfalllabor

Englischer Begriff emergency laboratory; short turnaround time laboratory; instant lab; STAT laboratory

Definition Kontinuierlich betriebene, separate Laborfunktionseinheit oder in den Routineablauf integrierte Funktion mit der Zielsetzung der permanenten Verfügbarkeit klinisch- chemischer Analysenergebnisse und Befunde von vitaler Bedeutung in einer möglichst kurzen Zeitspanne zwischen Eingang des Auftrages bzw. Untersuchungsmaterials und Verfügbarkeit des Ergebnisses ( $\triangleright$ STAT).

Beschreibung Die klinisch-chemische Notfalldiagnostik muss folgende Minimalkriterien erfüllen:

- Ständige Einsatzbereitschaft (Präsenzpflicht)

- Schnelle Verfügbarkeit der Ergebnisse (short turnaround time)

- Maximale Zuverlässigkeit analytischer Methoden und der mit ihnen gewonnenen Ergebnisse belegt durch Qualitätssicherungsmaßnahmen ( $\triangleright$ Qualitätssicherung)

- Rasche $>$ Befundübermittlung an die Stationen bzw. Einsender

Diesen Erfordernissen können prinzipiell 3 Organisationsformen des Notfalllabors in Verbindung mit dem zentralen Routinelabor entsprechen:

- In das Zentrallabor integrierte, aber autark arbeitende, separate Funktionseinheit

- Funktionell integriert in das Routinelabor, nicht autark, aber unter besonderer personeller Verantwortung stehend

- Dem Zentrallabor angeschlossen, aber autark und dezentralisiert arbeitend (z. B. im Operations- oder Notfallbereich).

Hochmechanisierte Geräte bieten heutzutage fast immer eine separate STAT-Funktion an, die eine zeitlich bevorzugte, d. h. sofortige Einschleusung und Analysendurchführung von Notfallproben in den Serienbetrieb der Routinegeräte ermöglicht und somit eine Integration in das Routinelabor erlaubt.

Das Notfalluntersuchungsspektrum muss als Mindestprogramm die absoluten Vitalparameter wie $>$ Blutbild, kleines, - Thromboplastinzeit, partielle aktivierte, D Thromboplastinzeit, \Glukose, \ Harnstoff, \Kreatinin, \ Kalium, - Natrium, Protein, $>$ Calcium und $>$ Troponin sowie Blutgase enthalten. Modifikationen und Erweiterungen durch spezifische Klinik- und Organisationsstrukturen sowie durch punktuelle Ergänzung mit der patientennahen Sofortdiagnostik ( $\triangleright$ Patientennahe Sofortdiagnostik; Point-of-care-Diagnostik, POCT) sind ortsspezifischen Gegebenheiten vorbehalten (z. B. toxikologische Nachweisreaktionen, endokrinologische Kenngrößen).

\section{Literatur}

Gressner AM (1981) Klinisch-chemische Notfalluntersuchungen Medizinische und organisatorische Aspekte. Krankenhausarzt 54: 793-800 


\section{Stat-Übersicht}

> Notfall-Monitoring

\section{Staubinde}

W. G. Guder

Synonym(e) Stauschlauch

Englischer Begriff tourniquet

Definition Spezielles Gerät zur Stauung des venösen Bluts am Oberarm bei der $\gg$ Blutentnahme. Als solche verwendet werden Gummischläuche (nicht empfohlen), eigene Geräte mit Stauband aus dehnbarem Mischgewebe oder Blutdruckmessgeräte.

\section{Literatur}

Guder WG, Hagemann P, Wisser H, Zawta B (2007) Fokus Patientenprobe. Kompendium Präanalytik. BD Diagnostics, Heidelberg/ Schwechat/Basel

Von Meyer A, Cadanuro J, Streichert T, Gurr E, Fiedler MG, Leichtle A, Petersmann A, Töpfer G, Guder WG (2017) Standard-Arbeitsanleitung zurperipher venösen Blutentnahme für die labormedizinische Diagnostik. J Lab Med 41:333-340

\section{Stauschlauch}

$>$ Staubinde

\section{Stauung als Einflussgröße}

• Einflussgrößen

\section{Steady state}

- Fließgleichgewicht

\section{Stearinsäure}

$\triangleright$ Fettsäuren

\section{Steatokrit}

A. M. Gressner und O. A. Gressner

Synonym(e) Steatokrit-Test

Englischer Begriff steatocrit test

Definition Semiquantitative Kenngröße der Stuhlfettausscheidung unter Verwendung einer Hämatokritzentrifuge zur Diagnostik und Verlaufskontrolle von Malassimilationssyndromen.

Funktion - Pathophysiologie Ausgeprägte exkretorische Pankreasinsuffizienz und/oder Malabsorption führen zu einer Steatorrhoe ( $>7$ g Fettsäurenausscheidung/Tag), die durch quantitative Bestimmung des Stuhlfettes ( $\triangleright$ Stuhlfett) objektiviert wird.

Untersuchungsmaterial - Entnahmebedingungen Repräsentatives Aliquot eines 24-Stunden-Sammelstuhls.

Probenstabilität Konservierung des Materials kurzfristig bei $4{ }^{\circ} \mathrm{C}$ oder längerfristig $-20^{\circ} \mathrm{C}$.

Präanalytik Der Proband sollte 2 Tage vor und während der Stuhlsammelperiode eine ausgeglichene Nahrungsaufnahme mit mindestens 90 und höchstens $200 \mathrm{~g}$ Fett/Tag haben.

Analytik Eine Stuhlprobe von $0,5 \mathrm{~g}$ wird mit $2,5 \mathrm{ml} \mathrm{H}_{2} \mathrm{O}$ und $0,06 \mathrm{~g}$ feinem Sand standardisiert verdünnt, homogenisiert und $70 \mu \mathrm{l}$ davon werden in ein Hämatokritröhrchen aspiriert, um anschließend in einer $>$ Hämatokrit-Zentrifuge bei $13.000 \mathrm{Upm} 15$ Minuten zentrifugiert zu werden. Es ergeben sich 3 Lagen: untere Partikel-, mittlere Zwischenund obere Fettzone. Die Höhe der Fettzone wird in Prozent der Gesamthöhe angegeben. Eine Fettfärbung mit Sudan-III ( $\triangleright$ Sudan-Schwarz) ermöglicht genauere Ablesung.

Referenzbereich - Erwachsene $<2,1 \%$.

\section{Indikation}

- Adjuvante Diagnostik eines Maldigestions- oder Malabsorptionssyndroms

- Verlaufskontrolle der exkretorischen Pankreasinsuffizienz (besonders in der Pädiatrie)

Interpretation Das semiquantitative Verfahren sollte durch eine quantitative Bestimmung des Stuhlfettes ergänzt und durch andere Kenngrößen wie pankreasspezifische Elastase ( $\triangleright$ Elastase, pankreasspezifische) heutzutage ersetzt werden. 
Diagnostische Wertigkeit. Orientierende, semiquantitative Kenngröße von Maldigestion und/oder Malabsorption.

\section{Literatur}

Colombo C, Maiavacca R, Ronchi M et al (1987) The steatocrit: a simple method for monitoring fat malabsorption in patients with cystic fibrosis. J Pediatr Gastroenterol Nutr 6:926-930

\section{Steatokrit-Test}

$>$ Steatokrit

\section{Stechapfelzelle}

H. Baum

Synonym(e) Akanthozyt; Echinozyt

Englischer Begriff acanthocyte

Definition Erythrozyt mit unregelmäßiger Form.

Beschreibung Die Stechapfelzelle ist ein Erythrozyt ( $\triangleright$ Erythrozyten) mit einem unregelmäßigen Rand mit Ausziehungen. Unterschieden werden dabei runde Erythrozyten mit einem stacheligen Zytoplasmarand (Echinozyten) und solche mit einer ungleichmäßigen Form ( $\triangleright$ Akanthozyten im Urin).

Die Abbildung zeigt Stechapfelzellen - 1 Akanthozyten, 2 Echinozyten $(1000 \times$, May-Giemsa-Grünwald-Färbung):

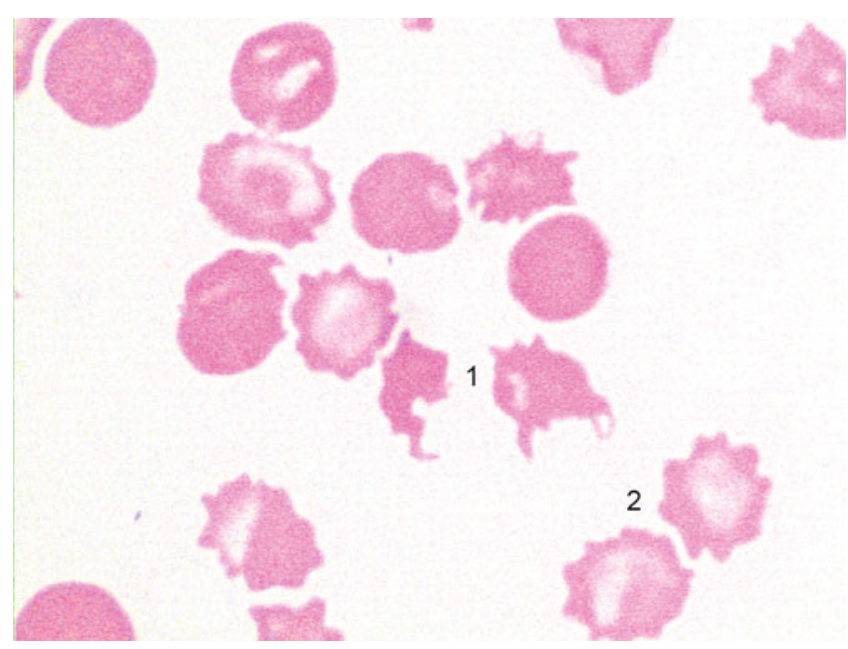

Meist handelt es sich um ein Artefakt durch eine schlechte Ausstrichtechnik oder ungeeignete Färbelösungen. Jedoch können Stechapfelformen auch bei bestimmten Fettstoffwechselstörungen, einer Leberzirrhose, bei hämolytischen Anämien oder nach einer Splenektomie im peripheren Blut vermehrt nachgewiesen werden.

\section{Literatur}

Koeppen KM, Heller S (1991) Differentialblutbild (panoptische Färbung). In: Boll I, Heller S (Hrsg) Praktische Blutzelldiagnostik. Springer, Berlin/Heidelberg/New York, S 172

\section{Stechinstrumente für Kapillarblutentnahme}

$>$ Lanzette

\section{Steel factor}

- Stem Cell Factor

\section{Steilheit einer Elektrode}

$\checkmark$ Ionenselektive Elektrode

\section{Steinanalyse}

W. G. Guder

Synonym(e) Harnsteinanalyse; Harnsteine; Konkrementanalyse

Englischer Begriff analysis of urinary stones

Definition Analyse der Zusammensetzung von Konkrementen des Urogenitaltraktes.

Physikalisch-chemisches Prinzip Chemische Analyse, Röntgendiffraktion, Infrarotspektroskopie ( Infrarot-Spektrometrie).

Einsatzgebiet Analyse von spontan abgegangenen oder durch Extraktion und Operation gewonnenen Konkrementen der Niere und ableitenden Harnwege. Auch Gallensteine und Speichelsteine sowie andere im Körper gebildete Konkremente können auf diese Weise analysiert werden, ihre Analyse ist jedoch selten medizinisch indiziert. 
Untersuchungsmaterial Gries aus dem Harnsediment oder sichtbare Konkremente aus dem Urin oder aus operativ oder zystoskopisch gewonnenem Material, eventuell nach Steinzertrümmerung (Lithotripsie) in vivo.

Instrumentierung Röntgendiffraktometer oder Infrarotspektroskop mit Spektrenatlas für Harnsteinanalyse.

Messbereich Die Analyse der Struktur und halbquantitative Zusammensetzung von folgenden Steinen und Kristallformen sollten gewährleistet sein:

- Kalzium- $>$ Oxalatsteine ( $>$ Weddellit, $>$ Whewellit)

- Phosphatsteine ( $\triangleright$ Struvit, Carbonatapatit, Brushit)

- Harnsäuresteine (Uratsteine)

- Cystinsteine

- Xanthin

- 2,8-Dihydroxyadenin

- Artefakte und natürliche Mineralien, die als Harnsteine deklariert werden

Praktikabilität - Automatisierung - Kosten Wegen der höheren Spezifität hat sich die in der Anschaffung gegenüber der chemischen Analytik teurere Methode der Infrarotspektrometrie durchgesetzt, da sie gegenüber der ebenso guten Röntgendiffraktion in der Anschaffung günstiger ist.

Bewertung - Methodenhierarchie (allg.) Von den angewandten Verfahren haben sich die Infrarotspektroskopie und die Röntgendiffrationsanalyse als die überlegenen Methoden erwiesen. Dies wurde durch jahrelange Ringversuchsergebnisse und vergleichende Anwendung dokumentiert. Beide Methoden erlauben neben der Substanzanalyse eine Erkennung der Komponenten zusammengesetzter Steine aus mehreren Kristallformen und so oft eine Aussage über die Genese der Steine.

\section{Literatur}

Asper A (1982) Harnsteinanalytik. Habilitationsschrift Medizinische Fakultät Zürich

Hesse A, Claßen A, Röhle G (1989) Labordiagnostik bei Urolithiasis. Wissenschaftliche Verlagsgesellschaft, Stuttgart

Hesse A, Tiselius H-G, Jahnen A (2002) Urinary stones, diagnosis, treatment and prevention of recurrence. A. Karger, Basel

\section{Steinmetaphylaxe}

W. G. Guder

Synonym(e) Vermeidung von Harnsteinbildung
Englischer Begriff prevention of recurrence of urinary stones; follow up measures in stone formers

Definition Untersuchungsprogramm zur Vermeidung der Neubildung von Harnsteinen bei Patienten, die Steinträger waren oder sind.

Beschreibung Die Wiederholungsrate bei Steinträgern, d. h. die erneute Bildung eines Harnsteins, beträgt 60-100 \%. Dies machte es notwendig, ein Programm zur Vermeidung erneuter Harnsteinbildung zu entwickeln. Es wurde im Zentrum für Urologie der Universität Bonn entwickelt und als Leitlinie publiziert. Neben Anweisungen für diätetische und Verhaltensmaßnahmen enthält das Programm eine regelmäßige Untersuchung von Urin auf steinbildende oder -fördernde und Steinbildung verhindernde Bestandteile. Neben dem Harnteststreifen, Urin-pH-Wert und Urinsediment enthält dieses Programm die quantitative Analyse von Calcium, Harnsäure, Phosphat und Kreatinin im Plasma/ Serum sowie die Messgrößen (in Klammern die Grenzwerte für den Einsatz therapeutischer Maßnahmen)

- $>$ Calcium $(>5 \mathrm{mmol} / 24 \mathrm{~h})$,

- P Phosphat $(>35 \mathrm{mmol} / 24 \mathrm{~h})$,

- Magnesium $(<3 \mathrm{mmol} / 24 \mathrm{~h})$,

- Oxalat ( $\triangleright$ Oxalat(e) im Urin) $(>0,5 \mathrm{mmol} / 24 \mathrm{~h})$,

- Citrat ( $\triangleright$ Citrat im Urin) $(<2,5 \mathrm{mmol} / 24 \mathrm{~h})$ und

- > Harnsäure (>4 mmol/24 h)

im 24-Stunden-Sammelurin, der entsprechend der verschiedenen $\mathrm{pH}-$ Empfindlichkeit zu stabilisieren ist. Dabei werden therapeutische Zielbereiche angestrebt, die eine Steinbildung vermeiden helfen.

\section{Literatur}

Hesse A, Jahnen A, Klocke K et al (1994) Nachsorge bei HarnsteinPatienten. Gustav Fischer Verlag, Jena/Stuttgart

Weber A, Claßen A, Hesse A (1989) Harnanalyse: Probensammlung und Konservierung. In: Hesse A, Claßen A, Röhle G (Hrsg) Labordiagnostik bei Urolithiasis. Wissenschaftliche Verlagsgesellschaft, Stuttgart, S 103-110

\section{Stem Cell Factor}

H. Baum

Synonym(e) KIT-Ligand; Mast cell growth factor; SCF; Steel factor 
Englischer Begriff stem cell factor

Definition Hämatologischer Wachstumsfaktor der primär auf unreife Vorläuferzellen wirkt.

Beschreibung Der humane SCF ist ein Protein, das durch alternatives Splicing in 2 Isoformen, einer löslichen Isoform bestehend aus 164 Aminosäuren und einer 157 Aminosäuren großen transmembranen Isoform, nachweisbar ist. Durch Bindung an den c-KIT Rezeptor, eine Typ-III-Tyrosinkinase, die auf hämatopoetischen Vorläuferzellen, aber auch Mastzellen sowie anderen Geweben exprimiert wird, werden intrazellulär verschiedene Signaltransduktionswege aktiviert. In der Hämatopoese ist der SCF wichtig als Wachstums- und Überlebensfaktor der Stamm- und Progenitorzellen. Zudem reguliert er die Mastzelldifferenzierung, die Ausreifung der Prä-B-Zelle, des frühen Thymozyten und der NK-Zellen.

\section{Literatur}

Smith MA, Pallister CJ, Smith JG (2001) Stem cell factor: biology and relevance to clinical practice. Acta Haematol 105:143-150

\section{Sterkobilin(ogen)}

A. M. Gressner und O. A. Gressner

Englischer Begriff stercobilin; stercobilinogen

Definition Sterkobilinogen gehört als lineares, farbloses Tetrapyrrol zur Gruppe der Urobilinogene, die im Intestinum durch mikrobielle enzymatische Reduktion des Bilirubins entstehen.

Beschreibung Das von der Leber mit der $>$ Galle in das Darmlumen ausgeschiedene konjugierte $>$ Bilirubin wird im Darm mikrobiell zu den Urobilinogenen ( $>$ Urobilin (ogen)) reduziert, unter denen Sterkobilinogen ein Vertreter ist. Im Kolon erfolgt dessen Oxidation zum Sterkobilin, das für die orange-braune Farbe des Stuhls (mit)verantwortlich ist (tägliche Ausscheidungsmenge ca. 100-200 mg, Abb. 1).<smiles>C=CC1=C(C)/C(=C\C2=N/C(=C/c3[nH]c(/C=C4/NC(=O)C(C)=C4C=C)c(C)c3CCC(=O)O)C(CCC(=O)O)=C2C)NC1=O</smiles><smiles>C=CC1=C(C)/C(=C\c2[nH]c(Cc3[nH]c(/C=C4/NC(=O)C(C)=C4C=C)c(C)c3CCC(=O)O)c(CCC(=O)O)c2C)NC1=O</smiles>

Bilirubin<smiles>C=CC1=C(C)C(=O)NC1Cc1[nH]c(C)c(CCC(=O)O)c1C</smiles><smiles>C=CC1=C(C)/C(=C\C2=N/C(=C/C)C(CCC(=O)O)=C2C)NC1=O</smiles>
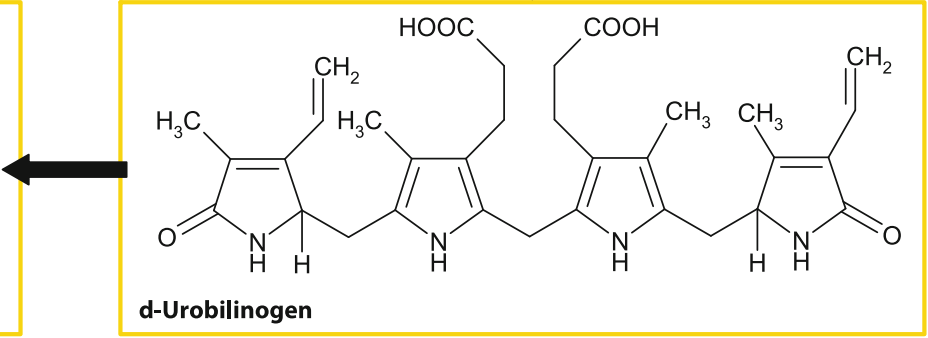<smiles>CCCCOC(=O)OCCC(=O)O</smiles>

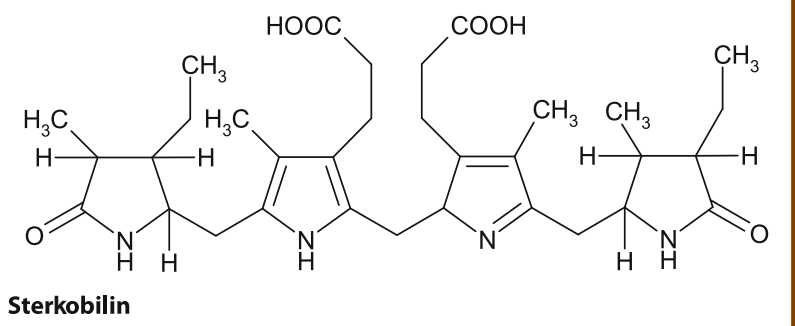

Sterkobilin(ogen), Abb. 1 Oxidoreduktiver Abbau des Bilirubins im Darm 


\section{Literatur}

Greiling H, Gressner AM (Hrsg) (1995) Lehrbuch der Klinischen Chemie und Pathobiochemie, 3. Aufl., Schattauer, Stuttgart/New York

\section{Sternberg-Zelle}

- Reed-Sternberg-Zelle

\section{Steroid-5-alpha-Reduktase- Genmutation}

- 5- $\alpha$-Reduktase-Genmutation

\section{Steroid-11- $\beta$-Hydroxylase-}

\section{Genmutation}

CYP450 11B1-Mutation

\section{Steroid-11 $\beta$-Hydroxylase-Defizienz}

• CYP450 11B1-Mutation

\section{Steroid-11 $\beta$-Hydroxylase-Mutation}

- CYP450 11B1-Mutation

\section{Steroid-21-Hydroxylase-Genmutation}

- CYP450 21A2-Mutation

\section{Steroide}

- Steroidhormone

\section{Steroidhormone}

W. Hubl

Synonym(e) Glukokortikoide; Mineralokortikoide; Steroide

Englischer Begriff steroid hormones

Definition Die Steroidhormone werden in der Nebennierenrinde, in den Hoden, im Ovar sowie der fetoplazentaren Einheit gebildet. Die Steroidgenese vollzieht sich in diesen Organen nach dem gleichen Prinzip. Unterschiedliche quantitative Enzymausstattungen bewirken Unterschiede in den produzierten Steroidprofilen und Endprodukten, die für das einzelne endokrine Organ charakteristisch sind (s. Abb. 1).

Struktur Steroide enthalten als Grundstruktur einen Cyclopentano-Perhydrophenanthren-Kern, der aus 3 Hexanringen und einem Pentanring besteht:

- C-21-Steroide sind gekennzeichnet durch 2 Methylgruppen sowie eine Seitenkette mit 2 Kohlenstoffatomen am Steranskelett: Kortikosteroide, Progesteron etc.

- C-19-Steroide entstehen durch Abspaltung der Seitenkette der C-21-Steroide mit den 2 Kohlenstoffatomen: Androgene

- C-18-Steroide werden durch Aromatisierung des A-Rings der Androgene mit Abspaltung der Methylgruppe gebildet: Estrogene

Molmasse S. Einzelkenngrößen: > Kortisol, > Aldosteron, - Testosteron, > Dehydroepiandrosteronsulfat, > 17-Hydroxyprogesteron etc.

Synthese - Verteilung - Abbau - Elimination Die Biosynthese der Steroidhormone erfolgt mit folgenden hochspezifischen Enzymen (Abb. 1):

- CYP450SCC (SCC: side chain cleavage): Cholesterinseitenketten-abspaltendes Enzym

- CYP450C17 $\alpha$ : C17-Hydroxylase

- CYP450C21: C21-Hydroxylase

- CYP450C11: C11ß-Hydroxylase

- CYP450AS: Aldosteronsynthase

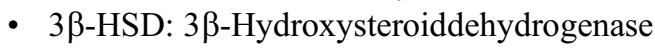

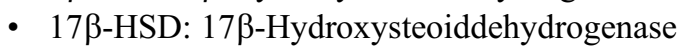

Transport: Die Steroidhormone werden im Blut mit unterschiedlicher Kapazität bzw. Affinität an Transportproteine, 


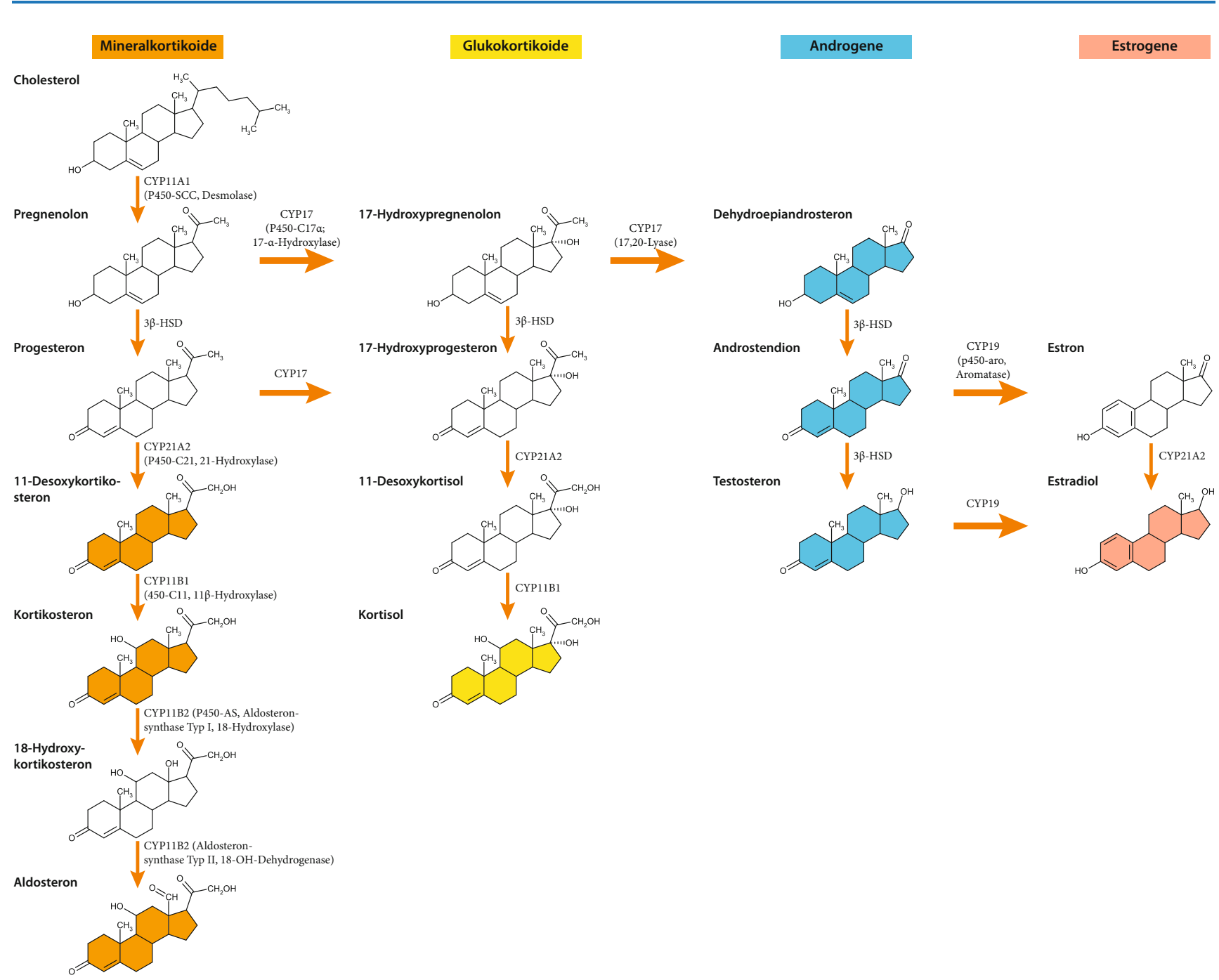

Steroidhormone, Abb. 1 Biosynthese der Steroidhormone

wie z. B. an > Transkortin (kortisolbindendes Globulin, CBG), A Albumin etc., gebunden und zu den Zielzellen transportiert.

Abbau: Die Steroidinaktivierung erfolgt in der Leber mit einer Reduktion des A-Rings und einer Konjugation mit Glukuronsäure in Position 3. Die gebildeten wasserlöslichen Produkte werden über die Niere ausgeschieden.

Halbwertszeit S. Einzelkenngrößen: \ Kortisol, \ Aldosteron, \ Testosteron, $\triangleright$ Dehydroepiandrosteronsulfat, $\triangleright 17$ Hydroxyprogesteron etc.

\section{Pathophysiologie}

\begin{tabular}{|l|l|l|l|}
$\begin{array}{l}\text { Steroide } \\
\text { C-21- } \\
\text { Steroide }\end{array}$ & Glukokortikoide & $\begin{array}{l}\text { Pathophysiologie } \\
\text { Cushing-Syndrom, } \\
\text { Morbus Addison }\end{array}$ & Kortisol \\
& Mineralokortikoide & $\begin{array}{l}\text { Hyperaldosteronismus, } \\
\text { Hypoaldosteronismus }\end{array}$ & Aldosteron \\
\hline & & (Fortsetzung)
\end{tabular}

\begin{tabular}{|l|l|l|l|}
\hline $\begin{array}{l}\text { Steroide } \\
\text { C-19- } \\
\text { Steroide }\end{array}$ & Androgene & $\begin{array}{l}\text { Pathophysiologie } \\
\text { Hyperandrogenämie, } \\
\text { Hypogonadismus, } \\
\text { adrenogenitales } \\
\text { Syndrom }\end{array}$ & $\begin{array}{l}\text { Testosteron, } \\
\text { DHEAS, } \\
\text { Androstendion }\end{array}$ \\
\begin{tabular}{l|l|l|} 
C-18- \\
Steroide
\end{tabular} & Estrogene & $\begin{array}{l}\text { Ovarialinsuffizienz, } \\
\text { polyfollikuläres Ovar, } \\
\text { Ovarialkarzinome }\end{array}$ & Estradiol \\
\hline
\end{tabular}

Untersuchungsmaterial Serum, Plasma, Urin.

Analytik $>$ Radioimmunoassay, $>$ Enzymimmunoassay, Lumineszenz-Immunoassay, $>$ Hochleistungs-Flüssigkeitschromatographie.

Referenzbereich S. Einzelkenngrößen: $>$ Kortisol, $>$ Aldosteron, $>$ Testosteron, $>$ Dehydroepiandrosteronsulfat, $>17$ Hydroxyprogesteron etc. 
Bewertung Steroidhormone besitzen aufgrund ihrer vielfältigen relevanten Wirkungen eine herausragende diagnostische Relevanz, die bei den Einzelkenngrößen ausführlich beschrieben ist: Kortisol, Aldosteron, Testosteron, Dehydroepiandrosteronsulfat, 17-Hydroxyprogesteron etc.

\section{Literatur}

Gaudl A, Kratzsch J, Ju Bae Y et al (2016) Liquid chromatography quadrupole linear ion trap mass spectrometry for quantitative steroid hormone analysis in plasma, urine, saliva and hair. J Chromatogr A 1464(S):64-71

Lehnert H (Hrsg) (2014) Rationelle Diagnostik und Therapie in Endokrinologie, Diabetologie und Stoffwechsel. Thieme-Verlag, Stuttgart

\section{Stewart-Modell}

> Säure-Basen-Modell nach Stewart

\section{sTfR}

- Transferrinrezeptor, löslicher

\section{STH}

- Wachstumshormon

\section{STH-Stimulationstest}

$>$ Exercise-Test

\section{STH-Stimulationstest (unter körperlicher Belastung)}

$\checkmark$ Exercise-Test

- Wachstumshormon-Stimulationstest (GHRH- und/oder Arginin-induziert)

\section{Stichprobe}

\section{R.-D. Hilgers, N. Heussen und S. Stanzel}

$\operatorname{Synonym(e)~Zufallsstichprobe~}$

Englischer Begriff sample; random sample

Definition Zufällig gezogene Teilmenge der Grundgesamtheit.

Beschreibung Die Elemente der Stichprobe werden zufällig aus der $\triangleright$ Grundgesamtheit gezogen, d. h. jedes Element der Grundgesamtheit sollte dieselbe Chance haben, in die Stichprobe eingeschlossen zu werden. Bei ausreichender Stichprobengröße kann dann davon ausgegangen werden, dass die gezogene Stichprobe die Grundgesamtheit widerspiegelt; somit kann die gezogene Stichprobe als repräsentativ für die zugehörige Grundgesamtheit bezeichnet werden. Die Elemente der Stichprobe werden als Beobachtungseinheiten ( $\triangleright$ Beobachtungseinheit) bezeichnet. An ihnen werden die Ausprägungen mehrerer Merkmale ( $\triangleright$ Merkmal) beobachtet oder gemessen. Die so erhobenen Daten werden mit den Methoden der deskriptiven Statistik ( $\triangleright$ Statistik, deskriptive) adäquat beschrieben, zusammengefasst und grafisch veranschaulicht. Anschließend können die gefundenen Ergebnisse unter Verwendung der Methodik der induktiven Statistik ( $\triangleright$ Statistik, induktive) auf die zugehörige Grundgesamtheit übertragen werden.

\section{Literatur}

Hilgers R-D, Bauer P, Scheiber V (2002) Einführung in die Medizinische Statistik. Springer, Berlin/Heidelberg/New York

\section{Stichprobenkontrolle}

R.-D. Hilgers, N. Heussen und S. Stanzel

Englischer Begriff sampling inspection

Definition Statistische Kontrolle von Produktionsprozessen auf der Basis geeigneter Stichproben ( $\triangleright$ Stichprobe).

Beschreibung Die Stichprobenkontrolle kommt immer dann zum Einsatz, wenn eine > Totalkontrolle aus Kosten- 
gründen oder aufgrund fehlender materieller Ressourcen nicht realisiert werden kann.

\section{Literatur}

Büttner H (1967) Statistische Qualitätskontrolle in der Klinischen Chemie. Zeitschrift für Klinische Chemie und Klinische Biochemie $5: 41-48$

\section{Stickoxid}

Stickstoffmonoxid

\section{Stickstoffbestimmung nach Kjeldahl}

> Kjeldahl-Methode

\section{Stickstoffbilanz}

> Kjeldahl-Methode

\section{Stickstoffmonoxid}

\section{A. M. Gressner und O. A. Gressner}

\section{Synonym(e) Stickoxid; NO}

\section{Englischer Begriff nitric oxide}

Definition Extrem kurzlebiges ( $<5 \mathrm{~s})$, gasförmiges und frei diffusibles Signalmolekül, das von einer der 3 Isoformen der NO-Synthasen in Endothelzellen, Neuronen, Makrophagen und anderen Zelltypen gebildet wird und starke vasodilatatorische (blutdrucksenkende), antimikrobielle und zentralnervöse Funktionen ausübt.

Beschreibung NO wird in vaskulären und sinusoidalen Endothelzellen der Leber, neuronalen Zellen, Makrophagen, Muskelzellen und anderen Zelltypen durch die mischfunktionellen Oxidasen vom Typ der NO-Synthasen in Anwesenheit von molekularem Sauerstoff und unter Verbrauch von NADPH aus $>$ Arginin gebildet, wobei neben dem Radikal
NO die Aminosäure Citrullin entsteht. Es gibt 3, von differenten Genen kodierte Isoformen der NO-Synthasen (NOS):

- 2 konstitutive Isoformen: Dazu gehören NOS der Endothelzellen (eNOS) und Neuronalzellen (nNOS). Die Aktivitäten dieser Isoformen hängen von dem Kofaktor Calmodulin ab und reagieren auf $\triangleright$ Calcium. Trotz ihrer Bezeichnung als „konstitutiv“, werden diese NOS-Isoformen in ihrer Aktivität durch Hypoxie, Scherstress und - Zytokine moduliert.

- Induzierbare Isoform (iNOS): Diese Isoform wird transkriptionell reguliert durch Zytokine und/oder Lipopolysaccharide ( $\vee$ Endotoxin-Reaktivität) unter Vermittlung des Transkriptionsfaktors NFKB, der die iNOSGentranskription stimuliert. Durch NO selbst wird die Transkription negativ reguliert (negativer Feedback). Die iNOS befindet sich vorwiegend in Makrophagen, KupfferZellen, Hepatozyten, Lebersternzellen (Ito-Zellen) und anderen Zelltypen.

Das frei diffusible NO-Radikal vermittelt seine Wirkungen über den intrazellulären Rezeptor Guanylatcyclase, die NO bindet, aktiviert, die intrazelluläre cGMP-Konzentration erhöht und somit cGMP-gesteuerte Kinasen aktiviert, die zellspezifische Effekte auslösen:

- Relaxation der glatten Muskelzellen der Gefäßwände und der Lebersternzellen (ITO-Zellen) der Lebersinusoide durch das von Endothelzellen gebildete, parakrin wirkende NO. Folgen sind Abnahme des systemischen Blutdruckes, Regulation des regionalen Blutflusses und Reduktion des Portalvenendruckes (daher frühere Bezeichnung von $\mathrm{NO}$ als $\mathrm{EDRF}=$,endothelial-derived relaxing factor"). In dieser Funktion ist NO Antagonist des vasokonstriktiv wirkenden Endothelins. Das therapeutisch bei Angina pectoris eingesetzte Nitroglyzerin wirkt als NO-Donor und somit dilatierend auf die Koronargefäße des Herzens

- Primäre Infektabwehr durch Makrophagen aufgrund zytotoxischer, antimikrobieller Wirkungen des NO und verwandter Produkte (z. B. Peroxinitrite)

- Neuromodulatorische Wirkung durch Beteiligung an der exzitatorischen Neurotransmission.

Die quantitative Bestimmung von NO kann elektrochemisch mittels Clark-Elektrode, ( $\triangleright$ Sauerstoffpartialdruck), durch Gasphasen-Chemolumineszenzdetektion oder indirekt durch Messung der Metabolite $\mathrm{NO}_{2}$ und $\mathrm{NO}_{3}$ im Blut mit dem - Griess-Test erfolgen. Gegenwärtig ist eine klinisch-diagnostische Indikation zur Bestimmung von $\mathrm{NO}$ und seinen Derivaten nicht gegeben, u. a. weil die Effekte lokal wirksam sind. 


\section{Literatur}

Moncada S, Higgs A (1993) The L-arginine-nitric oxide pathway. N Engl J Med 329:2002-2012

Sessa WC (1994) The nitric oxide synthase family of proteins. J Vasc Res $31: 131-143$

\section{Stöchiometrischer Punkt}

> Äquivalenzpunkt

\section{Stoffmenge}

$\checkmark$ Masse, molare

$>$ Mol

\section{Stoffmengenkonzentration}

C. Vidal und W.-R. Külpmann

Englischer Begriff amount of substance concentration

Definition Stoffmenge eines Bestandteils geteilt durch Volumen des Systems, das den Bestandteil enthält.

Beschreibung Der Bestandteil ist spezifiziert durch seine relevante Struktur, z. B. Atom, Molekül, Ion. Die SI-kohärente Maßeinheit lautet $\mathrm{mol} / \mathrm{m}^{3}$, in der Klinischen Chemie ( $\triangleright$ Klinische Chemie) wird jedoch gewöhnlich die nicht kohärente Einheit $\mathrm{mol} / \mathrm{L}\left(=\mathrm{mol} / \mathrm{dm}^{3}\right)$ verwendet.

\section{Literatur}

Dybkaer R (1997) Vocabulary for use in measurement procedures and description of reference materials in laboratory medicine. Eur J Clin Chem Clin Biochem 35:141-173

\section{Stoffwechselerkrankungen,} angeborene

$\triangleright$ Inborn errors of metabolism

\section{Stoffwechselscreening, selektives}

G. F. Hoffmann, C.-D. Langhans und A. Schulze

Englischer Begriff selective metabolic screening

Definition In Speziallabors durchgeführtes Untersuchungsprogramm zur Diagnostik angeborener Stoffwechselkrankheiten.

Beschreibung Das Programm des selektiven Stoffwechselscreenings setzt sich zusammen aus einer Reihe qualitativer, sogenannter Spot-Tests ( $\triangleright$ Metabolische Vorteste), der Bestimmung der organischen Säuren im Urin ( $\triangleright$ Säuren im Urin, organische) und der $>$ Aminosäuren im Plasma. Eine Erweiterung erfährt das selektive Screening durch Einbeziehung des Acylcarnitinprofils aus Trockenblutkarten ( $\triangleright$ Acylcarnitinprofil mit ESI-MS/MS aus Trockenblut).

Das selektive Stoffwechselscreening wird von Speziallaboratorien durchgeführt und liefert Informationen zur Diagnostik angeborener Stoffwechselkrankheiten, wobei es den wichtigsten Krankheiten Rechnung trägt. Obwohl es manche monogene Stoffwechselerkrankungen nicht erfasst, trägt es dazu bei, den Aufwand, der mit weitergehenden sehr spezifischen enzymatischen und molekularbiologischen Analysemethoden verbunden ist, so gering wie möglich zu halten.

Als Ausgangsmaterial wird in der Regel eine Spontanurinprobe, eine Plasmaprobe (nüchtern oder zumindest 4 Stunden postprandial) sowie eine Trockenblutkarte benötigt. Ein 24-Stunden-Sammelurin ist routinemäßig nicht notwendig.

\section{Literatur}

Zschocke J, Hoffmann GF (2012) Vademecum Metabolicum - Diagnose und Therapie erblicher Stoffwechselkrankheiten, 4. Aufl. MilupaSchattauer Verlag, Stuttgart

Stokes-Regel

Lumineszenz

Stomatozyt

H. Baum

Englischer Begriff stomatocyte 
Definition Erythrozyten mit maulförmiger, zentraler Aufhellungszone.

Die Abbildung zeigt eine Stomatozytose mit typischer fischmaulartiger Aufhellungszone der Erythrozyten, daneben ein großer granulierter Lymphozyt $(1000 \times$, May-GiemsaGrünwald-Färbung)

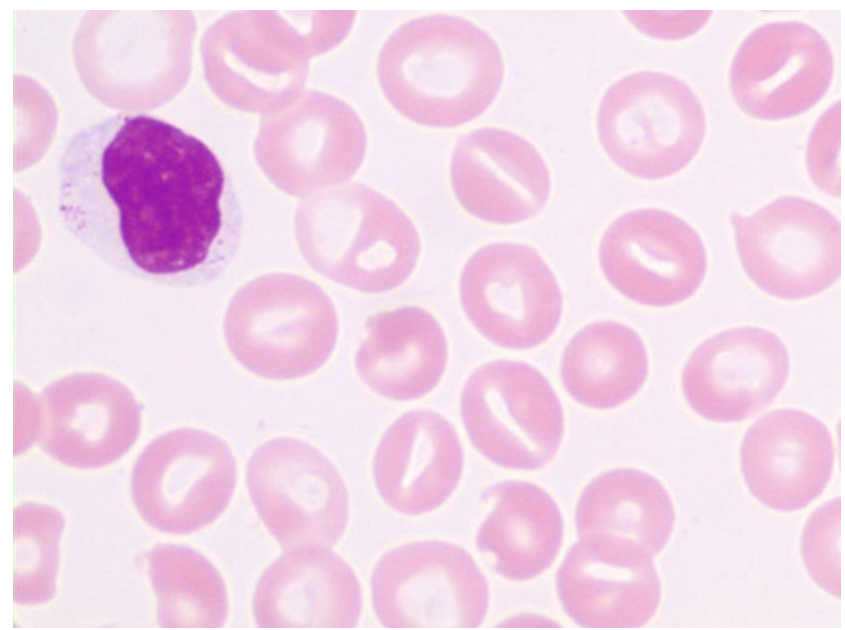

Beschreibung Stomatozyten sind $\triangleright$ Erythrozyten mit einer maulförmigen zentralen Aufhellungszone im Ausstrichpräparat. Sie sind häufig bei Alkoholikern oder Patienten mit Stoffwechselstörungen, aber auch als Artefakte nachweisbar. Sehr selten sind sie ein Hinweis auf eine hereditäre Stomatozytose.

\section{Literatur}

Koeppen KM, Heller S (1991) Differentialblutbild (panoptische Färbung). In: Boll I, Heller S (Hrsg) Praktische Blutzelldiagnostik. Springer, Berlin/Heidelberg/New York, S 172-173

\section{Stopfen}

- Verschlusskappe

\section{Stopp-Mutation}

- Nonsense-Mutation

\section{Störfaktor}

> Störgrößen

\section{Störgrößen}

W. G. Guder

\section{Synonym(e) Störfaktor}

Englischer Begriff interference factor; interferent

Definition Störgrößen sind Stoffe oder Mechanismen, die das Ergebnis der Analyse eines definierten Analyten durch analytische Interferenz verändern. Sie sind Bestandteil der Matrix in der analytischen $>$ Probe und sind in ihrer Struktur verschieden vom Analyten ( $\triangleright$ Analyt).

Beschreibung Herkunft von Störgrößen: Sie können nach ihrer Herkunft und/oder nach der Natur der Störung eingeteilt werden:

- Ex vivo endogen: Die Störgröße stellt einen normalen oder pathologischen Bestandteil der Matrix dar, der mit der angewendeten Methode positiv oder negativ interferiert. Beispiele: endogene Antikörper, die die Messung des Antigens stören; \ Hämolysin, die optisch oder durch chemische Interferenz die Quantifizierung von z. B. > Bilirubin stört; Lipämie, die durch Trübung oder Verminderung des Wasserraumes zu falschen Ergebnissen verschiedener Analyten führt; ikterische Proben, die durch ihre Farbe oder durch Vorhandensein pathologisch hoher Metabolite (z. B. \ Gallensäuren) mit der Analytik interferieren.

- Ex vivo exogen: Die Störgröße kommt von außen (z. B. als Nahrungsbestandteil oder als Therapeutikum) in den Patienten und so mit der Probe in die Analytik. Beispiele: Arzneimittelinterferenzen, Verfärbungen des Urins durch Nahrungsbestandteile.

- In vitro exogen: Die störende Substanz wird nach Gewinnung der Probe dem Untersuchungsmaterial zugesetzt und stört durch optische, chemische oder immunologische Interferenz. Beispiele: Kontamination durch Staub oder andere Fremdstoffe bei Öffnung des Probenröhrchens; Störung durch Antikoagulanzien oder damit in die Probe eingebrachte endogene Stoffe (z. B. Fibrinogen bei Verwendung von Heparin) oder exogene Begleitstoffe (z. B. Zusätze von Stopfen und sog. Trenngelen).

Maßnahmen zur Vermeidung unerwünschter Störungen: Jedes unerwartete oder mit anderen Symptomen oder Befunden des Patienten nicht in Einklang befindliche Ergebnis sollte auf Störgrößen geprüft werden:

- Vergleich mit dem Ergebnis, das mit einer zweiten Methode mit anderem Mechanismus gewonnen wurde.

- Bei Feststellung eines Unterschieds zweier Ergebnisse aus der gleichen Probe mit zwei Methoden Versuch der Auf- 
klärung des Mechanismus' und der Störsubstanz in der Probe.

- Information über die zum Zeitpunkt der Probengewinnung in der Probe befindlichen Medikamente, die Art des Antikoagulans und des Probengefäßes und der Transportbedingungen. Überprüfung möglicher Interferenzen durch Vergleich mit vorhandenen Datenbanken.

Bei häufigem Auftreten des gleichen Störfaktors ist ein Wechsel zu einer spezifischeren Methode zu empfehlen.

\section{Literatur}

Guder WG, Hagemann P, Wisser H, Zawta B (2007) Fokus Patientenprobe. Kompendium Präanalytik. BD, Heidelberg. Schwechat, Basel

Guder WG, Fiedler GM, da Fonseca-Wollheim F, Schmitt Y, Töpfer G, Wisser H, Zawta B (2015) Quality of Diagnostic Samples. 4th Ed. BD Diagnostics, Preanalytical Systems, Oxford

ISO EN DIN 15189 (2012) Medical laboratories - particular requirements for quality and competence. Geneva, Bruxelles, Berlin

Raffick A, Bowen R, Adcock-Funk DM (2015) Interferences from blood sampling device materials on clinical assays: I Blood collection devices and their constituents and additives. II Special devices and procedures; recommendations. In: Guder WG, Narayanan S (Hrsg) Pre-examination procedures in laboratory diagnostics. Walter de Gruyter, Berlin/Boston, S 170-216

Young DS (2000) Effects of drugs on clinical laboratory tests, 5. Aufl. AACC Press, Washington, DC

\section{Störung der genomischen Prägung}

$>$ Imprinting-Defekt

\section{Stoßaktivierung}

- Massenspektrometrie

STP

- Shielded twisted pair

\section{STPD}

- Standard temperature and pressure, dry

\section{STR}

- Short Tandem Repeat (STR)

\section{Strahlenschutzverordnung}

T. Arndt

Synonym(e) Verordnung über den Schutz vor Schäden durch ionisierende Strahlen

Definition Zweck dieser Verordnung ist es, zum Schutz des Menschen und der Umwelt vor der schädlichen Wirkung ionisierender Strahlung Grundsätze und Anforderungen für Vorsorge- und Schutzmaßnahmen zu regeln, die bei der Nutzung und Einwirkung radioaktiver Stoffe und ionisierender Strahlung zivilisatorischen und natürlichen Ursprungs Anwendung finden. Die jeweils aktuelle Fassung ist über die Webseite des Bundesministeriums der Justiz und für Verbraucherschutz unter http://www.gesetze-im-internet.de/ verfügbar.

\section{Strahlungsfluss}

- Lambert-Beer-Gesetz

\section{Strand Displacement Amplifikation (SDA)}

\section{J. Arnemann}

Synonym(e) MDA; Multiple Displacement Amplifikation; SDA

Englischer Begriff strand displacement amplification; SDA; multiple displacement amplification; MDA

Definition Strand Displacement Amplifikation (SDA), alternativ auch Multiple Displacement Amplifikation (MDA) genannt, ist eine Methode, geringe, aber durchaus hochmolekulare DNA-Mengen isothermal zu amplifizieren.

Beschreibung Durch Einsatz der Phi-29-DNA-Polymerase lässt sich durch eine isothermale Amplifikation aus gerings- 
ten, durchaus hochmolekularen (bis zu $100 \mathrm{~kb}$ langen) DNAMengen eine Anreicherung um den Faktor 1000-10.000 erreichen. Die minimale DNA-Mengen werden in der Literatur mit $100 \mathrm{fg}$ bis $1 \mathrm{pg}$ angegeben, d. h. eine Verdünnung 1:1000 der herkömmlichen DNA-Menge für eine klassische PCR-Reaktion.

Im Gegensatz zur klassischen PCR-Amplifikation mit einer Fehlerquote von 1:2000 bp liegt die Fehlerquoten der Phi-29-DNA-Polymerase bei 1:3.000.000 bp und erlaubt daher eine hohe diagnostische Sicherheit bei den amplifizierten DNA-Fragmenten.

Die Phi-29-DNA-Polymerase ist ein sehr stabiles Enzym und kann pro Bindung an die Ziel-DNA bis zu 70.000 Basenpaare mit einer Rate von 25-50 Nukleotiden/s am Stück synthetisieren und die Ziel-DNA damit ersetzen (Displacement).

Die hohe Amplifikationsrate ist dadurch bedingt, dass bei laufender Reaktion sekundäre Primer-Annealing-Ereignisse an den primären Produkten ansetzen und die Syntheserate dadurch vervielfältigen. Die Primer können je nach Applikation variieren. So können Random- oder Hexamer-Primer eingesetzt werden, um potenziell das gesamte Genom einer Zelle zu amplifizieren, aber auch gen- oder sequenzspezifische Primer können eingesetzt werden, um gezielte Regionen, wie z. B. Translokationen oder klonale Rezeptorrearrangements in der Leukämie oder Lymphomdiagnostik, zu analysieren.

In der praktischen Durchführung wird die zu amplifizierende DNA durch Hitzedenaturierung einzelsträngig gemacht und unter Zugabe von Nukleotiden, Primern und Phi-29DNA-Polymerase zum Reaktionsgemisch über Nacht bei $30{ }^{\circ} \mathrm{C}$ (isothermal) inkubiert. Eine bis zu 10.000 -fache Vermehrung der DNA erlaubt eine sichere diagnostische Analyse.

\section{Literatur}

Luthra R, Medeiros LJ (2004) Isothermal multiple displacement amplification - A highly reliable approach for generating unlimited high molecular weight genomic DNA from clinical specimens. J Mol Diagn 6:236-242

\section{Straßennamen von Drogen}

T. Arndt

Synonym(e) Deckname von Drogen; Street names; Szenenamen von Drogen

Englischer Begriff street names of drugs; street terms of drugs
Definition In der Drogenszene gebräuchliche Bezeichnungen für einzelne Drogen, Drogengemische und bestimmte Darreichungs- und Konsumformen dieser Substanzen.

Beschreibung Einzelne oder ähnliche Begriffe können sich durchaus auf verschiedene Drogen(wirkstoffe) beziehen oder aufgrund geografischer und demografischer Unterschiede eine verschiedene Bedeutung besitzen. Tab. 1 zeigt eine Auswahl für die in Deutschland wichtigsten Drogen. Spätestens

Straßennamen von Drogen, Tab. 1 Auswahl (die häufigsten Namen sind fett gedruckt)

\begin{tabular}{|c|c|}
\hline Wirkstoff(-gruppe) & Straßennamen \\
\hline $\begin{array}{l}\text { Amphetamine (sog. } \\
\text { Designerdrogen*) }\end{array}$ & $\begin{array}{l}\text { Allgemein: Bennies, Dop, Goof Balls, Pep } \\
\text { Pills, Speed } \\
\text { Amphetamin: A, Bennies, Crystal, Speed, } \\
\text { Frisco Speed (mit Heroin) } \\
\text { Methamphetamin: Meth, Crank, Speed } \\
\text { MDA*: Love Pill, Love Drug, Speed for } \\
\text { Lovers } \\
\text { MDMA*: Ecstasy, Adam, XTC, Ecsta, } \\
\text { Love Pill } \\
\text { MDEA*: Eva, Eve } \\
\text { DOM*: STP (Serenity, Tranquility, Peace) } \\
\text { DOB*: 100X, Golden Eagle }\end{array}$ \\
\hline Barbiturate & $\begin{array}{l}\text { Babies, Balls, Barbs, Black Beauties, } \\
\text { Downers, Down Pills }\end{array}$ \\
\hline Benzodiazepine & $\begin{array}{l}\text { Allgemein: Benzos, Nerve Pills } \\
\text { Bromazepam: Lexos, Wiener Mischung } \\
\text { Flunitrazepam: Rohyps (Rohypnol als } \\
\text { wichtigster Handelsname) } \\
\text { Triazolam: Blue Bomb, Horror Pills }\end{array}$ \\
\hline Cannabinoide & $\begin{array}{l}\text { Haschisch (s. Hanf): Acapulco Gold, } \\
\text { Bhang, Charas, Ganja, Hasch, Hemp, } \\
\text { Joint, Sticks, Kiff, Pot, Shit, Tea, Tüte, } \\
\text { Weed } \\
\text { Haschischöl: Red Oil, Honey Oil } \\
\text { Marihuana (s. Hanf): Gras, Grass, Kanten, } \\
\text { Lady Mary Jane, Thai Stick (mit Opium } \\
\text { getränkt) }\end{array}$ \\
\hline$\gamma$-Hydroxybuttersäure & $\begin{array}{l}\text { Liquid X, Liquid E, Liquid XTC, Liquid } \\
\text { Ecstasy u. v. m. }\end{array}$ \\
\hline Kokain & $\begin{array}{l}\text { Allgemein: C, Candy, Charley, Koks, } \\
\text { Powder, Schnee, Snief, Snow u. v. m. } \\
\text { Crack (s. Kokastrauch): Kokain-Stein, } \\
\text { Volkskokain, Fast-Food-Kokain }\end{array}$ \\
\hline LSD & $\begin{array}{l}\text { Ace, Acid, Crackers, Frisco Speed Balls } \\
\text { (mit Kokain und Heroin), Purple Haze, } \\
\text { Yellow Submarine u. v. m. }\end{array}$ \\
\hline Methadon & Dollies, Po \\
\hline Opiate & $\begin{array}{l}\text { Codein: Saft } \\
\text { Dihydrocodein: Remmis } \\
\text { Heroin: Brown Sugar, China White, } \\
\text { Cocktail (mit Kokain), „H“, Hero, Hit, } \\
\text { Junk, Powder, Stoff, Sugar, Weißes, White } \\
\text { Stuff } \\
\text { Morphin: Base }\end{array}$ \\
\hline Phencyclidin & $\begin{array}{l}\text { Angel Dust, DOA (,,dead on arrival“), } \\
\text { Elephant Tranquilizer, Magic Dust, } \\
\text { Monkey Tranquilizer, Peace Pills }\end{array}$ \\
\hline
\end{tabular}


mit dem Vertrieb von vorgeblich drogenfreien, rein natürlichen Kräutermischungen mit oft sehr phantasiereichen Namen und mit der fortlaufenden Einführung neuer Designerdrogen wurde die Thematik des Straßennamens von Drogen, auch für den Experten, unüberschaubar. Die nachfolgende Tabelle kann deshalb nur eine sehr unvollständige Auflistung für die eher „klassischen“ Drogen und Drogengruppen geben. Siehe auch $\triangleright$ Neue Psychoaktive Substanzen.

\section{Literatur}

Daunderer M (1995) Drogenhandbuch für Klinik und Praxis: Diagnostik, Therapie, Nachweis, Prophylaxe, Recht, Drogenprofile. ecomed, Landsberg

Europäische Beobachtungsstelle für Drogen und Drogensucht (2016) Europäischer Drogenbericht 2016: Trends und Entwicklungen. Amt für Veröffentlichungen der Europäischen Union, Luxemburg unter. http://www.emcdda.europa.eu Zugegriffen am 30.12.2016

Schütz H (1999) Screening von Drogen und Arzneimitteln mit Immunoassays. Wissenschaftliche Verlagsabteilung Abbott GmbH, Wiesbaden

\section{Street names}

- Straßennamen von Drogen

\section{Streifentest}

> Teststreifen

\section{Streptavidin-Biotin-Technologie}

- Biotin-Streptavidin-Technik

\section{Stress, endoplasmatischer Retikulum}

$\triangleright$ Proteinstruktur

\section{Stress, nitrosativer}

H. Fiedler

Synonym(e) Nitrativer Stress
Englischer Begriff nitrosative stress; nitroxidative stress

Definition Nitrosativer Stress ist die Imbalanz zwischen Bildung und Beseitigung von reaktiven Stickstoffspezies ( $\triangleright$ Reaktive Stickstoffspecies) (RNS). Er wird von reaktiven Sauerstoffspezies ( $\vee$ Reaktive Sauerstoffspecies; ROS) unterstützt bzw. ermöglicht. Übermäßige Belastung (pathologischer Stress) durch RNS schädigt Zellen, (Metallo-) Proteine, Lipide, DNA, Mitochondrien und Stoffwechselprodukte und ist an zahlreichen Krankheiten beteiligt.

Beschreibung Das $>$ Stickstoffmonoxid-Radikal ( NO) und $\checkmark$ Citrullin werden durch eine der 3 Isoformen der NO-Synthasen aus Arginin und Sauerstoff gebildet. Als Immunantwort auf Bakterien und Parasiten werden in Makrophagen und neutrophilen Granulozyten durch die induzierbare NOS größere Mengen NO (und ROS) gebildet, die gemeinsam die Erreger abtöten und/oder zur Apoptose oder Nekrose der betroffenen Zellen führen können. Durch ROS (vorwiegend durch das Superoxidradikal) wird NO in stark oxidierende und aggressive Folgeprodukte umgewandelt. Besonders die Bildung von Peroxynitrit $\left(\mathrm{ONOO}^{-}\right)$wird durch Infektionen, Entzündungen (aktiviert durch Zytokine, INF- $\gamma$ und TNF- $\alpha$ ) und akute kardiovaskuläre Krankheiten verstärkt (bis zum Millionenfachen). Nitrosativer Stress wird auch durch starke körperliche Belastung, Nitratbelastete Lebensmittel, Smog, Autoabgase, Pestizide, Potenzmittel, Statine, Textilhilfsmittel und Kosmetika ausgelöst.

Die nitrosative und nitrative Modifizierung (S-Nitrosylierung und Nitration, $>$ Modifikation, posttranslationale) von Proteinen, Enzymen und Lipiden verändert Struktur und Funktion der Makromoleküle, deren Signalübermittlung und die zelluläre Organisation. Durch Hemmung der $>$ Atmungskette kommt es zu Energiedefiziten, auch an neuronalen und kardialen Zellen, zu endothelialer Dysfunktion sowie Störungen des Zitratzyklus und des Lipidmetabolismus. Nitrosativer Stress ist offenbar an verschiedenen Krankheiten beteiligt: Alzheimer- und Parkinson-Krankheit, Colitis ulcerosa, rheumatoide Arthritis, Typ-2-Diabetes, Atherosklerose, Asthma und septischer Schock. Gleichzeitiger oxidativer Stress und endotheliale Dysfunktion zerstören Kofaktoren (Tetrahydrobiopterin) und entkoppeln die endotheliale NOSynthase, sodass weniger NO, aber vermehrt ROS produziert werden.

Labordiagnostisch ist der nitrosative Stress nur begrenzt zu erfassen, da die Kenngrößen auch durch andere Prozesse entstehen oder zerstört werden können. Im Urin wird die Messung von Nitrophenylessigsäure und Citrullin (4- bis 10 -fach erhöht, normal $<100 \mu \mathrm{mol} / \mathrm{L}$ ) empfohlen. Im Plasma wird 3-Nitrotyrosin mit ELISA oder HPLC gemessen. Die 
unspezifische Griess-Methode ( $\triangleright$ Nitrit im Urin) für Nitrat/ Nitrit ist nicht für die Quantifizierung von NO verwendbar.

\section{Literatur}

Neri M, Riezzo I, Pomara C, Schiavone S, Turillazzi E (2016) Oxidativenitrosative stress and myocardial dysfunctions in sepsis: evidence from the literature and postmortem observations. Mediat Inflamm 2016:3423450 (PMC 4870346)

White PJ, Charbonneau A, Cooney GJ, Marette A (2010) Nitrosative modifications of protein and lipid molecules by reactive nitrogen species. Am J Physiol Endcrinol Metab 299:E868-E878

\section{Stress, oxidativer}

H. Fiedler

Englischer Begriff oxidative stress; oxidant stress; oxidative stress status

Definition Der 1985 eingeführte Begriff Oxidativer Stress bezeichnet zusammenfassend ein Ungleichgewicht zwischen Prooxidantien (ROS) ( $\triangleright$ Reaktive Sauerstoffspecies) und - Antioxidantien bzw. die akute oder chronische Erhöhung des Steady-state-Spiegels der reaktiven Sauerstoffspezies. Die Akkumulation von ROS (oft unterstützt von reaktiven Stickstoff- [RNS-] und Schwefelspezies[RSS]) überfordert das ,redox signaling“ für die normale Reparatur- und Entgiftungsfunktion der Zellen und Organe und führt zu Alterungsprozessen und Schäden an zellulären und extrazellulären Makromolekülen und Stoffwechselwegen bis hin zu \ Apoptose, Nekrose oder Autophagie. Für die weitere Forschung und deren Translation in die klinische Medizin muss das Konzept des nitroxidativen Stresses und der Antioxidantien sowie der Redoxprozesse und -funktionen in den verschiedenen Kompartimenten durch standardisierte Analysen erweitert und validiert werden. Viele bisherigen Ergebnisse beziehen sich auf Tier- und Zellexperimente.

Beschreibung Oxidativer Stress wird ausgelöst durch endogene und exogene Störungen der Energie- und Metabolismushomöostase. Trotz zahlreicher Korrelationen von oxidativem Stress und pathologischen Zuständen ist in vielen Fällen nicht gesichert, ob es sich um kausale Zusammenhänge oder nur um Korrelationen, Mitbeteiligungen (,,cofounder") oder sekundäre Veränderungen handelt. Außerdem sind Bildung, Wirkung und Entfernung (Degradation oder Scavenging durch Antioxidantien) der ROS auf bestimmte Komparti- mente beschränkt, sodass der extrazelluläre Raum und die Urinausscheidung oft keine Interpretation erlauben. Wichtig ist auch die Höhe und der zeitliche Verlauf des oxidativen Stresses, da unter physiologischen Verhältnissen reaktive Sauerstoffspezies auch wichtige Signal- und Botenstofffunktionen besitzen (Inflammation, Angiogenese, Proliferation). Sowohl sehr niedrige als auch hohe Konzentrationen von ROS sind schädlich, die Wirkungskurve ist nicht linear, sondern hat einen U-förmigen Verlauf, was als Hormesis/Mitohormesis bezeichnet wird (Ristow und Schmeisser 2011) und eine Form der Präkonditionierung darstellen kann.

Die Entstehung von oxidativem Stress hat viele Ursachen:

- Mitochondriale Dysfunktion und/oder Entkopplung der oxidativen Phosphorylierung

- Infektionen und deren Abwehrmechanismen, wie > oxidativer Burst durch $\triangleright$ Myeloperoxidase und Laktoperoxidase

- Inflammation, induziert durch $>$ Tumornekrosefaktor- $\alpha$ (TNF- $\alpha$ ), MIP-2 (Chemokinligand) und $>$ Transforming Growth Factor $\beta$ (TGF- $\beta$ )

- Umweltgifte und Noxen (Stickstoffoxide, Dieselabgase, Ozon, Lösungsmittel, Pestizide, Konservierungsstoffe, toxische Schwermetalle, Alkohol und Rauchen) sowie Medikamente

- UV- und ionisierende Strahlung, besonders bei Karzinomtherapie

- Starke körperliche Belastung und exzessiver Sport

- Akute Erkrankungen, wie Ischämie und Reperfusion, Hyperoxie, Herzinfarkt, Schlaganfall, Polytraumata und Sepsis

- Chronische Erkrankungen, wie Hämochromatose, WilsonsKrankheit, metabolisches Syndrom, Diabetes mellitus mit Glykoxidation, Atherosklerose, Urämie, neurodegenerative Krankheiten und Karzinome; in vielen Fällen ist die Abklärung zwischen Ursache und Wirkung bisher nicht eindeutig (s. Tabelle)

Oxidativer Stress kann auch durch Defekte der antioxidativen Schutzsysteme entstehen: angeborene oder erworbene Enzyminsuffizienz (Superoxiddismutase, verschiedene Peroxidasen, Glutathion- und Thioredoxin-Redoxidasen und Katalase), Mangel an endogenen (Harnsäure, Glutathion, Ubichinon, Askorbinsäure, Vitamin A und E) und exogenen - Antioxidantien oder Stoffen zur Bildung von antioxidativen Schutzsystemen (Metallchelatoren: > Ferritin, > Metallothionein, $>$ Coeruloplasmin).

Oxidativer Stress und die resultierenden Zellschäden sind bei chronischen Erkrankungen vorhanden.

In der folgenden Abbildung ist die medizinische Bedeutung des oxidativen Stresses zusammengestellt: 


\begin{tabular}{|c|c|}
\hline Krankheit/Effekt & Ursache/Rückwirkung \\
\hline Ischämie, Reperfusion, Sepsis & $\begin{array}{l}\text { Höhe des oxidativen Stresses } \\
\text { korreliert mit der Schädigung, } \\
\text { Monitoring des Verlaufes möglich. } \\
\text { Sepsis mit gesteigertem } \\
\text { oxidativem Burst. }\end{array}$ \\
\hline $\begin{array}{l}\text { Metabolisches Syndrom, } \\
\text { Diabetes mellitus und } \\
\text { Folgekrankheiten }\end{array}$ & $\begin{array}{l}\text { Hyperglykämie und Glyk- und } \\
\text { Lipoxidation steigern ROS und } \\
\text { reaktive Carbonylverbindungen, } \\
\text { bewirken endotheliale } \\
\text { Dysfunktion und führen zu Mikro- } \\
\text { und Makroangiopathie }\end{array}$ \\
\hline $\begin{array}{l}\text { Atherosklerose, } \\
\text { Kardiomyopathie }\end{array}$ & $\begin{array}{l}\text { Oxidativer und nitrosativer Stress } \\
\text { führen zu Lipidoxidation, } \\
\text { Glykoxidation und } \\
\text { Karbamylierung sowie } \\
\text { chronischer Inflammation und } \\
\text { endothelialer Dysfunktion } \\
\text { (Reduktion von NO und } \\
\text { Adhäsionsmolekülen) }\end{array}$ \\
\hline $\begin{array}{l}\text { Chronisch obstruktive und } \\
\text { akute Lungenkrankheiten, } \\
\text { Asbestose }\end{array}$ & $\begin{array}{l}\text { Exogene Noxen, Rauchen und } \\
\text { Inhalation von reinem Sauerstoff } \\
\text { erhöhen RNS/ROS, } \\
\text { Carbonylstress und Lipidperoxide }\end{array}$ \\
\hline $\begin{array}{l}\text { Neurodegenerative } \\
\text { Erkrankungen }\end{array}$ & $\begin{array}{l}\text { Lipid(per)oxide, Zytotoxizität, } \\
\text { Modifizierung von } \\
\text { Neurotransmittern und } \\
\text { amyloidogenen Proteinen } \\
\text { ( } \alpha \text {-Synuclein, } \\
\text { B-Amyloidpeptide) } \\
\text { Änderungen des }>\text { Kynurenin- } \\
\text { Abbauweges }\end{array}$ \\
\hline Karzinome & $\begin{array}{l}\text { Fördernde oder hemmende } \\
\text { Wirkungen in Abhängigkeit von } \\
\text { Höhe und Lokalisation des } \\
\text { oxidativen Stresses (s. Text) }\end{array}$ \\
\hline Alterungsprozesse & $\begin{array}{l}\text { Bisher keine Verallgemeinerung } \\
\text { möglich. Gesichert sind } \\
\text { stressbedingte Prozesse bei } \\
\text { Katarakt und Makuladegeneration } \\
\text { Ablagerungen von Lipofuszin, } \\
\text { wie bei neuronaler Ceroid- } \\
\text { Lipofuszinose }\end{array}$ \\
\hline Infektabwehr & $\begin{array}{l}\text { Oxidativer Burst in } \\
\text { Neutrophilen und Phagozyten } \\
\text { durch Myelo- und } \\
\text { Laktoperoxidase } \\
\text { (Superoxidanion, } \mathrm{H}_{2} \mathrm{O}_{2},{ }^{1} \mathrm{O}_{2} \text {, } \\
\text { Hypochlorit, Peroxynitrit) }\end{array}$ \\
\hline $\begin{array}{l}\text { Hämolytische Anämie } \\
\text { (G6PDH-Defekt) }\end{array}$ & $\begin{array}{l}\text { Wenn Erythrozyten hohen } \\
\text { Konzentrationen von ROS } \\
\text { ausgesetzt sind, reicht bei } \\
\text { Glukose-6-phosphat- } \\
\text { Dehydrogenase-Insuffizienz das } \\
\text { NADPH + } \mathrm{H}^{+} \text {nicht für } \\
\text { Regenerierung von Glutathion }\end{array}$ \\
\hline
\end{tabular}

In jüngerer Zeit wird intensiv der Einfluss von oxidativem Stress auf neurodegenerative Erkrankungen untersucht, denn die Schädigung von Proteinen, DNA und Signalwegen sowie die Ablagerungen von Plaques bei Demenzerkrankungen
(Alzheimer- und Parkinson-Krankheit sowie bei amyotropher Lateralsklerose) sind mit oxidativem Stress assoziiert oder werden davon ausgelöst. Diabetische Neuropathien und Nephropathien haben Zeichen von oxidativem und Carbonylstress, wobei sowohl die Glykoxidation als auch die Bindung der $\triangleright$,advanced glycation end products“ ( $\varepsilon$-Carboxymethyllysin, > Pentosidin) an den $>$ AGE- Rezeptor reaktive Sauerstoff- und Stickstoffspezies induzieren. Das frei permeable $\mathrm{H}_{2} \mathrm{O}_{2}$ aktiviert über $\mathrm{NF \kappa B}$ verschiedene Zytokine, Endothelin-1, \ vaskulären endothelialen Wachstumsfaktor und TGF- $\beta$ (Baynes und Thorpe 1999). Die Wirkung von oxidativem Stress auf Entstehung, Progression oder Hemmung von Karzinomen ist noch weitgehend ungeklärt und von Art, Genetik, Lokalisation und Entwicklungszustand des Karzinoms abhängig. Einerseits werden Transkriptionsfaktoren (NFкB, AP-1 und „hypoxy-induced factor-1“) für Entzündungen, Proliferation, Angiogenese und Metastasierung induziert und DNA geschädigt (Oxidation, Strangbrüche, „,cross-links"), andererseits aber auch die Expression von Tumorsuppressorgenen (p53, Retinoblastomprotein und PTEN [,,phosphatase and tensin homolog"]) gesteigert. Auch Radio- und Chemotherapie werden wahrscheinlich durch den ausgelösten oxidativen Stress unterstützt und Resistenzen beseitigt, während normale Zellen weniger sensitiv gegenüber erhöhten ROS sind.

Oxidativer Stress ist auch bei akuten Erkrankungen deutlich vorhanden und ist als prognostischer Indikator bei Sepsis, multiplem Trauma, Schlaganfall und akuten Herzinfarkt, Ischämie und Reperfusion verwendbar. Im Notfall und auf Intensivstation bleibt nicht so viel Zeit, die einzelnen reaktiven Sauerstoffspezies spezifisch zu erfassen. Die Messung des totalen Redoxpotenzials (zukünftig möglichst als POCT) und der Redoxkapazität ist deshalb für Erfassung und Monitoring des oxidativen Stresses und der Prüfung der eingesetzten Pharmaka notwendig. Eine andere Möglichkeit ist die automatisierte Messung der, ,advanced oxidation protein products" (AOPP, Dityrosin, Carbonylproteine und Pentosidin) bei $340 \mathrm{~nm}$ mit Chloramin $\mathrm{T}$ als Standard (Selmeci et al. 2005). Bewährt haben sich Messungen der Ratio der reduzierten und oxidierten Formen von Harnsäure/Allantoin, Askorbinsäure, Glutathion und Ubichinon (Kandár 2016). Weitere Messungen zum oxidativen Stress s. u. $>$ Reaktive Sauerstoffspecies.

\section{Literatur}

Bar-Or D, Bar-Or R, Rael LT, Brody EN (2015) Oxidative stress in severe acute illness. Redox Biol 4:340-345

Baynes JW, Thorpe SR (1999) Role of oxidative stress in diabetic complications. A new perspective on an old paradigma. Diabetes 48:1-9

Fiedler H (2018) Oxidativer und antioxidativer Stress. MTA Dialog 19:272-278 
Gupta SC, Hevia D, Patchva P et al (2012) Upsides and downsides of reactive species for cancer: the roles of reactive species in tumorigenesis, prevention, and therapy. Antioxid Redox Signal 16:1295-1322

Kandár R (2016) The ratio of oxidatve and reductive forms of selected antioxidants as a possible marker of oxidative stress in humans. Biomed Chromatogr 30:13-28

Made AK, Plummer LE, Carosini C, Pinkerton KE (2014) Nanoparticles, lung injury, and the role of oxidative stress. Annu Rev Physiol $76: 447-465$

Ristow M, Schmeisser S (2011) Extending life span by oxidative stress. Free Radic Biol Med 51:327-336

Selmeci L, Seres L, Antal M et al (2005) Advanced oxidation protein products (AOPP) for monitoring oxidative stress in critically ill patients: a simple, fast and inexpensive automated technique. Clin Chem Lab Med 43:294-297

Semchyshyn HM, Lushchak V (2012) Chapter 2. Interplay between oxidative and carbonyl stresses: molecular mechanisms, biological effects and therapeutic strategies of protection. In: Semchyshyn HM, Lushchak V (Hrsg) Oxidative stress - molecular mechanisms and biological effects. InTech Europe, Rijeka

Sies H (2015) Oxidative stress: a concept in redox biology and medicine. Redox Biol 4:180-183

\section{Streulichtmessung}

$>$ Immunnephelometrie

\section{Streuung}

> Variabilität

\section{Streuung, biologische}

D Differenz, kritische

$\checkmark$ Longitudinalbeurteilung

$\checkmark$ Medizinisches Erfordernis

\section{Strong lon Difference}

> Säure-Basen-Modell nach Stewart

\section{Strong lon Gap}

> Säure-Basen-Modell nach Stewart

\section{Strontium}

D. Meißner und T. Arndt

\section{Englischer Begriff strontium}

Definition Strontium (chemisches Symbol: Sr) ist ein Element der II. Hauptgruppe des Periodensystems der Elemente mit der Ordnungszahl 38 und einer relativen Atommasse von 87,62. Obwohl biochemische Funktionen des Strontiums bekannt sind, zählt es bisher nicht zu den essenziellen > Ultraspurenelementen.

Beschreibung Strontium ist in der Umwelt allgegenwärtig und relativ häufig, weshalb die ausreichende Versorgung des Menschen gegeben ist. Die Strontiumbasiskonzentration von 100 gesunden Personen betrug 6-41 $\mu \mathrm{g} / \mathrm{L}$ (Median $16 \mu \mathrm{g} / \mathrm{L}$ ) im Blut und 18-75 $\mu \mathrm{g} / \mathrm{L}$ (Median $29 \mu \mathrm{g} / \mathrm{L}$ ) im Plasma. Der Körperbestand (wenige Hundert Milligramm) findet sich zu 99 \% im Knochen. Die Eliminationshalbwertszeit im Urin nach einmaliger oraler Gabe von Strontiumchlorid-Hexahydrat betrug im Mittel 40 Stunden. Die basale Strontiumausscheidung im Urin Gesunder lag studienabhängig bei 20-413, 41-506, 11-675 $\mu \mathrm{g} / \mathrm{L}$ (Mittel 90, 144, $166 \mu \mathrm{g} / \mathrm{L}$ ). In einer weiteren, 30 Tage erfassenden, Studie wurden circa 18-21\% einer oralen Dosis über den Urin, 58-68 \% über den Stuhl ausgeschieden (Baselt 2014).

In seinen biochemischen Eigenschaften ist Strontium dem - Calcium sehr ähnlich. Das betrifft insbesondere den Einbau in die Strukturen des Knochens. Aus diesem Grunde wird Strontium pharmakologisch genutzt und in Form des Strontiumranelats in der Therapie der Osteoporose angewendet, da es einerseits die Synthese von kollagenen und nicht kollagenen Proteinen steigert und somit die Knochenbildung fördert und andererseits dem Knochenabbau entgegen wirkt. In Studien konnte gezeigt werden, dass sich bei Osteoporose das Risiko von Wirbelsäulen- und Hüftgelenksfrakturen verringerte.

Das stabile Isotop $\left({ }^{88} \mathrm{Sr}\right)$ gilt als relativ ungiftig. Dagegen wird das radioaktive Isotop ${ }^{90} \mathrm{Sr}$, das bei Kernreaktionen und Atomwaffenversuchen entsteht, als gefährlich eingestuft, weil es sich in Knochen einlagert und mit einer Halbwertszeit von 28,8 Jahren eine langandauernde Strahlenbelastung bewirkt.

Deutlich erhöhte post-mortem Strontiumkonzentrationen (z. B. 30-50-fach über der Basalkonzentration nicht ertrunkener Toter) im peripheren oder im (Herzkammer-)Blut können einen Ertrinkungstod, besonders in Salzwasser, anzeigen. Da Salzwasser 10-50-fach höhere Strontiumkonzentrationen als Trinkwasser oder Süßwasser aufweist, wird durch Ertrin- 
ken in Salzwasser eine große Strontiummenge aufgenommen und im Körper verteilt, mindestens solange der Blutkreislauf funktioniert.

\section{Literatur}

Baselt RC (2014) Disposition of toxic drugs and chemicals in man, 10. Aufl. Biomedical Publications, Seal Beach, S 1873-1874

Kisters K, Quang-Nguyen M, Zimny G et al (2006) Strontiumrenalat und Osteoporose. In: Anke M, Kisters K, Müller R, Schäfer U, Schenkel H, Seifert M (Hrsg) Macro and trace elements. SchubertVerlag, Leipzig, S 10-12

\section{Struvit}

W. G. Guder

Synonym(e) Magnesium-Ammonium-Phosphat-Hexahydrat; Nierenbeckenstein; Infektstein; Phosphatstein

Englischer Begriff phosphate stone; struvite stone

Definition Konkrement der ableitenden Harnwege aus Magnesium-Ammonium-Phosphat-Hexahydrat $\left(\mathrm{MgNH}_{4} \mathrm{PO}_{4} \times 6 \mathrm{H}_{2} \mathrm{O}\right)$.

Beschreibung In reiner Form seltene, in gemischter Form häufige Form des Harnsteins, der bei alkalischem pH-Wert typischerweise auf der Basis einer Nierenbeckeninfektion sich entwickelt und am häufigsten als sog. Infektstein oder Nierenausgussstein in Kombination mit Carbonatapatit entsteht. Er wird durch Röntgendiffraktion oder Infrarotspektroskopie analytisch aufgeklärt und durch antibiotische Therapie der Infektion und pH-Steuerung sowie Steigerung der Harnmenge vermieden. Im $>$ Harnsediment auftretende Struvitkristalle, die in Sargdeckelform auftreten, weisen zwar auf alkalischen Urin hin, sind aber ohne diagnostischen Wert für die Diagnose einer Steinbildung ( $\triangleright$ TripelphosphatKristalle).

\section{Literatur}

Hesse A, Jahnen A, Klocke K, Nolde A, Scharell O (1994) Nachsorge bei Harnstein- Patienten. Gustav Fischer Verlag, Jena/Stuttgart

\section{Struvit-Carbonatapatit}

Apatit-Kristalle
Struvit

\section{Strychnin}

C. Vidal und W.-R. Külpmann

\section{Englischer Begriff strychnine}

Definition Hauptalkaloid der Samen der Brechnuss (Strychnos nux vomica), Krampfgift.

Strukturformel:

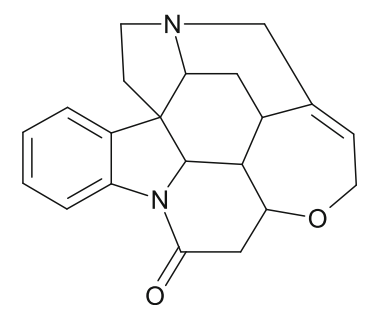

Molmasse $334,42 \mathrm{~g}$.

Synthese - Verteilung - Abbau - Elimination Nach oraler Aufnahme wird Strychnin rasch resorbiert und in der Leber abgebaut. Im Urin finden sich neben wenig Muttersubstanz überwiegend die Metabolite.

Halbwertszeit 10-16 Stunden (Plasma).

Funktion - Pathophysiologie Bei schwerer Vergiftung kommt es zu schweren Krämpfen und Risus sardonicus (krampfhaftes Grinsen durch Lähmung der Gesichtsmuskulatur) mit Hyperthermie. Der Tod tritt ein durch Erstickung oder Herz-Kreislauf-Versagen. Für Kinder können bereits $10 \mathrm{mg}$, für Erwachsene $30 \mathrm{mg}$ tödlich sein.

Untersuchungsmaterial - Entnahmebedingungen Urin, Serum (S), Plasma (P), Haare.

Analytik > GC-MS, LC-MS/MS, \ Dünnschichtchromatographie.

Indikation Verdacht auf Intoxikation.

Interpretation Strychnin ist in Deutschland humanmedizinisch nur noch in homöopathischen Präparaten enthalten. Es findet sich in Tierarzneimitteln und wurde als Rodentizid eingesetzt. In Einzelfällen sollen Drogen mit Strychnin verschnitten gewesen sein.

Therapeutischer Bereich (S, P): unbekannt; toxisch: $>0,075-1,0 \mathrm{mg} / \mathrm{L}$; komatös-letal: >0,5 mg/L. 


\section{Literatur}

Geldmacher-von Mallinckrodt M, Käferstein H (2009) Strychnine. In: Külpmann WR (Hrsg) Clincial toxicological analysis. Wiley-VCH, Weinheim, S 642-646

\section{Stuart-Prower-Faktor}

> Gerinnungsfaktor X

\section{Studien, diagnostische}

\section{R.-D. Hilgers, N. Heussen und S. Stanzel}

Englischer Begriff diagnostic studies

Definition Diagnostische Studien sind Spezialformen klinischer bzw. epidemiologischer Studien mit der Zielsetzung der Bewertung unterschiedlicher Aspekte eines diagnostischen Prozesses.

Beschreibung Je nach Zielsetzung sind die in der folgenden Tabelle aufgelisteten Studientypen zu verwenden.

\begin{tabular}{|c|c|c|}
\hline $\begin{array}{l}\text { Allgemeine } \\
\text { Studientypen }\end{array}$ & Fragestellung & $\begin{array}{l}\text { Mögliche } \\
\text { Studientypen }\end{array}$ \\
\hline \multirow[t]{8}{*}{ Klinische Studien } & \multirow{4}{*}{$\begin{array}{l}\text { Diagnostische } \\
\text { Accuracy }\end{array}$} & Querschnittstudie \\
\hline & & Fall-Kontroll-Studie \\
\hline & & $\begin{array}{l}\text { Stichprobensammlung } \\
\text { basierend auf } \\
\text { Testresultaten }\end{array}$ \\
\hline & & $\begin{array}{l}\text { Befragungen in } \\
\text { indizierten } \\
\text { Populationen }\end{array}$ \\
\hline & \multirow{4}{*}{$\begin{array}{l}\text { Wertigkeit eines } \\
\text { diagnostischen Tests } \\
\text { für die Prognose oder } \\
\text { das } \\
\text { Behandlungsregime }\end{array}$} & $\begin{array}{l}\text { Randomisierte } \\
\text { kontrollierte klinische } \\
\text { Studie }\end{array}$ \\
\hline & & Kohortenstudie \\
\hline & & Fall-Kontroll-Studie \\
\hline & & $\begin{array}{l}\text { Vor-Nach- } \\
\text { Vergleichsstudie }\end{array}$ \\
\hline \multirow{4}{*}{$\begin{array}{l}\text { Zusammenfassende } \\
\text { Bewertung }\end{array}$} & \multirow{3}{*}{$\begin{array}{l}\text { Zusammenfassung der } \\
\text { Ergebnisse aus } \\
\text { mehreren Studien }\end{array}$} & Systematischer \\
\hline & & Review \\
\hline & & Meta-Analyse \\
\hline & $\begin{array}{l}\text { Bestimmung der } \\
\text { kosteneffektivsten } \\
\text { diagnostischen } \\
\text { Strategie }\end{array}$ & $\begin{array}{l}\text { Klinische } \\
\text { Entscheidungsanalyse } \\
\text { Kosten-Effektivitäts- } \\
\text { Analyse }\end{array}$ \\
\hline
\end{tabular}

\begin{tabular}{|c|c|c|}
\hline $\begin{array}{l}\text { Allgemeine } \\
\text { Studientypen }\end{array}$ & Fragestellung & $\begin{array}{l}\text { Mögliche } \\
\text { Studientypen }\end{array}$ \\
\hline \multirow{5}{*}{$\begin{array}{l}\text { Nutzung der } \\
\text { Ergebnisse in der } \\
\text { Praxis }\end{array}$} & \multirow[t]{3}{*}{$\begin{array}{l}\text { Übertragung der } \\
\text { Ergebnisse in die } \\
\text { Praxis }\end{array}$} & $\begin{array}{l}\text { Integration der } \\
\text { Ergebnisse aus den } \\
\text { vorangehenden } \\
\text { Studientypen }\end{array}$ \\
\hline & & $\begin{array}{l}\text { Experten-Konsensus- } \\
\text { Konferenz }\end{array}$ \\
\hline & & $\begin{array}{l}\text { Entwicklung von } \\
\text { Leitlinien }\end{array}$ \\
\hline & \multirow[t]{2}{*}{ ICT-Studien } & $\begin{array}{l}\text { Überprüfung der } \\
\text { Lösung des } \\
\text { diagnostischen } \\
\text { Problems }\end{array}$ \\
\hline & & $\begin{array}{l}\text { Evaluation der } \\
\text { Implementierung in die } \\
\text { Praxis }\end{array}$ \\
\hline
\end{tabular}

\section{Literatur}

Knottnerus JA, van Weel C, JWM M (2002) Evidence base of clinical diagnosis - evaluation of diagnosis procedures. BMJ 23:477-480

\section{Stufendiagnostik}

O. Colhoun

Synonym(e) Reflextestung

Englischer Begriff reflex testing

Definition Eine in der Labor-EDV hinterlegte, sinnvoll gestufte Abarbeitungslogik für ausgewählte medizinische Fragestellungen.

Beschreibung Die im Konsens zwischen Labormedizin und Klinik erarbeiteten Regeln für die Stufendiagnostik bestimmter medizinischer Fragestellungen wird in einem Regelwerk im Labor-EDV-System hinterlegt (Beispiel: Schilddrüsenscreening mittels TSH, bei pathologischem Ausfall Bestimmung von fT4, bei dessen unauffälligem Ergebnis Bestimmung von fT3).

\section{Stuhl als Spezimen}

- Stuhlprobe 


\section{Stuhlfett}

\section{A. M. Gressner und O. A. Gressner}

Synonym(e) Fett im Stuhl; Fettmalabsorption

Englischer Begriff fecal fat; stool fat

Definition Die Stuhlfettausscheidung/Tag ist die definitive Kenngröße ( $\triangleright$ Kenngröße, klinisch-chemische) zum Nachweis einer Steatorrhoe (Fettstuhl) bei Malassimilation, erlaubt jedoch keine Differenzierung in Maldigestion und -absorption.

Synthese - Verteilung - Abbau - Elimination Fäkale Lipide sind überwiegend freie, sowohl gesättigte als auch ungesättigte $>$ Fettsäuren, nur eine kleine Fraktion sind Neutralfette ( $\triangleright$ Triglyzeride), die durch Lipasen hydrolytisch gespalten werden.

Funktion - Pathophysiologie Die normale fäkale Fettausscheidung ist konstant und relativ unabhängig von der Nahrungsaufnahme. Quelle des Stuhlfettes bei Gesunden sind intestinale Mukosazellen, die bakteriell freigesetzt werden. Da bei exokriner Pankreasinsuffizienz als erstes die Fettverdauung beeinträchtigt ist, kommt der Zunahme des Stuhlfettgehaltes für die Diagnostik der pankreatogenen Maldigestion größere Bedeutung zu. Eine selektive Erfassung der $\triangleright$ Triglyzeride und freien $>$ Fettsäuren hat keine diagnostische Relevanz, da Triglyzeride mikrobiell im Kolon in wechselndem Ausmaß hydrolysiert werden.

Untersuchungsmaterial - Entnahmebedingungen Stuhlsammelmenge in 24-Stunden-Sammelperioden an 3-4 aufeinander folgenden Tagen. Der Proband hat 2 Tage vorher und während der Sammelperiode eine tägliche Fettzufuhr von mindestens $90 \mathrm{~g}$ bis maximal $200 \mathrm{~g}$ einzuhalten.
Präanalytik Konservierung des Materials kurzfristig bei $4{ }^{\circ} \mathrm{C}$ oder längerfristig bei $-20^{\circ} \mathrm{C}$ während der Sammelperiode.

Korrekte Sammlung notwendig, Kontamination mit Urin vermeiden, Absetzen interferierender Medikamente, tägliche Fettzufuhr $>90$ bis $<200 \mathrm{~g}$.

Analytik

- Titrimetrische Methode nach van de Kamer et al. (1949): Diese am häufigsten eingesetzte Methode bestimmt den gesamten Fettgehalt (Triglyzeride und freie Fettsäuren) eines Aliquots von ca. $5 \mathrm{~g}$ des homogenisierten Stuhls. Nach Verseifen mit konzentrierter Kalilauge in Ethanol, saurer Hydrolyse zur Freisetzung von Fettsäuren und Extraktion mit Petroleumether werden die Fettsäuren mit $0,1 \mathrm{~mol} / \mathrm{L}$ $\mathrm{NaOH}$ in Anwesenheit von Thymolblau als Indikator oder mit einem $\mathrm{pH}$-Titriergerät (pH-Stat) titriert. Variationskoeffizient 4,6\%. Ein Nachteil besteht in dem Verlust flüchtiger Fettsäuren und in der Variabilität des Titrationsfaktors, der von der Art der zur Kalibration verwendeten freien Fettsäure abhängt. Allgemein wird auf eine mittlere Molmasse der freien Fettsäure von $284 \mathrm{~g} / \mathrm{mol}$ bezogen.

- Mikroskopische Bestimmung: Heute obsolete, allenfalls semiquantitative mikroskopische Bestimmung von Zahl und Größe der Fetttropfen in einem mit Sudan III, Methylenblau oder Nilblau gefärbten Ausstrich des Stuhlmaterials.

- Gravimetrische Methode: Nach Extraktion und Verdampfung des Lösungsmittels erfolgt direkte Wägung der extrahierten Fette.

Referenzbereich - Erwachsene $<7$ g Fettsäuren/Tag (Mittelwert von 3 Tagesstühlen), 15-25\% des Stuhltrockengewichtes, $>95 \%$ Fettabsorptionskoeffizient.

Berechnung des Fettabsorptionskoeffizienten (\%) nach folgender Formel:

Stuhlfett, Tab 1. Diagnostische Bewertung der Steatorrhoe

\begin{tabular}{|l|l|l|l|l|l|l}
\hline Myndrom & Exkretorische Pankreasinsuffizienz \\
\hline & Cholanopathien (Gallensäurestoffwechselstörungen) \\
\hline & \\
\hline Malabsorption &
\end{tabular}

\section{Erkrankung}

Chronische Pankreatitis

Teilresektion

Tumoren

Schwere Leberzellinsuffizienz

Gallgengangsobstruktion (Stein- oder Tumorverschluss)

Verminderung konjugierter Gallensäuren infolge mikrobieller Dekonjugation

Unterbrechung der enterohepatischen Gallensäurezirkulation (z. B. Ileumresektion)

Sprue, Morbus Crohn, Morbus Whipple, Amyloidose, intestinale Tuberkulose u. a. 


$$
\frac{\text { Fettaufnahme }[\mathrm{g}] \times \text { fäkale Fettausscheidung }[\mathrm{g}]}{\text { Fettaufnahme }[\mathrm{g}]} \times 100
$$

\section{Indikation}

- Bestätigungsdiagnose einer Steatorrhoe

- Diagnose und Verlaufskontrolle der Malabsorption

- Diagnose und Verlaufskontrolle der exkretorischen Pankreasinsuffizienz, z. B. bei Enzymsubstitution

Interpretation Fettausscheidung $>7 \mathrm{~g} /$ Tag (Steatorrhoe) tritt wegen großer Funktionsreserve des Pankreas erst bei weitreichendem ( $>75 \%$ ) Parenchymuntergang auf, die Lipasesekretion muss mindestens auf ein Zehntel der Norm abgefallen sein. Deshalb ist die Stuhlfettmenge keine zur Frühdiagnose der Pankreasinsuffizienz geeignete Kenngröße.

Diagnostische Wertigkeit In Verbindung mit dem Stuhlgewicht ( $\triangleright$ Stuhltrockengewicht) liegt der positive und negative Vorhersagewert des Stuhlfettgehaltes für die Pankreasinsuffizienz um $75 \%$, Sensitivitäten ( $>$ Sensitivität, diagnostische) und Spezifitäten ( $>$ Spezifität, diagnostische) um $80 \%$. Die Spezifität für die Diagnose der exokrinen Pankreasinsuffizienz ist eingeschränkt, da verschiedene Malabsorptionssyndrome, z. B. Dünndarmerkrankungen mit Mukosaatrophie und gesteigerte Dekonjugation von Gallensäuren sowie andere Cholanopathien (Gallensäurestoffwechselstörungen) zur Steatorrhoe führen (Tab. 1) (s. a. $>$ Steatokrit).

Diagnostische Bewertung der Steatorrhoe:

Die Bestimmung des Stuhlfettes ist heute durch die weniger aufwendige Messung der pankreasspezifischen Elastase ( $\triangleright$ Elastase, pankreasspezifische) im Stuhl (ca. 100 mg Stuhlprobe) weitgehend ersetzt.

Zur Differenzierung dienen:

- Parameter der Malabsorption: $>$ Xylose-Test, $>$ Laktosetoleranz-Test, V Vitamin-B12-Resorptionstest, Vitamin-A-Test und der Pankreasinsuffizienz: z. B. Pankreolauryltest, Elastase ( $\triangleright$ Elastase, pankreasspezifische) und $>$ Chymotrypsin im Stuhl

- Substitution mit lipasereichen Enzympräparaten, die nur bei exokriner Pankreasinsuffizienz (und nicht bei Malabsorption) eine Verringerung der Fettausscheidung herbeiführen

\section{Literatur}

Lembcke B, Braden B, Stein J (1994) Diagnostik der Steatorrhoe Z Gastroenterol 32:256-261
Kamer JH van de, ten Bokkel Huinink H, Meyer HA (1949) Rapid method for the determination of fat in feces. J Biol Chem 177(1) $347-355$.

Stein J, Wehrmann T (Hrsg) (2006) Funktionsdiagnostik in der Gastroenterologie, 2. Aufl. Springer Medizin Verlag, Heidelberg.

\section{Stuhlfeuchtgewicht}

A. M. Gressner und O. A. Gressner

Synonym(e) Stuhlmasse

Englischer Begriff fecal weight; stool weight

Definition Mittelwert des an 3 aufeinander folgenden Tagen gemessenen Stuhlfeuchtgewichtes.

Funktion - Pathophysiologie Malassimilationssyndrome, die entweder auf einer intestinalen Malabsorption oder auf einer hepatobiliären oder pankreatogenen Maldigestion beruhen, führen zu einer verminderten Ausnutzung der Nahrung mit Ausscheidung unverdauter Zellkerne und Muskelfasern (Kreatorrhoe), erhöhter Fettausscheidung (Steatorrhoe) und erhöhter Stärkeausscheidung (Amylorrhoe), was sich bei ausgeprägteren Krankheitsstadien in einer Erhöhung des täglichen Stuhlfeuchtgewichtes zeigt.

Untersuchungsmaterial - Entnahmebedingungen An 3 konsekutiven Tagen separat gesammelte 24-StundenStuhlmengen.

Präanalytik Materialkonservierung kurzfristig bei $4{ }^{\circ} \mathrm{C}$ oder längerfristig bei $-20^{\circ} \mathrm{C}$.

Vollständige Sammlung notwendig, Kontamination mit Urin vermeiden, ausgeglichene Ernährung.

Analytik Gravimetrisch, es werden die Stuhlgewichte von 3 aufeinander folgenden 24-Stunden-Sammelperioden gemessen und das mittlere Stuhlfeuchtgewicht/Tag berechnet.

Referenzbereich - Erwachsene 100-200 g Feuchtgewicht/ Tag (abhängig von Nahrungszusammensetzung).

Referenzbereich - Kinder Kleinkinder: $<10$ g/kg KG/Tag.

Indikation Diagnostik und Verlaufskontrolle von Malassimilationssyndromen, insbesondere der pankreatogenen Maldigestion. 
Interpretation Stuhlmengen $>400 \mathrm{~g}$ sind eindeutig pathologisch. Ein normales Stuhlgewicht schließt eine beginnende Pankreasinsuffizienz nicht aus, da erst bei einem Verlust von $>75 \%$ der exkretorischen Pankreasfunktion ein pathologisches Ergebnis zu erwarten ist. Das Stuhlgewicht ist somit kein empfindlicher Parameter zur Frühdiagnostik der Pankreasinsuffizienz. Spezifität ist eingeschränkt, da das Stuhlgewicht auch bei nicht pankreatogener Malabsorption (Dünndarmerkrankungen) und hepatobiliären Erkrankungen aufgrund eines Mangels an $>$ Gallensäuren erhöht sein kann. Ergänzende Untersuchungen betreffen die Bestimmung von $>$ Stuhlfett, $>$ Elastase, pankreasspezifische, > Chymotrypsin im Stuhl sowie Pankreasfunktionsteste.

Diagnostische Wertigkeit Stuhlfett- und Stuhlgewichtsbestimmung weisen prädiktive Werte um $75 \%$ für exokrine Pankreasinsuffizienz auf. Sensitivitäten ( $>$ Sensitivität, diagnostische) und Spezifitäten ( $\triangleright$ Spezifität, diagnostische) liegen bei 88 bzw. $79 \%$. Bei 10-15\% der Patienten sind pathologische Stuhlfettausscheidung und erhöhtes Stuhlgewicht nicht kongruent.

\section{Literatur}

Feurle GE, Morgenstern W, Pfaff H (1983) Diagnosis of exocrine pancreatic insufficiency from stool fat and weight. Klin Wochenschr 61:199-202

\section{Stuhlmasse}

Stuhlfeuchtgewicht

$>$ Stuhltrockengewicht

\section{Stuhlprobe}

W. G. Guder

\section{Synonym(e) Faeces}

Englischer Begriff feces sample; part of stool

Definition Teil oder vollständige Menge des anal oder aus künstlichem Ausgang des Kolons ausgeschiedenen Exkrets mit dem Ziel der diagnostischen Untersuchung.

Beschreibung Stuhlproben dienen der diagnostischen Untersuchung in der Neugeborenenperiode bis ins hohe Alter. Genetische, mikroskopische, mikrobiologische oder metabolische Untersuchungen dienen dem Nachweis infektiöser
(Erregernachweis bei Darminfektionen, Wurmeieridentifikation), metabolischer (Elastase im Stuhl zum Nachweis einer Pankreasinsuffizienz; > Elastase, pankreasspezifische), genetischer (z. B. bei genetischer Untersuchung auf Polyposis intestinalis) und zur Früherkennung von Krebserkrankungen des Darmtrakts (Blut im Stuhl; > Hämoccult-Test; $>$ Okkultblut, fäkales).

\section{Literatur}

Neumeister B, Besenthal I, Liebich H (2003) Klinikleitfaden Labordiagnostik, 3. Aufl. Urban und Fischer, München

\section{Stuhltrockengewicht}

A. M. Gressner und O. A. Gressner

Synonym(e) Fäzestrockengewicht

Englischer Begriff feces dry weight

Definition Das Gewicht des getrockneten Stuhls ist bei Malassimilationssyndromen (Malabsorption, -digestion) teilweise gegensätzlich verändert und kann somit zur Differenzialdiagnostik beider Formen herangezogen werden.

Beschreibung Im Normalzustand beträgt das Stuhltrockengewicht $25 \%$ des Feuchtgewichtes, das Verhältnis Trockengewicht zu Feuchtgewicht somit 1:4. Zur Bestimmung des Trockengewichtes werden nach Wägung der Gesamtstuhlmenge $50 \mathrm{~g}$ Feuchtstuhlmenge mit $20 \mathrm{~g}$ Quarzsand vermischt und in Heißluft unter mehrmaligem Zusatz von absolutem Alkohol für etwa 3 Stunden getrocknet. Die getrocknete und gewogene Stuhlprobe wird (unter Abzug des Quarzsandgewichts) auf das Gesamtstuhlgewicht umgerechnet und im Verhältnis zum Feuchtgewicht angegeben. Die medizinische Bewertung einer Zunahme des Trockengewichts weist auf ein (pankreatogenes) Malassimilationssyndrom hin, eine Abnahme des Trockengewichts als Folge eines hohen prozentualen Wassergehalts des Stuhles deutet auf hepatogene Formen oder Sprue hin. Spezifische Funktionsteste zur Diagnostik einer Fettmalabsorption ( $\triangleright$ Stuhlfett) sollten herangezogen werden.

\section{Literatur}

Gitter A, Heilmeyer L (Hrsg) (1963) Taschenbuch klinischer Funktionsprüfungen, 8. Aufl. Gustav Fisher Verlag, Stuttgart 


\section{S-Typ-Cholinesterasen}

- Pseudocholinesterase

\section{Suberinsäure}

G. F. Hoffmann, C.-D. Langhans und A. Schulze

Synonym(e) 1,8-Oktandisäure; Korksäure

Englischer Begriff suberic acid

Definition Die mittelkettige Dicarbonsäure $\left(\mathrm{C}_{8} \mathrm{H}_{14} \mathrm{O}_{4}\right)$ entsteht als pathologischer Metabolit bei einer Reihe von Fettsäureoxidationsstörungen.

Struktur Strukturformel:<smiles>O=C(O)CCCCCCC(=O)O</smiles>

Molmasse $174,19 \mathrm{~g}$.

Synthese - Verteilung - Abbau - Elimination Die im Verlauf der mitochondrialen $\beta$-Oxidation aus dem trifunktionellen Protein freigesetzten mittelkettigen $>$ Fettsäuren werden durch die mittelkettige Acyl-CoA-Dehydrogenase weiter verkürzt und im weiteren Verlauf zu Acetyl-CoA (geradzahlige Fettsäuren) bzw. zu Propionyl-CoA (ungeradzahlige Fettsäuren) abgebaut, die schließlich in den Citratzyklus einfließen.

Bei Defekten der mittelkettigen Acyl-CoA-Dehydrogenase (MCAD) und in geringerem Ausmaß der überlangkettigen Acyl-CoA-Dehydrogenase (VLCAD) werden die mittelkettigen Fettsäuren alternativ durch $\omega$-Oxidation zu mittelkettigen Dicarbonsäuren ( $\vee$ Adipinsäure, Suberinsäure, \ Sebacinsäure) abgebaut. Diese werden entweder in freier Form oder als Glyzinkonjugate (Hexanoylglycin, Suberylglycin) im Urin ausgeschieden.

Funktion - Pathophysiologie Suberinsäure hat keine bekannte Funktion im Intermediärstoffwechsel. Untersuchungen zur individuellen Toxizität der durch $\omega$-Oxidation entstandenen Dicarbonsäuren (Adipinsäure, Suberinsäure, Sebacinsäure) liegen erst in Ansätzen vor. In der Summe hemmen diese pathologischen Metabolite und/oder ihre Konjugate den mitochondrialen Energiestoffwechsel.

Untersuchungsmaterial - Entnahmebedingungen Urin.

\section{Präanalytik}

- Durch > Flüssig-Flüssig-Extraktion im sauren Medium mittels Ethylacetat oder Diethylether

- Mittels Gaschromatographie-Massenspektrometrie (๖ GCMS) als Di-Trimethylsilylester

Retentionsindex RI: 1702

$\mathrm{M}+(\mathrm{m} / \mathrm{z}): 318$

Quant Ion (m/z): 303

Conf. Ion (m/z): 169

Internationale Einheit $\mathrm{mmol} / \mathrm{mol}$ Kreatinin (Urin).

Referenzbereich - Kinder Normalbereich - Urin (altersabhängig):

- 0-4 Monate: $1-15 \mathrm{mmol} / \mathrm{mol}$ Kreatinin

- Bis 2 Jahre: $2-15 \mathrm{mmol} / \mathrm{mol} \mathrm{Kreatinin}$

- Bis 10 Jahre: $1-10 \mathrm{mmol} / \mathrm{mol}$ Kreatinin

- >10 Jahre: 1-6 mmol/mol Kreatinin

Pathologischer Bereich:

- $6-4000 \mathrm{mmol} / \mathrm{mol} \mathrm{Kreatinin} \mathrm{(MCAD)}$

- $0-500 \mathrm{mmol} / \mathrm{mol} \mathrm{Kreatinin} \mathrm{(VLCAD)}$

- $0-500 \mathrm{mmol} / \mathrm{mol} \mathrm{Kreatinin} \mathrm{(Glutaracidurie} \mathrm{Typ} \mathrm{II)}$

- 10-620 mmol/mol Kreatinin (MCT angereicherte Ernährung)

Indikation Hypoketotische Hypoglykämien, rezidivierende Hepatopathien und Enzephalopathien, insbesondere ReyeSyndrom, Myopathien, Rhabdomyolyse.

Interpretation Erhöhte Suberinsäureausscheidungen im Urin werden bei zahlreichen genetischen und sekundären Störungen der Fettsäureoxidation beobachtet. Entscheidend für die Beurteilung ist zuerst die Kenntnis des aktuellen Ernährungsstatus und -modus sowie des Abstandes von der letzten Nahrungsaufnahme. Die Differenzierung erfordert ferner Kenntnisse über die Konzentrationen anderer Fettsäureoxidationsprodukte. Die Suberinsäure findet sich zusammen mit Adipinsäure und Sebacinsäure als führender Metabolit beim MCAD-Mangel. Bei Ketosen und Formulanahrung auf der Basis von mittelkettigen Triglyzeriden (Alfaré-Spezialnahrung) tritt Suberinsäure auch bei Normalpersonen vermehrt auf.

Diagnostische Wertigkeit Stark erhöhte Urinausscheidungen von Suberinsäure weisen auf eine gestörte Fettsäureoxidation hin. Die weitere Differenzierung erfordert Kenntnisse über die individuelle Stoffwechselsituation des Patienten, die Konzentrationen weiterer Metabolite und schließlich eine enzymatische oder molekularbiologische Bestätigungsdiagnostik. 


\section{Literatur}

Blau N, Duran M, Gibson KM, Dionisi-Vici C (Hrsg) (2014) Physician's guide to the diagnosis, treatment, and follow-up of inherited metabolic diseases. Springer, Berlin/Heidelberg

\section{Sublimation}

T. Arndt

Synonym(e) Dehydratisierung; Gefriertrocknung; Vakuumsublimation

Englischer Begriff sublimation; lyophilisation; freeze-drying

Definition Übergang einer Substanz aus dem festen in den gasförmigen Zustand und seine anschließende Ausscheidung in fester Form, ohne jeweils den flüssigen Aggregatzustand zu durchlaufen.

Beschreibung Die Sublimation einer Substanz ist möglich, wenn bei einem bestimmten Druck für eine bestimmte Temperatur die sog. Sublimationsdruckkurve im Phasendiagramm der Substanz getroffen wird. Oft sind hierzu Kühlung und/oder Vakuum erforderlich. Die Sublimation wird häufig zur Reinigung und Trocknung (auch Aufkonzentrierung) von temperatur- und sauerstoffempfindlichen Substanzen genutzt. Eine typische Anwendung in der Klinischen Chemie ( $>$ Klinische Chemie) ist die Gefriertrocknung ( $>$ Lyophilisation) von wässrigen Lösungen (Serum, Plasma, Urin) zur Herstellung von Materialien für die interne, vor allem aber die externe Qualitätskontrolle (käufliches Qualitätskontrollmaterial und Ringversuchsproben). Hierbei wird die wässrige Lösung bis zum Einfrieren abgekühlt und das Wassereis im Vakuum sublimiert. Die nichtflüchtigen Bestandteile bleiben in einem trockenen Pulver zurück, das bei Bedarf mit einer definierten Menge Wasser erneut gelöst werden kann (Rekonstitution).

\section{Literatur}

Falbe J, Regitz M (Hrsg) (1990) Römpp Chemie Lexikon. Georg Thieme Verlag, Stuttgart/New York

\section{Submolekül}

$>$ Untereinheit

\section{Subokzipitalliquor (SOP-Liquor)}

Liquor cerebrospinalis

\section{Substantia granulofilamentosa}

H. Baum

Englischer Begriff substantia granulofilamentosa

Definition Konglomerat aus Ribonukleoproteinen und einem Vitalfarbstoff in Retikulozyten.

Beschreibung Die Substantia granulofilamentosa ist ein morphologisch nachweisbares Produkt der Reaktion von Ribonukleoproteinen des jungen Erythrozyten ( $>$ Retikulozyt) und einem Supravitalfarbstoff, wie z. B. Brillantkresylblau oder Nilblausulfat. Ihr Nachweis dient der Erkennung und Zählung der Retikulozyten.

\section{Literatur}

Enne W (1993) Zellen der Erythropoese. In: Begemann H, Rastetter J (Hrsg) Klinische Hämatologie, 4. Aufl. Georg Thieme Verlag, Stuttgart, S 35-36

\section{Substanz P}

A. M. Gressner und O. A. Gressner

Englischer Begriff substance $P(p=$ pain $)$

Definition Kurzkettiges, innerhalb von Nervenzellen und spezifischen endokrinen Zellen des Gastrointestinaltrakts im Körper weit verbreitetes Polypeptid mit Funktionen als sensorischer Neurotransmitter (von Schmerzreizen) und potenter Vasodilatator.

Beschreibung Das aus 11 Aminosäuren bestehende, als Präproprotein synthetisierte und proteolytisch prozessierte Peptid ist weit verbreitet im Gastrointestinaltrakt sowie im peripheren und zentralen Nervensystem, wo es als sensorischer Neurotransmitter, insbesondere bei Nozirezeptoren wirkt. Überträgt Schmerzreize (analgetischer Faktor), stimuliert glatte Muskelkontraktion im Gastrointestinaltrakt, 
Speichelsekretion, > Histamin-Freisetzung, Vasodilatation und Superoxidproduktion in $>$ Makrophagen. Aufgrund ihrer Aminosäuresequenz H-Arg-Pro-Lys-Pro-Gln-Gln-Phe-Phe-GlyLeu-Met- $\mathrm{NH}_{2}$, die im Carboxy-terminalen Bereich mit der anderer amidierter Neuropeptide identisch ist (Phe-X-GlyLeu-Met- $\mathrm{NH}_{2}$ ), gehört Substanz $\mathrm{P}$ gemeinsam mit Neuromedin und Substanz K zur Familie der Tachykinine. Nüchternplasmakonzentration stark methodenabhängig, Richtwert $<240 \mathrm{ng} / \mathrm{L}$, Analyt instabil (eisgekühltes, Aprotinin-versetztes EDTAPlasma, was sofort tiefgefroren werden muss). Bestimmung mit $\triangleright$ Enzymimmunoassay (EIA) oder $\triangleright$ ChemolumineszenzAssay (CLIA).

Erhöhungen der Plasmakonzentration bei Karzinoidtumor, medullärem Schilddrüsenkarzinom und weiteren hormonaktiven gastrointestinalen Tumoren.

Selektive Katheterisierung zur Bestimmung von Substanz P dient der Lokalisationsdiagnostik des Karzinoidtumors.

\section{Literatur}

Severini C, Petrella C, Calissano P (2016) Substance P and Alzheimer's disease: emerging novel roles. Curr Alzheimer Res 13(9):964-972

\section{Substanz S}

11-Desoxykortisol

\section{Substanzen, homologe}

\section{T. Arndt}

Synonym(e) Homolog

Englischer Begriff homologous substances; homolog

Definition Bezeichnung für strukturell und in ihren Eigenschaften sehr ähnliche Substanzen.

Beschreibung Hierbei ist der Begriff ,ähnlich“ nicht streng definiert. Bei Betrachtung verschiedener Charakteristika können dieselben Substanzen durchaus größere oder kleinere Unterschiede aufweisen und als mehr oder weniger ähnlich beurteilt werden.

Im hier verwendeten Sinn ist der Begriff von jenem der homologen Reihe zu differenzieren, der Gruppen von chemisch nahe verwandten Substanzen bezeichnet, die sich ledig- lich durch ein Kettenglied voneinander unterscheiden und durch eine allgemeine Formel beschrieben werden können, z.B. die aliphatischen Alkohole mit $\mathrm{C}_{\mathrm{n}} \mathrm{H}_{2 \mathrm{n}+2} \mathrm{O}$ (Methanol $\mathrm{CH}_{4} \mathrm{O}$, Ethanol $\mathrm{C}_{2} \mathrm{H}_{6} \mathrm{O}$, Propanol $\mathrm{C}_{3} \mathrm{H}_{8} \mathrm{O}$ etc.).

\section{Literatur}

Falbe J, Regitz M (1990) Römpp Chemie Lexikon, Bd 3 H-L, 9. Aufl. Georg Thieme, Stuttgart/New York, S 1845-1846

\section{Substanzmenge}

Mol

\section{Substrat}

> Nährmedium

\section{Subtelomer-Region}

\section{J. Arnemann}

Synonym(e) Telomer-flankierender Bereich

Englischer Begriff subtelomeric region

Definition Die beiden Subtelomer-Regionen im p- und q-Arm eines Chromosoms stellen die chromosomenspezifischen DNA-Abschnitte dar, die am weitesten vom Zentromer entfernt liegen.

Beschreibung Die Subtelomer-Region ist aufgrund der chromosomenspezifischen Muster wichtig für die Erkennung und meiotische Paarung homologer Chromosomen. Diese Regionen setzen sich vordergründig aus segmentalen Duplikationen und subtelomerischen Repeat-(Srpt-)Sequenzen, insbesondere variablen Kombinationen von degenerativen TTAGGG-Repeats zusammen. TTAGGG-Repeats von bis zu $20 \mathrm{~kb}$ Länge bilden die eigentlichen Telomere, das Ende der Chromosomen, die das Chromosom vor Degradation schützen und in degenerativer Form in die SubtelomerRegion übergehen.

In der Subtelomer-Region sind auch transkribierte Gene lokalisiert, wie z. B. Zinkfinger- oder olfaktorische Rezeptorgene, aber auch weitere ORFs (,open reading frames"). Dele- 
tionen in dieser Region bedingen genetisch bedingte Erkrankungen, wie fazioskapulohumerale Muskeldystrophie (FSHD) oder auch Formen mentaler Retardierung.

\section{Literatur}

Ravnan JB et al (2006) Subtelomere FISH analysis of 11,688 cases: an evaluation of the frequency and pattern of subtelomere rearrangements in individuals with developmental disabilities. J Med Genet 43:478-489

\section{Succinylaceton}

G. F. Hoffmann, C.-D. Langhans und A. Schulze

Synonym(e) 4,6-Dioxo-Heptansäure

Englischer Begriff succinylacetone

Definition Dioxocarbonsäure tritt als pathologischer Metabolit im Stoffwechsel der aromatischen Aminosäure > Tyrosin auf.

Struktur $\mathrm{C}_{7} \mathrm{H}_{10} \mathrm{O}_{4}$; Strukturformel:<smiles>CC(=O)CC(=O)CCC(=O)O</smiles>

Molmasse $158,16 \mathrm{~g}$.

Synthese - Verteilung - Abbau - Elimination Das Transaminierungsprodukt von $>$ Tyrosin, 4-Hydroxyphenylbrenztraubensäure, wird durch die 4-Hydroxyphenylpyruvat Dioxigenase zu Homogentisinsäure oxidativ decarboxyliert.

Im weiteren Verlauf des Abbauwegs wird durch die Homogentisat-Dioxigenase Maleylacetessigsäure und weiter Fumarylacetessigsäure gebildet. Diese wird durch die Fumarylacetoacetase zu $\triangleright$ Fumarsäure und Acetessigsäure ( $\vee$ Acetoacetat) gespalten. Ein Defekt der Fumarylacetoacetase resultiert in einer Akkumulation von Fumarylacetessigsäure und Maleylacetessigsäure, die in einer Sekundärreaktion Succinylacetessigsäure bilden. Letzteres wird zu Succinylaceton decarboxyliert.

Succinylaceton verteilt sich in allen Körperflüssigkeiten und wird renal effizient ausgeschieden.

Funktion - Pathophysiologie Succinylaceton entsteht im Abbau von Tyrosin und hat keine bekannte physiologische Funktion. Es ist ein potenter Inhibitor der 4-Hydroxyphenyl-
pyruvat-Dioxigenase wie auch der $>5$-Aminolävulinsäuredehydratase. Das Krankheitsbild ist durch schwere, ohne Behandlung tödlich verlaufende Leber- und Nierenfunktionsstörungen gekennzeichnet. Durch die Beeinträchtigung der Hämsynthese kommt es zu einem Anstieg von $\delta$-Aminolävulinsäure ( $\triangleright$ Porphyrine) mit konsekutiver Porphyrie und neurologischen Krisen.

Untersuchungsmaterial - Entnahmebedingungen Urin, in Ausnahmefällen Liquor, Plasma oder Trockenblut.

\section{Präanalytik}

- Flüssig-Flüssig-Extraktion im sauren Medium mittels Ethylacetat oder Diethylether nach vorangegangener Oximierung mit Pentafluorbenzylhydroxylamin (PFBHA)

- Gaschromatographie-Massenspektrometrie (॰ GC-MS) als Di-Pentafluorbenzyloxim-Trimethylsilylester

- Retentionsindex RI: 2431, 2457, 2472, 2485

- M+ (m/z): 620

- Quant Ion (m/z): 181

- Conf. Ion (m/z): 620

- Enzymatisch: Der semiquantitative Bloodspot-Test basiert auf der Inhibition der $\delta$-Aminolävulinat-Dehydratase durch Succinylaceton

- Prinzip: Endpunktbestimmung der $\delta$-AminolevulinsäureDehydrataseaktivität

- Reaktion:

$$
\delta \text {-Aminolevulinsäure } \frac{\delta \text {-Aminolevulinsäure- }}{\text { Dehydratase }} \text { Porphobilinogen }
$$

- Detektion (es wird spektrometrisch die Absorption bei $550 \mathrm{~nm}$ gemessen):

$$
\text { Porphobilinogen } \stackrel{\text { Ehrlich-Reagenz }}{\longrightarrow} \text { violetter Farbstoff }
$$

- Nachweisgrenze: 0,3 $\mu \mathrm{mol} / \mathrm{L}$

- Tandem-Massenspektrometrie: im Neugeborenenscreening aus Trockenblut als butyliertes Succinylacetonhydrazon

Internationale Einheit $\mathrm{mmol} / \mathrm{mol}$ Kreatinin (Urin). $\mu \mathrm{mol} / \mathrm{L}$ (Plasma, Liquor).

Referenzbereich - Kinder $<0,1 \mathrm{mmol} / \mathrm{mol}$ Kreatinin. Pathologischer Bereich: 0,5-1000 mmol/mol Kreatinin.

Indikation Akute oder chronische Hepatopathie bis Leberversagen im Säuglings- oder Kleinkindesalter, chronische Gedeihstörungen.

Interpretation Erhöhte Konzentrationen von Succinylaceton sind beweisend für eine Tyrosinämie Typ I, auch wenn Tyrosin selbst und andere charakteristische Metabolite wie 
erhöhtes Methionin, 4-Hydroxyphenylbrenztraubensäure und ihre Derivate 4-Hydroxyphenylmilchsäure und 4-Hydroxyphenylessigsäure oder $\delta$-Aminolävulinsäure normwertig wären. Diese Metabolite sollten mit untersucht und eine Bestätigungsdiagnostik in Fibroblasten oder Mutationsanalytik initiiert werden.

Diagnostische Wertigkeit Der Nachweis von Succinylaceton ist beweisend für eine Tyrosinämie Typ I, eine Stoffwechselstörung, deren Ursache ein Defekt der Fumarylacetoacetase ist. Daneben werden vermehrt auch 4-Hydroxyphenylbrenztraubensäure, 4-Hydroxyphenylmilchsäure und 4-Hydroxyphenylessigsäure ausgeschieden.

Einige Patienten scheiden nur sehr geringe Mengen Succinylaceton aus. In diesem Fall muss Succinylaceton mittels der spezifischen Stabilen-Isotopen-Verdünnungsanalyse ( $\triangleright$ Isotopenverdünnung) exakt quantifiziert und die Diagnose durch die Bestimmung der Fumarylacetoacetaseaktivität in Leukozyten oder Fibroblasten bestätigt werden.

\section{Literatur}

Blau N, Duran M, Gibson KM, Dionisi-Vici C (Hrsg) (2014) Physician's guide to the diagnosis, treatment, and follow-up of inherited metabolic diseases. Springer, Berlin/Heidelberg

Sander J, Janzen N, Peter M, Sander S, Steuerwald U, Holtkamp U, Schwahn B, Mayatepek E, Trefz FK, Das AM (2006) Newborn screening for hepatorenal tyrosinemia: tandem mass spectrometric quantification of succinylacetone. Clin Chem 52:482-487

Schulze A, Frommhold D, Hoffmann GF, Mayatepek E (2001) Spectrophotometric microassay for $\delta$-aminolevulinate dehydratase in driedblood spots as confirmation for hereditary tyrosinemia type I. Clin Chem 8:1424-1429

\section{Succinyl-CoA:glycin \\ C-succinyltransferase}

\5-Aminolävulinsäuresynthase

\section{Suchanalyse, allgemeine}

- Analyse, systematische toxikologische

\section{Suchfunktion}

O. Colhoun

Synonym(e) Suche

Englischer Begriff search function

Definition Funktionalität des Labor-EDV-Systems für die Suche von Befunden oder Patienten.

Beschreibung Die Suchmaske für die Befundauskunft im - Labor-EDV-System benötigt folgende Funktionen: Es kann - auch in eingegrenzten Zeitintervallen - nach Patienten, Auftragsnummern, Auftragsdatum, Patientengeburtsdatum, Messgröße, Laborbereich und/oder Einsender gesucht werden. Darauf erscheint eine Auswahlliste der infrage kommenden Patienten, chronologisch nach deren Aufenthalt sortiert, aktuellste zuerst.

Hier soll die Befundanzeige noch weiter eingrenzbar sein:

- Für jede definierte Befundart (Klinische Chemie, Hämatologie, Speziallabor/Serologie, Bakteriologie, Blutbank, Konservenstatus, Blutzucker etc.).

- Zeitliche Eingrenzung der Befunddarstellung: Als Vorgabe sollen alle Bereiche angewählt und keine zeitliche Eingrenzung vorgenommen sein.

- Eingrenzung auf einen Analyten: Hierauf sollen die Befunde direkt kumuliert einsehbar sein, aktuellste Aufträge zuerst. Dieser Kumulativbefund soll vor- und zurückblätterbar und direkt ausdruckbar sein.
Suchtest

Screening-Untersuchung

\section{Suchzellen}

- Antikörpersuchtest

\section{Suche}

Suchfunktion

\section{Sucrase-Isomaltase}

- Saccharase-Isomaltase 


\section{Sucrose-Hämolyse-Test}

- Zuckerwasser-Test

\section{Sudan-Schwarz}

H. Baum

Englischer Begriff sudan black

Definition Lipophiler Farbstoff, der irreversibel an granuläre Komponenten in neutrophilen und eosinophilen Granulozyten bindet.

Beschreibung Sudan-Schwarz ist ein lipophiler Farbstoff, der spezifisch die Granula in den myeloischen Vorläuferzellen sowie den reifen neutrophilen und eosinophilen Granulozyten anfärbt. Sudan-Schwarz kann alternativ zur $>$ Myeloperoxidase-Färbung in der Diagnostik der akuten myeloischen Leukämien verwendet werden. Dabei zeigen beide zytochemische Methoden die gleichen Ergebnisse.

\section{Literatur}

Swirsky D, Bain BJ (2001) Erythrocyte and leucocyte cytochemistry - leukaemia classification. In: Lewis SM, Bain BJ, Bates I (Hrsg) Dacie and Lewis Practical Haematology, 9. Aufl. Churchill Livingstone, London, S 279-280

\section{Sudor}

- Schweiß

\section{Sulfhämoglobin}

H. Baum

Synonym(e) S-Hb; Verdoglobin

Englischer Begriff sulfhemoglobin

Definition Schwefelhaltiges, grünliches Hämoglobinderivat.
Beschreibung Sulfhämoglobin ensteht aus $>$ Hämoglobin durch irreversible Bindung eines Schwefelatoms in den Porphyrinring ( $\triangleright$ Porphyrine) des Häms. Dadurch kann das Sulfhämoglobin keinen Sauerstoff mehr transportieren. Die gleichzeitige Verbesserung der Sauerstoffabgabe an das Gewebe durch eine Rechtsverschiebung der Sauerstoffbindungskurve mildert allerdings die klinische Symptomatik.

Die Bildung von Sulfhämoglobin kann erfolgen bei gleichzeitigem Vorhandensein eines oxidativen Zustandes und einer Schwefelquelle. Dabei kommen vor allem Arzneimittel als Schwefelquelle in Frage (z. B. Sulfonamide, Phenacetin, Dapsone). Sulfhämoglobin ist sehr stabil und wird erst mit dem Erythrozytenuntergang freigesetzt und abgebaut.

Die Bestimmung von Sulfhämoglobin erfolgt in der Regel simultan mit den anderen Hämoglobinen in der $>$ Oximetrie.

Referenzbereich: $<1 \%$ des Gesamthämoglobins.

\section{Literatur}

Lu HC, Shih RD, Marcus S et al (1998) Pseudomethemoglobinemia. A case report and review of sulfhemoglobinemia. Arch Pediatr Adolesc Med 152:803-805

Tietz NW (Hrsg) (2006) Clinical guide to laboratory tests. W. B. Saunders, Philadelphia

\section{Sulfitoxidase(-Defizienz)}

- Sulfit-Test

\section{Sulfit-Schnelltest}

- Sulfit-Test

\section{Sulfit-Test}

A. M. Gressner und O. A. Gressner

Synonym(e) Sulfit-Schnelltest; Test auf Molybdän-CofaktorDefizienz

Englischer Begriff test of molybdenum cofactor deficiency

Definition Zum Nachweis erhöhter Sulfitkonzentrationen im Urin bei Neugeborenen und Kleinkindern eingesetzter Streifen- bzw. Stäbchentest, der bei positivem Ergebnis auf genetische Molybdän-Cofaktor-Defizienzen hinweist. 
Beschreibung Der semiquantitative Stäbchentest ist indiziert bei Verdacht auf Vorliegen der 1978 erstmalig beschriebenen, autosomal-rezessiven, von 3 Genen kodierten Molybdän-Cofaktor-Defizienzen (MoCoDe) ( $\triangleright$ Molybdän) bei Neonaten und im frühen Kindeslater. Klinische Hinweise auf die (unbehandelt) bereits frühkindlich zum Tode führende Erkrankung sind u. a. ausgeprägte Entwicklungsverzögerungen, schwere Krampfanfälle, zerebrale Atrophien mit Mikrozephalie, grobe Gesichtszüge und ektope Augenlinsen.

Als Screening-Verfahren ( $\triangleright$ Screening-Untersuchung) für MoCoDe dient der mit kommerziellen Teststreifen oder -stäbchen, kolorimetrisch oder titrimetrisch (iodometrisch) durchgeführte Sulfit-Test im Urin zum Nachweis deutlich erhöhter Sulfitkonzentrationen $\left(\mathrm{SO}_{3}{ }^{2-}\right)$ : Frisch-gelassener Urin wird innerhalb von 10 Minuten dreimal getestet. Bei positivem Ergebnis muss eine Abgrenzung von einer isolierten Sulfitoxidasedefizienz durch zusätzliche Bestimmung der Harnsäurekonzentration im Plasma/Serum vorgenommen werden, deren Konzentration nur bei MoCoDe deutlich erniedrigt ist. Molybdän-Cofaktor-abhängige Enzyme sind u. a. Sulfitoxidase, Xanthindehydrogenase, Aldehydoxidase, deren Aktivitätsverluste u. a. zur Akkumulation von Sulfit, - Taurin, S-Sulfocystein und Thiosulfat führen. Diese Metabolite sind kausal für die o. g. schweren neurologischen Symptomen.

Die definitive molekulargenetische Diagnostik wird mit EDTA-Blut, DNA oder Zellkulturen des Patienten durchgeführt, die aufgrund der Vielzahl beteiligter Gene und Heterogenität der pathogenen Mutationen mit daraus resultierenden zahlreichen Sequenzierungen sehr aufwendig und demzufolge Speziallaboratorien vorbehalten ist. Bei positiver Elternanamnese ist auch eine pränatale Diagnostik möglich.

\section{Literatur}

Atwal PS, Scaglia F (2016) Molybdenum cofactor deficiency. Mol Genet Metab 117(1):1-4

Nagappa M, Bindu PS, Taly AB et al (2015) Child neurology: molybdenum cofactor deficiency. Neurology 85(23):e175-e178

\section{Sulfosalizylsäure-Test}

W. G. Guder

Synonym(e) Eiweißprobe im Urin

Englischer Begriff sulfosalicylic acid method

Definition Heute obsoleter Test zum Nachweis von Protein (Albumin) im Urin.
Beschreibung Der Sulfosalizylsäure-Test wurde als qualitatives Nachweisverfahren von Protein im Urin neben anderen Säurefällungsmethoden und Kochproben eingeführt und hatte gegenüber diesen den Vorteil, dass man keine Erhitzung benötigte, das Ergebnis sofort ablesbar war und auch $>$ BenceJones-Protein damit erfasst werden kann. Dem Urin wird dabei tropfenweise 10- bis 20 \%ige Sulfosalizylsäure zugesetzt. Bei erhöhten Proteinmengen (positiv ab $150 \mathrm{mg} / \mathrm{L}$ Albumin; empfindlicher als der später eingeführte $>$ Teststreifen mit dem Prinzip der pH-Verschiebung eines Indikators) wurde eine quantitative Methode angeschlossen. Henry entwickelte eine semiquantitative Methode auf dieser Basis, die aber durch die $>$ Biuretmethode als quantitativem Verfahren verdrängt wurde. Heute hat dieses Verfahren keine Bedeutung mehr, da sensitivere und spezifischere Methoden für - Albumin im Urin entwickelt worden sind.

\section{Literatur}

Hallmann L (1980) Klinische Chemie und Mikroskopie, 11. Aufl. Georg Thieme Verlag, Stuttgart

Henry RJ, Sobel C, Segalove M (1956) Turbidometric determination of proteins with sulfosalicylic and trichloroacetic acids. Proc Soc Exp Biol Med 92:748

\section{Sulkowitch-Probe}

- Sulkowitch-Test

\section{Sulkowitch-Test}

\section{A. M. Gressner und O. A. Gressner}

Synonym(e) Calciumreaktion nach Sulkowitch; SulkowitchProbe

\section{Englischer Begriff Sulkowitch's test}

Definition Heute obsolete, semiquantitative Bestimmung von Calcium im Urin ( $\triangleright$ Calciumausscheidung).

Beschreibung Die mit einigen Tropfen Essigsäure angesäuerte, klare (ggf. zu filtrierende) Urinprobe zeigt ca. 3 Minuten nach Mischung im Verhältnis 1:1 mit SulkowitchReagenz (Essigsäure-gepufferte Oxalatlösung) im Normalfall eine langsam zunehmende, feine, weißliche Trübung. Bei erhöhter Calciumkonzentration tritt schnell eine milchige bis flockige Trübung auf. Die Stärke der Präzipitation kann semi- 
quantitativ ausgewertet werden. Die obsolete Methode (Barney und Sulkowitch 1937) ist heute durch die quantitative Bestimmung von $>$ Calcium im (Sammel-)Urin ersetzt.

\section{Literatur}

Barney JD, Sulkowitch HW (1937) Progress in management of urinary calculi. J Urol 37:746-762

Hallmann L (1980) Klinische Chemie und Mikroskopie, 11. Aufl. Georg Thieme Verlag, Stuttgart/New York

\section{Sultiam}

C. Vidal und W.-R. Külpmann

Englischer Begriff sultiame; sulthiame

Definition Antiepileptikum; Antikonvulsivum.

Strukturformel:

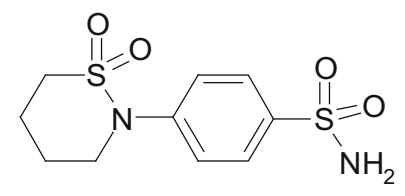

Molmasse 290,36 g.

Synthese - Verteilung - Abbau - Elimination Nach oraler Gabe wird Sultiam rasch und vollständig resorbiert. Die Proteinbindung beträgt etwa $30 \%$. Die Ausscheidung erfolgt zu 80-90 \% renal, zu 10-20\% biliär.

Halbwertszeit 3-30 Stunden.

Pathophysiologie Sultiam wird eingesetzt zur Behandlung der Rolando-Epilepsie, wenn die Behandlung mit anderen Antiepileptika erfolglos war. Als häufige Nebenwirkungen der Sultiamgabe sind Magenbeschwerden beschrieben. Sultiam besitzt eine geringe Toxizität, sodass Überdosierungen von 4-5 g Sultiam überlebt wurden. Ein Todesfall wurde beobachtet nach Einnahme von $20 \mathrm{~g}$ Sultiam in suizidaler Absicht.

Untersuchungsmaterial-Entnahmebedingungen $\operatorname{Serum}(\mathrm{S})$, Plasma (P), Urin.

Analytik Hochleistungs-Flüssigkeitschromatographie, $>$ GC-MS, LC-MS/MS.

Indikation Therapeutisches Drug Monitoring, Verdacht auf Intoxikation.
Interpretation Therapeutischer Bereich (S, P): $2-8 \mathrm{mg} / \mathrm{L}$; toxisch: ab $12 \mathrm{mg} / \mathrm{L}$ (Hiemke et al. 2012); komatös-letal: ab 20-25 mg/L (Schulz et al. 2012).

\section{Literatur}

Hiemke C et al (2012) AGNP-Konsensus-Leitlinien für therapeutisches Drug-Monitoring in der Psychiatrie: Update 2011. Psychopharmakotherapie 19:91-122

Rote Liste (2008) Ospolot ${ }^{\circledR}$. In: FachInfo-Service. Rote Liste Service $\mathrm{GmbH}$, Berlin

Schulz M, Iwersen-Bergmann S, Andresen H, Schmoldt A (2012) Therapeutic and toxic blood concentrations of nearly 1000 drugs and other xenobiotics. Crit Care 16:R136

\section{SUMO (small ubiquitin-like modifier)}

Ubiquitin

\section{Superoxiddismutase}

A. M. Gressner und O. A. Gressner

Synonym(e) SOD

Englischer Begriff superoxide dismutase

Definition SOD ist ein in Mitochondrien und Cytosol zahlreicher Zellen (Erythrozyten, Granulozyten, Hepatozyten, Motoneuronen u. a.) vorkommendes Enzym, das in einer Disproportionierungsreaktion mit den Kofaktoren $>$ Kupfer, - Zink und Mangan der Elimination von hochreaktiven Superoxidradikalen dient.

Beschreibung Die SOD ist ein zentrales Enzym der Detoxifikation reaktiver Sauerstoffmetabolite. Es katalysiert folgende Disproportionierungsreaktion $>$ Dismutation, bei der die Reduktion des Superoxidanions und die Oxidation des Wasserstoffs gleichzeitig ablaufen:

$$
2 \mathrm{O}_{2}^{\bullet-}+2 \mathrm{H}^{+} \rightleftarrows \mathrm{O}_{2}+\mathrm{H}_{2} \mathrm{O}_{2}
$$

Entstehendes Wasserstoffperoxid wird durch Katalase in Sauerstoff und Wasser umgesetzt. Beide Enzyme sind von zentraler Bedeutung für die Begrenzung des oxidativen Stress ( $\triangleright$ Stress, oxidativer).

Etwa 20 Mutanten der SOD mit unterschiedlichen katalytischen Aktivitäten und Kofaktorabhängigkeiten (Typ 1: 
Cu-Zn-SOD1 und Typ 2: Mn-Fe-SOD2) sind gegenwärtig bekannt.

Da die SOD (und Katalase) in der Elimination toxischer Sauerstoffprodukte eine zentrale Funktion haben, kann deren Aktivitätsbestimmung im EDTA- oder Heparin-Vollblut mit einem photometrischen Messverfahren indiziert sein. Stressbedingte und altersabhängige Aktivitätserniedrigungen sowie SOD-Aktivitätsabnahmen bei einigen neurologischen, obstruktiv pulmonalen, destruktiven Gelenk- und dermatologischen Erkrankungen (Belastung durch UV-Strahlen) sind bekannt. Weiterhin ist die SOD bei der Überwindung von Schwermetallintoxikationen, z. B. durch Quecksilber, von Bedeutung.

Die SOD-Aktivitätsbestimmung im Blut wird vorzugsweise in der Naturheilkunde eingesetzt.

\section{Literatur}

Mondola P, Damiano S, Sasso A et al (2016) The cu, Zn superoxide dismutase: not only a dismutase enzyme. Front Physiol 29(7):594-599

\section{Suppressor-/zytotoxische T-Zellen}

Liquor-CD8-T-(Suppressor)-Lymphozyten

\section{Surface-enhanced Laser Desorption/ Ionization}

- Ionisationsmethoden (Massenspektrometrie)

\section{Surface-Enhanced-Laser/Desorption- Ionization-Time-of-Flight- Massenspektrometrie}

$>$ SELDI-TOF

\section{Surfaktantfaktor}

H. Fiedler

Synonym(e) Antiatelektasefaktor; Surfaktantproteine (SP)

Englischer Begriff pulmonary surfactant factor
Definition Surfaktant ist ein Oberflächen-aktiver Lipoproteinkomplex, der in den Pneumozyten II aus Phospholipiden und Proteinen im Verhältnis 10:1 gebildet, zunächst in Lamellarkörperchen gespeichert und dann in den Alveolarraum sezerniert wird. Dort wird das sezernierte Surfaktant in das tubuläre Myelin und schließlich in eine Surfaktantschicht umgewandelt.

Beschreibung Surfaktant besteht zu ca. $90 \%$ aus Lipiden, davon zur Hälfte aus Dipalmitoylphosphatidylcholin (Lecithin) und zu ca. $40 \%$ aus weiteren Phospholipiden und Sphingomyelin. Die Proteine (total ca. $10 \%$ ) setzen sich zusammen aus Plasmaproteinen (ca. $50 \%$ ), den hydrophoben Surfaktantproteinen B (SP B, $9 \mathrm{kDa}$ ) und C (SP C) sowie den hydrophilen Surfaktantproteinen A (SP A) und D (SP D), die zur Collectinfamilie gehören und auch immunologische und regulatorische Funktionen besitzen. Surfaktant senkt die Oberflächenspannung und den Eröffnungsdruck kleiner Alveolen, erhöht die Lungencompliance und verhindert den Alveolenkollaps am Ende der Ausatmung sowie die Bildung hyaliner Membranen. Da sich die Oberfläche der Alveolen bei Ein- und Ausatmung vergrößert bzw. verkleinert, ändert sich auch die Belegung der Oberfläche mit Surfaktant und verhindert dadurch Atelektasen oder Gewebsschädigung.

Die Surfaktantbildung beginnt ab der 28. Schwangerschaftswoche (SSW) und ist erst in der 34./35. SSW für die Beatmung des Neugeborenen ausreichend. Durch fetale Atembewegungen gelangt Surfaktant ins Fruchtwasser und kann durch deren Punktion für Messungen gewonnen werden. Ohne oder bei zu wenig Surfaktant fallen bei Frühgeburten die Alveolen zusammen, es kommt zum „newborn respiratory distress syndrome" (Prävalenz ca. $50 \%$ bei Frühgeburten in der 28.-33. SSW). Schädigung oder erhöhten Verbrauch von Surfaktant findet man bei Diabetes der Mutter, bei Infektionen und Sepsis (auch bei Erwachsenen) und Langzeitanwendung hoher Sauerstoffkonzentrationen (Lorrain-Smith-Effekt bei Tauchern und hyperbarer Sauerstofftherapie). Beim adulten Atemnotsyndrom (ARDS) wird außerdem Surfaktant durch Proteine im Alveolarraum inaktiviert bzw. in Fibrin und hyaline Membranen eingeschlossen. Mutationen können zu einer intrazellulären SP-B-Defizienz führen, wodurch die Reifung von SP C verhindert wird und aberrante SP-Formen in den Alveolen abgelagert werden.

Die Lungenreife der Feten kann durch Messung von Surfaktant im zentrifugierten (2 Minuten bei $400 \mathrm{~g}$ ) Fruchtwasser ( $\triangleright$ Amnionflüssigkeit) geprüft werden:

- Schaumtest (obsolet).

- Lecithin-Sphingomyelin-Verhältnis $\quad(\triangleright$ Lecithin-Sphingomyelin-Ratio im Fruchtwasser im Fruchtwasser) nach Dünnschichtchromatographie und Densitometrie.

- FLM-II-Test: Der FLM-II-Test (FLM = ,fetal lung maturity“) prüft die Bindung eines synthetischen Fluoreszenz- 
farbstoffs an Albumin und Surfaktant mittels der Fluoreszenzpolarisation (Albumin hohe, Surfaktant niedrige Bindung). Berechnet wird die Surfaktant-Albumin-Ratio. Ausreichende Lungenreife ist wahrscheinlich bei $>50 \mathrm{mg}$ Surfaktant/g Albumin.

- Amniostat-FLM prüft das Vorkommen von Phosphatidylglyzerin.

- Zählung der Lamellarkörperchen.

Bei drohender Frühgeburt kann die Surfaktantproduktion durch Glukokortikoidgabe angeregt bzw. extrahiertes oder künstlich hergestelltes Surfaktant zugeführt werden. Künstliches Surfaktant ist in der WHO Model List of Essential Medicines (2015) enthalten.

Patienten mit chronischer Herzinsuffizienz haben einen erhöhten pulmonalen mikrovaskulären Druck, der die alveolokapilläre Schranke schädigt und den Übertritt von SP B ins Blut ermöglicht. Die erhöhten Plasmakonzentrationen geben Hinweise auf den Schweregrad und korrelieren weitgehend mit den $>$ Pro-NT-Brain natriuretic peptide Konzentrationen und den NYHA-Stadien der Herzinsuffizienz. SP A und D werden wegen ihrer Bedeutung für die Bakterienabwehr und die Entwicklung von interstitiellen und chronisch obstruktiven Lungenerkrankungen (COPD) intensiv untersucht. Bei der pulmonalen alveolären Proteinose kommt es zur Akkumulation von Surfaktant in den Alveolen mit Dyspnoe, Husten und Gewichtsverlust. Als Ursache konnten Autoantikörper gegen ,granulocyte macrophage colony-stimulating factor" nachgewiesen werden.

\section{Literatur}

Akiki Z, Fakih D, Jounblat R et al (2016) Surfactant D, a clinical biomarker for chronic obstructive pulmonary disease with excellent discriminant values. Exp Ther Med 11:723-730

DePasquale CG, Anolda LF, Doyle IR et al (2004) Plasma surfactant protein B. A novel biomarker in chronic heart failure. Circulation 110:1091-1096

Sorensen GL, Husby S, Holmskov U (2007) Surfactant protein A and surfactant protein D variation in pulmonary disease. Immunbiology 212:381-416

Waner RR (2005) Surfactanttherapie. Grundlage, Diagnostik, Therapie. Georg Thieme Verlag, Stuttgart

\section{Surfaktantproteine (SP)}

- Surfaktantfaktor

\section{Suspensionsarray}

> Mikropartikel-Array

\section{Suszeptibilitåtsgen}

\section{J. Arnemann}

Synonym(e) Gen mit erhöhter Krankheitswahrscheinlichkeit

Englischer Begriff susceptibility gene

Definition Unter Suszeptibilitätsgen versteht man ein Gen, das per se bei Geburt keine Krankheit, aber durch eine Kombination von genetischen und Umwelteinflüssen eine erhöhte Erkrankungswahrscheinlichkeit für eine multifaktorielle Erkrankung bedingt.

Beschreibung Versuche, häufigen Erkrankungen, wie z. B. Krebs, Asthma, Diabetes oder kardiovaskulären Erkrankungen, monogene Erbgänge zuzuordnen, sind in der Vergangenheit erfolglos geblieben, weshalb heutzutage das Konzept der multifaktoriellen Erkrankungen favorisiert wird. Grundlage soll danach eine Kombination aus genetischen Risikofaktoren sowie Umwelt- und Lifestyleeinflüssen sein. $\mathrm{Zu}$ den genetischen Risikofaktoren werden u. a. ungewöhnliche DNAVarianten oder Kopplungsungleichgewichte in Schlüsselgenen für den Erkrankungsprozess gezählt, die in statistischen Erhebungen eine erhöhte Wahrscheinlichkeit für eine multifaktorielle Erkrankung zeigen. Zur Identifizierung dieser Suszeptibilitätsgene werden im Hochdurchsatz sehr große Kollektive gescreent.

\section{Literatur}

McCarthy et al (2003) New methods for finding disease-susceptibility genes: impact and potential. Genome Biol 4:119

\section{Sutherland, Earl Wilbur}

W. Hubl

Lebensdaten Amerikanischer Mediziner, geboren am 29. November 1915 in Burlingame (Kansas, USA), gestorben am 9. März 1974 in Miami (Florida). Er studierte in Topeka, der Hauptstadt seines Heimatstaates, von 1933 bis 1937 Medizin, promovierte im Jahr 1942 an der Washington University in Saint Louis und wurde 1953 als Professor für Pharmakologie an die Western Reserve University in Cleveland (Ohio) berufen. Von 1963 bis 1973 lehrte Sutherland als 
Professor für Physiologie an der Vanderbilt University in Nashville (Tennessee) und ging dann an die Universität in Miami.

Verdienste Sutherland entdeckte im Jahr 1957 das zyklische Adenosinmonophosphat. Er erlangte wissenschaftliche Anerkennung mit seinen Arbeiten über hormongesteuerte Zellaktivitäten. Er entwickelte das Second-Messenger-System, wobei die Wirkung der Hormone von der Zellmembran an den ,second messenger“", das zyklische Adenosinmonophosphat, übertragen wird. Sutherland erhielt im Jahr 1971 den Nobelpreis für Physiologie und Medizin für seine Entdeckungen über die Wirkungsmechanismen von Hormonen. Earl Sutherland erhielt zahlreiche weitere Ehrungen einschließlich des Albert-Lasker-Preises (1970) und der National Medal of Science (1973).

\section{Literatur}

Herder WW (2014) Heroes in endocrinology: nobel prizes. Endocr Connect 3:R99

Lindsten J (1992) Nobel lectures, physiology or medicine 1971-1980. World Scientific Publishing Co., Singapore

Raju TN (1999) The Nobel chronicles. 1971: Earl Wilbur Sutherland, Jr. (1915-74). Lancet 354(9182):961

\section{Sutter-Antigen}

- Kell-Blutgruppensystem

\section{Svedberg, Theodor}

T. Arndt

Lebensdaten Schwedischer Chemiker, geboren am 30. August 1884 in Valbo, gestorben am 26. Februar 1971 in Kopparberg.

Verdienste Ab 1904 Studium an der Universität Uppsala, ab 1907 dort Dozent für Chemie, 1912 im Fach Physikalische Chemie zum Professor ernannt und ein Jahr später Mitglied der Königlich Schwedischen Akademie der Wissenschaften, 1949-1967 Direktor des Gustav-Werner-Instituts für Nuklearchemie.

Svedberg führte vor allem Forschungen über $>$ Kolloide (Lösungen von fein verteilten Makromolekülen, z. B. von Proteinen in Wasser) durch. Dazu konstruierte er Ultrazentrifugen ( $\triangleright$ Ultrazentrifuge), mit denen er dann unter anderem die Molekülmassen von Proteinen bestimmen konnte. Svedberg erhielt für seine Arbeiten über disperse Systeme im Jahr 1926 den Nobelpreis für Chemie. Nach ihm ist die Maßeinheit des Sedimentationskoeffizienten ( $\triangleright$ Svedberg-Einheit) bezeichnet.

\section{Literatur}

www.leopoldina.org/mitglieder/mitgliederverzeichnis/member/5258/.

Zugegriffen am 27.12.2016

\section{Svedberg-Einheit}

\section{T. Arndt}

Englischer Begriff Svedberg unit

Definition Einheit für den Sedimentationskoeffizienten, d. h. den Quotienten aus der Sedimentationsgeschwindigkeit eines Teilchens und dem Zentrifugalfeld (Winkelgeschwindigkeit $^{2} \times$ Radius) .

Ein Svedberg (S) entspricht $10^{-13}$ Sekunden.

Beschreibung Der Sedimentationskoeffizient eines Teilchens hängt ab: (a) von der Masse (schwerere Teilchen sedimentieren schneller als leichtere), (b) von der Dichte (dichtere Teilchen sedimentieren schneller als weniger dichte wegen der geringeren Auftriebskraft), (c) von der Form (kompakte Teilchen sedimentieren schneller als großräumige wegen des geringeren Reibungskoeffizienten) und (d) von der Dichte der Lösung. Unter Konstanthaltung der Zentrifugenparameter und Lösungsmitteleigenschaften werden die substanzspezifischen Unterschiede in den Sedimentationskoeffizienten zur Trennung von Substanzgemischen z. B. nach ihrer Masse (z. B. Plasmaproteine) oder Dichte (z. B. LipoproteinSubklassen) in einer $>$ Ultrazentrifuge (Beschleunigungen bis zu mehreren Hundertausend der einfachen Erdbeschleunigung) genutzt.

\section{Literatur}

Stryer L (1990) Biochemie. Spektrum der Wissenschaft Verlagsgesellschaft $\mathrm{mbH}$, Heidelberg

\section{sVEGFR-1}

> fms-like tyrosine kinase 1, lösliche 


\section{Swain-Langley-Antigen}

- Knops-Blutgruppensystem

\section{SWATH Acquisition}

D Data-independent acquisition

\section{Switch}

O. Colhoun

\section{Englischer Begriff switch}

Definition Typ eines Hubs, der verschiedene Stationen eines Netzwerks direkt miteinander verbindet.

Beschreibung Ein Switching Hub ist ein spezieller $>$ Hub, der Datenpakete von einem Computer genau an den Zielcomputer weiterleitet.

\section{Sydney-Kriterien}

- Sapporo-Kriterien

\section{Synacthen-Test}

$\checkmark$ ACTH-Test

\section{Synaptophysin}

S. Holdenrieder und P. Stieber

\section{Englischer Begriff Synaptophysin}

Definition Synaptophysin ist ein in synaptischen Vesikeln neuroendokriner Zellen vorkommendes Membranprotein.
Struktur Das saure $N$-glykosylierte 38 kDa schwere Synaptophysinprotein bindet Calciumionen und eignet sich für die histopathologische Diagnostik von Tumorerkrankungen.

Molmasse $38 \mathrm{kDa}$.

Indikation Histopathologische Diagnose von kleinzelligen Bronchialkarzinomen und anderen neuroendokrinen Karzinomen (z. B. APUDome, medulläre Schilddrüsenkarzinome).

Interpretation Synaptophysin kommt in synaptischen Vesikeln neuroendokriner Zellen vor. Es eignet sich als immunhistologischer Marker für die Charakterisierung neuroendokrinen Gewebes und wird neben neuronenspezifischer Enolase ( $\triangleright$ Neuronenspezifische Enolase im Blut) und - Pro-Gastrin Releasing Peptide in der Diagnostik von verschiedenen neuroendokrinen Tumoren und dem kleinzelligen Bronchialkarzinom eingesetzt. Die Bestimmung von Synaptophysin im Serum oder Plasma wird zur Tumordiagnostik nicht durchgeführt.

\section{Literatur}

Fallert-Müller A (2000) Lexikon der Biochemie. Spektrum-Verlag, Heidelberg

\section{Syndecane}

H.-D. Haubeck

Synonym(e) Amphiglycan; Fibroglycan; Ryudocan

Englischer Begriff syndecans

Definition Syndecane bilden eine Familie von zellmembranassoziierten Heparansulfat-Proteoglykanen, die durch eine Transmembrandomäne in der Zellmembran verankert sind.

Beschreibung Heparansulfat-Proteoglykane, d. h. neben den Glypicanen vor allem die Syndecane, werden auf der Zelloberfläche der meisten Körperzellen in hoher Dichte exprimiert (z. B. auf Endothelzellen bis zu 100.000 Moleküle/Zelle). Über spezifische Domänen der HeparansulfatKetten binden sie zahlreiche Liganden und wirken für viele dieser Liganden als Korezeptor, z. B. bei der Bindung von FGF-2 an den hochaffinen FGF-Rezeptor-1. Neben Zytokinen und Wachstumsfaktoren (u. a. EGF, FGFs, IGF-II, PDGF, TGF- $\beta$, IL-2, IL-3, IL-4, GM-CSF, Interferon- $\gamma$, TNF- $\alpha$ ) binden Heparansulfat-Proteoglykane auch Wachstumsfaktorbindungsproteine (z. B. IGF-BP-3), Chemokine, antiangiogene 
Faktoren (Angiostatin, Endostatin), Proteine der Extrazellulärmatrix (z. B. \ Kollagene, \ Laminine, \ Thrombospondine, - Vitronectin, - Fibronectin, > Tenascin), Lipoprotein-Lipase, Proteinasen (Neutrophilen-Elastase, Cathepsin-G) und Gerinnungsfaktoren (z. B. Gewebsplasminogen-Aktivator, Plasminogen-Aktivator-Inhibitor, Thrombin, Antithrombin-III). Dementsprechend besitzen die Syndecane (und $>$ Glypicane) vielfältige Funktionen, z. B. trägt die Bindung von Antithrombin-III über Heparansulfat-Proteoglykane an die Oberfläche von Endothelzellen entscheidend zur gerinnungshemmenden Eigenschaft der normalen Endothelzelloberfläche bei. Aus den spezifischen Interaktionen mit den genannten Liganden ergeben sich viele weitere Funktionen der Zelloberflächen-Heparansulfat-Proteoglykane, u. a. in der Morphogenese während der Embryonalentwicklung, der Angiogenese, der Gerinnung und der Wundheilung.

Die Mitglieder der Syndecan-Familie sind strukturell verwandt und aus einem gemeinsamen Vorläufermolekül durch Genduplikation entstanden. Die Grundstruktur der Syndecane besteht jeweils aus einem Core-Protein und den kovalent gebundenen Heparansulfatketten. Die Größe der Core-Proteine beträgt $69 / 82 \mathrm{kDa}$ für Syndecan-1, $48 \mathrm{kDa}$ für Syndecan-2, $125 \mathrm{kDa}$ für Syndecan-3 und $35 \mathrm{kDa}$ für Syndecan-4. Die verschiedenen Syndecane zeigen eine unterschiedliche Expression während der einzelnen Entwicklungsstadien, aber auch in verschiedenen Zelltypen des Organismus (z. B. Syndecan-3 bevorzugt im Nervensystem) sowie innerhalb einer Zelle, z. B. wird Syndecan-1 überwiegend auf der basolateralen Oberfläche von Epithelzellen exprimiert und Syndecan-4 in Zelladhäsionsdomänen (,focal adhesions"). Charakteristisch ist für alle Syndecane die Existenz einer Proteinaseschnittstelle in der Ektodomäne nahe der Zelloberfläche, über die lösliche Formen der Syndecane gebildet werden können (,shedding“). Im Gegensatz zu den membrangebundenen Formen, die als Korezeptoren für viele Zytokine und Wachstumsfaktoren wirken, sind diese löslichen Formen häufig inhibitorisch.

Für die Messung der Serumkonzentration der löslichen Syndecane steht aktuell nur für Syndecan-1 ein kommerzieller Immunoassay zur Verfügung.

\section{Literatur}

Bernfield M, Götte M, Park PW et al (1999) Functions of cell surface heparan sulfate proteoglycans. Annu Rev Biochem 68:720-777

Kramer KL, Yost HJ (2003) Heparan sulfate core proteins in cell signaling. Annu Rev Genet 37:461-484

\section{Syndrax}

Synthacain

\section{Syndromdiagnostik}

\section{J. Arnemann}

Synonym(e) Dysmorphologie

Englischer Begriff dysmorphology

Definition Syndromdiagnostik ist eine in der medizinischen Genetik angesiedelte Disziplin, die sich mit der Eingruppierung, Ätiologie und den Mustern angeborener Fehlbildungen beschäftigt.

Beschreibung Im Vordergrund der Syndromdiagnostik stehen sorgfältige klinische Beschreibungen und die wissenschaftliche Aufarbeitung der meist seltenen angeborenen Fehlbildungen und der Versuch, deren Ätiologie und Pathogenese als Syndrom zu beschreiben. Leitfrage dabei ist, ob es sich in einem gegebenen Fall aufgrund der einzigartigen klinischen Auffälligkeiten um ein bereits bekanntes oder unbekanntes Syndrom handelt. Hieraus lassen sich Hinweise zur Vererbung und/oder zum Wiederholungsrisiko ableiten, die eine weitergehende Behandlung des Patienten und die genetische Beratung der Familie verbessern.

Im Einzelfall muss immer geklärt werden, ob die festgestellten Dysmorphien einen heterogenen oder pleiotropen Effekt haben, wobei die heterogenen Effekte ähnlich sind, aber auf unterschiedliche Ursachen oder Gene zurückzuführen sind, während die pleiotropen Effekte unterschiedlich sein können, aber auf eine gemeinsame Ursache oder Gen zurückzuführen sind.

Die sorgfältige Ermittlung der genetischen Ursachen ermöglicht eine sichere Diagnose und eine kompetente genetische Beratung hinsichtlich Vererbungsmuster und Wiederholungsrisiko.

\section{Literatur}

Reardon W, Donnai D (2007) Dysmorphology demystified. Arch Dis Child Fetal Neonatal Ed 92:F225-F229

\section{Synovia-Analyse}

H.-D. Haubeck

Synonym(e) Analyse der Synovialflüssigkeit

Englischer Begriff analysis of synovial fluid (SF) 
Definition Ziel der Analyse der Synovialflüssigkeit ist die Differenzialdiagnose entzündlicher und degenerativer Gelenkerkrankungen.

Beschreibung Die Analyse der Synovialflüssigkeit (SF) ist für die Diagnose und Differenzialdiagnose der verschiedenen Gelenkerkrankungen sinnvoll (Tab. 1). Bei den Kristallinduzierten Gelenkerkrankungen wie Gicht und Pseudogicht, aber auch bei der septischen Arthritis erlaubt sie die direkte Diagnose. Bei chronisch-entzündlichen und degenerativen Gelenkerkrankungen gibt die Analyse der SF zusätzliche differenzialdiagnostische Hinweise.

Die Analyse der SF umfasst eine Reihe von Basisuntersuchungen und darüber hinaus ein Spektrum von klinischchemischen, serologischen und immunologischen Zusatzuntersuchungen. Für die meisten Untersuchungen ist, aufgrund der hohen Viskosität, eine Vorbehandlung der SF mit Hyaluronidase notwendig.
$\mathrm{Zu}$ den Basisparametern gehören:

- Die Beurteilung des Aussehens und der Menge der SF. Normale Synovialflüssigkeit ist klar und hellgelb bis strohgelb. Bei entzündlichen Erkrankungen wird die Farbe der SF grünlich-grau und, in Abhängigkeit von der Zellzahl, trübe. Das Volumen der SF im normalen Kniegelenk beträgt ca. $3,5 \mathrm{~mL}$.

- Die Bestimmung der Gesamtzellzahl und ihre Differenzierung (Granulozyten, Monozyten, Lymphozyten). In der normalen SF und bei degenerativen Gelenkerkrankungen ist die Zellzahl niedrig $(<200 / \mu \mathrm{L})$, und es werden überwiegend kleine Lymphozyten gefunden. Bei entzündlichen Gelenkerkrankungen werden deutlich höhere Zellzahlen und ein hoher Anteil an Granulozyten gefunden: z. B. rheumatoide Arthritis 5000-50.000/ $\mu \mathrm{L}$, Gichtarthritis $>5000 / \mu \mathrm{L}$. Die Osteoarthritis (,aktivierte Arthrose“) zeigt in der Regel leicht erhöhte Zellzahlen (1000-5000/ $\mathrm{L})$.

Synovia-Analyse, Tab. 1 Diagnose und Differenzialdiagnosen entzündlicher und degenerativer Gelenkerkrankungen

\begin{tabular}{|c|c|c|c|c|c|c|c|c|c|}
\hline & Farbe & Trübung & $\begin{array}{l}\text { Viskosität } \\
\text { (mPas) }\end{array}$ & $\begin{array}{l}\text { Zellzahl } \\
(\mathrm{n} / \mathrm{L})\end{array}$ & $\begin{array}{l}\text { Anteil an } \\
\text { Granulozyten } \\
(\%)\end{array}$ & Kristalle & $\begin{array}{l}\text { Gesamtprotein } \\
(\mathrm{g} / \mathrm{L})\end{array}$ & $\begin{array}{l}\text { Harnsäure } \\
(\mathrm{mg} / \mathrm{dL})\end{array}$ & Bakteriennachweis \\
\hline $\begin{array}{l}\text { Normale } \\
\text { Synovialflüssigkeit }\end{array}$ & Strohgelb & Klar & $30-80$ & $<200$ & $<10$ & - & $<20$ & $<7$ & - \\
\hline \multicolumn{10}{|c|}{ nichtentzündliche Gelenkerkrankungen } \\
\hline Trauma & $\begin{array}{l}\text { Strohgelb, } \\
\text { evt. blutig }\end{array}$ & $\begin{array}{l}\text { Klar/ } \\
\text { leicht } \\
\text { getrübt }\end{array}$ & $>30$ & $<2000$ & $<10$ & - & $20-30$ & $<7$ & - \\
\hline Arthrose & Strohgelb & Klar & $>30$ & $<2000$ & $<10$ & $\begin{array}{l}-/ \mathrm{Ca}- \\
\text { Phosphat }\end{array}$ & $20-30$ & $<7$ & - \\
\hline \multicolumn{10}{|c|}{ Entzündliche Gelenkerkrankungen } \\
\hline $\begin{array}{l}\text { Rheumatoide } \\
\text { Arthritis }\end{array}$ & Gelbgrün & Trüb & $<20$ & $5000-50.000$ & $>75$ & $\begin{array}{l}-/ \mathrm{Ca}- \\
\text { Phosphat }\end{array}$ & $40-60$ & $<7$ & - \\
\hline $\begin{array}{l}\text { Rheumatisches } \\
\text { Fieber }\end{array}$ & Gelblich & Trüb & $<30$ & $>5000$ & ca. 50 & - & $30-40$ & $<7$ & - \\
\hline Arthritis urica & Gelblich & Trüb & $<30$ & $>5000$ & $>75$ & Urat & $30-50$ & $>7$ & - \\
\hline Chondrokalzinose & Gelblich & Trüb & $<30$ & $1000-5000$ & $>50$ & $\begin{array}{l}\text { Ca- } \\
\text { Pyrophosphat }\end{array}$ & $30-40$ & $<7$ & - \\
\hline $\begin{array}{l}\text { Kollagenose } \\
\text { (Lupus } \\
\text { erythematodes, } \\
\text { Sklerodermie etc.) }\end{array}$ & Strohgelb & $\begin{array}{l}\text { Leicht } \\
\text { getrübt }\end{array}$ & $<30$ & $5000-10.000$ & $<50^{*}$ & $\begin{array}{l}\text {-/Ca- } \\
\text { Phosphat }\end{array}$ & $30-40$ & $<7$ & - \\
\hline M. Bechterew & Gelb & $\begin{array}{l}\text { Klar/ } \\
\text { leicht } \\
\text { getrübt }\end{array}$ & $<30$ & $1000-5000$ & ca. 50 & - & $30-40$ & $<7$ & - \\
\hline Psoriasis-Arthritis & Gelbgrün & Trüb & $<30$ & $>5000$ & $60-80 *$ & - & $30-50$ & $<7$ & - \\
\hline $\begin{array}{l}\text { Aktivierte Arthrose } \\
\text { (Osteoarthritis) }\end{array}$ & Gelb & $\begin{array}{l}\text { Leicht } \\
\text { getrübt }\end{array}$ & $<30$ & $1000-5000$ & $<50$ & $\begin{array}{l}-/ \mathrm{Ca}- \\
\text { Phosphat }\end{array}$ & $30-40$ & $<7$ & - \\
\hline $\begin{array}{l}\text { Reaktive bzw. } \\
\text { postinfektiöse } \\
\text { Arthritis (Yersinia, } \\
\text { Chlamydia, etc.) }\end{array}$ & Gelblich & $\begin{array}{l}\text { Leicht } \\
\text { getrübt }\end{array}$ & $<30$ & $1000-5000$ & $<50$ & - & $20-40$ & $<7$ & - \\
\hline Septische Arthritis & $\begin{array}{l}\text { Graugelb/ } \\
\text { evtl. blutig }\end{array}$ & Trüb & $<20$ & $>20.000$ & $>90$ & $\begin{array}{l}-/ \mathrm{Ca}- \\
\text { Phosphat }\end{array}$ & $40-60$ & $<7$ & + \\
\hline
\end{tabular}

*Evtl. LE (Lupus erythematodes)-Zell-Phänomen 
- Die quantitative Bestimmung der Viskosität (Viskosimeter), die bei entzündlichen Prozessen in der Regel deutlich erniedrigt ist.

- Bakteriologische Untersuchungen (Gram-Präparat, Kulturen) zum Ausschluss oder Nachweis einer septischen Arthritis.

- Die polarisationsmikroskopische Untersuchung zum Nachweis von Mononatriumurat-Kristallen (Gicht) und Calciumpyrophosphatdihydrat-Kristallen (Pseudogicht bzw. Chondrocalcinose).

Neben diesen Basisuntersuchungen können noch eine Reihe von ergänzenden Untersuchungen durchgeführt werden:

- Bestimmung des Gesamtproteingehalts der SF. In der normalen SF liegt die Konzentration des Proteins $<20$ g/L. Bei entzündlichen Gelenkerkrankungen kommt es infolge der gestörten Blut-Synovia-Schranke zu einem deutlichen Anstieg der Gesamtproteinkonzentration.

- Als Maß für die Entzündungsaktivität können darüber hinaus noch Laktat, Glukose und die LDH bestimmt werden.

- Rheumafaktoren, weitere Autoantikörper und Zytokine. Die Bestimmung des Rheumafaktors in der SF ist nur sinnvoll bei Verdacht auf eine seronegative rheumatoide Arthritis. Die Bestimmung weiterer Autoantikörper und Zytokine in der SF ist für die Diagnose und Differenzialdiagnose der Gelenkerkrankungen von begrenztem Wert.

\section{Literatur}

Schumacher HR Jr (1993) Synovial fluid analysis and Synovial biopsy. In: Kelley WN, Harris ED Jr, Ruddy S et al (Hrsg) Textbook of rheumatology, 4. Aufl. WB Saunders, Philadelphia, S 541-S 561

Swan A, Amer H, Dieppe P (2002) The value of synovial fluid assays in the diagnosis of joint disease: a literature survey. Ann Rheum Dis 61:493-498

\section{Synovialflüssigkeits-Viskosität}

> Viskosität der Synovialflüssigkeit

\section{Synthacain}

T. Arndt

Synonym(e) „Legales Kokain“
Englischer Begriff synthacaine; legal cocaine

Definition Szenename für eine nicht näher definierte Mischung vorgeblich legaler psychoaktiver Substanzen, die, durch Schniefen konsumiert, kokainähnliche stimulierende Wirkungen entfaltet.

Beschreibung In Synthacainprodukten wurden Methiopropamin und 2-Aminoindan bzw. Methiopropamin und Benzocain gefunden. Im Blut eines intoxikierten Synthacainkonsumenten mit Konfusion, paranoidem Verhalten, Halluzinationen und Sprachstörungen wurden 13 Stunden nach Aufnahme in der Notaufnahme $14 \mathrm{ng} / \mathrm{mL}$ Methiopropamin gemessen. Ein anderer Synthacainpatient mit Erregtheit, Xerostomie, Brustschmerzen, schwerer Dyspnoe und Tachykardie hatte $11 \mathrm{ng} / \mathrm{mL}$ MAM-2201 und Benzocain im Blut.

Offenbar enthalten Synthacaine, wie viele $>$ Neue Psychoaktive Substanzen (NPS), hersteller- und chargenabhängig qualitativ und quantitativ variierende Wirkstoffe. Dies erschwert die Dosierung für den Konsumenten, führt $\mathrm{zu}$ einem „,bunten“ Intoxikationsbild und erfordert letztlich eine allgemeine Suchanalyse zur Wirkstoffidentifizierung.

Anmerkungen Das Lokalanästhetikum Benzocain betäubt die durch die nasale Applikation gereizten Schleimhäute. Methiopropamin, ein Thiophenanalog zum Methamphetamin (s. Abbildung), ist ein selektiver Noradrenalin-DopaminReuptake-Hemmer, bewirkt also eine höhere Neurotransmitterkonzentration im synaptischen Spalt und damit eine stärkere Erregung der postsynaptischen Zelle. Methiopropamin (syn. MPA, Methedrene, Syndrax) ist dem Betäubungsmittelgesetz (BtMG) in Anlage I als nicht verkehrsfähiges Betäubungsmittel unterstellt. MAM-2201 ist ein sog. synthetisches Cannabinoid ( $\triangleright$ Cannabinoide). Es war zum Zeitpunkt des Redaktionsschlusses noch nicht dem BtMG unterstellt.

Strukturen von Methamphetamin und Methiopropamin (Thiophen, syn. Thiofuran, in Rot):
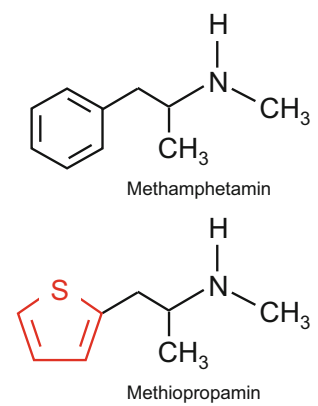

\section{Literatur}

Cumba LR, Kolliopoulos AV, Smith JP et al (2015) Forensic electrochemistry: indirect electrochemical sensing of the components of the new psychoactive substance „Synthacaine“. Analyst 140:5536-5545 
Daveluy A, Castaing N, Cherifi H et al (2016) Acute methiopropamine intoxication after "Synthacaine“ consumption. J Anal Toxicol 40:758-760

Lonati D, Buscaglia E, Papa P et al (2014) MAM-2201 (analytically confirmed) intoxication after "Synthacaine“ consumption. Ann Emerg Med 64:629-632

\section{Synthetisches Kokain}

$>$ Ketamin

\section{$\alpha$-Synuclein}

> Protein-Fehlfaltungs-Erkrankungen (tau, alpha-Synuclein, Polyglutamin, Huntingtin, Transthyretin)

\section{System}

C. Vidal und W.-R. Külpmann

Englischer Begriff system

Definition Abgegrenztes Teil oder Phänomen des wahrnehmbaren oder vorstellbaren Universums, materiell oder immateriell, das als bestehend aus zusammengehörigen Elementen oder Beziehungen aufgefasst werden kann.

Beschreibung Beispiele für Systeme: eine Uhr, ein Messgerät, eine Urinportion.

\section{Literatur}

Dybkaer R (1997) Vocabulary for use in measurement procedures and description of reference materials in laboratory medicine. Eur J Clin Chem Clin Biochem 35:141-173

\section{Systematische Abweichung}

- Messabweichung, systematische

\section{Système international d'unités}

$>$ SI-Einheiten

\section{Systemkonfiguration}

O. Colhoun

Englischer Begriff system configuration

Definition Anpassung eines installierten (Standard-)LaborEDV-Systems ( $>$ Labor-EDV) an das medizinische Labor und seine Arbeitsweise.

Beschreibung Neben der reinen Hardwarekonfiguration (Installation auf der Hardwareplattform des Laboratoriums, Einbindung in bestehende Netzwerke, Einrichtung der Serverfunktionalität für die Clients ( $\triangleright$ Client) im Labor, Einrichtung der Onlines, Einsender, Schnittstellen, Hardware im Labor etc.) ist vor allem die Anpassung an die Arbeitsabläufe und Analytik des Laboratoriums mittels Anlage der $>$ Stammdaten von Bedeutung.

\section{Systemstatus}

O. Colhoun

Englischer Begriff system status

Definition Abfragefunktion zum aktuellen Betriebszustand des Labor-EDV-Systems.

Beschreibung Hierbei kann eine Vielzahl von Parametern eingesehen werden, die Auskunft über den Betriebszustand (Hardwareauslastung, Anzahl und Übersicht aktiver User, Anzahl und Übersicht angeschlossener Online-Geräte, Speicherbelegung, Systemnutzungsgrad - auch nach Usern aufgeschlüsselt -, aufgelaufene und aktuelle Fehlermeldungen, Stand der Datensicherung, Status der Online-Befundübermittlung, Status des Fax-Servers) des $>$ Labor-EDV-Systems geben.

\section{Szasz-Quotient}

A. M. Gressner und O. A. Gressner

Synonym(e) CK/AST-Quotient; CK/GOT-Verhältnis

Englischer Begriff Szasz-ratio; CK/AST-ratio 
Definition Verhältnis der Enzymaktivitäten im Serum von Kreatinkinase $(\mathrm{CK})$ und Aspartat-Aminotransaminase (GOT, AST) unterstützt bei einer Entscheidungsgrenze (Trennwert) von 9 (10) die Differenzialdiagnose von Herzmuskel- gegenüber Skelettmuskelschädigungen.

Beschreibung Der von G. Szasz und E.W. Busch vor ca. 40 Jahren entwickelte Quotient aus den Aktivitäten von Gesamt-CK und AST (GOT) trennt bei einem Diskriminationswert von 9 bzw. 10 myokardiale Schädigungen (Infarkte, Entzündungen), Mittelwert 4,6 ( $\triangleright$ Mittelwert, arithmetischer); Bereich 2,2-9,67, von Skelettmuskelschädigungen, Mittelwert 19,9; Bereich 9,09-49,1. Für den Quotienten wird eine diagnostische Treffsicherheit von über $90 \%$ ( $>$ Sensitivität, diagnostische) angegeben, wenn die CK über $160 \mathrm{U} / \mathrm{L}$ beträgt und GOT-(AST-)Erhöhungen durch Lebererkrankungen auszuschließen sind. Von anderen Autoren wird ein Diskriminationswert von 10 angegeben. Der Quotient hat nach Einführung von Troponin $\mathrm{T}$ ( $>$ Troponin $\mathrm{T}$, kardiales) und Troponin I ( $>$ Troponin I, kardiales) sowie Isoenzym CK-MB seine Bedeutung weitgehend verloren.

\section{Literatur}

Schmidt E, Schmidt FW, Chemnitz G, Kubale R, Lobers J (1980) The Szasz-ratio (CK/GOT) as example for the diagnostic significance of enzyme ratios in serum. Klin Wochenschr 58:709-718

\section{Szenenamen von Drogen}

- Straßennamen von Drogen

\section{Szent-Györgyi von Nagyrapolt, Albert}

\section{A. M. Gressner und O. A. Gressner}

Lebensdaten Ungarischer Mediziner, geboren am 16. September 1893 in Budapest, gestorben am 22. Oktober 1986 in Woods Hole, Massachusetts.

Verdienste Studium der Humanmedizin ab 1911 in Budapest mit anschließender wissenschaftlicher Tätigkeit in Pharmakologie, Physiologie und Biochemie an verschiedenen europäischen (Prag, Berlin, Hamburg, Leiden, Groningen, Szeged, Budapest u. a.) und amerikanischen Universitäten (Cambridge, Rochester). Seine wissenschaftlichen Verdienste liegen besonders in der Erforschung biologischer Verbren- nungsprozesse, Bioenergetik, Ascorbinsäure und $>$ Vitamin C sowie Fumarsäure und Flavine. Szent-Györgyi von Nagyrapolt erhielt im Jahr 1937 den Nobelpreis für Medizin. Er stellte die Identität von Vitamin C und Ascorbinsäure fest und erkannte ihre antioxidative und Skorbutverhindernde Wirkung.

\section{Szent-Györgyi-Formel}

- Szent-Györgyi-Quotient

\section{Szent-Györgyi-Quotient}

O. Müller-Plathe

Synonym(e) Szent-Györgyi-Formel; S-G-Qu

\section{Englischer Begriff Szent-Györgyi-Ratio}

Beschreibung Der nach dem ungarischen Arzt und Biochemiker Albert Szent-Györgyi von Nagyrapolt ( $>$ Szent-Györgyi von Nagyrapolt, Albert) benannte Elektrolytquotient dient der Zustandsbeschreibung der neuromuskulären Erregbarkeit:

$$
\text { S-G-Qu }=\frac{\left[\mathrm{K}^{+}\right] \times\left[\mathrm{HCO}_{3}^{-}\right] \times\left[\mathrm{HPO}_{4}{ }^{2-}\right]}{\left[\mathrm{Ca}^{2+}\right] \times\left[\mathrm{Mg}^{2+}\right] \times\left[\mathrm{H}^{+}\right]}
$$

Eine Erhöhung des Quotienten durch Alkalose, Hyperkaliämie oder Hypokalzämie, Hypomagnesiämie zeigt eine Steigerung der neuromuskulären Erregbarkeit mit Neigung zur Tetanie an. Eine Abnahme weist entsprechend auf eine Untererregbarkeit mit Lähmungsneigungen hin.

\section{Literatur}

Szent-Györgyi A (1963) Lost in the twentieth century. Ann Rev Biochem 32:1-14

\section{Szintillator}

W. Stöcker und W. Schlumberger

Englischer Begriff scintillator 
Definition Ein Szintillator ist ein Stoff mit der Eigenschaft, nach Anregung durch ionisierende Strahlen Lichtquanten auszusenden. Er ist wesentlicher Bestandteil des Szintillationszählers, mit dem beim $>$ Radioimmunoassay die Häufigkeit radioaktiver Zerfallsereignisse gemessen wird.

Beschreibung Bei Radioimmunoassays werden zur Markierung radioaktive $>$ Isotope eingesetzt, bei deren Zerfall ionisierende Strahlung freigesetzt wird. Ein bestimmter Anteil der innerhalb einer Messzeit in der Probe entstehenden Strahlen erzeugt im Szintillator Lichtblitze. Diese werden im Szintillationszähler durch einen Photomultiplier verstärkt, und jeder Impuls wird elektronisch gezählt.

Die im medizinischen Laboratorium gebräuchlichen Betaund Gammazähler unterscheiden sich voneinander aufgrund der unterschiedlichen Reichweite der $\beta$ - und der $\gamma$-Strahlung
(Radioisotope). Zur Erfassung der $\beta$-Strahlen mit ihrer Reichweite von nur wenigen Millimetern muss die radionuklidhaltige Probe in unmittelbaren Kontakt mit dem Szintillator gebracht werden: Sie wird mit einer Szintillationsflüssigkeit vermischt, die z. B. Naphthalin oder Oxazolderivate enthält. Die Messung der (weiterreichenden) $\gamma$-Strahlen ist einfacher und billiger: Der Szintillator ist fest ins Messgerät eingebaut und befindet sich außerhalb des Messröhrchens, aber in nächster Nähe. Er besteht z. B. aus Natriumiodid-Einkristallen, die geringe Spuren von Thallium aufweisen.

\section{Literatur}

Sokolowski G, Wood G (1981) Radioimmunoassay in Theorie und Praxis. Schnetztor-Verlag, Konstanz, S 27-29 